FRANCISCO YASTAMI NAKAMOTO

\title{
PROJETO DE SISTEMAS MODULARES DE CONTROLE PARA SISTEMAS PRODUTIVOS
}

Tese apresentada à Escola Politécnica da Universidade de São Paulo para obtenção do título de Doutor em Engenharia

São Paulo 


\section{PROJETO DE SISTEMAS MODULARES DE CONTROLE PARA SISTEMAS PRODUTIVOS}

Tese apresentada à Escola Politécnica da Universidade de São Paulo para obtenção do título de Doutor em Engenharia

Área de Concentração:

Engenharia de Controle e Automação Mecânica - Engenharia Mecatrônica

Orientador:

Prof. Dr. Diolino José dos Santos Filho

São Paulo 
Este exemplar foi revisado e alterado em relação à versão original sob responsabilidade única do autor e com a anuência de seu orientador.

São Paulo, 08 de outubro de 2008.

Francisco Yastami Nakamoto

Prof. Dr. Diolino José dos Santos Filho

Autor

Orientador

FICHA CATALOGRÁFICA - EDIÇÃO REVISADA

Nakamoto, Francisco Yastami

Projeto de sistemas modulares de controle para sistemas

produtivos / F.Y. Nakamoto. - ed.rev. - São Paulo, 2008.

$158 \mathrm{p}$.

Tese (Doutorado) - Escola Politécnica da Universidade de São Paulo. Departamento de Engenharia Mecatrônica e de Sistemas Mecânicos.

1.Sistema de controle (Produção) 2.Redes de petri 3. Alocação de recursos (Controle) I.Universidade de São Paulo. Escola Politécnica. Departamento de Engenharia Mecatrônica e de Sistemas Mecânicos II.t. 


\section{DEDICATÓRIA}

Dedico este trabalho à Leila Haruko Nakamoto, minha esposa, e a nossa Katharine. Aos meus pais, Gunji Nakamoto e Mariko Nakamoto.

Aos meus irmãos, Nori e Mie, Cláudio e Clarissa, Kanji, Mako e Tsutomu, Fumie, Mitsuyo e Setsuya. 


\section{AGRADECIMENTOS}

Agradeço ao meu orientador, Prof. Dr. Diolino José dos Santos Filho, pelo voto de confiança, incentivo, paciência, amizade e apoio, minha eterna gratidão.

Agradeço ao Prof. Dr. Paulo Eigi Miyagi, pelas contribuições para o desenvolvimento deste trabalho, pelo voto de confiança, incentivo e paciência.

Ao Prof. Dr. Newton Maruyama, pelas contribuições para o desenvolvimento deste trabalho, pelo voto de confiança, incentivo e paciência.

Ao Prof. Dr. José Reinaldo Silva pelo voto de confiança e incentivo.

Aos colegas doutorandos Ms. Oswaldo Luis Asato e Ms. Marcosiris Amorim de Oliveira Pessoa pelo voto de confiança, apoio e paciência (muita paciência).

Ao Sr. Eng ${ }^{\circ}$. Nobuo Shinohara pelo apoio e incentivo, minha eterna gratidão.

A Sra. Andréa Parizotto pelas contribuições e incentivo.

Agradeço a todos do Grupo de Modelagem Controle e Decisão do Departamento de Engenharia Mecatrônica e de Sistemas Mecânicos da EPUSP, pela amizade, apoio e incentivo.

A todos do Departamento de Engenharia Mecatrônica da EPUSP que direta e indiretamente contribuíram de alguma forma para a realização deste trabalho, muito obrigado. 
A busca do conhecimento e do crescimento interno é incessante e árduo, pois o ser humano é um ser de potencialidades que está sempre em busca de algo que vai além daquilo que já atingiu, pela qual o possibilita alcançar o seu estado de plenitude... é a beleza da natureza humana. 


\section{RESUMO}

A competição no mercado globalizado, do ponto de vista do consumidor, aumentou consideravelmente a oferta de produtos e serviços, permitindo a escolha pela qualidade, preço, prazos e/ou disponibilidade. Entretanto, do ponto de vista das empresas, o desafio de atuar em um mercado saturado, dinâmico, competitivo e com aumento da demanda de produção orientado ao consumidor altera consideravelmente toda a estrutura da empresa. Desta forma, a flexibilidade torna-se um pré-requisito fundamental para que as empresas possam atuar neste mercado.

Considerando-se o contexto apresentado, o objeto de estudo do presente trabalho são os Sistemas Produtivos Flexíveis (SPFs). Os SPFs são sistemas concebidos para atender às necessidades de um mercado dinâmico e competitivo. Isto causa complexidade no comportamento global desses sistemas exigindo diferentes propostas para o projeto de Sistemas de Controle de SPFs. A complexidade advém do fato de se perder a informação quanto ao pré-determinismo da seqüência de eventos que ocorrem no sistema global, além do fato de não existir previamente a definição de todos os processos de transporte com a designação prévia de todas as ordens de transporte que os transportadores presentes na planta devem executar.

Neste contexto, o objetivo deste trabalho é apresentar como resultado uma proposta de sistema de controle modular para SPFs que atenda os requisitos de fluxo de informações envolvendo hierarquia e colaboração simultânea entre os módulos, respeitando a diversidade semântica presente na arquitetura. Apresenta-se então uma sistematização de projeto dos diversos módulos de controle e uma proposta de implementação de um algoritmo de designação dos transportadores para ser utilizado em tempo real permitindo a realização eficiente das atividades de transporte.

Palavras-chave: Sistema de controle. Redes de Petri. Alocação de recursos. 


\begin{abstract}
The competition in the globalized market increased considerably the demand for products and services "to the customer point of view". However, the consumer's driven demand change the whole structure of the company. Thus, flexibility becomes an essential pre-requisite for companies to compete in the market. Considering the context presented, the object of study of this work is the Flexible Production System (FPS).

The FPS must fulfill the needs on a dynamic and competitive market. This situation causes complexity in the overall performance of these systems, requiring different proposals for the design of the control systems. The complexity arises due to the fact that loses the information about the sequence of events that occur in the global system. Besides there is no previous exist definition for all processes of transport and prior designation for it.

In this context, the objective of this work is to present a proposal for modular control systems to FPS that fits the requirements of information flow involving hierarchy and simultaneous collaboration between the modules. It will be presented systematization for the modular design of control as well as an implementation of an algorithm for designation of transport in real time leading to an efficient management of these activities.
\end{abstract}

Keywords: System Control. Petri Nets. Resource Allocation. 


\section{LISTA DE FIGURAS}

Figura 2.1 Evolução dos estados em um SDED (a) e SDVC (b)...........................10

Figura 2.2 Níveis de automação (adaptado de GROOVER, 2007)........................12

Figura 2.3 Correlação entre os conceitos de SPF, Flexibilidade e Automação.........14

Figura 2.4 Diagrama conceitual do sistema de controle de SDED (MIYAGI, 1996)..17

Figura 2.5 Arquitetura do sistema de controle proposto por Santos Filho (2000).....18

Figura 2.6 Evolução das arquiteturas de controle. ...........................................20

Figura 2.7 Hierarquia funcional de atividades (ANSI/ISA95.00.03) ......................23

Figura 3.1 Exemplo de uma célula de manufatura flexível (REVELIOTIS, 2005).....28

Figura 3.2 Exemplo de deadlock em tráfego de automóveis...................................30

Figura 3.3 Exemplo de deadlock em banco de dados...........................................

Figura 3.4 Exemplo de deadlock em célula de manufatura flexível...........................32

Figura 3.5 GAR individual (a) e GAR global (b) ................................................. 34

Figura 3.6 Estrutura de controle proposta por Fanti (2004)...................................45

Figura 3.7 Arquitetura de controle para AGVS conforme Wu e Zhou (2007). ...........47

Figura 3.8 Esquema de um recurso de transformação. .......................................49

Figura 3.9 SMF da Vought Aircraft (Adaptado de GROOVER, 2007) .....................50

Figura 3.10 Exemplo de estrutura topológica representada por grafo......................51

Figura 4.1 SPF, Flexibilidade, Automação e Controle Modular................................55

Figura 4.2 Identificação dos módulos de controle para SPF..................................56

Figura 4.3 Proposta de arquitetura de controle para SPF. ...................................57

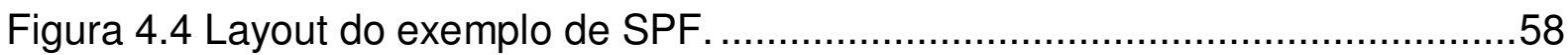

Figura 4.5 Fluxo das informações entre os módulos da arquitetura proposta...........60

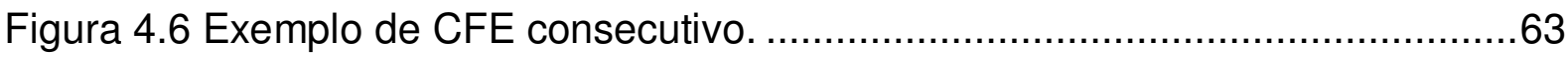

Figura 4.7 Fluxo das informações CAT/CDT/CUV/objeto de controle.......................65

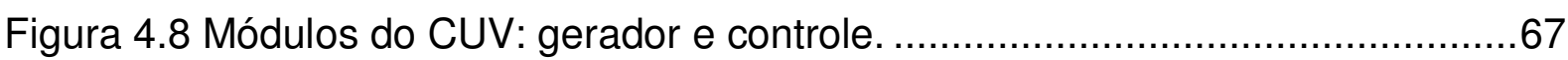

Figura 4.9 Fluxo das informações CUV/CV/objeto de controle. ……......................68

Figura 4.10 Geração do E-MFG inicial a partir do GAR do processo........................69

Figura 4.11 Refinamento sucessivo - Itens a produzir.......................................70

Figura 4.12 Alocação de recursos de transformação e transporte............................71

Figura 4.13 Refinamento sucessivo - Execução da atividade. ...............................72

Figura 4.14 Refinamento sucessivo: itens produzidos. .....................................73

Figura 4.15 Alocação de recursos de transformação e transporte prioritário.............73 
Figura 4.16 Passos I, II e III da síntese do CUR. .75

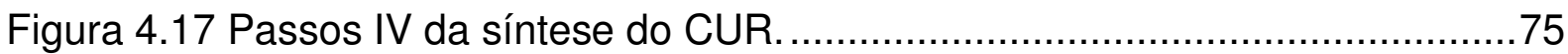

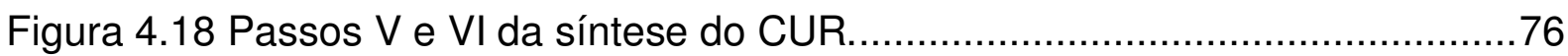

Figura 4.19 Sub-grafo de comunicação (a) e sub-grafo de comunicação recovery. . 77

Figura 4.20 GAR individual (a) e E-MFG individual (b).....................................77

Figura 4.21 Dinâmica de recepção e envio de mensagem CAT-CUR. …….............78

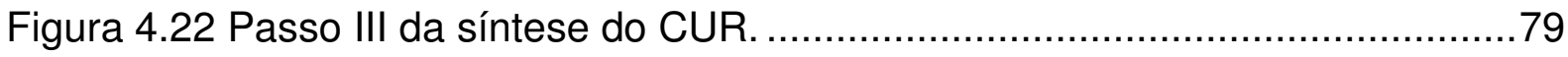

Figura 4.23 Passo IV - geração do E-MFG global de utilização de recursos. ............80

Figura 4.24 Sub-grafo recovery de um CFE com dois processos. ...........................81

Figura 4.25 Exemplo da dinâmica do sub-grafo recovery - Parte 1 1........................82

Figura 4.26 Exemplo da dinâmica do sub-grafo recovery - Parte 2..........................83

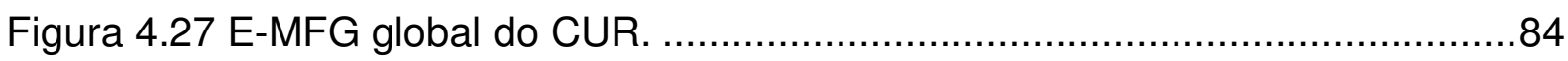

Figura 4.28 Metodologia PFS/E-MFG para a síntese do CDT . ..............................85

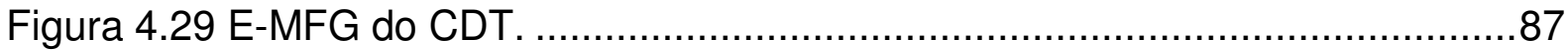

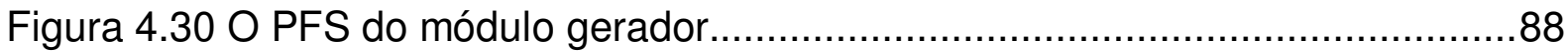

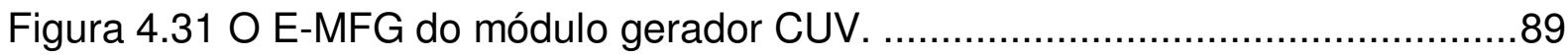

Figura 4.32 Algoritmo para geração do módulo controle.......................................90

Figura 4.33 Zonas de carregamento/descarregamento e zona de parada................91

Figura 4.34 Tipos de nós do GAR das vias.......................................................

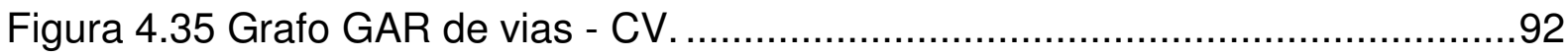

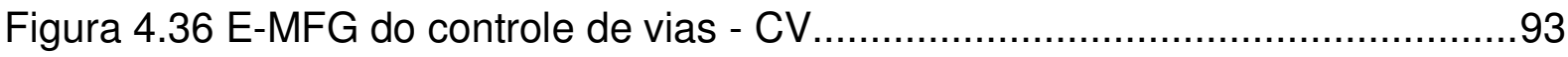

Figura 4.37 Eventos para a análise qualitativa do controle...................................95

Figura 4.38 Arquitetura hierárquica modificada do controle. ...................................96

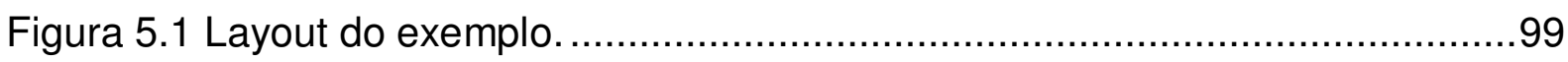

Figura 5.2 GAR individual(a) e o mapeamento para o E-MFG (b)......................100

Figura 5.3 Primeiro refinamento do módulo CAT. .............................................100

Figura 5.4 Segundo refinamento do módulo CAT - Parte I...................................101

Figura 5.5 Segundo refinamento do módulo CAT - Parte II.....................................102

Figura 5.6 Passo 2: Determinação do GAR global do exemplo. ............................103

Figura 5.7 Passo 3: Determinação dos CFEs. .................................................103

Figura 5.8 Passo 1 e 2: Mapeamento do E-MFG a partir do GAR. .......................105

Figura 5.9 Passo 3: E-MFG de cada processo com sub-grafo de comunicação....106

Figura 5.10 Passo 4, 5 e 6: E-MFG do módulo CUR. ......................................107

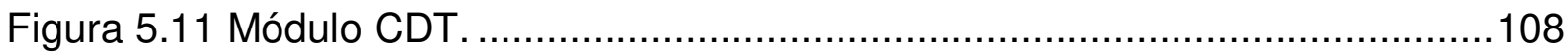


Figura 5.12 Módulo gerador do CUV. 109

Figura 5.13 Grafo de Gantt fornecido pelo planejamento da produção. 110

Figura 5.14 Lista de eventos de início de atividade. 111

Figura 5.15 Lista de eventos de início de atividade - Exemplo 2. 120

Figura 5.16 Lista de eventos de início de atividade - Exemplo 3. 121

Figura 5.17 Lista de eventos de início de atividade - Exemplo 4 123

Figura A.1 Um exemplo de RdP. 137

Figura A.2 Estruturas Siphon (a) e Trap (b). 138

Figura A.3 Elementos fundamentais de um GAR. 139

Figura A.4 Elementos de um CFE. 140

Figura A.5 Elementos básicos do MFG. 141

Figura A.6 Exemplo de estrutura de uma marca individual. 142

Figura A.7 Os boxes funcionais básicos e um exemplo de marca individual composta. 143

Figura A.8 Representação de um box controlador alterando o estado de uma marca individual. 143

Figura A.9 Representação de um procedimento de filtragem seletiva. 144

Figura A.10 Alteração dos atributos das marcas decorrentes do disparo. 145

Figura A.11 Elementos comunicadores do E-MFG (Matsusaki, 2004). 146

Figura A.12 Elementos do PFS 148

Figura $\mathrm{A} .13$ Elemento atividade em rede $\mathrm{L} / \mathrm{T}$. 149

Figura A.14 Elemento distribuidor em rede L/T. 149

Figura B.1: Algoritmo de Dijkstra (CORMEN et al, 2002) ...................................150

Figura B.2: Algoritmo de relaxamento (CORMEN et al, 2002) ............................150

Figura B.3: Exemplo de grafo para cálculo do caminho mínimo. ..........................151

Figura B.4: Execução do algoritmo de Dijkstra.................................................151

Figura B.5: Representação da árvore binomial com 13 nós..................................152

Figura B.6: Representação do nó de um Heap binomial.........................................153

Figura B.7: Representação do nó de um Heap binomial......................................153

Figura C1 Interface para entrada da matriz de adjacência do simulador. ................155

Figura D1 GAR de utilização das vias...........................................................157

Figura D2 E-MFG de utilização das vias. .....................................................158 


\section{LISTA DE TABELAS}

Tabela 2.1 Tipos de flexibilidade em SPs (GROOVER, 2007) ..............................11

Tabela 4.1 Atributos da marca no CAT. ..............................................................

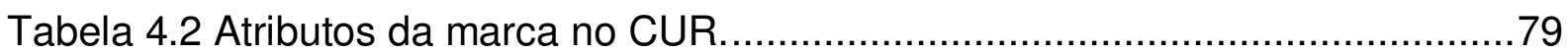

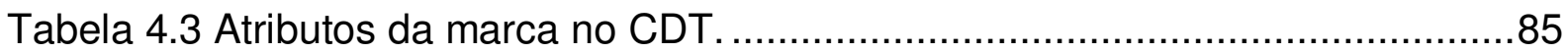

Tabela 4.4 Atributos da marca do módulo gerador do CUV..................................89

Tabela 4.5 Atributos da marca do módulo CV ...................................................93 


\section{LISTA DE ABREVIATURAS E SIGLAS}

AGV

AGVS

ANSI

CAT

CDT

CON-RAS

CFE

COR-RAS

CPs

CPX-RAS

$\mathrm{CR}$

CRs

CRSS

CTPN

CUR

CUV

CV

DAA

DIS-RAS

E-MFG

FLD

GAR

INA

ISA

LIN-RAS

LIN-SU-RAS
Automated Guided Vehicle

Automated Guided Vehicle Systems

American National Standards Institute

Controle de Atividades de Transformação

Controle de Designação de Transportadores

Conjunctive Resource Allocation Systems

Ciclo Fechado de Espera

Coordinating Resource Allocation Systems

Controle de Processos

Complex Resource Allocation Systems

Controle de Rotas

Controle de Recursos

Conjunctive Resource Service Systems

Colored Timed Petri net

Controle de Utilização de Recursos

Controle de Utilização de Vias

Controle de Vias

Deadlock Avoidance Algorithm

Disjunctive Resource Allocation Systems

Enhanced Mark Flow Graph

First Level Deadlock

Grafo de Alocação de Recurso

Integrated Net Analyzer

Instrumentation, Systems and Automation Society

Linear Resource Allocation Systems

Linear-Single-Unit Resource Allocation System 


\begin{tabular}{|c|c|}
\hline MFG & Mark Flow Graph \\
\hline PPN & Production Petri Net \\
\hline RDA & Randomized Deadlock Avoidance \\
\hline $\mathrm{RdP}$ & Redes de Petri \\
\hline RUN & Resource Upstream Neighborhood \\
\hline SA & Sistemas Antropocêntricos \\
\hline SAP & Sistemas Antropocêntricos de Produção \\
\hline SAR & Sistema de Alocação de Recursos \\
\hline SCP & Structural Control Policies \\
\hline SDED & Sistema Dinâmico a Eventos Discretos \\
\hline SDVC & Sistema Dinâmico de Variáveis Contínuas \\
\hline SED & Sistemas a Eventos Discretos \\
\hline SLD & Second Level Deadlock \\
\hline SM & Sistema de Manufatura \\
\hline SMA & Sistema de Manufatura Automática \\
\hline SMF & Sistema de Manufatura Flexível \\
\hline SP & Sistema Produtivo \\
\hline SPF & Sistema Produtivo Flexível \\
\hline SPR & Sistema de Processos Repetitivos \\
\hline ST-RAS & Single Type Resource Allocation Systems \\
\hline SU-RAS & Single Unit Resource Allocation Systems \\
\hline S3RP & Systems of Simple Sequential Processes with Resources \\
\hline TLD & Third Level Deadlock \\
\hline
\end{tabular}




\section{LISTA DE SÍMBOLOS}

$\begin{array}{ll}\Xi_{\mathrm{jk}} & \text { Atividade k do processo j } \\ m_{R} & \text { Capacidade do dispositivo de recepção } \\ m_{D} & \text { Capacidade do dispositivo de despacho } \\ E & \text { Conjunto de arcos } \\ P & \text { Conjunto de processos } \\ N & \text { Conjunto de nós } \\ R & \text { Conjunto de tipos de recursos } \\ S_{j} & \text { Conjunto da seqüência de atividades do processo } \Xi_{\mathrm{j}} \\ W_{i} & \text { Estação de trabalho i } \\ G_{j} & \text { Estrutura de dados que descreve a seqüência lógica de execução } \\ A & \text { Função de alocação de recurso } \\ T & \text { Função de tempo } \\ C & \text { Função capacidade do sistema } \\ G & \text { Grafo orientado } \\ \Pi_{\mathrm{j}} & \text { Processo j } \\ R_{i} & \text { Recurso i }\end{array}$




\section{SUMÁRIO}

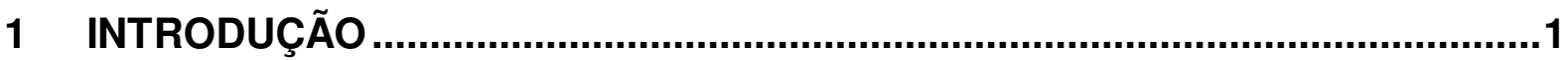

1.1. Evolução do Tratamento da Complexidade em SPFs................................2

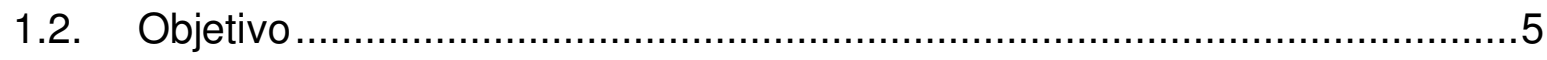

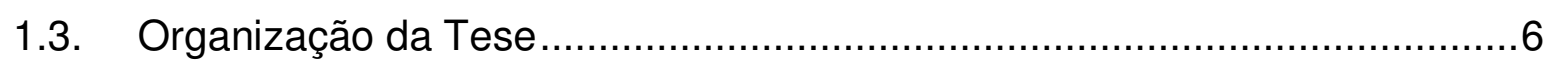

2 SISTEMA DE CONTROLE PARA SISTEMA PRODUTIVO FLEXÍVEL ..............7

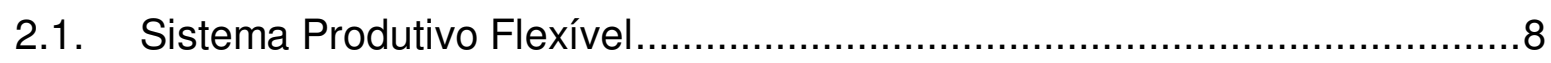

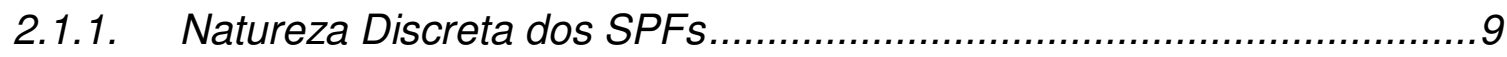

2.1.2. Flexibilidade e Automação ............................................................. 10

2.2. Sistema de Controle para SPFs............................................................

2.2.1. Complexidade e Modelo de Restrições ......................................... 15

2.2.2. Diagrama Conceitual do Sistema de Controle ...................................17

2.2.3. Arquitetura de Controle ............................................................. 18

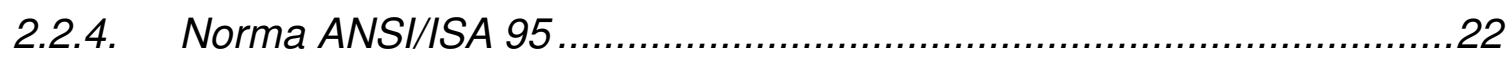

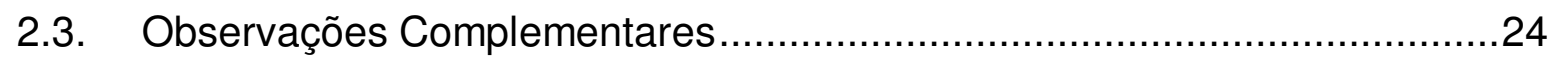

3 DEADLOCK EM SISTEMAS PRODUTIVOS FLEXÍVEIS ….............................25

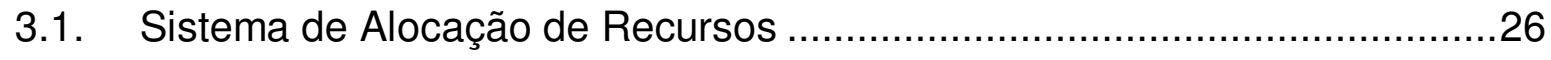

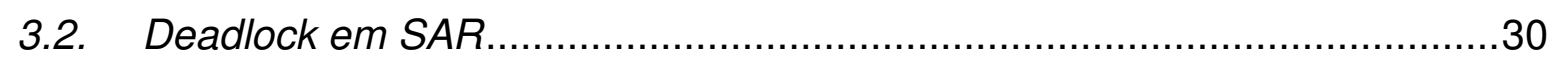

3.2.1. Condições Mínimas para a Ocorrência do Deadlock ...........................33

3.2.2. Métodos para Tratar o Problema de Deadlock ...................................34

3.3. Método Híbrido para Tratar o Deadlock em SPFs ...................................48

3.4. Natureza das Atividades Realizadas pelos Recursos em SPFs ................49

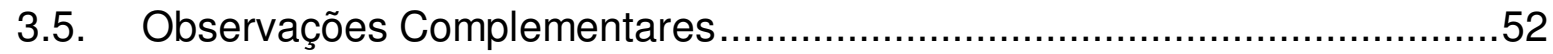

4 SISTEMÁTICA PARA GERAÇÃO DO SISTEMA DE CONTROLE ...................53

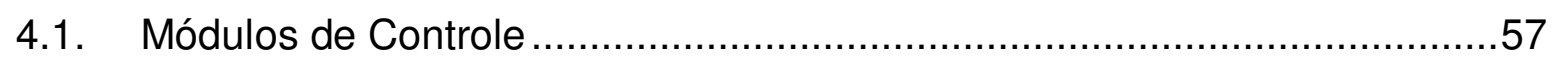

4.1.1. Controle de Atividades de Transformação (CAT) ..............................59

4.1.2. Controle de Utilização de Recursos (CUR)......................................61

4.1.3. Controle de Designação de Transporte (CDT)..................................64

4.1.4. Controle de Utilização de Vias (CUV) ............................................67

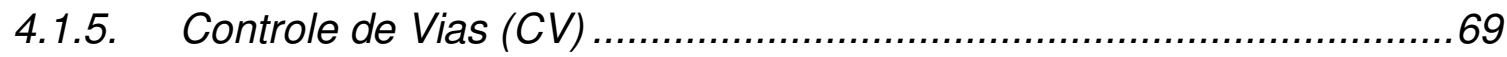

4.2. Síntese do Controle de Atividades de Transformação .................................69

4.3. Síntese do Controle de Utilização de Recursos .........................................74

4.4. Síntese do Controle de Designação de Transporte .....................................85 
4.5. Síntese do Controle de Utilização de Vias ...............................................8

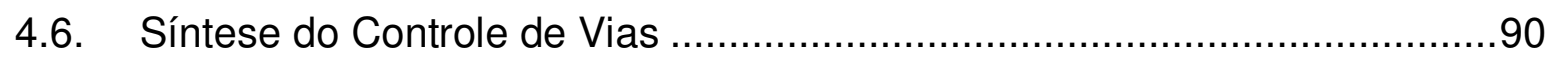

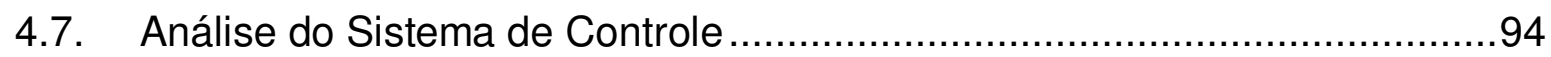

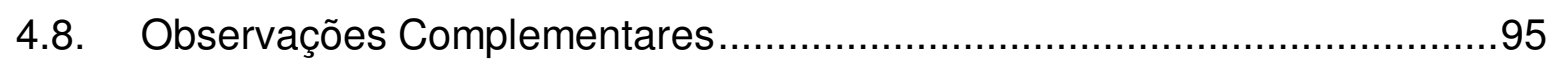

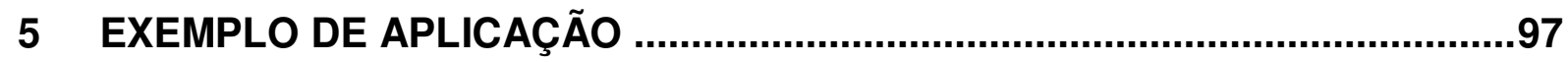

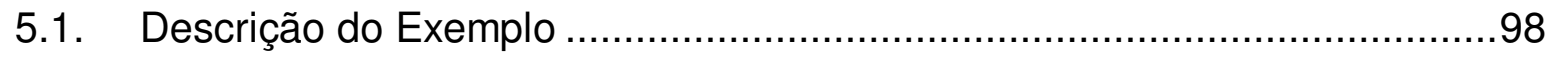

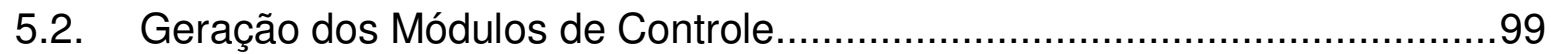

5.2.1. Módulo de Controle de Atividades de Transformação (CAT)................99

5.2.2. Módulo de Controle de Utilização de Recursos (CUR) ......................103

5.2.3. Módulo de Controle de Designação de Transporte (CDT).................108

5.2.4. Módulo de Controle de Utilização das Vias (CUV).............................109

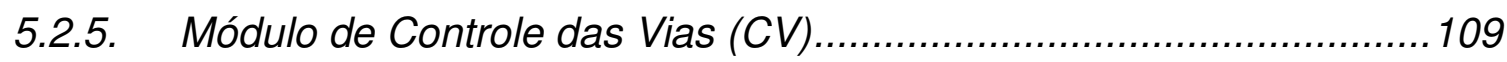

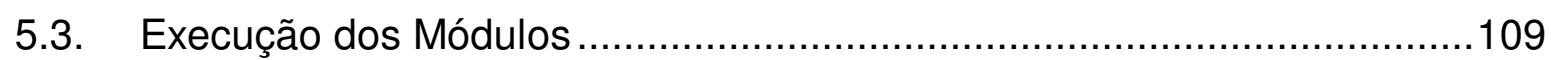

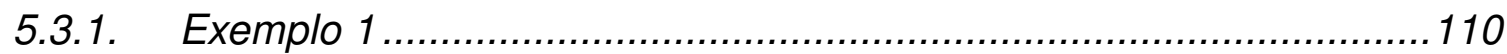

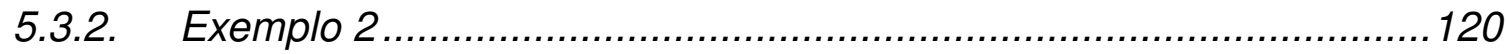

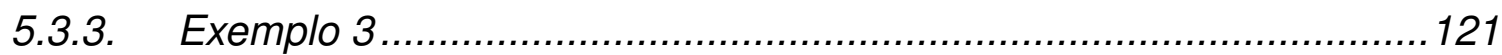

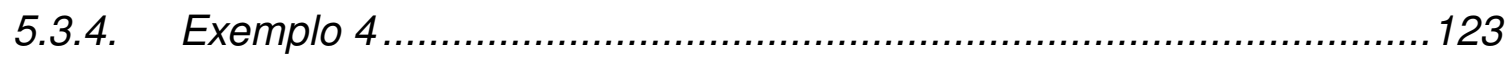

5.4. Observações Complementares ..........................................................124

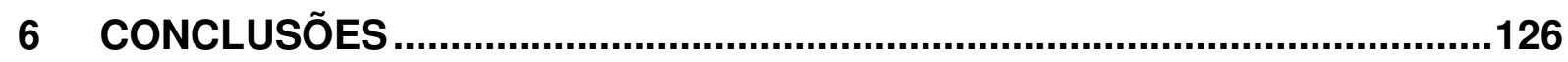

6.1. Contribuições deste Trabalho .......................................................127

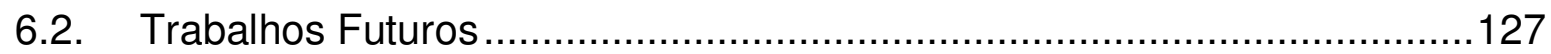

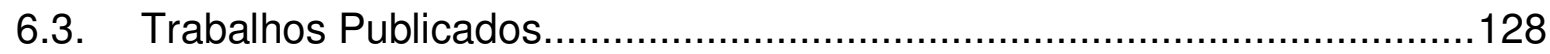

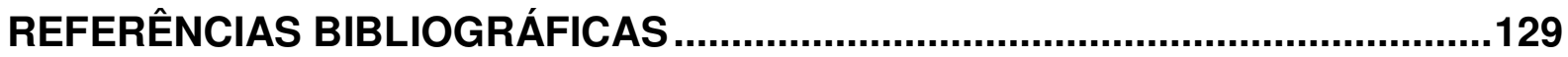

ANEXO A - FERRAMENTAS DE MODELAGEM ...........................................137

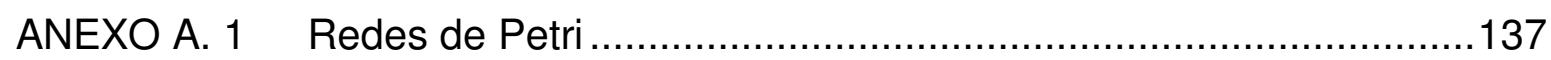

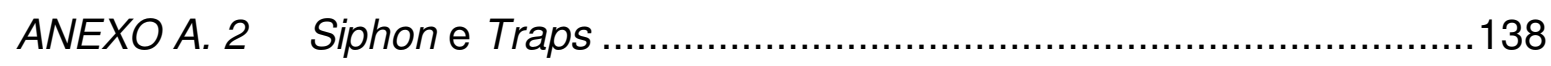

ANEXO A. 3 Grafo de Alocação de Recursos - GAR …...............................138

ANEXO A. 4 Ciclo Fechado de Espera (CFE) ..........................................140

ANEXO A. 5 Mark Flow Graph - MFG ................................................140

ANEXO A. 6 Enhanced Mark Flow Graph - E-MFG.....................................141

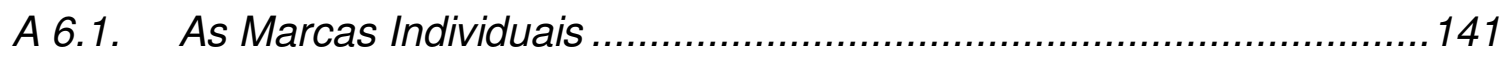

A 6.2. Marcas Individuais Compostas ................................................. 142

A 6.3. Manipulação dos Atributos das Marcas .........................................143

A 6.4. Dinâmica das Regras de Disparo ............................................. 144 


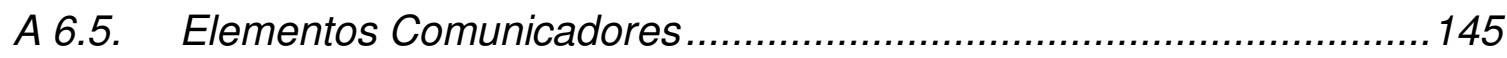

ANEXO A. 7 Mapeamento GAR/E-MFG.................................................147

ANEXO A. 8 Production Flow Schema - PFS ……................................148 ANEXO B - FERRAMENTA COMPUTACIONAL PARA DETERMINAR O CAMINHO

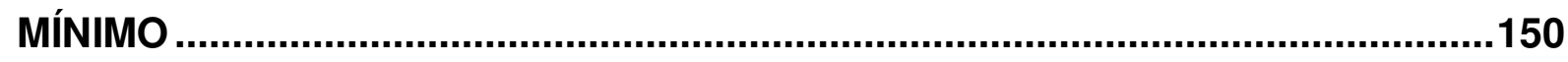
ANEXO C - FERRAMENTA COMPUTACIONAL PARA SIMULAÇÃO DA REDE EMFG 155

ANEXO D - REDES. 156 


\section{CAPÍTULO}

\section{INTRODUÇÃO}

A globalização é um processo contínuo e irreversível que promove gradativamente a integração social, econômica e cultural de povos a mais de uma década (RAMAN, 2000; JIN-HAl et al., 2003). Como conseqüência principal desta mudança, presencia-se uma unificação de mercados e uma dinâmica significativamente diferente de competitividade entre as empresas.

A competição neste mercado globalizado, do ponto de vista do consumidor, resultou em um aumentou considerável da oferta de produtos e serviços, permitindo a aplicação de critérios seletivos baseados em padrões de qualidade, preço, prazos e/ou disponibilidade. Critérios que permitem analisar objetivamente a melhor decisão a ser adotada para atender a um determinado conjunto de necessidades. Entretanto, do ponto de vista das empresas, o desafio de atuar em um mercado saturado, dinâmico, competitivo e com aumento da demanda de produção orientada ao consumidor, altera consideravelmente toda a estrutura da empresa, obrigando-as a rever seus modelos de gestão (GLEGHORN, 2005).

Em alguns casos, envolve mudanças de paradigmas, como por exemplo:

- A implantação de uma política contínua de redução de custos (fabricação, operacional, logística, estoque, recursos e pessoal), embasada no conceito de eficiência, tendo como meta o melhor uso dos recursos disponíveis e espaço físico disponível;

- Investimento em tecnologias e a prática da inovação como forma de aprimoramento continuo da qualidade dos produtos fabricados e serviços prestados;

- A análise criteriosa da questão de inserção em cadeias produtivas envolvendo situações que impactam na terceirização de processos e serviços (SAAD et al., 2003).

Além disso, as mudanças necessárias não são apenas estratégias para ganhos em competitividade em relação aos demais competidores, mas envolve inclusive questões fundamentais que determinam a própria sobrevivência da empresa. 
O pré-requisito fundamental para que as empresas possam atuar nesta dinâmica de mercado é a flexibilidade. Isto é, de uma forma sistemática faz-se necessário implantar nas indústrias a flexibilidade nos diversos níveis do sistema produtivo como, por exemplo, em estações de trabalho, dispositivos de movimentação e transporte de itens. Dentro deste contexto, outros fatores merecem destaque:

- A disponibilidade de tecnologias de comunicação e tecnologia de informação;

- A disponibilidade de diversos paradigmas de modelagem e controle;

- A presença de elementos independentes com autonomia;

- A necessidade de sistemas capazes de adquirir, armazenar e processar um volume crescente de informações.

Considerando-se o contexto apresentado, o objeto de estudo do presente trabalho são os Sistemas Produtivos Flexíveis (SPFs). Os SPFs são sistemas que foram concebidos para atender à demanda de um mercado dinâmico e competitivo em que a característica principal é a capacidade de adaptar-se rapidamente às mudanças do ambiente em que atua. Entretanto, para poder atender as necessidades do mercado dinâmico e competitivo que se apresenta, os gestores dos SPFs estão adotando modelos de gestão produtiva cada vez mais elaborados. A complexidade inerente ao seu comportamento dinâmico implica na necessidade de elaborar-se estratégias de controle alternativas associadas a ferramentas capazes de controlar de forma efetiva os SPFs. Desta forma, o objetivo deste trabalho é apresentar como resultado uma proposta de controle modular para SPFs que contemple tais necessidades.

\subsection{Evolução do Tratamento da Complexidade em SPFs}

O maior desafio no projeto do controle para SPFs é o desenvolvimento de um controle que garanta o fluxo dos processos e resulte nos níveis de produção estabelecidos pelo planejamento da produção. Um outro aspecto fundamental é quanto à produtividade dos SPFs. Isto está relacionado com o uso eficiente dos recursos disponíveis.

Os SPFs executam múltiplos processos paralelos com um intenso compartilhamento de um mesmo conjunto finito de recursos entre os processos (SANTOS FILHO, 
2000). A primeira grande dificuldade é modelar o comportamento desejado do sistema. Do ponto de vista do controle para um único processo, denominado controle local, é suficiente a garantia da execução seqüencial das atividades do processo controlado. Entretanto, quando visto pela perspectiva do controle global do sistema, perde-se o seqüenciamento das atividades do processo quando existe a execução de múltiplos controles locais compartilhando um mesmo conjunto de recursos e/ou informação. Neste contexto, a execução simultânea e paralela dos processos gera um alto grau de dificuldade na modelagem do comportamento, característica de um sistema complexo.

A complexidade é um atributo do sistema em que a representação do comportamento global é impossível de ser formulado de modo puramente seqüencial, mesmo sabendo-se o comportamento individual das partes ou componentes do sistema (EDMONDS, 1995). Ou seja, o somatório das partes não é igual ao todo (SANTOS FILHO, 2000). Uma outra característica que influi consideravelmente no processo de modelagem é a explosão combinatória dos possíveis estados alcançáveis do sistema.

A característica que envolve o compartilhamento de um mesmo conjunto finito de recursos pode levar o sistema a evoluir para um estado indesejável denominado auto-travamento ou deadlock. O problema de deadlock é um assunto exaustivamente estudado em diversas áreas que envolvem a comunicação, compartilhamento de informações e recursos (TANENBAUM, 1995; DATE, 2000; SILBERSCHATZ et. al., 2000). O deadlock é caracterizado quando o fluxo dos processos são permanentemente impedidos devido à falta de materiais, recursos e/ou informações (COFFMAN et al., 1971; BANASZAK e KROGH, 1990; VISWANADHAM et al., 1990; SANTOS FILHO, 2000; LI, ZHOU e WU, 2008).

O deadlock em SPFs é assunto muito estudado por diversos pesquisadores a décadas. Entretanto, ainda é objeto de estudo que apresenta constantemente novos problemas e desafios. Reduzindo-se a uma análise dos últimos dez anos, verifica-se que muitos autores buscavam um processo global que garantisse o seqüenciamento de diversos processos que são executados paralelamente e pudessem ser controláveis. Autores como Basnazak e Polak (2002) tentaram encontrar um equilíbrio entre os seqüenciamentos de execução das atividades de transformação dos processos, com o uso racional de buffers e estado inicial do Sistema Produtivo 
(SP). Outros, seguindo a linha de Ezpeleta et al. (1995), Trincas e Ezpeleta (2003), Li e Zhou (2003; 2004; 2008), Li et al. (2004), entre outros, buscavam explorar as propriedades das redes de Petri (ANEXO A) para encontrar uma forma de especificar o controle do processo global. Embora os resultados apresentados sejam interessantes do ponto de vista de SP de pequeno porte, a aplicação em sistemas em que há o envolvimento de grande quantidade de variáveis pode desencadear uma explosão combinatória de estados alcançáveis do sistema. Sendo necessário um grande esforço computacional que poderá inviabilizar a especificação do controle do processo global neste caso.

Em contra partida, outro grupo de pesquisadores como Fanti et al. (1995; 1997; 2000; 2002), Gang e Ming (2004), Gang e Zhiming (2003), Lawley e Ferreira (1994), Lawley et al. (1997; 1998), Lawley e Reveliotis (2001), Lawley e Sulistyono (2002), Santos Filho (1998; 2000), Wu e Zhou (2003; 2004; 2005; 2007) entre outros buscaram não um controle global, mas um controle baseado em restrições. Ou seja, o comportamento do sistema é conhecido até um dado estado, a partir deste estado não é possível determinar qual será o novo comportamento do sistema, portanto, restringe-se a evolução para que este não atinja estados indesejáveis. Para este cenário foram considerados recursos de transformação utilizando-se transportes fixos como esteiras ou robôs para a manipulação de itens. Ainda, alguns pesquisadores realizaram estudos considerando outro tipo de recurso: os transportadores guiados automaticamente, caracterizados pela alta flexibilidade e alto grau de complexidade do controle (GANESHARAJAHA et al., 1998; REVELIOTIS, 2000; QIU et al., 2002; VIS, 2006; WU e ZHOU, 2005; 2007). Isso se deve ao fato de que, enquanto processo de transformação, o seqüenciamento e o recurso são conhecidos. Porém em transportadores desta natureza, não há prévio conhecimento do processo ou do recurso que executará o processo. Desta forma, observa-se uma distinção dos domínios semânticos nas atividades realizadas pelos processos, ou seja, atividades de transformação e atividades de transporte. Trabalhos recentes como os de Fanti (2004), Wu e Zhou (2007) indicam que estes iniciaram também estudos explorando o compartilhamento concomitante de estações de trabalho e transportadores.

Desta forma, as motivações para a realização deste trabalho são: 
a) A complexidade inerente dos SPFs e a ocorrência de deadlock em alocação de recursos nos SPF;

b) Diferentes semânticas envolvidas nas atividades dos processos;

c) Acesso a um volume crescente de informações.

\subsection{Objetivo}

O objetivo deste trabalho é propor um sistema de controle modular para SPFs que permita a execução simultânea de processos com compartilhamento de um mesmo conjunto finito de recursos, implicando na realização dos seguintes procedimentos:

- Análise do comportamento dinâmico da classe de sistema produtivo abordada no presente trabalho;

- Identificar os diferentes domínios semânticos;

- Definir os respectivos módulos de controle;

- Propor de um modelo de interação dos módulos de controle;

- Elaborar a síntese dos algoritmos de controle de cada módulo utilizando ferramentas gráficas e matemáticas.

- Tratamento de deadlock em alocação de recursos

- Classificação quanto à natureza das atividades realizadas pelos recursos: recursos de transformação e recursos de transporte;

- Proposição de uma visão integrada para o tratamento de deadlock em recursos de transformação e recursos de transporte mediante uma técnica híbrida de abordagem;

- Análise e validação dos modelos de controle propostos

- Desenvolver uma ferramenta computacional para análise e validação por simulação dos modelos de controle considerando a interação dos módulos hierarquicamente subordinados e módulos colaborativos. 


\subsection{Organização da Tese}

No Capítulo 2 apresentam-se a caracterização e as definições de Sistema Produtivo Flexível (SPF) delineado pelos conceitos de sistemas produtivos, flexibilidade, automação e controle. Em seguida, é apresentada a relação entre o grau de automação requerida relacionado ao conceito de automação, complexidade do sistema, modelo de restrições e a classificação de arquiteturas de controle. Finalizando, será apresentada a importância de adequação à norma ANSI/ISA 95-3.

O Capítulo 3 apresenta inicialmente uma classificação dos sistemas de alocação de recursos e os conceitos básicos referente ao problema de deadlock em SPFs, decorrente do compartilhamento de recursos. Os processos nos SPFs competem entre si pela utilização de um conjunto finito de recursos compartilhados. Esta competição pode causar uma condição indesejável denominado deadlock. Neste capítulo é realizada uma descrição do fenômeno de deadlock, as condições suficientes para a ocorrência e as formas de tratar o problema do ponto de vista de três métodos.

O Capítulo 4 apresenta uma proposta de controle modular aplicado em uma arquitetura hierárquica modificada do controle e a sistemática para a geração dos módulos. Primeiramente são apresentadas as considerações que nortearam a proposição desta arquitetura e uma descrição dos módulos de controle que compõem o sistema. Em seguida, será apresentada a sistematização de cada um dos módulos, bem como o formato e a forma de comunicação entre os módulos. A arquitetura proposta no presente trabalho tem como objetivo garantir o controle do SPF quanto ao fluxo dos processos. A divisão do controle sobre os recursos de transformação e sobre os recursos de transporte permite um controle diferenciado em cada área de atuação, colaborando para garantir o controle global do sistema.

No Capítulo 5 apresenta-se um caso de uso aplicando-se a sistemática proposta para a geração dos módulos de controle e uma análise qualitativa quanto à evolução dos estados nos módulos. As conclusões, contribuições e trabalhos futuros que finalizam a tese seguem no Capítulo 6. 


\section{CAPÍTULO}

\section{SISTEMA DE CONTROLE PARA SISTEMA PRODUTIVO FLEXÍVEL}

Apresenta-se aqui a classe de sistemas produtivos flexíveis (SPFs) e suas características. A caracterização de SPFs faz-se necessária para estabelecer as ações de controle que reflitam o comportamento dinâmico desejado para esses sistemas.

A imposição de um determinado comportamento dinâmico implica, a priori, na necessidade do conhecimento da natureza dinâmica desses sistemas. Entretanto, a grande dificuldade em determinar o comportamento se deve a dificuldade em modelar-se o controle desses sistemas.

Neste contexto, são apresentados os conceitos de sistemas produtivos (SPs), de flexibilidade, de automação e de controle que delineiam o conceito de SPFs. Apresenta-se também as arquiteturas de controle para SPFs, bem como a importância da normatização dos processos presentes em um SPF. Cabe ressaltar, que a normatização citada visa melhor a comunicação entre os vários níveis do sistema produtivo, para que haja convergência com as estratégias da empresa. 


\subsection{Sistema Produtivo Flexível}

A dinâmica das necessidades do mercado, em que se observa um conjunto de requisitos altamente voláteis ao longo do tempo, coloca as empresas diante de um ambiente extremamente competitivo. As empresas são confrontadas com desafios que podem comprometer a sua sobrevivência dentro de certas áreas de atuação. Aquelas que aceitam o desafio mobilizam-se nos vários níveis do sistema produtivo, buscando soluções com base em novas tecnologias e/ou inovações tecnológicas que, em muitos casos, ocasionam mudanças de paradigma no comportamento e/ou na estrutura da organização (GANG e ZHIMING, 2003; BLANC et al., 2008).

As atividades produtivas realizadas nestas empresas envolvem a produção de bens ou prestação de serviços como o uso de materiais, equipamentos e mão-de-obra. Desta forma, é possível visualizar e tratar os processos dentro destas empresas sob o conceito de sistemas produtivos (SPS) (SANTOS FILHO, 2000; VILLANI et al., 2007). Incluem-se nesta classe de sistemas os sistemas de manufatura (SMs), os sistemas de comunicação, os sistemas prediais, os sistemas de transporte, entre outros (SANTOS FILHO, 2000; MATSUSAKI, 2004; VILLANI, 2004; ARAÚJO JUNIOR, 2006).

O SP tratado neste trabalho envolve a produção de bens materiais, itens ou produtos. Desta forma, um primeiro aspecto a ser observado é quanto ao comportamento dinâmico das operações realizadas pelos SPs em questão. As operações podem ser caracterizadas pela execução de um conjunto finito de processos seqüenciais e/ou paralelos (SANTOS FILHO, 2000; VILLANI, 2004; NAKAMOTO et al., 2007), pertinentes à classe de SP de produção do tipo Job-Shop (KALPAKJIAN e SCHMID, 2005; ARAÚJO JUNIOR, 2006; GROOVER, 2007).

Um segundo aspecto a ser considerado é quanto à redução gradativa dos ciclos de vida dos produtos que, devido à natureza volátil dos requisitos impostos pelo mercado, aumenta consideravelmente a diversificação de produtos de uma mesma família (GANG e ZHIMING, 2003; BLANC et al., 2008). Como terceiro aspecto relevante, tem-se a questão da eficiência no uso dos recursos das organizações, 
implicando na utilização do conceito de agilidade no processo produtivo (JIN HAI et al., 2003; GLEGHORN, 2005).

Considerando-se os três aspectos apresentados a classe de sistemas a ser objeto de estudo do presente trabalho, contempla as seguintes características:

* A natureza discreta da evolução dos estados do SP;

* A produção simultânea de uma variedade de produtos;

- A necessidade de flexibilidade de atendimento às alterações na demanda de variedade de produtos e/ou quantidade de itens de produtos;

* A necessidade de uso eficiente dos recursos, principalmente no que se refere ao transporte e movimentação.

\subsubsection{Natureza Discreta dos SPFs}

O comportamento de um SPF pode ser classificado de acordo com a natureza das variáveis de estado a serem controladas (CASSANDRAS e LAFORTUNE, 2007):

* Variáveis contínuas (quantitativas) ou;

* Variáveis discretas (qualitativas).

Os sistemas em que o comportamento é governado por leis invariantes da Física onde a evolução dos estados ocorre de forma contínua em função do tempo, pertencem à classe de sistemas dinâmicos de variáveis contínuas (SDVC). Entretanto, há casos em que não é possível modelar o sistema utilizando-se as leis Físicas, como nos SDVC. Consequentemente tem-se uma outra classe de sistemas onde o comportamento envolve uma evolução de estados definidos qualitativamente e que é denominado sistemas dinâmicos a eventos discretos (SDED) (MIYAGI, 1996; CARDOSO e VALETTE, 1997; CASSANDRAS e LAFORTUNE, 2007).

A evolução dos estados em um SDED ocorre de forma assíncrona com base na ocorrência de eventos que causam uma transição abrupta de estados. Isto é, há um indeterminismo quanto à ocorrência destes eventos em função do tempo (assincronismo) e, inclusive, sendo possível o paralelismo e o conflito na ocorrência destes eventos. Os valores das variáveis nos SDED são modificados de forma instantânea de acordo com a ocorrência de eventos e permanecem constantes entre 
as ocorrências dos mesmos (MIYAGI, 1996; CARDOSO e VALETTE, 1997; CASSANDRAS e LAFORTUNE, 2007). A Figura 2.1 ilustra um exemplo comparativo do comportamento de um SDED e SDVC.

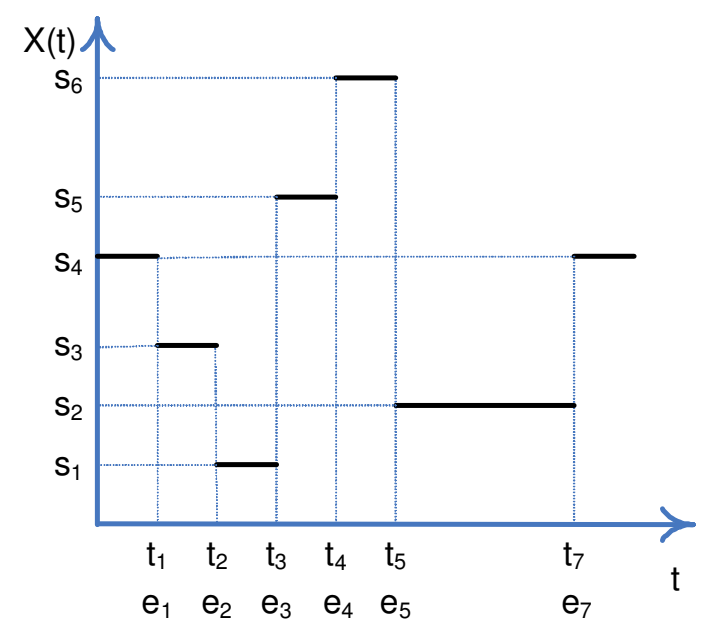

(a)

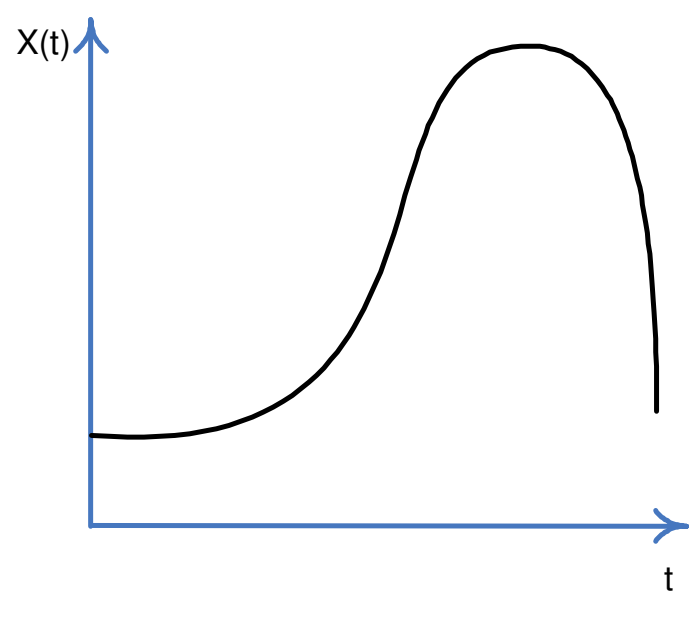

(b)

Figura 2.1 Evolução dos estados em um SDED (a) e SDVC (b).

Individualmente, cada um dos processos executados pelo SPF é constituído por um conjunto finito de atividades seqüencialmente pré-definidas que envolvem a transformação, a montagem, a manipulação e/ou o transporte de itens ao longo do processo produtivo (NAKAMOTO, et al., 2007). A execução seqüencial das atividades do processo caracteriza um comportamento dinâmico do SP regido pela ocorrência de eventos que alteram de forma discreta os estados do sistema. Deste modo, os SPF tratados neste trabalho pertencem à classe de sistemas dinâmicos a eventos discretos (SDED).

\subsubsection{Flexibilidade e Automação}

A produção simultânea de uma variedade de produtos e a rápida resposta no atendimento às alterações na demanda de tipos de produtos e/ou quantidade de itens de produtos são características de SPs que possuem a flexibilidade como atributo.

Desta forma, a flexibilidade é que permite os SPs adaptarem-se às diferentes situações internas ou externas que influenciam na execução de seus processos, tais como o processamento de diferentes itens, a execução de diferentes processos segundo rotas alternativas, o gerenciamento de fluxos alternativos para 
movimentação dos itens no sistema e a alocação dinâmica das estações de trabalho (SANTOS FILHO, 2000; MATSUSAKI, 2004; ARAÚJO JUNIOR, 2006).

A habilidade de identificar e distinguir os vários tipos de processos executados pelo sistema, alterando as instruções de operação e as configurações físicas de acordo com os recursos disponíveis, são algumas características necessárias para que um SP possa ser considerado flexível (GROOVER, 2007).

Segundo Groover (2007), o conceito de flexibilidade possui múltiplas dimensões de acordo com fatores internos e externos no contexto de SPs, conforme apresentado na Tabela 2.1.

Tabela 2.1 Tipos de flexibilidade em SPs (GROOVER, 2007).

\begin{tabular}{|c|c|c|}
\hline Tipos de Flexibilidade & Definição & Fatores \\
\hline Máquina & $\begin{array}{l}\text { Capacidade da máquina executar uma } \\
\text { variedade de operações. }\end{array}$ & $\begin{array}{c}\text { Tempo de setup, facilidade de } \\
\text { reprogramação, capacidade de } \\
\text { armazenar ferramentas, habilidade e } \\
\text { versatilidade dos operadores no sistema }\end{array}$ \\
\hline Produção & $\begin{array}{l}\text { Capacidade de produção de uma variedade } \\
\text { de processos. }\end{array}$ & Flexibilidade das máquinas \\
\hline Mix & $\begin{array}{l}\text { Habilidade de alterar o mix de produção } \\
\text { enquanto mantém a mesma quantidade total } \\
\text { de produção. }\end{array}$ & $\begin{array}{c}\text { Similaridade das operações de processo } \\
\text { e flexibilidade das máquinas. }\end{array}$ \\
\hline Produto & Capacidade de produzir um novo produto. & $\begin{array}{l}\text { Similaridade do novo produto para } \\
\text { classificá-lo em uma família de produto } \\
\text { existente e flexibilidade das máquina. }\end{array}$ \\
\hline Rotas & $\begin{array}{l}\text { Capacidade de produzir mediante } \\
\text { sequências alternativas. }\end{array}$ & $\begin{array}{l}\text { Similaridade de mix, similaridade de } \\
\text { estações de trabalho, duplicação de } \\
\text { estações de trabalho. }\end{array}$ \\
\hline Volume & $\begin{array}{l}\text { Habilidade de produzir de forma econômica } \\
\text { baixo e alto volume de um mesmo produto. }\end{array}$ & $\begin{array}{l}\text { Nível de trabalho manual executado na } \\
\text { produção. }\end{array}$ \\
\hline Expansão & $\begin{array}{l}\text { Capacidade de expansão do sistema para } \\
\text { aumentar a quantidade total produzida. }\end{array}$ & $\begin{array}{l}\text { Aquisição de estações de trabalho, } \\
\text { disponibilidade física. }\end{array}$ \\
\hline
\end{tabular}

Desta forma, verifica-se que não há um conceito único de flexibilidade, mas sim um conjunto de habilidades que tornam um SP de fato flexível. A grosso modo pode-se considerar que um SPF possui alguma forma de flexibilidade física e flexibilidade lógica para atender os objetivos do sistema.

A implantação das habilidades de flexibilidade de um SPF é influenciada por três aspectos a serem consideradas. O primeiro aspecto está relacionado à seleção das tecnologias de automação a serem implantadas no sistema produtivo para atender 
ao nível de flexibilidade desejada (KALPAKJIAN e SCHMID, 2005; GROOVER, 2007).

O segundo aspecto é quanto ao custo da implementação da flexibilidade desejada, isto é, o grau de flexibilidade define o grau de complexidade do controle (SANTOS FILHO, 2000). O terceiro aspecto é quanto à escolha da arquitetura de controle do sistema (PELS et al., 1997), pois a flexibilidade é limitada pelo projeto da arquitetura escolhida para o controle do SPF. Os dois últimos aspectos estão relacionados com o sistema de controle e com a sua complexidade que são vistos nos próximos itens.

Quanto à questão da automação, a disponibilidade das diversas tecnologias tem auxiliado significativamente no projeto e implantação de SPFs. Entretanto, a aplicação da automação em um SPF depende do mercado em que o sistema em questão visa atender (GROOVER, 2007), isto é, a escolha do nível de automação é de acordo com a variedade de produtos e a quantidade de itens a serem produzidos, conforme apresentado na Figura 2.2.

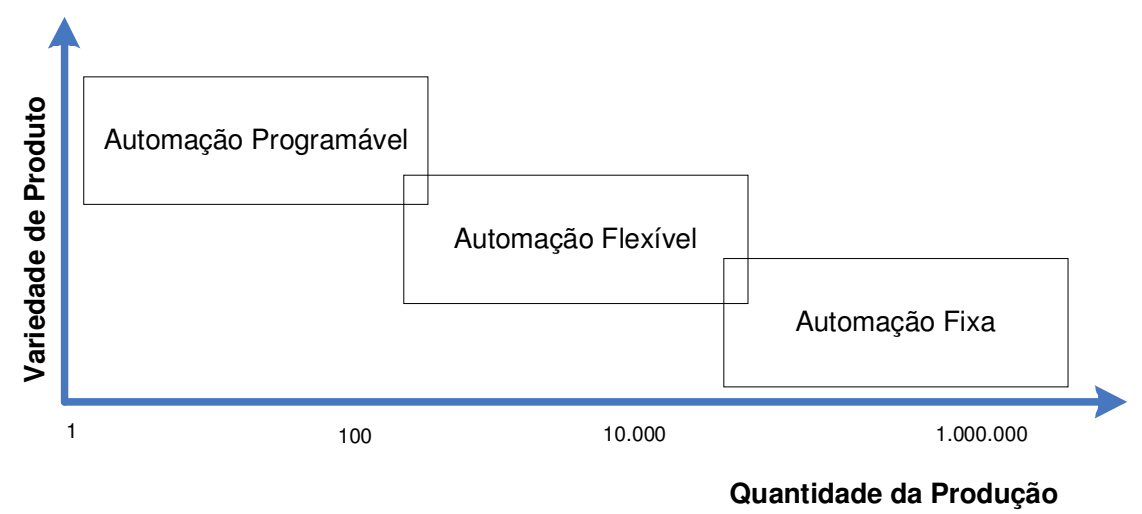

Figura 2.2 Níveis de automação (adaptado de GROOVER, 2007).

De acordo com Kalpakjian e Schmid (2005) a automação justifica-se pelos seguintes aspectos:

* Aumenta a produtividade;

* Melhora a qualidade do produto;

* Integra os elementos que realizam as operações de manufatura;

- Melhora o controle da produção e eficiência no uso dos recursos;

* Reduz o envolvimento humano e as perdas de produção;

* Eleva o nível de segurança; 


\section{* Otimiza o espaço físico.}

A automação permite ainda a obtenção de dados dos processos que podem ser registrados, armazenados e analisados posteriormente, promovendo um melhor entendimento dos processos e conseqüentes melhorias contínuas dos mesmos (NASCIMENTO JR. e YONEYAMA, 2000).

Segundo Groover (2007), as diretrizes que devem nortear a aplicação das tecnologias de automação para que os objetivos possam ser alcançados são:

* Redução do tempo de produção

* Redução do custo de mão-de-obra;

* Redução do refugo e o uso racional dos insumos;

* Automatização das operações repetitivas ou que envolvem riscos ao operador;

* Organização eficiente das máquinas, da movimentação de materiais e dos equipamentos auxiliares.

Em 1988, Masip salientou que o nível de flexibilidade a ser implantada em um SP não deve ser fundamentado em motivações tecnológicas, mas sim em razões econômico-produtivas, ou seja, são decisões realizadas no nível empresarial, de acordo com as estratégias da empresa. Além disso, o mesmo autor já sinalizava que o projeto de um sistema produtivo deve ser tão rígido quanto seja possível e tão flexível quanto seja necessário (MASIP, 1988). São orientações válidas ainda para a realidade atual.

Pelo exposto, o SPF abordado no presente trabalho é do tipo Job-Shop (ARAÚJO JUNIOR, 2006; GROOVER, 2007) que possui:

* Um nível de flexibilidade para o atendimento de uma produção de baixos volumes e alta variabilidade de produtos;

* Um nível de automação flexível, capaz de atender a diferentes processos simultâneos.

A Figura 2.3 ilustra a relação entre os conceitos de SP, flexibilidade e automação que permitem a definição do nível de flexibilidade e automação requerida em um SPF. 


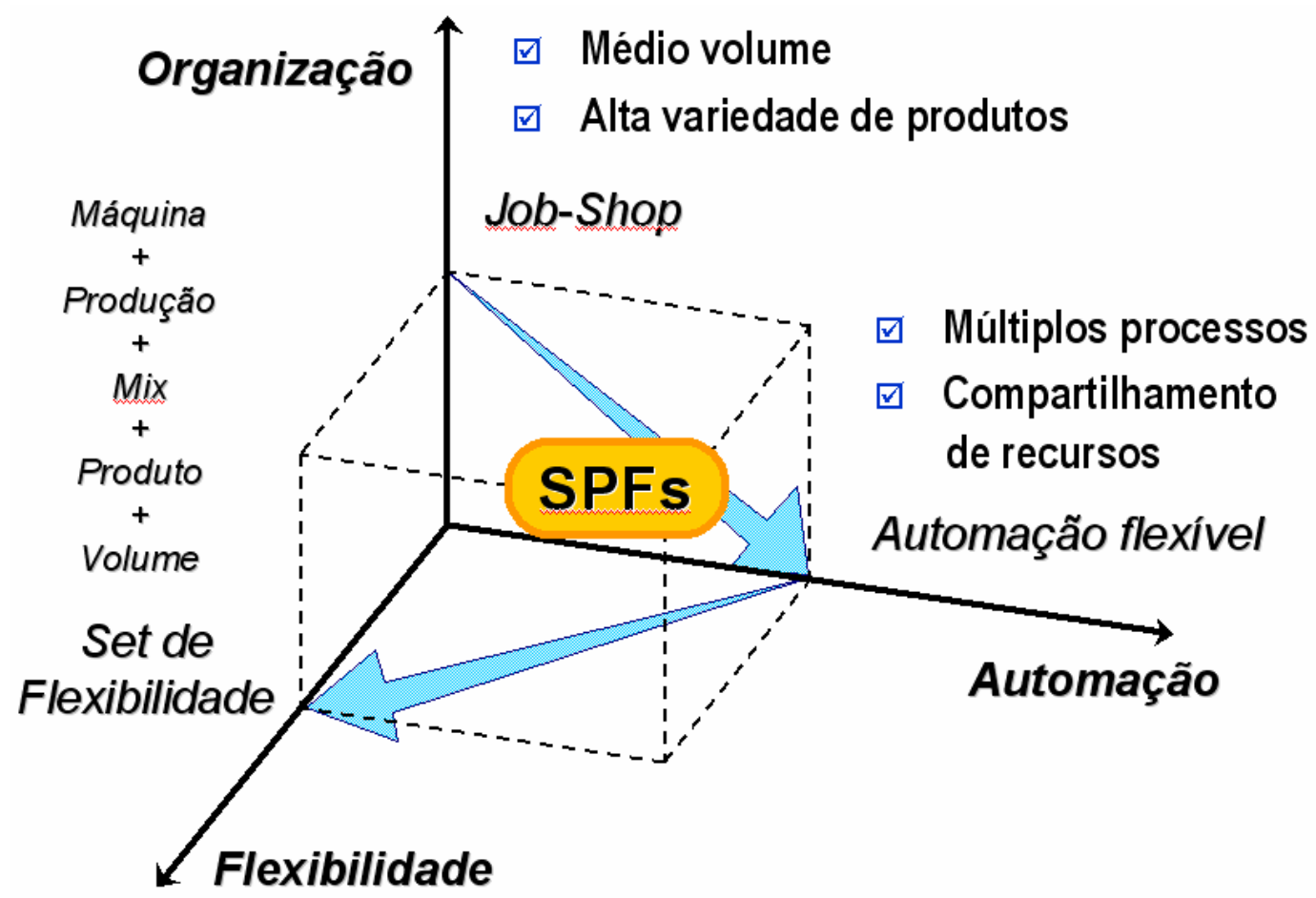

Figura 2.3 Correlação entre os conceitos de SPF, Flexibilidade e Automação.

Concluindo, a automatização de um processo e/ou do sistema como um todo envolve a execução dos procedimentos pré-estabelecidos no projeto garantindo-se o comportamento dinâmico desejado do sistema. Sendo que a realização de tais procedimentos e das operações de manufatura devem ser executadas de forma automática. Assim, para qualquer nível de automação aplicado em um SPF faz-se necessário projetar-se um sistema de controle adequado, a fim de garantir a atingibilidade dos objetivos propostos.

\subsection{Sistema de Controle para SPFs}

O controle é definido como a aplicação de um conjunto de ações pré-estabelecidas para que, aquilo que se considera como objeto de controle, atinja objetivos determinados, refletindo o comportamento dinâmico desejado para o sistema (MIYAGI, 1996; SANTOS FILHO, 2000). O comportamento desejado de um SPF é o cumprimento do plano de produção estabelecido pelo planejamento, resultando na variedade de produtos, com os respectivos volumes, dentro dos prazos estabelecidos e utilizando os recursos disponibilizados para os processos. 
Considerando-se que as estratégias de controle para SPFs são atualmente baseadas na tecnologia de computadores, isto é, o controle é realizado mediante a execução de um programa e um algoritmo de controle (MIYAGI, 1996), a execução do controle de um único processo é garantida pela execução efetiva e seqüencial das atividades do processo. Porém, no SPF não há apenas um único processo, mas um conjunto de processos, logo, a prescrição de um algoritmo de controle global é uma tarefa singular.

\subsubsection{Complexidade e Modelo de Restrições}

A origem do termo complexidade vem do latim complexus que significa entrelaçado ou torcido junto (HOUAISS, 2007). A complexidade é um atributo do sistema em que a representação do comportamento global não é possível de ser formulado a partir do comportamento individual das partes ou componentes do sistema (EDMONDS, 1995). Isto é, um sistema complexo (SC) possui numerosos componentes com interconexões, interações ou interdependências que o tornam o ato de descrever, entender, prescrever, gerenciar, projetar ou alterar não trivial (MAGEE e WECK, 2004). Portanto, é importante destacar que para o presente trabalho é valida a interpretação segundo a qual o comportamento dinâmico do SPF como um todo não goza das mesmas propriedades do comportamento dinâmico de uma das partes do SPF.

Santos Filho (2000) destacou que a complexidade da execução simultânea de um conjunto de processos em SPs deve-se a coexistência de:

* Indeterminismo em relação à ocorrência de eventos: Devido ao fato do SP pertencer à classe de SDED, não é possível predeterminar o instante em que ocorrerá um determinado evento;

- Indeterminismo em relação à seqüência dos eventos: Devido à característica do SP poder executar múltiplos processos simultâneos com compartilhamento de um mesmo conjunto finito de recursos, deixa de ser possível determinar-se qual evento precede o outro no contexto global.

Desta forma, em um SPF o controle de um único processo é relativamente simples, pois envolve somente a garantia do seqüenciamento das atividades do processo. Entretanto, não é possível determinar o comportamento global do sistema de modo 
puramente seqüencial (SANTOS FILHO, 2000; SANTOS FILHO et al., 2001; NAKAMOTO, 2002), porque a propriedade de seqüenciamento pré-determinado, valida para cada processo individual, deixa de ser válido no processo global. É importante observar que os indeterminismos apresentados até o momento estão relacionados apenas aos recursos de transformação inerentes aos processos. Se as atividades de transformação são executadas em estações de trabalho o processo envolve também atividades de transporte entre as estações, o que resulta em ao menos mais dois indeterminismos dependendo do sistema de transporte de material adotado:

* Indeterminismo em relação à designação do recurso de transporte: Isto ocorre quando se considera transportadores do tipo universal, isto é, que o recurso de transporte pode atender aos pedidos de transporte de qualquer das estações de trabalho;

* Indeterminismo em relação à atividade de transporte: Isto ocorre quando se considera que é necessário gerar uma nova atividade de transporte de acordo com a evolução dinâmica dos processos.

Uma das conseqüências da coexistência dos indeterminismo citados é a explosão combinatória de estados alcançáveis de SPFs, que dificulta o projeto do sistema de controle. Uma das formas de abordar o problema da explosão de estados, que será explorado neste trabalho, é a adoção de um modelo de restrições no controle de SPF, a exemplo do que foi aplicado com sucesso no trabalho de Santos Filho (2000).

O modelo de restrições consiste em identificar os estados indesejáveis do sistema e criar mecanismos ou executar ações que impeçam o sistema de evoluir para estes estados. Alguns estados indesejáveis que podem ser citados são o deadlock em alocação de recursos e situações de falhas, como por exemplo, quebra de máquinas. Para que a aplicação desta técnica possa ser implementada no sistema de controle, é necessária uma escolha adequada de arquitetura de controle para o SPF. 


\subsubsection{Diagrama Conceitual do Sistema de Controle}

Considerando-se a natureza discreta dos SPFs, o modelo conceitual básico do sistema de controle é apresentado na Figura 2.4 (MIYAGI, 1996). O sistema de controle atua sobre o objeto de controle através dos dispositivos de atuação (variáveis de atuação) e a realimentação (feedback) é realizado mediante a leitura das variáveis controladas pelo dispositivo de detecção. $O$ dispositivo de realização do controle recebe as informações das variáveis controladas e os comandos do operador e, considerando ainda certas variáveis internas define/atualiza as variáveis de atuação, conforme procedimentos pré-estabelecidos, para o dispositivo de atuação. O elemento humano, no caso o operador, monitora o sistema de controle pelos dispositivos de monitoração e atua no sistema através dos dispositivos de comando.

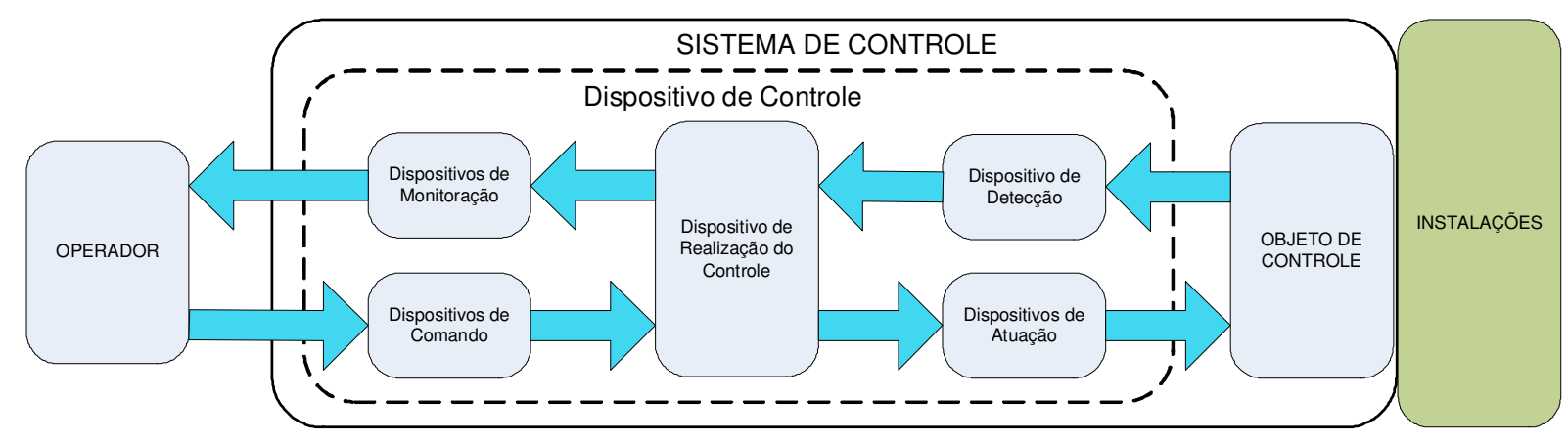

Figura 2.4 Diagrama conceitual do sistema de controle de SDED (MIYAGI, 1996).

O diagrama conceitual proposto em Miyagi (1996) sofreu alterações nos trabalhos de Santos Filho (2000) com a divisão do sistema de controle em níveis de controle hierárquicos, complementares e de semânticas distintas (Fig. 2.5).

O sistema de controle é agora dividido em dois níveis denominados controle de processos (CP) e controle de recursos (CR). O CP é responsável pelo seqüenciamento das atividades do processo, ou seja, é o controle que garante a execução das atividades de transformação do processo, enquanto o $\mathrm{CR}$ é responsável pela utilização dos recursos entre as atividades de cada um dos processos. O CP executa cada uma das atividades, requisitando o recurso de transformação, alocando o respectivo recurso e monitorando a sua execução. 


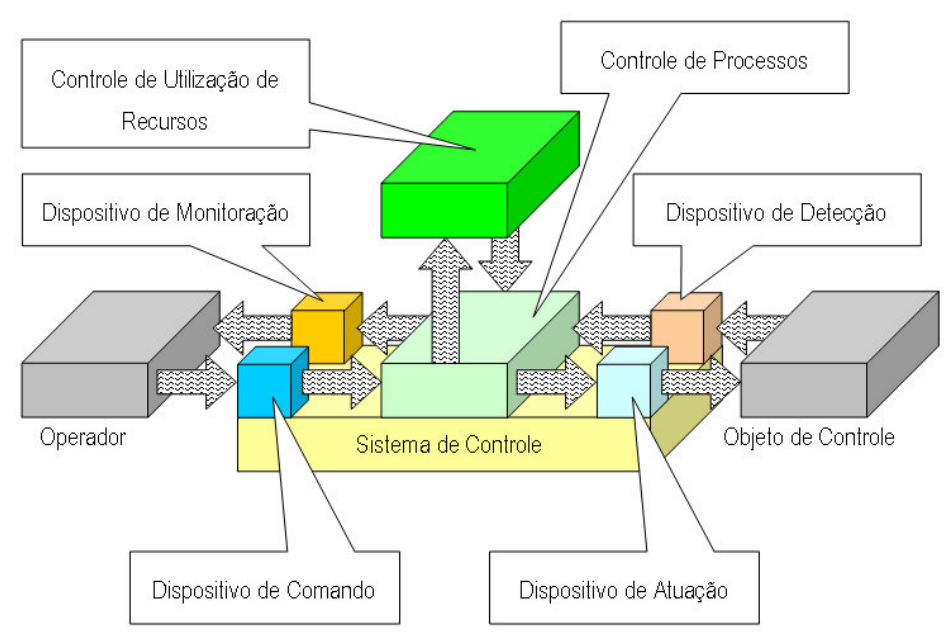

Figura 2.5 Arquitetura do sistema de controle proposto por Santos Filho (2000).

Quando é necessária a alocação de um recurso, o CP requisita o recurso para o CR que possui a visão global quanto à utilização dos recursos. Salienta-se que o controle de cada processo possui apenas uma visão de controle local. De acordo com regras pré-estabelecidas, o CR autoriza ou não a utilização de recursos, resolvendo desta forma, os conflitos entre os processos quanto à alocação de recursos.

As principais vantagens identificadas com o uso da divisão do controle apresentada por Santos Filho (2000) são:

* Distinção da natureza semântica dos controles quanto ao seu objeto de controle;

* Aplicação eficiente do modelo de restrições para abordar o problema de explosões de estado;

* Possibilidade de utilizar uma estrutura de controle modular.

\subsubsection{Arquitetura de Controle}

A flexibilidade é limitada pela arquitetura de sistema de controle escolhida. Segundo Houaiss (2007), a arquitetura é a arte de especificar, projetar, implementar, construir e edificar um ambiente estruturado. Desta forma, uma arquitetura de controle é o resultado da realização de um projeto, dado um conjunto de especificações que 
expressam à estruturação lógica e as funções de seus componentes, as interfaces, as inter-relações e as restrições entre os componentes (PELS et al., 1997).

As arquiteturas de controle podem ser classificadas em (PELS et al., 1997; MATSUSAKI, 2004):

- Centralizada: A arquitetura centralizada possui a característica de um único elemento executar as estratégias de controle. Em termos práticos, um único controlador é responsável pelo controle de todas as atividades envolvidas no sistema produtivo;

* Distribuída: A arquitetura distribuída ou descentralizada possui a característica de distribuir as estratégias de controle para vários elementos. Desta forma, cada controlador possui uma autonomia dentro do escopo de atuação.

Com base nos avanços tecnológicos dos dispositivos de realização de controle, das redes de comunicações e tecnologias de informações, a arquitetura distribuída é considerada uma evolução natural da arquitetura centralizada frente às limitações para a realização do controle. Principalmente quanto ao quesito flexibilidade no processo produtivo (PELS et al., 1997), conforme apresentado na Figura 2.6.

Verifica-se que os elementos que compõem o objeto de controle de SPFs, para que possuam a flexibilidade desejada, necessitam de sistemas de controle embarcados para executarem automaticamente diferentes operações. Portanto o conceito de controle distribuído torna-se essencial para o projeto de arquiteturas de controle para SPFs.

Os sistemas distribuídos podem ser classificados em (PELS et al., 1997; OU-YANG e LIN, 1998; BONGAERTS et al., 2000; MATSUSAKI, 2004; MARTINS, 2005):

* Hierárquico: A arquitetura hierárquica de controle apresenta níveis de controle que contém módulos dispostos em uma organização piramidal, caracterizando uma relação master-slave (PELS et al., 1997; OU-YANG e LIN, 1998; BONGAERTS et al., 2000). Basicamente, as funções de controle dos níveis superiores são decompostos sucessivamente para os controles dos níveis inferiores caracterizando uma abordagem de 
comando top-down e realimentação de informações botton-up (BONGAERTS et al., 2000);

Heterárquico: A arquitetura heterárquica de controle é caracterizada pelo elevado grau de autonomia dos elementos de controle implementados de modo que cooperam na resolução de problemas de controle (MATSUSAKI, 2004). As estratégias de controle são realizadas através da negociação entre os elementos de controle mediante 0 uso da comunicação e do compartilhamento e troca de informações entre os mesmos (BONGAERTS et al., 2000);

Híbridos: A arquitetura híbrida possui características hierárquicas e heterárquicas de controle, isto é, é uma arquitetura que mantém ainda certa relação master-slave entre os elementos, mas considera também certo grau de autonomia e cooperação entre os controladores (OU-YANG e LIN, 1998; MARTINS, 2005).

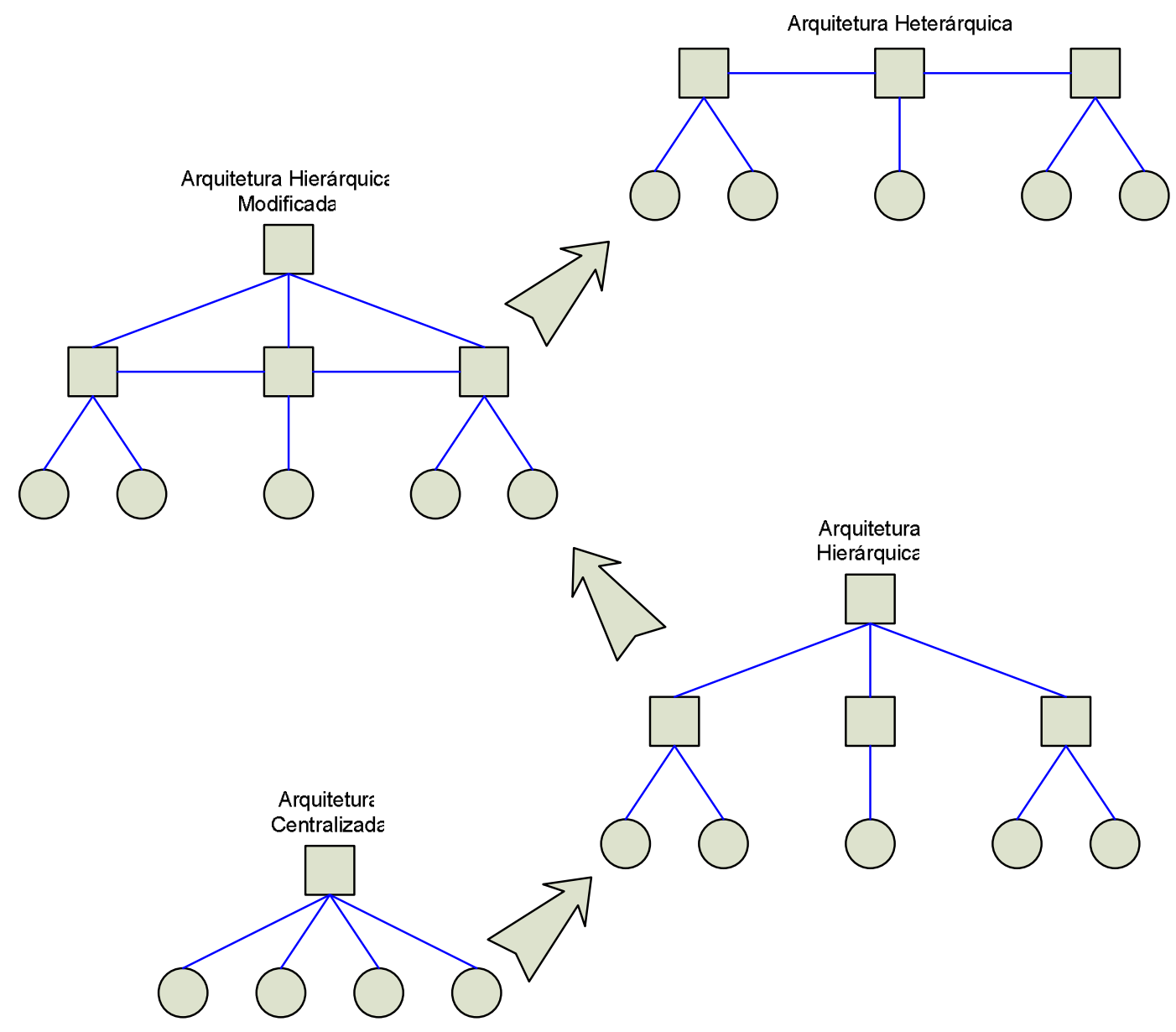

Figura 2.6 Evolução das arquiteturas de controle. 
Observa-se que a hierarquia pode ser implementada de duas formas (Fig. 2.6): realizando um controle distribuído coordenado (arquitetura hierárquica), ou realizando um controle hierárquico modificado (arquitetura hierárquica modificada). São variações que refletem os melhoramentos em diversos aspectos, por exemplo: enquanto a arquitetura de controle distribuído coordenado aplica a relação masterslave entre o controle supervisório, que atua como coordenador, e os módulos de controles, a arquitetura hierárquica modificada utiliza a comunicação ponto-a-ponto (peer-to-peer) entre os controladores do nível inferior, podendo sincronizar processos e reagir a determinadas perturbações de forma colaborativa.

Por sua vez, a arquitetura de controle heterárquica permite a implementação de um alto grau de flexibilidade do sistema de controle frente às alterações e/ou mudanças necessárias, entretanto apresenta em certo grau de imprevisibilidade do comportamento dinâmico do controle (BONGAERTS et al., 2000), situação que não é aceitável em controle.

As arquiteturas de controle hierárquico são amplamente empregadas no meio industrial, entretanto, a dificuldade em modificar e/ou incorporar as mudanças no sistema, tem motivado empresas e pesquisadores a desenvolverem novos modelos de controle e arquiteturas para atender às novas exigências do mercado (BONGAERTS et al., 2000). De fato, isto é devido à natureza rígida do relacionamento master-slave entre os elementos de controle na arquitetura hierárquica, o que seria atenuado quando se utiliza a estrutura hierárquica modificada.

Por outro lado, a integração dos diversos níveis inerentes aos processos de um sistema produtivo tornou-se requisito mínimo para que as empresas possam atuar no mercado globalizado. Esta integração envolve a comunicação e troca de informações que possam ser compreendidas por todas as partes envolvidas, ou seja, verificada as necessidades de adaptação a uma nova realidade de mercado, as novas estratégias de negócio são definidas e devem ser refletidas rapidamente no sistema produtivo. Desta forma, tem-se mais um aspecto de compromisso que fortalece a adoção da arquitetura hierárquica modificada para o sistema de controle de SPFs. 


\subsubsection{Norma ANSI/ISA 95}

A integração dos níveis que estabelecem as estratégias de negócio da empresa com o sistema produtivo é um fator fundamental para que a empresa possa atuar em um mercado dinâmico e competitivo de forma ágil.

A ANSI (American National Standards Institute) juntamente com a ISA (Instrumentation, Systems and Automation Society) criou um comitê e iniciaram o projeto ISA95 para a elaboração da norma ANSI/ISA95 Enterprise/Control System Integration. Os pontos que nortearam a elaboração da norma foram (ISA, 2003):

* Necessidade de identificação das interações envolvidas;

* Necessidade de distinção entre os processos de negócio e os processos de manufatura;

Necessidade de independência entre os sistemas de negócios e os sistemas de manufatura.

Atualmente, cinco partes da norma estão disponíveis, sendo que a norma considerada no presente trabalho é a ANSI/ISA-95 parte 3. A norma contém os modelos e as terminologias para a definição das interfaces entre o sistema de estratégias de negócio da empresa e o sistema de controle da manufatura ${ }^{1}$.

Nesta norma, o foco está na redução de riscos operacionais mediante a caracterização do grau de dificuldade de integração e interoperabilidade entre o planejamento e o sistema de controle. A norma identifica e estabelece um modelo de atividades e fluxos de dados das informações, denominado-o de diagrama de hierarquia funcional (Fig. 2.7).

Basicamente, o modelo identifica os seguintes níveis:

* Nível 0: Define o processo físico real;

\footnotetext{
1 ANSI/ISA-95.00.03-2005 Enterprise/Control System Integrations - Part 3: Models of Manufacturing Operations Management. São apresentadas as definições das atividades associadas para a realização das operações de manufatura, ou seja, fornece importantes indicações do que deve ser considerado para a realização da efetiva integração das atividades de planejamento da produção com a respectiva gestão operacional da manufatura envolvida.
} 
Nível 1: Define as atividades envolvidas na coleta de sinais e manipulação dos processos físicos, operando tipicamente dentro de "janelas de tempo"2 das grandezas de interesse em segundos ou menos;

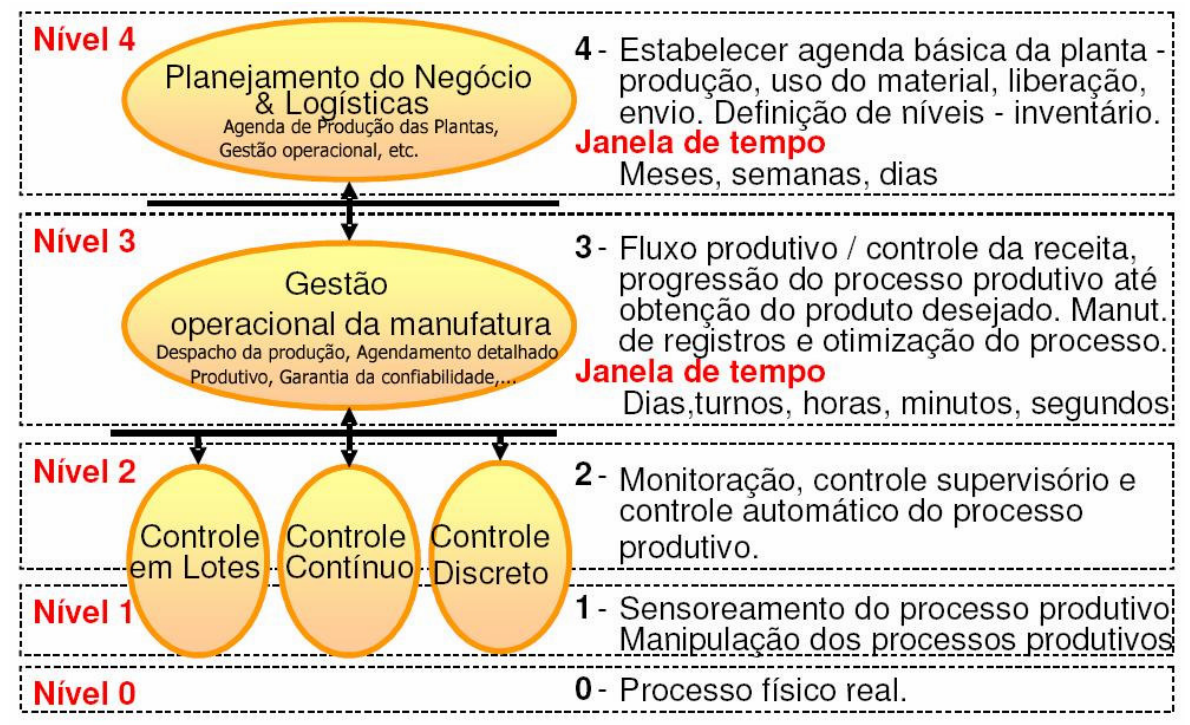

Figura 2.7 Hierarquia funcional de atividades (ANSI/ISA95.00.03).

* Nível 2: Define as atividades de monitoração e controle local dos processos físicos, operando dentro de "janelas de tempo" da ordem de minutos, segundos ou suas divisões. O nível 2 tipicamente trata de um equipamento dentro de um centro de trabalho, conforme a hierarquia proposta pela norma;

Nível 3: Define as atividades que realizam a progressão dos processos para gerar os produtos finais. Inclui as atividades de manutenção de registros e coordenação dos processos. O nível 3 opera tipicamente dentro de "janelas de tempo" de dias, turnos, horas, minutos e segundos, sobre áreas de centros de trabalho;

Nível 4: Define as atividades do negócio necessárias para manter o sistema de manufatura. Entre as atividades relacionadas com a manufatura estão os estabelecimentos da agenda principal da planta, determinação de níveis de inventário e garantia de que os materiais são liberados em tempo e no lugar certo para produção.

\footnotetext{
${ }^{2}$ Refere-se a unidade de tempo adequadamente adotada a cada nível funcional.
} 
A norma apresentada estabelece uma divisão conceitual das funções de controle dos SPFs. Desta forma, a arquitetura do sistema de controle deve, além de respeitar a norma, ser concebida para atender às necessidades do grau de flexibilidade requerido.

\subsection{Observações Complementares}

Neste capítulo foram apresentadas as caracterizações e as definições que norteiam o conceito de SPF adotado neste trabalho. Apresentou-se a relação entre o grau de flexibilidade, o conceito de automação, a complexidade do sistema, o modelo de restrições e as arquiteturas de controle.

Entretanto, os sistemas que possuem um compartilhamento de um conjunto finito de recursos podem levar o sistema a evoluir para um estado indesejável denominado deadlock. Desta forma, faz-se necessário a discussão sobre um sistema de alocação de recursos, as causas do deadlock e as formas possíveis para tratar o problema, que serão abordados no próximo capítulo. 


\section{CAPÍTULO}

\section{DEADLOCK EM SISTEMAS PRODUTIVOS FLEXÍVEIS}

Os processos executados no SPF compartilham entre si um conjunto finito de recursos. Neste contexto, os processos alocam e utilizam os recursos compartilhados de forma exclusiva, conseqüentemente, causando uma competição entre os processos. Esta competição pode permitir a evolução do estado do sistema para uma condição indesejável denominado deadlock.

O deadlock é um estado do sistema caracterizado quando os fluxos dos processos são permanentemente impedidos, aguardando por um evento que somente um outro processo poderia disparar. Entretanto, este também se encontra no mesmo estado. Neste caso, somente uma intervenção externa poderia restabelecer o sistema do deadlock.

Este capítulo apresenta inicialmente uma caracterização de sistema de alocação de recursos quanto a forma com que esses recursos são utilizados, as atividades que são desenvolvidas no SPF e os aspectos relacionados ao compartilhamento desses recursos com o problema de deadlock.

A seguir, apresenta-se uma caracterização do problema de deadlock, as condições mínimas para a ocorrência de deadlock, as formas para tratá-lo e uma revisão bibliográfica dos principais métodos empregados em SPF.

Ao término, apresenta-se o método que será adotado neste trabalho para solucionar o problema de deadlock. 


\subsection{Sistema de Alocação de Recursos}

Um processo é um conjunto seqüencial de atividades que devem ser executadas para resultar em um produto. Considerando-se um ambiente em que há um envolvimento de vários processos em execução simultânea com compartilhamento de recursos, característica do SPF, os processos competem entre si pela alocação de recursos. Evidentemente, uma das formas para tratar este problema é através do estabelecimento de regras de alocação para garantir a execução das atividade, conforme apresentada a seguir (SANTOS FILHO, 2000):

- Regra 1: requisitar o recurso: verificar a disponibilidade do recurso para a execução da atividade;

* Regra 2: alocar o recurso: autorizada a requisição, o processo reserva o recurso para si;

* Regra 3: utilizar o recurso: alocado o recurso, o processo aguarda a realização da atividade pelo recurso;

* Regra 4: liberar o recurso: concluída a atividade, somente o processo que o alocou poderá liberar o recurso para outros processos.

Desta forma, a efetiva alocação do recurso ocorrerá somente se o mesmo estiver disponível, ou seja, livre para alocação.

O sistema de alocação de recursos (SAR) é o responsável por definir a forma de alocação e a utilização dos recursos pelos processos para que as atividades possam ser realizadas. Segundo Reveliotis (2005), um SAR é definido como uma quíntupla $\Phi=\langle R, C, P, A, T\rangle$, em que:

* $R=\left\{R_{1}, R_{2}, \ldots, R_{m}\right\}$ é um conjunto formado pelos tipos de recursos de um sistema produtivo;

* $C: R \rightarrow Z^{+}$é a função capacidade do sistema, caracterizado pelo número de unidades idênticas de cada tipo de recurso disponível no sistema, isto é, a quantidade de instâncias de um determinado recurso. Os recursos são considerados como reutilizáveis, ou seja, cada utilização não afeta as 
propriedades de funcionalidade ou de disponibilidade do recurso. Tal que $C\left(R_{i}\right) \equiv C_{i} ;$

* $P=\left\{\Pi_{1}, \Pi_{2}, \ldots, \Pi_{j}\right\}$ é o conjunto de processos que serão executados no sistemas, sendo que, cada processo $\Pi_{j}$ é formado pelo par $\Pi_{j}=\left\{S_{j}, G_{j}\right\}$, tal que:

- $S_{j}=\left\{\Xi_{j 1}, \Xi_{j 2}, \ldots, \Xi_{j, l(j)}\right\}$ é uma seqüência de atividades do processo $\Pi_{j} ;$

- $G_{j}$ representa uma estrutura de dados que descreve uma gramática de execução do processo $\Pi_{j}$. A caracterização da seqüência pode ser realizada mediante o emprego de uma semântica.

* $A: \bigcup_{j=1}^{n} S_{j} \rightarrow \prod_{i=1}^{m}\left\{0,1, \ldots, C_{i}\right\}$ é a função de alocação de recurso associado a execução da atividade $\Xi_{j k}$ com uma requisição de alocação de recursos $A(j, k) \equiv A_{j k}$. Isto é, cada $A_{j k}$ é um vetor de dimensão $m$ em que o i-ésimo componente indica o número da unidade de recurso do tipo $R_{i}$ necessário para a execução da atividade $\Xi_{j k}$, sendo que $A_{j k}(i) \leq C_{i}, \forall j, k, i$;

- $T: \bigcup_{j=1}^{n} S_{j} \rightarrow D$ é a função de tempo. Para cada atividade $\Xi_{j k}$ corresponde a uma distribuição $D_{j k}$ que caracteriza uma estatística de tempo de processamento $t_{j k}$, durante a execução da atividade $\Xi_{j k}$.

Como exemplo, considere a célula de manufatura flexível apresentado na Figura 3.1 que é composta de três estações de trabalho $\left(W_{3}, W_{2}, W_{1}\right)$, um robô manipulador e um local de carregamento/descarregamento de itens atividades estas que representam a entrada e saída de itens do sistema. O robô é responsável pelo fluxo de itens na célula e atende a todas as estações de trabalho. As estações de trabalho possuem um dispositivo processador de capacidade unitária, que de fato realiza a atividade, e um dispositivo para recepção e despacho de itens (buffer) também de capacidade unitária. 
Observa-se que a natureza das atividades realizadas pelo robô neste exemplo são atividades de transporte, enquanto que nas estações de trabalho, o tipo de atividade é o de transformação. Ainda no exemplo, a célula produz dois tipos de itens ou job, identificados por $J_{1}=W_{1} \rightarrow W_{2} \rightarrow W_{3}$ e $J_{2}=W_{3} \rightarrow W_{2} \rightarrow W_{1}$. Cada item sofre transformação em todas as estações de trabalho, porém em seqüência distinta.

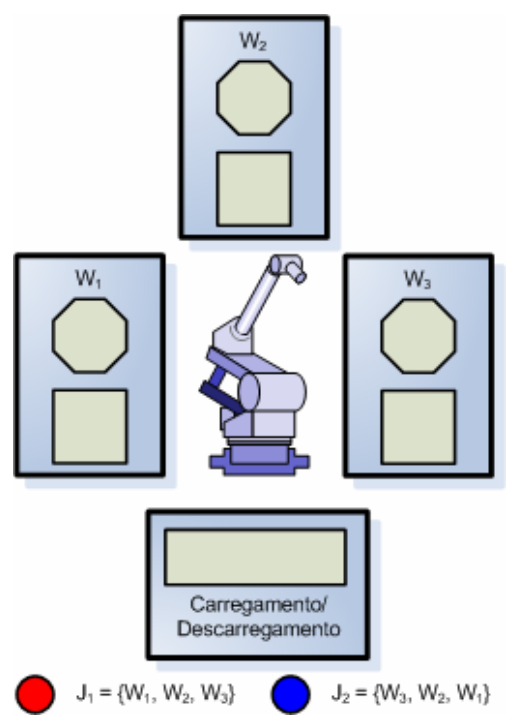

Figura 3.1 Exemplo de uma célula de manufatura flexível (REVELIOTIS, 2005).

Assim, o SAR $\Phi$ é composto por $R_{i}, i=0, \ldots, 3$ sendo que $\left\{R_{0}\right\}$ é o robô e $\left\{R_{1}, R_{2}, R_{3}\right\}$ são respectivamente as estações de trabalho. Os itens possuem a seqüência de alocação de recursos $\quad \Pi_{1}=R_{0} \rightarrow R_{1} \rightarrow R_{0} \rightarrow R_{2} \rightarrow R_{0} \rightarrow R_{3} \rightarrow R_{0} \quad$ e $\Pi_{2}=R_{0} \rightarrow R_{3} \rightarrow R_{0} \rightarrow R_{2} \rightarrow R_{0} \rightarrow R_{1} \rightarrow R_{0}$, logo, o processo $\Pi_{1}$ consiste de uma seqüência de atividades $S_{1}=\left\{\Xi_{11}, \Xi_{12}, \Xi_{13}, \Xi_{14}, \Xi_{15}, \Xi_{16}, \Xi_{17}\right\}$ e o processo $\Pi_{2}$ consiste de uma seqüência de atividades $S_{2}=\left\{\Xi_{21}, \Xi_{22}, \Xi_{23}, \Xi_{24}, \Xi_{25}, \Xi_{26}, \Xi_{27}\right\}$.

As definições e as condições descritas anteriormente estabelecem o comportamento geral de um SAR. Porém, ainda é possível classificar o SAR de acordo com a imposição de determinadas estruturas adicionais na seqüência lógica e na requisição de alocação de recursos $A_{j k}$ associado à atividade $\Xi_{j k}$.

Considerando-se a gramática de execução do processo e a função da requisição de alocação de recursos, as classes de SAR podem ser identificadas da seguinte forma (REVELIOTIS, 2005): 
* Linear Resource Allocation Systems (LIN-RAS): é uma classe em que cada tipo de processo $\Pi_{j}$ consiste de uma seqüência linear de execução das atividades definida por $G_{j}$ e $S_{j}$;

* Conjunctive Resource Allocation Systems (CON-RAS): é uma classe em que o vetor de requisição de alocação de recursos $A_{j k}$ pode ser qualquer vetor inteiro tal que $0 \leq A_{j k}(i) \leq C_{i}, i=1,2, \ldots, m$, ou seja, o pedido de requisição de alocação será atendido desde que seja possível, de acordo com a disponibilidade dos recursos requisitados;

- Disjunctive Resource Allocation Systems (DIS-RAS): é uma classe em que a gramática de execução $G_{j}$ de cada tipo de processo $\Pi_{j}$ pode ser representado por um grafo orientado acíclico (BANG-JENSEN e GUTIN, 2002) com um conjunto de nós igual a $S_{j}$, ou seja, cada arco orientado corresponde à execução de uma atividade. O comportamento desta classe de SAR é verificado em processos com rotas flexíveis (GROOVER, 2007);

* Coordinating Resource Allocation Systems (COR-RAS): é uma classe em que a gramática de execução $G_{j}$ de cada tipo de processo $\Pi_{j}$ pode ser representado por um grafo orientado acíclico (BANG-JENSEN e GUTIN, 2002) de montagem/desmontagem com um conjunto de nós igual a $S_{j}$. Consequentemente, cada tipo de processo que pertence a esta classe executa uma única seqüência principal envolvendo a realização de atividades em paralelo e sincronizadas;

* Complex Resource Allocation Systems (CPX-RAS): é a classe que inclui a combinação dos comportamentos das classes de SAR apresentados anteriormente.

* Single Unit Resource Allocation Systems (SU-RAS): é uma classe em que cada atividade do processo é executada por uma única instância de recurso;

* Single Type Resource Allocation Systems (ST-RAS): é uma classe em que cada atividade do processo é executada por um único tipo de recurso, porém pode ser executado por mais de uma instância. 
De acordo com a natureza dos processos no SPF é possível caracterizar o SAR como uma composição de classes. Por exemplo, um sistema produtivo de classe LIN-SU-RAS é o mais restritivo e com a menor complexidade, enquanto que um sistema de classe CPX-CON-RAS é a mais complexa.

\subsection{Deadlock em SAR}

Silberschatz et al. (2004) ilustram a ocorrência de deadlock citando uma lei, aprovada no século passado pelo estado norte-americano de Kansas, que dizia: "Quando dois trens se aproximarem um do outro em um cruzamento, ambos deverão parar completamente e nenhum dos dois deverá ser acionado até que o outro tenha partido". Observamos que a lei gera uma situação onde nenhum dos trens pode mais ser acionado, apesar de ser uma lei inadequada freqüentemente identificamos a ocorrência deste tipo de situação, principalmente envolvendo o tráfego de veículos nos grandes centros urbanos da atualidade. A Figura 3.2 ilustra a formação de deadlock em um cruzamento de duas grandes vias.

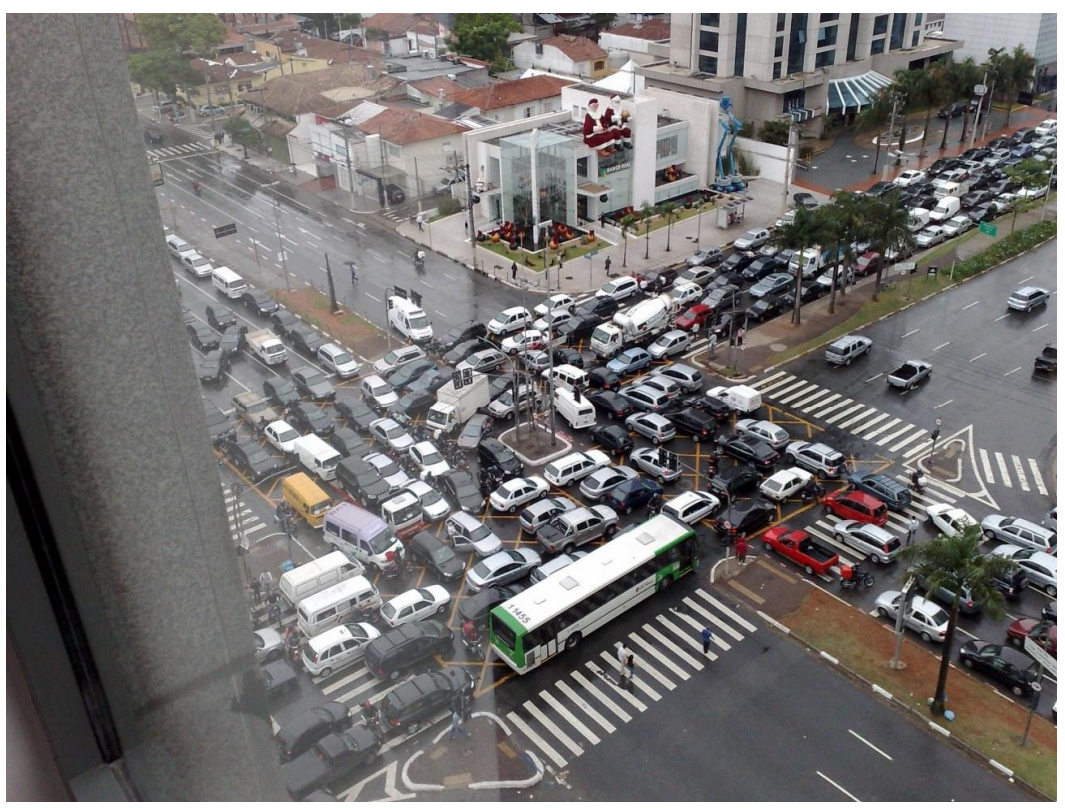

Figura 3.2 Exemplo de deadlock em tráfego de automóveis ${ }^{3}$.

\footnotetext{
${ }^{3}$ Disponível em < http://aramos.org/wp-content/uploads/2008/01/deadlock.jpg>. Acesso em 01 de Ago. 2008.
} 
Observa-se no exemplo que o número de veículos supera a capacidade física do cruzamento e que os automóveis utilizam o espaço físico da via de forma exclusiva, ou seja, somente será permitido o deslocamento do automóvel se houver espaço disponível à frente. Verifica-se que o espaço a frente é utilizado por outro automóvel que se encontra na mesma situação de espera.

O deadlock ou auto-travamento é caracterizado pelo bloqueio permanente no fluxo das atividades dos processos devido à falta de materiais, recursos e/ou informações. O deadlock é objeto de estudo que se iniciou na área de ciências da computação, principalmente em sistemas operacionais (TANENBAUM, 1995; SILBERSCHATZ et. al., 2004), sistemas de bancos de dados (DATE, 2000) e redes de computadores (TANENBAUM, 1996).

Em sistemas operacionais, os processos concorrentes competem entre si pelo uso da CPU, dispositivos de I/O, memória, dispositivos de disco, periféricos, entre outros. Se o recurso requisitado não estiver disponível no momento, o processo entra em estado de espera. Podem assim ocorrer situações em que os processos em estado de espera continuem indefinidamente aguardando a liberação de recursos que estão sendo mantidos por outros processos em estado de espera, caracterizando-se assim o deadlock em sistemas operacionais (TANENBAUM, 1995; et. al., 2000).

Similarmente, nos sistemas de banco de dados, a situação de deadlock é caracterizada quando as transações entram em estado de espera aguardando pela liberação de tabelas que são mantidas por outras transações em estado de espera (DATE, 2000). A Figura 3.3 ilustra o problema de deadlock em duas transações que utilizam tabelas.

\begin{tabular}{|c|c|c|}
\hline Transação A & Tempo & Transação B \\
\hline Aloca tabela 1 & $\mathrm{t} 1$ & - \\
\hline & $\mathrm{t} 2$ & Aloca tabela 2 \\
\hline Requisita tabela 2 & $\mathrm{t} 3$ & - \\
\hline aguarda & $\mathrm{t} 4$ & Requisita tabela 1 \\
\hline aguarda & $\mathrm{t} 5$ & aguarda \\
\hline aguarda & $\mathrm{t} 6$ & aguarda \\
\hline
\end{tabular}

Figura 3.3 Exemplo de deadlock em banco de dados.

Em redes de computadores, os protocolos de comunicação são utilizados para enviar e receber informações entre os computadores interligados. O deadlock é identificado quando não é mais possível enviar os pacotes de informações pela rede 
independente da seqüência de eventos. Isto é, são caracterizados pela existência de subconjuntos alcançáveis a partir do estado inicial que não possuem transições de saída do subconjunto e não há transições no subconjunto que permitam a evolução dos estados (TANENBAUM, 1996).

No contexto de SPF, o deadlock também ocorre devido a competição entre os processos concorrentes pela utilização de recursos compartilhados. Por exemplo, considerando-se a célula de manufatura flexível apresentada na Figura 3.4, composta por três recursos de transformação $\left(W_{1}, W_{2}, W_{3}\right)$, um robô manipulador e um buffer de carregamento/descarregamento, dois processos são executados $\left(J_{1}, J_{2}\right)$. No estado em que $W_{1}$ está sendo utilizado pelo processo $J_{1}$ e $W_{2}$ está sendo utilizado pelo processo $J_{2}$, verifica-se que no passo seguinte ambos os processos entram em conflito, pois o processo $J_{1}$ requer o uso do recurso $W_{2}$ que está ocupado pelo processo $J_{2}$. Enquanto que $J_{2}$ requer o uso do recurso $W_{1}$ que está ocupado pelo processo $J_{1}$. Nesta situação de travamento, somente uma intervenção externa poderá restabelecer o fluxo dos processos no sistema.

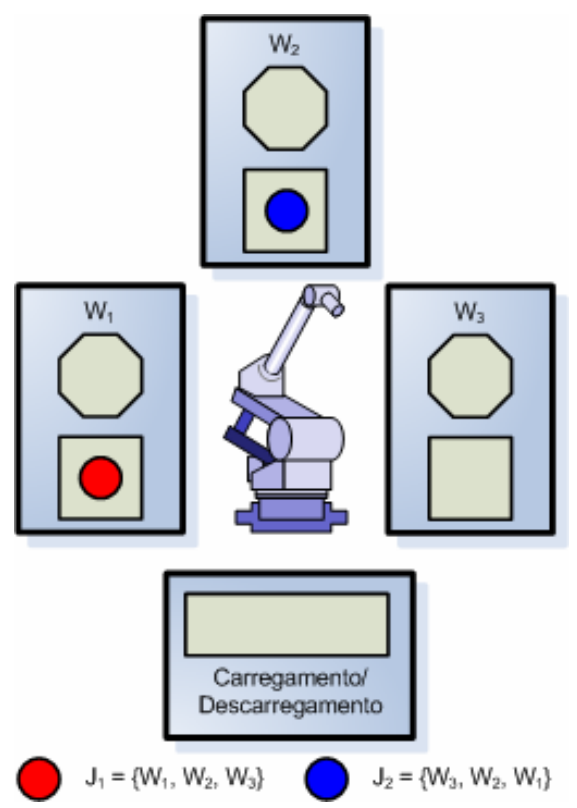

Figura 3.4 Exemplo de deadlock em célula de manufatura flexível.

O formalismo, as teorias e os métodos de resolução do problema de deadlock desenvolvidos na área de ciências da computação são as bases para o entendimento e resolução do problema de deadlock em SPF. Porém, um aspecto 
que diferencia os dois contextos é quanto ao objeto de processamento. Enquanto que em sistemas operacionais, em banco de dados ou em redes de computadores pode-se verificar, rever e repetir o processamento de informações, em SPF além do processamento de informações, tem-se o processamento de elementos físicos, isto é, atividades que envolvem a transformação e/ou o transporte de itens de processo que não admitem o retorno a estados anteriores.

\subsubsection{Condições Mínimas para a Ocorrência do Deadlock}

Coffman et al. (1971) apresentaram uma formalização para o problema de deadlock, cuja evolução para este estado é verificada se houver a ocorrência de quatro condições concomitantemente (BANASZAK; KROGH, 1990; VISWANADHAM et al., 1990; TANENBAUM, 1995; SILBERSCHATZ et. al., 2004; SANTOS FILHO, 2000):

* Mútua exclusão: o processo utiliza o recurso alocado de modo exclusivo;

Não há preempção: um recurso poderá ser liberado somente pelo processo que o alocou;

* Retenção enquanto aguarda: o processo não libera o recurso alocado enquanto aguarda a alocação do próximo recurso;

* Espera circular: é uma formação cíclica fechada de processos que aguardam a liberação de recursos alocados por outros processos pertencentes à mesma cadeia cíclica.

As três primeiras condições são inerentes ao SPF (BANASZAK e KROGH, 1990; SANTOS FILHO, 2000) e, uma vez que os recursos são alocados pelos processos, garantem que as atividades dos mesmos sejam executadas. Conseqüentemente, a quarta condição pode ser utilizada para tratar a ocorrência de deadlock no sistema, identificando e alterando as ações do sistema. No presente trabalho, a condição de espera circular será denominada como ciclo fechado de espera (CFE) (ANEXO A) (SANTOS FILHO, 2000).

A situação descrita acima é demonstrada no exemplo a seguir de SPF:

* Um conjunto de processos $P=\left\{\Pi_{1}, \Pi_{2}, \Pi_{3}\right\}$ e um conjunto de recursos de transformação $R=\left\{R_{1}, R_{2}, R_{3}, R_{4}\right\}$; 
* As seqüências de alocação de recursos dos processos:

- $\quad \Pi_{1}: R_{2} \rightarrow R_{4} \rightarrow R_{3}$

- $\quad \Pi_{2}: R_{1} \rightarrow R_{2}$;

- $\quad \Pi_{3}: R_{3} \rightarrow R_{4} \rightarrow R_{1}$

* As seqüências das atividades dos processos:

- $S_{1}=\left\{\Xi_{11}, \Xi_{12}, \Xi_{13}\right\} ;$

- $S_{2}=\left\{\Xi_{21}, \Xi_{22}\right\}$;

- $S_{3}=\left\{\Xi_{31}, \Xi_{32}, \Xi_{33}\right\}$.

A Figura 3.5 ilustra a representação de cada processo utilizando o grafo de alocação de recursos (GAR) (ANEXO A) e o GAR global dos processos do exemplo citado. O GAR é um grafo bipartido, orientado e não marcado que representa a alocação de recursos pelos processos (SANTOS FILHO, 2000) Após a identificação de formação de CFEs, o controle da quarta condição consiste em impedir a formação de cadeia cíclica de processos em estado de espera por recursos que não serão liberados no CFE.

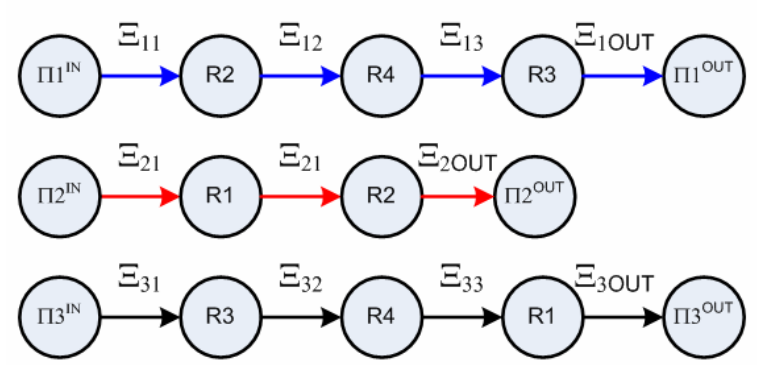

(a)

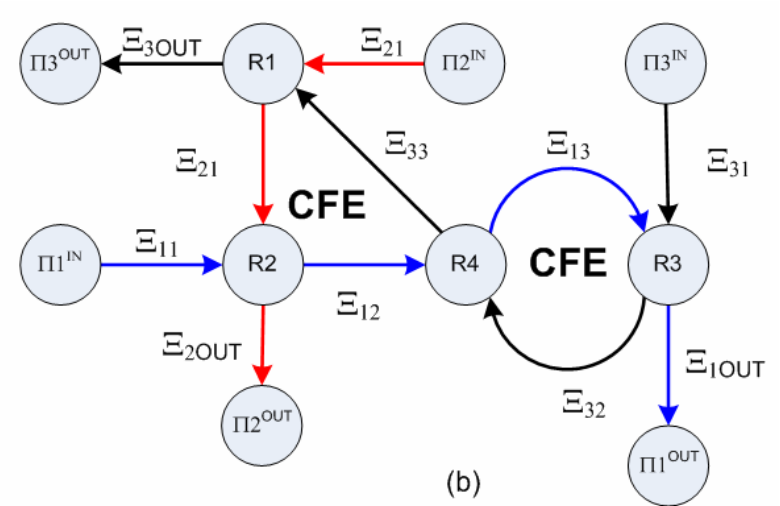

(b)

Figura 3.5 GAR individual (a) e GAR global (b).

\subsubsection{Métodos para Tratar o Problema de Deadlock}

Os possíveis tratamentos do problema de deadlock podem ser classificados dentro de três métodos básicos (COFFMAN et al., 1971; BANASZAK; KROGH, 1990; VISWANADHAM et al., 1990; TANENBAUM, 1995; SILBERSCHATZ et. al., 2004; SANTOS FILHO, 2000; LI; ZHOU; WU, 2008): 
- Método de Prevenir (Deadlock Prevent): consiste em conceber um sistema livre de deadlock determinando todos os estados alcançáveis do sistema e, mediante um arranjo estrutural do sistema, não se permite que o mesmo evolua para os estados indesejáveis de travamento, ou seja, não permite a ocorrência de pelo menos uma das quatro condições necessárias. Considerando-se que o método envolve um processamento para a determinação de todos os estados alcançáveis do sistema, este pode tornar-se computacionalmente inviável devido à explosão de estados decorrentes da quantidade de elementos envolvidos e as suas interrelações. Porém, requer menos esforço computacional em tempo de execução do controle se os problemas forem identificados e solucionados na fase de projeto do controle;

Método de Detectar e Restabelecer (Deadlock Detection and Recovery): consiste na execução de algoritmos que detectam o estado de deadlock $\mathrm{e}$ executam ações para sair deste estado. Nos sistemas em que há apenas o processamento de informações, a volta ao passado e a eliminação de processos são as ações mais usuais, enquanto que no SPF, a ação de preempção é a mais utilizada. A ação de preempção é realizada através da transferência temporária de um dos processos bloqueados para um buffer temporário, liberando a movimentação para os demais processos. Ao término, o processo no buffer temporário é atendido. A complexidade computacional é mais reduzida se comparada com os demais métodos para abordar o problema de deadlock. Entretanto, o uso de buffers temporários requer espaço físico do SPF e a movimentação temporária de itens pode reduzir o rendimento do SPF se não realizado de forma adequada;

Método de Evitar (Deadlock Avoidance): consiste na execução de algoritmos que monitoram os processos quanto à alocação de recursos. A identificação de estados imediatamente anteriores ao travamento dispara ações em tempo real para que o sistema não evolua para o estado de deadlock. A grande vantagem deste método é quanto ao uso otimizado dos recursos, entretanto em alguns casos é possível gerar um novo estado de deadlock decorrente das restrições introduzidas no sistema. 
De acordo com o contexto de ocorrência do deadlock e a natureza das atividades realizadas pelos recursos: transformação, transporte, montagem, entre outros, alguns métodos são mais indicados do que outros. Desta forma, é necessário avaliar em cada caso, identificando as limitações e adequando o melhor método ou a composição de métodos (abordagem híbrida). A seguir serão apresentadas as principais referências sobre os métodos utilizados para solucionar o deadlock.

\subsubsection{Método de Prevenir}

No trabalho de Viswanadham et al. (1990) foi proposta uma abordagem do problema de deadlock para sistema de manufatura flexível (SMF). Os autores utilizaram os métodos de deadlock prevent e deadlock avoidance aplicados em uma rede de Petri (RdP) (ANEXO A). O método de deadlock prevent consiste em realizar uma análise utilizando o grafo de atingibilidade da RdP identificando os estados de ocorrência do deadlock com base nas quatro condições necessárias. A prevenção é realizada inibindo-se o disparo das transições que permitem a evolução para o deadlock. $O$ método de deadlock avoidance consiste em monitorar o sistema quanto à alocação de recursos do sistema, identificando o estado anterior ao travamento e impedindo o disparo das transições. Entretanto, a aplicação do método de deadlock avoidance proposto pelos autores não evitava a ocorrência do deadlock em alguns casos. Por isso, os autores propuseram também uma combinação com ações de restabelecimento nestes casos (deadlock recovery).

No trabalho de Ezpeleta et al. (1995) foi aplicado o método deadlock prevent em SMF modelando-o com uma classe especial de RdP denominado systems of simple sequential processes with resources ( $\left.{ }^{3} \mathrm{RP}\right)$, em que se realiza uma análise em busca de elementos estruturais na rede conhecidos como siphons (traps).

A classe $S^{3} R P$ é uma sub-classe ordinária e conservativa de RdP (PETERSON, 1981; REISIG, 1985; MURATA, 1989), isto é, o peso dos arcos são constantes iguais a 1 e a quantidade total de marcas na rede é sempre constante (Anexo A).

Ezpeleta et al. (1995) propuseram um algoritmo para calcular os siphons e inserir um monitor para cada siphon identificado na RdP. Um monitor é um tipo de lugar (lugar controlado) em RdP que restringe e controla a evolução das marcas no siphon. A maior dificuldade observada nos trabalhos de Ezpeleta et al. (1995) é o esforço computacional necessário para a determinação dos siphons na RdP. 
Banaszak (1997) investigou o problema de deadlock em uma classe de SPF denominado sistema de processos repetitivos (SPR). O SPR executa múltiplos processos ciclicamente compartilhando um mesmo conjunto finito de recursos entre os processos. $\mathrm{O}$ autor verificou a ocorrência de gargalos no sistema relacionando a capacidade dos buffers associados com regras de alocação de recursos. O controle de gargalo é realizado definindo-se um conjunto de regras de alocação de recursos ou regras prioritárias de alocação. Basicamente, as regras identificam os pontos críticos (gargalos) em recursos ou nos processos e limitam a entrada de novos processos de acordo com a capacidade do ciclo, o tempo de transporte e o tempo de ocupação dos recursos (máquinas e buffers). O objetivo é capacitar um sistema a retornar sempre para um estado cíclico produtivo estável em caso de ocorrência de alguma perturbação. A maior dificuldade da proposta é quanto à explosão de combinações de estados alcançáveis.

Banaszak e Polak (2002) continuaram os trabalhos investigando a relação entre a capacidade de recursos (máquinas e buffers) e regras de alocação de recursos, porém considerando a influência do estado inicial do SPR quanto à ocorrência de deadlock. Além disso, verificaram a possibilidade de aumentar a capacidade do buffer em pontos críticos. Mediante o uso de um grafo para representar a utilização de recursos, investigaram a ocorrência de estados de ciclo estável, isto é, ciclos que não evoluem para o estado de deadlock de acordo com o estado inicial adotado. Os trabalhos de Banaszak (1997) e Banaszak e Polak (2002) descrevem métodos caracterizados pela explosão de combinações de estados e a inclusão de um novo processo no SPR, que significa a execução de todo procedimento para determinar o conjunto de regras e do estado inicial.

No trabalho de Trincas e Ezpeleta (2003) é apresentada uma comparação do algoritmo proposto por Boer e Murata (1994) com o método de Lautenbach (LAUTENBACH apud TRUINCAS e EZPELETA, 2003) para a determinação dos siphons mínimos utilizando processamento paralelo.

Os resultados da comparação dos algoritmos apresentados por Trincas e Ezpeleta (2003) indicaram que a computação paralela reduz consideravelmente o tempo de processamento para o cálculo dos siphons na RdP. Todavia, o esforço computacional para determinar o local para inserir os monitores e a respectiva capacidade torna-se maior de acordo com a quantidade de siphons considerados. 
Li e Zhou (2003) propuseram uma classificação dos siphons mínimos estritos em siphon elementar e redundante. Os autores apresentaram o controle de siphons elementares que permite a redução do número de monitores necessários mediante a inserção de apenas um monitor para cada siphon elementar identificado. Conforme os autores, o controle dos siphons elementares garante que os siphons redundantes também sejam controlados. Em Li e Zhou (2004) os autores apresentam os algoritmos de deadlock prevent aplicados na RdP baseado no controle de siphons elementares. A marcação inicial dos monitores é obtida mediante a aplicação de programação inteira (GOLDBARG; LUNA, 2005).

No trabalho de Li et al. (2005) foi apresentado um aperfeiçoamento dos algoritmos para a determinação dos siphons elementares e foi realizada uma comparação de desempenho entre os algoritmos apresentados em Ezpeleta et al. (1995) e Li e Zhou (2004). Conforme os autores, o algoritmo proposto reduziu o número de monitores e de arcos adicionados na RdP.

Li e Zhou (2008) apresentaram um algoritmo com complexidade em tempo polinomial para a identificação dos siphons elementares e a aplicação de programação inteira mista para determinar a marcação inicial dos monitores. $\mathrm{O}$ algoritmo proposto pelos autores determina os siphons identificando-se a formação de circuitos de recursos, isto é, os CFEs. Os autores realizaram ainda uma comparação com os algoritmos proposto por Boer e Murata (1994) e o método INA. O método INA integrada (Integrated Net Analyzer - INA) consiste em uma ferramenta computacional que permite uma análise da RdP para identificar os siphons. Os resultados apresentados indicam que o algoritmo proposto possui um melhor desempenho em relação aos demais.

Pelo exposto, em relação à estratégia de deadlock prevent, o método pode ser eficaz e possivelmente eficiente, desde que seja possível determinar todos os estados alcançáveis do sistema. Porém, na prática apresenta algumas limitações devido à complexidade computacional envolvida em tempo de projeto (off-line).

Grande parte dos trabalhos estão focados em prevenção com base na teoria de $\mathrm{RdP}$, especificamente quanto a formação de estruturas de siphons. Verifica-se que a quantidade de siphons em uma $\mathrm{RdP}$, a determinação dos monitores e as respectivas capacidades crescem de acordo com o tamanho da rede. 


\subsubsection{Método de Detectar e Restabelecer}

No trabalho de Fanti et al. (2002) foi apresentada uma análise de deadlock em sistemas automatizados de manufatura da classe de SAR CON-RAS, ou seja, um estudo do auto-travamento em sistemas em que são necessárias múltiplas aquisições de recursos para a execução da atividade do processo, denominado pelos autores de conjunctive resource service systems (CRSS). Os autores modelam o sistema mediante o uso de dígrafos denominado working procedure digraph $D_{\omega}=\left(\eta, \varepsilon_{\omega}\right)$, em que cada vértice do conjunto $\eta$ representa um recurso $r_{i}$ e $\varepsilon_{\omega}$ os arcos orientados, as atividades do processo. O estado de travamento é verificado quanto da ocorrência da condição de espera circular, ou seja, a capacidade do ciclo de espera torna-se igual à capacidade de processos que pertencem ao ciclo. A ação de restabelecimento é realizada mediante o uso de um buffer central para acomodação temporária dos processos em travamento.

Gang e Ming (2004) apresentaram uma abordagem do problema de deadlock em SMF na classe de sistemas $S^{3} \mathrm{PR}$ aplicando-se os métodos de deadlock detection and recovery, deadlock prevent e deadlock avoidance. O método de deadlock prevent é aplicado de modo off-line resultando em um re-scheduling dos processos que é armazenado em um banco de dados. O objetivo inicial é a geração de uma RdP temporizada dos processos e recursos, mediante a aplicação de algoritmo genético e o uso do grafo de Gantt, através da análise de uma árvore de atingibilidade da RdP.

O re-scheduling corresponde à seqüência de genes do cromossomo que está associado ao conjunto de transições disparáveis da RdP. A cada situação de deadlock identificada, é inserido um buffer no processo, isto é, aumenta-se a capacidade do buffer, e o algoritmo busca uma seqüência de alocação de recursos factíveis. Entretanto, a quantidade de buffers é limitada de acordo com as disponibilidades do SMF que está sendo modelado. Em caso de identificação de uma situação de travamento e não houver mais buffers disponíveis, por exemplo, o re-scheduling incompleto é descartado; o algoritmo procede escolhendo um novo cromossomo e realiza novamente o procedimento. Salienta-se que os autores não incluem no procedimento de re-scheduling os transportadores tipo AGV, pois consideram que, neste caso, o escopo envolveria o controle on-line. 
Após a realização do processo off-line, o controle monitora o sistema com base no método de deadlock avoidance e deadlock detection and recovery. O método de deadlock avoidance é aplicado mediante a execução do algoritmo do banqueiro (CORMEN et al., 2002) nos recursos, enquanto que o deadlock detection é aplicado na verificação de siphons vazio na $\mathrm{RdP}$. O processo de recovery é realizado transferindo-se um dos processos em deadlock para um buffer.

A abordagem apresentada por Gang e Ming (2004) utiliza todos os métodos para resolver o problema de deadlock com diversas técnicas desde o planejamento da produção, isto é, o processo de scheduling, até o controle dos processos. Entretanto, baseado nos trabalhos pesquisados, a abordagem proposta pelos autores pode não ser factível em sistemas complexos.

\subsubsection{Método de Evitar}

Banaszak e Krogh (1990) abordaram o problema de deadlock em SMF utilizando o production Petri net (PPN), derivada da RdP. O algoritmo para evitar o deadlock, denominado deadlock avoidance algorithm (DAA), particiona as atividades do processo em um conjunto de zonas, e cada zona consiste de seqüências de recursos compartilháveis e não compartilháveis. O DAA restringe o número de processos de acordo com duas regras:

* Regra 1: permite a entrada de um processo na zona somente se a quantidade de recursos da zona de recursos não compartilháveis for maior que o número de processos que estão presentes na zona corrente;

- Regra 2: assegura que se um recurso compartilhado é requisitado por um processo, todos os demais recursos compartilhados pertencentes a zona estarão disponíveis naquele momento.

Lawley e Ferreira (1994) apresentaram um estudo sobre os aspectos fundamentais da modelagem e controle de SMF com uma proposta de controle hierárquico. A proposta do controle hierárquico consiste em combinar três tipos de modelos de sistemas gerados a partir do SMF: modelo computacional, modelo estrutural e modelo de desempenho. O objetivo de cada modelo é prover uma abstração específica do SMF. O modelo computacional gera o grupo de transições habilitadas de acordo com as informações coletadas do SMF. O modelo estrutural permite a implementação das políticas do controle estrutural (structural control policies - SCP). 
O modelo SCP envolve uma abordagem de alto nível de abstração que divide as transições habilitadas em grupos de transições possíveis (livres de deadlock) e não possíveis (estados indesejáveis). A partir desta informação, o modelo de desempenho determina quais os caminhos que podem ser selecionados que otimizam o desempenho do sistema. O modelo do sistema de controle é gerado em RdP colorida. A tarefa de terminar as transições livre de deadlock é a maior dificuldade neste trabalho, exigindo um grande esforço computacional.

Fanti et al. (1995; 1997) apresentaram uma abordagem utilizando dígrafos, ou grafos orientados (BANG-JENSEN; GUTIN, 2002), em SMF com LIN-SU-RAS. As políticas de alocação, ou regras de alocação de recursos são definidas de acordo com as informações obtidas sobre o estado do sistema quanto à alocação de recursos entre os processos. As regras geradas habilitam ou inibem a alocação/liberação de recursos utilizados pelos processos. O SMF é modelado por dígrafos denominado working procedure digraph $D_{\omega}=\left(\eta, \varepsilon_{\omega}\right)$, em que cada vértice do conjunto $\eta$ representa um recurso $r_{i}$ e $\varepsilon_{\omega}$ os arcos orientados que representam as atividades do processo. A partir do dígrafo $D_{\omega}$, identificam-se as condições de espera circular e as respectivas capacidades dos ciclos de espera. Com base nestas informações, determina-se o estado anterior ao deadlock de acordo com ciclo de espera evolvidos em três níveis:

* First level deadlock (FLD): estado imediatamente anterior ao deadlock que ocorre em um único ciclo;

* Second level deadlock (SLD): estado que envolve o deadlock iminente entre dois ciclos, ou seja, pelo menos um vértice em comum;

* Third level deadlock (TLD): estado que envolve o deadlock iminente entre três ciclos, ou seja, pelo menos dois vértices em comum.

O deadlock é evitado restringindo-se a entrada de processos nos três níveis de deadlock. Observa-se que o método é extremamente restritivo e no pior caso o TLD poderá permitir a execução de apenas um único processo.

Lawley et al. (1997) apresentaram os requisitos necessários com maiores detalhes para a implementação da metodologia geral para o desenvolvimento do modelo SCP (LAWLEY e FERREIRA, 1994). Inclusive, neste trabalho, é realizado um estudo 
detalhado sobre as causas do deadlock em SPF, as estratégias e as respectivas limitações para abordar o problema de deadlock. Os autores apresentaram uma classificação inicial dos tipos do SAR, sendo que a classificação completa foi apresentada por Reveliotis (2005) e descrita no item anterior deste capítulo.

No trabalho de Reveliotis (1998) foi proposta uma abordagem analítica para o problema de deadlock em SMF, além de uma solução algorítmica utilizando autômatos e máquinas de estados mediante a aplicação de uma política de deadlock avoidance denominada resource upstream neighborhood (RUN). A idéia básica do RUN é o uso da capacidade de recursos para a função de buffers temporários dos processos que estão sendo executados pelo sistema. Desta forma, o número total de processos em execução em um RUN nunca exceder a capacidade dos recursos. A política de restrição RUN é expressa através de um sistema de inequações lineares e a otimização do sistema é realizada mediante a aplicação de programação linear da função objetivo (GOLDBARG e LUNA, 2005).

No trabalho de Fanti et al. (2000) foi apresentado uma comparação entre as abordagens utilizando o dígrafo $D_{\omega}$ e RdP para evitar o deadlock em SMF. Basicamente tem-se a aplicação das políticas que foram apresentadas nos trabalhos de Fanti et al. $(1995 ; 1997)$ em RdP. Os autores apresentaram a relação entre dígrafos $D_{\omega}$ e as RdP descrevendo um formalismo matemático para a conversão entre os modelos estudados. De fato, a relação é muito próxima e as potencialidades são exploradas neste trabalho. A proposta apresentada por Fanti et al. (2000) é interessante do ponto de vista da elaboração do controle utilizando-se as RdP. Porém, são adotadas as mesmas políticas de restrições para o tratamento do deadlock apresentadas nos trabalhos de Fanti et al. (1995; 1997), o que torna o modelo em RdP proposto também restritivo.

No trabalho de Santos Filho (2000) foi proposto um método de deadlock avoidance baseado em uma arquitetura hierárquica do sistema de controle de SPF. O método consiste em dividir o sistema de controle em dois módulos com semânticas distintas:

(i) Controle de Processos e (ii) Controle de Recursos.

O controle de processos é responsável pelo seqüenciamento das atividades de processo. A cada execução de uma atividade, o controle requisita a alocação de recursos para o controle de recursos, enquanto que o controle de recursos é 
responsável pela utilização dos recursos pelos processos. Mediante um modelo global de utilização de recursos e um conjunto de regras de produção, o controle de recursos autoriza a utilização de recursos pelos processos, definindo-se a alocação de recursos no nível inferior. O modelo hierárquico aborda o problema de deadlock com base em um modelo de restrição, ou seja, não é possível mapear todos os estados alcançáveis do sistema. Contudo, é possível mapear os estados indesejáveis, identificá-los e realizar um conjunto de ações impedindo a evolução para este estado. No trabalho de Nakamoto (2002) foi realizada a sistematização do método proposto por Santos Filho (2000) resultando na implementação de uma ferramenta computacional para geração do controle e das regras adicionais de controle.

Reveliotis (2000) apresentou uma investigação entre os métodos de deadlock avoidance e detection and recovery para o problema de alocação de buffers em SMF. O autor propôs uma extensão para a modelagem do sistema introduzindo uma dimensão probabilística no comportamento de SAR, associado com uma estratégia alternativa para a resolução do problema de deadlock denominado randomized deadlock avoidance (RDA). Do ponto de vista teórico, o RDA consiste na introdução de um nível de incerteza na evolução das requisições de alocação em um SAR.

Desta forma, o comportamento do sistema é analisado modelando-se o sistema por cadeia de Markov (CASSANDRAS; LAFORTUNE, 2007). A seleção das estratégias de resolução de deadlock é gerada conforme apresentado por Reveliotis (1998). Porém, o autor promoveu a simplificação para uma formulação equivalente, visando a redução do número de variáveis e restrições, obtendo-se os resultados pelo método dual ${ }^{4}$ de programação linear (GOLDBARG; LUNA, 2005).

Lawley e Reveliotis (2001) apresentaram um estudo sobre o método de deadlock avoidance no SAR seqüenciais. A dificuldade na implementação dos métodos de evitar o travamento é quanto à complexidade computacional que pode pertencer à

\footnotetext{
${ }^{4}$ A dualidade é um conceito que possibilita o tratamento de duas naturezas distintas de uma mesma entidade. Define-se como um par de modelos de programação linear (primal e dual) que possuem funções objetivos simétricas, isto é, se o primal for de minimização, o dual será de maximização e vice-versa (GOLDBARG; LUNA, 2005).
} 
classe de NP-Completo ${ }^{5}$. Juntamente com os resultados da investigação, foi apresentado também uma classificação dos casos relativamente fáceis e os difíceis de serem tratados computacionalmente em um SU-RAS.

No trabalho de Lawley e Sulistyono (2002) foram aplicados os estudos desenvolvidos por Lawley e Reveliotis (2001) para investigar o SAR com recursos "não-confiáveis", isto é, recursos que podem falhar devido à avarias na ferramenta, má qualidade dos sinais de controle, ausência de sinais de controle ou problemas na programação ou ferramentas, entre outros. Os autores propuseram a modelagem do sistema de controle supervisório de forma a alocar os recursos entre os processos verificando um conjunto de propriedades que satisfaçam a condição de estado seguro. Em caso de falha, o processo que necessita do recurso que falhou será transferido para um buffer e aguardará o término de reparo do recurso.

Wu e Zhou (2003) apresentaram uma proposta de resolução de conflitos em sistema de veículos guiados automaticamente ou automated guided vehicle systems (AGVS) com vias bidirecionais.

O AGVS é um sistema que transporta materiais, itens, produtos e/ou ferramentas entre as estações de trabalho e as estações de carregamento/descarregamento. $\mathrm{O}$ processo de transporte consiste em movimentar itens de uma origem (source) para um destino (destination) mediante o uso de recursos de transportadores do tipo AGV realizando as operações de carregamento e descarregamento nos respectivos locais pré-determinados. A movimentação dos AGVs é realizada ao longo de guias físicos ou virtuais pré-determinados, embutidas no layout e coordenados por um sistema de controle centralizado ou distribuído (REVELIOTIS, 2005).

Wu e Zhou (2003) propõem a modelagem do AGVS mediante o uso de RdP colorida orientado a recurso, onde as marcas são os transportadores que recebem cores. $\mathrm{O}$ método de deadlock avoidance consiste de um algoritmo que identifica os circuitos de espera, determina as condições livre de deadlock com bases na capacidade do circuito e controla o disparo das transições de acordo com as condições determinadas.

\footnotetext{
${ }^{5}$ São uma classe de problemas computacionais que não podem ser resolvidos em tempo polinomial, ou ainda não foi descoberto nenhum algoritmo de tempo polinomial para um problema NP-Completo (CORMEN et al., 2002).
} 
Fanti (2004) propôs a aplicação de deadlock avoidance em sistemas automatizados de manufatura com CRSS utilizando o dígrafo $D_{\omega}$ para determinar as políticas de alocação que devem ser aplicadas nas transições do modelo de RdP colorida temporizada (colored timed Petri net - CTPN). As estratégias de evitar o deadlock são aplicadas nas transições e executam duas ações principais. Primeiramente, verifica-se a existência de algum processo que pode alocar o próximo conjunto de recursos baseado nas informações do estado atual. A segunda ação é verificar se a entrada de novos processos no sistema causará o deadlock futuramente. A autora propôs também uma estrutura hierárquica de sistema de controle (Figura 3.6) em dois níveis.

O nível superior gerencia os pedidos de produção, as políticas de escalonamento, as decisões quanto à execução de processos e a execução de novos processos. $\mathrm{O}$ segundo nível é responsável pelo gerenciamento do fluxo dos processos.

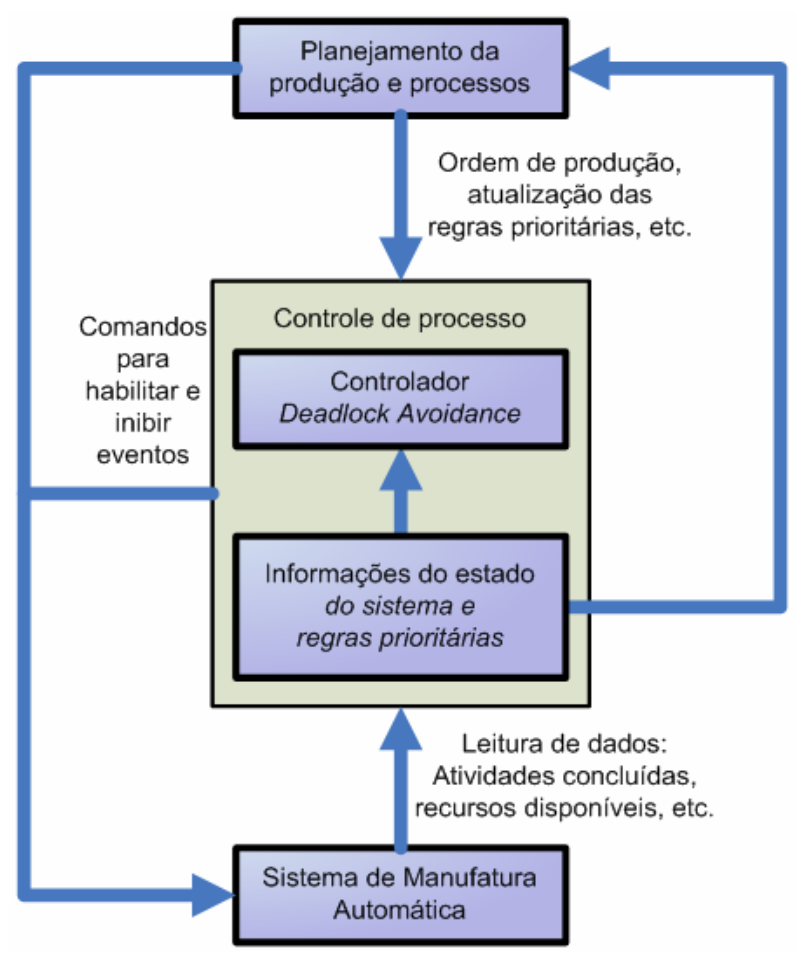

Figura 3.6 Estrutura de controle proposta por Fanti (2004).

No trabalho de WANG et al. (2004) foi apresentado uma abordagem de deadlock avoidance baseado em RdP mediante realização de uma análise parcial do grafo de alcançabilidade da RdP. Os autores identificam os estados classificando-os em: 
marcação morta (dead markings), marcação inadequada (bad markings) e marcação ameaçadora (dangerous markings). A marcação inadequada significa que a RdP evoluirá para o estado de deadlock inevitavelmente enquanto que a marcação ameaçadora que poderá alcançar o estado de travamento. A política de deadlock avoidance é gerada identificando-se os grupos de estados de marcação inadequada e de estados de marcação ameaçadora na RdP. Após a classificação, determinamse as transições que permitem a evolução para estes estados e as regras para evitar o travamento são geradas mediante o controle do disparo das transições. Conceitualmente, a proposta é baseada no método de deadlock avoidance. Entretanto, mesmo com uma análise parcial do grafo de alcançabilidade, pode ser necessário um esforço computacional relativamente grande e tal abordagem pode também não mapear todos os estados de marcação ameaçadora.

No trabalho de Wu e Zhou (2004) foi apresentado um algoritmo para a resolução do problema de deadlock e bloqueio de AGVs de forma dinâmica baseado nos trabalhos desenvolvidos por Wu e Zhou (2003). A cada novo processo de transporte do AGV, o algoritmo calcula um trajeto de menor tempo e gera a respectiva sub-rede que modela tal atividade. $O$ diferencial está na proposta de modelar uma sub-rede do trajeto de cada AGV e gerar uma única rede a partir da união das sub-redes.

Wu e Zhou (2005) apresentaram a modelagem de um sistema de manufatura automatizada (SMA) baseado no método de deadlock avoidance com múltiplos AGVs. Os autores destacaram que o problema de deadlock sempre foi tratado de forma separada para os recursos de transformação com os recursos de transporte nos SMA, especificamente nos casos dos AGVs. Tal abordagem não utiliza as vantagens oferecidas pela flexibilidade do AGVS. Assim sendo, a proposta apresentada pelos autores consiste na modelagem do AGVS e das atividades de transformação em duas redes respectivamente, mediante uso de RdP coloridas orientado a recurso. A RdP das atividades de transformação é formada por lugares e transições. Os lugares representam as máquinas e/ou buffers e as transições são denominadas de macro transições. A macro transição corresponde a uma sub-rede que representa o processo de transporte do lugar origem para o lugar destino. Desta forma, a RdP do AGVS é elaborado conforme apresentado por Wu e Zhou (2004).

Huang e Wu (2006) propuseram uma abordagem do problema de deadlock em SMF com bases nos trabalhos desenvolvidos por Fanti et al. $(1995 ; 1997)$ em um controle 
distribuído. O critério para a divisão do sistema de controle em subsistemas é de acordo com a formação de ciclos second level deadlock (SLD) no dígrafo $D_{\omega}$ do SMF. O objetivo é tratar os casos de SLD de forma diferenciada, aplicando-se as regras de alocação em cada um dos subsistemas de forma independente. Porém, o critério para a divisão dos subsistemas pode aumentar a complexidade do controle, pois o seqüenciamento das atividades não foi considerado, isto é, considera-se somente a formação dos ciclos em SLD. Desta forma, existe a possibilidade de ocorrer fluxo de processos entre os subsistemas, dificultando a execução do controle.

No trabalho de Wu e Zhou (2007) foi proposto um melhoramento para a solução do problema de deadlock em AGVS utilizando o método de deadlock avoidance apresentado em Wu e Zhou (2005). A RdP colorida do AGVS, gerada por Wu e Zhou (2004), deve ser fortemente conexo (BANG-JENSEN; GUTIN, 2002) e o número de AGVs deve ser menor que o número de nós da rede.

Wu e Zhou (2007) destacaram a dificuldade encontrada no processo de geração da RdP, uma vez que os trajetos dos AGVs são dinâmicos, isto é, a cada novo processo de transporte não está definido o transportador e, conseqüentemente, o trajeto depende da escolha do transportador. Neste sentido, os autores propuseram a aplicação de um controle supervisório em conjunto com um controle de planejamento e roteirização de AGVs, conforme apresentado na Figura 3.7.

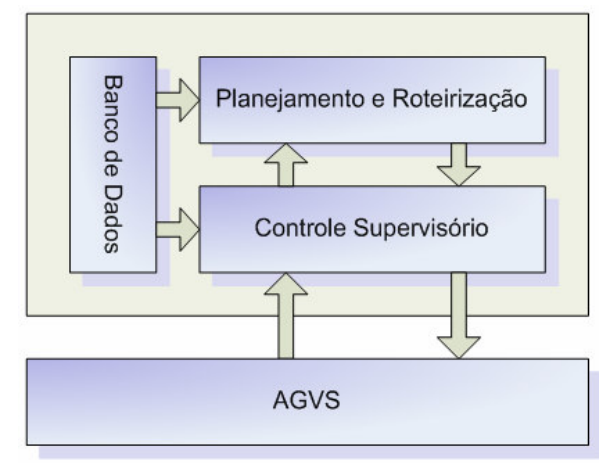

Figura 3.7 Arquitetura de controle para AGVS conforme Wu e Zhou (2007).

Basicamente, o controle de planejamento e roteirização definem o transportador e o respectivo trajeto e, o controle supervisório somente executa o que foi planejado. 
O método de deadlock avoidance é aplicado pelo controle de planejamento e roteirização que identifica a formação de condição de espera circular e a situação de bloqueio na RdP. Os autores destacam que para um AGVS, a proposta da arquitetura com o método de deadlock avoidance é a mais adequada e apresenta melhores resultados se comparado com os métodos de deadlock prevent e deadlock detection and recovery disponíveis para este contexto. Isto se deve às características dinâmicas a serem consideradas na determinação do transportador e da definição do trajeto de transporte. Além disso, o AGVS deve gerenciar problemas como a determinação da via de menor tempo (WU; ZHOU, 2005), conflito nas vias, bloqueio, deadlock e colisão, principalmente se considerado vias bidirecionais.

\subsection{Método Híbrido para Tratar o Deadlock em SPFs}

Considerando-se o exposto no item anterior, destacam-se os seguintes aspectos relacionados com o problema de deadlock em SAR de SPFs:

* Aplicar recursos computacionais para o mapeamento de todos os estados alcançáveis do sistema, identificar os estados indesejáveis e evitá-los estruturalmente não são inviáveis para sistemas considerados no presente trabalho. Entretanto, o método de deadlock prevent, onde não se permite a ocorrência da quarta condição, isto é, ciclos fechados de espera, é mais interessante do ponto de vista prático;

* A aplicação exclusiva do método de deadlock avoidance não é eficaz. Se houver a formação de CFEs consecutivos, as regras para evitar o travamento podem ser muito restritivas e consequentemente gerar um novo estado de deadlock. Porém, o método de deadlock avoidance permite um melhor uso dos recursos quando empregado em conjunto com outras soluções;

* Em grande parte dos trabalhos, não há um controle específico sobre a alocação global de recursos entre os processos concorrentes.

A ocorrência do deadlock em SAR compartilhados de SPFs é parte inerente destes sistemas que possuem características de sistemas complexos. Assim sendo, não há 
como excluir a ocorrência do deadlock, mas deve-se assim evitar o quando possível a sua ocorrência e minimizar os efeitos quando inevitável.

Partindo-se deste princípio, a abordagem híbrida para a solução de deadlock contempla os pontos apresentados. A diferenciação da natureza das atividades realizadas pelos recursos em atividades de transformação e atividades de transporte permite a aplicação de semânticas distintas para o projeto das estratégias que compõem o sistema de controle do SPF.

Neste sentido, um controle específico para o compartilhamento de recursos de transformação poderia verificar as situações anteriores ao travamento e promover ações para evitá-los, conforme comprovado nos trabalhos de Santos Filho (2000) e Nakamoto (2002). Entretanto, verificado a situação de deadlock, a ação de restabelecimento poderia ser realizada pelos recursos de transporte. A flexibilidade do sistema AGV poderia contribuir neste sentido (WU; ZHOU, 2007).

\subsection{Natureza das Atividades Realizadas pelos Recursos em SPFs}

A seguir serão caracterizados e classificados os recursos que serão adotados no presente trabalho para a aplicação de uma abordagem híbrida na solução do deadlock em SAR para SPF.

As atividades de transformação são realizadas nos recursos de transformação que recebem, processam e despacham itens, isto é, os recursos são as estações de trabalho que executam as atividades. Uma estação de trabalho possui os seguintes dispositivos: processador, recepção e despacho (Fig. 3.8).

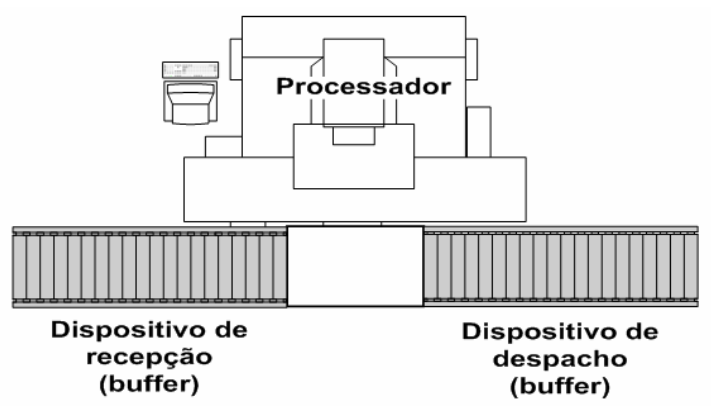

Figura 3.8 Esquema de um recurso de transformação. 
O dispositivo processador é o que de fato realiza a atividade de transformação. $O$ dispositivo processador possui capacidade unitária, enquanto que os dispositivos de recepção e despacho possuem capacidades $m_{R}$ e $m_{D}$, sendo que $\left(m_{R} \geq 1 \wedge m_{D} \geq 1\right)$.

Os processos são compostos por atividades de transformação que devem ser executadas numa certa seqüencia, sendo que utiliza-se um único recurso para cada atividade executada. Além disso, o seqüenciamento das atividades do processo não pode ser alterado durante a sua execução, pois descaracteriza o item a ser produzido. Pelo exposto, o SAR de transformação considerado neste trabalho pertence à classe LIN-SU-RAS (Linear-single-unit resource allocation).

Quanto aos processos de transporte, o recurso que realiza o processo é um transportador do tipo AGV, como visto anteriormente. Desta forma, o sistema de transporte (AGVS) é composto por um conjunto limitado de AGVs que atende a demanda dos processos quanto ao transporte de itens entre as estações de trabalho. A Figura 3.9 apresenta um exemplo de AGVS em um sistema de manufatura flexível (SMF) (GROOVER, 2007).

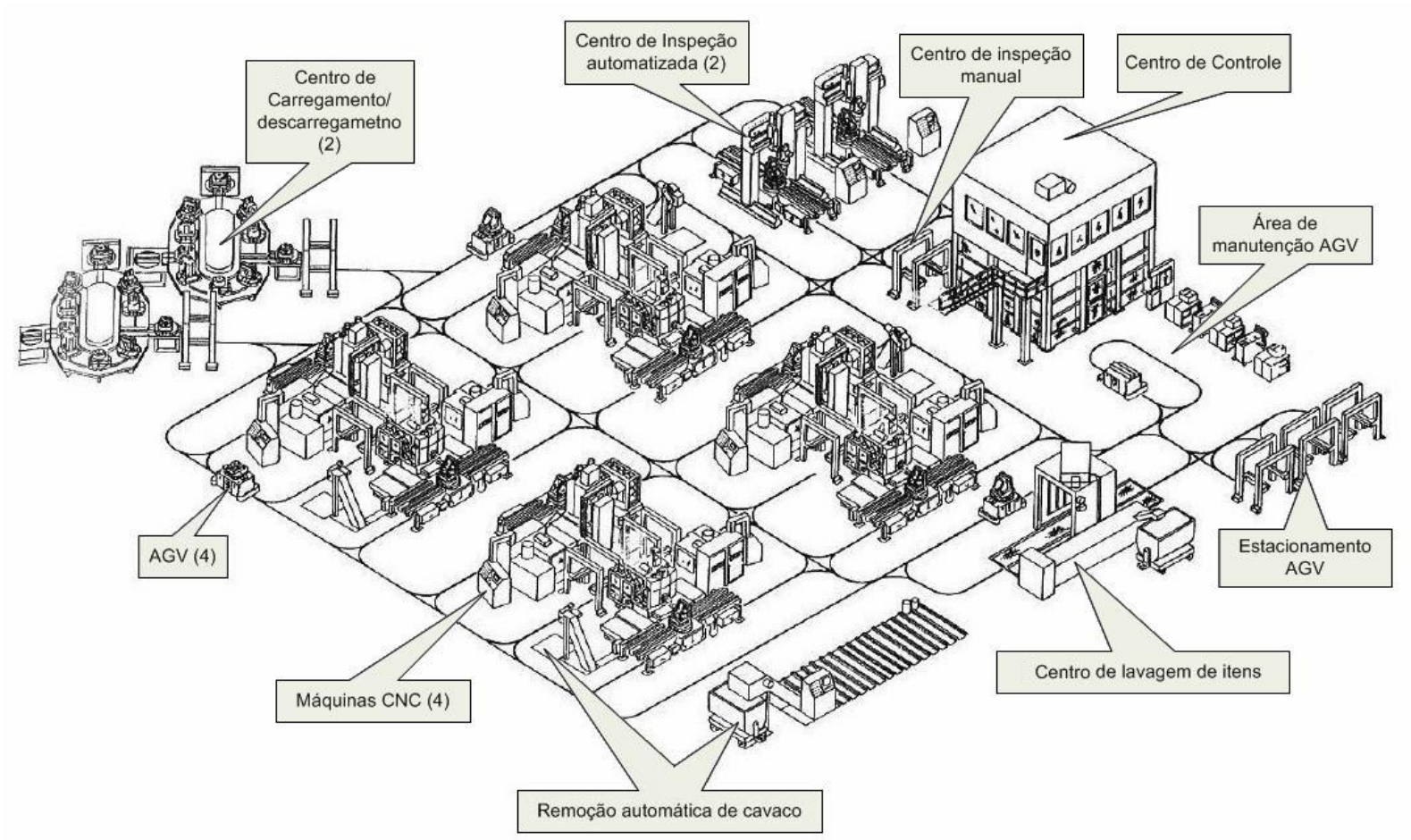

Figura 3.9 SMF da Vought Aircraft (Adaptado de GROOVER, 2007). 
Neste trabalho, o AGV possui capacidade unitária e percorre por vias de sentido único. Considera-se ainda neste trabalho o conceito de zonas conforme apresentado por Groover (2007).

As atividades envolvidas no processo de transporte são mais bem caracterizadas através de um modelo. Assim, adota-se a estrutura topológica do sistema de transporte modelada por um grafo orientado (dígrafo) $G=(N, E)$, sendo (Fig. 3.10):

$N$ representa o conjunto de nós que correspondem às interseções de vias, estações de trabalho, pontos de carregamento, pontos de descarregamento e pontos de parada ou trânsito. Destaca-se que o elemento ponto de parada/espera não é necessariamente associado a um local físico como pontos de carregamento, por exemplo. Os pontos de parada/espera possuem a função de parada temporária dos transportadores, isto é, os transportadores podem estar aguardando a disponibilidade de um trecho da via;

* E representa o conjunto de arcos que corresponde as vias que unem os elementos nós.

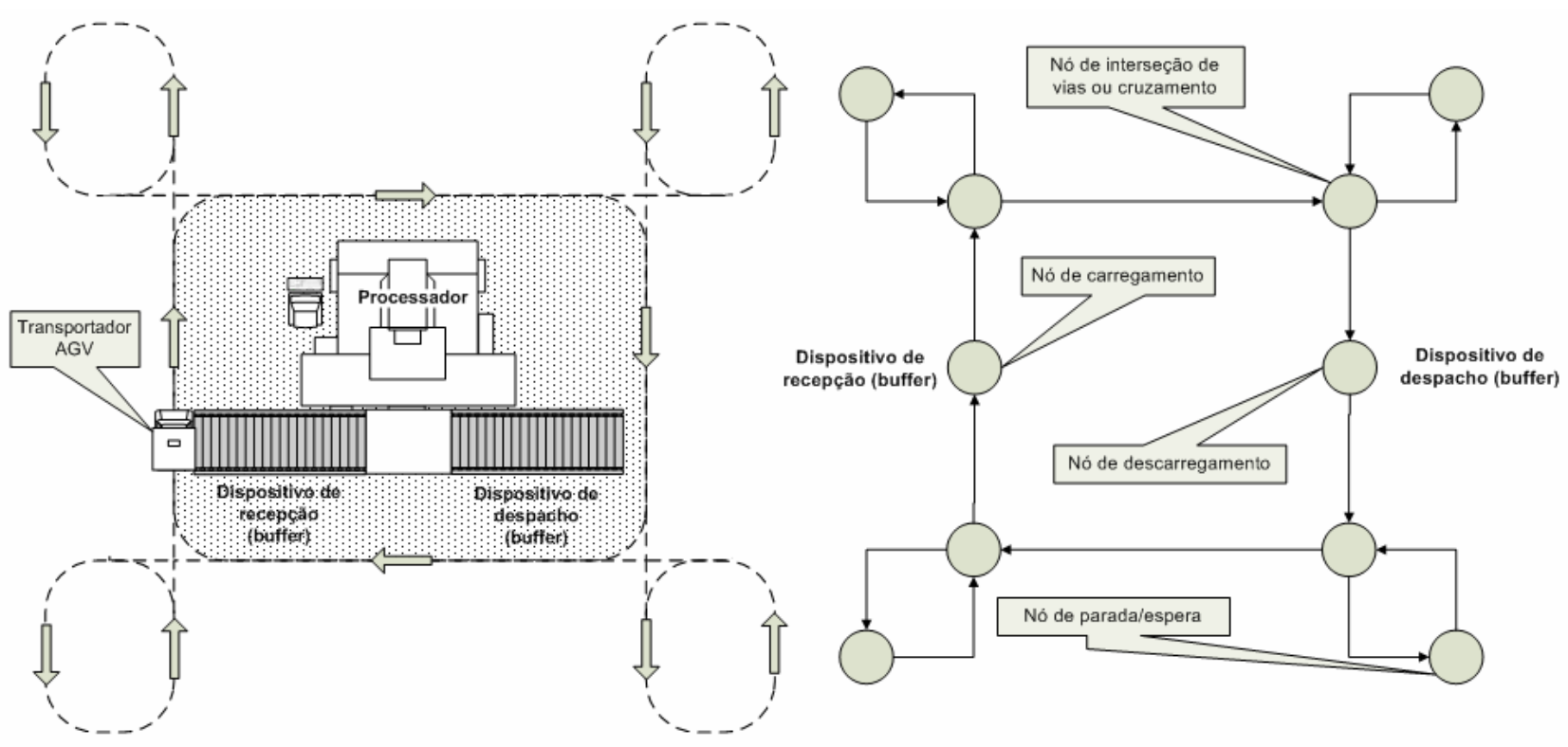

Figura 3.10 Exemplo de estrutura topológica representada por grafo.

Assim, o processo de transporte é composto por um conjunto de nós que o transportador deverá percorrer numa certa seqüência para atendimento de um 
pedido de transporte, denominado trajeto. O SAR de transporte considerado neste trabalho também pertence à classe LIN-SU-RAS (Linear-single-unit resource allocation).

Ainda em relação ao processo de transporte, dois aspectos devem ser considerados:

(i) Referente à designação do recurso de transporte e;

(ii) Referente à definição do processo de transporte.

A priori, não há transportadores com processos pré-estabelecidos e não há processos de transporte com trajetos pré-definidos. Consequentemente, a designação de transportador é realizada a cada solicitação de transporte. Somente após a designação é que se realiza a definição do processo de transporte, isto é, a definição do trajeto do transportador.

\subsection{Observações Complementares}

Neste capítulo foi discutido o problema de alocação de recursos, da ocorrência de deadlocks devido ao compartilhamento de recursos entre processos concorrentes e as formas para resolver isto.

A proposta de tratamento do problema de deadlock em SAR de SPFs aqui apresentada é baseada em uma abordagem híbrida do método de deadlock avoidance, detection and recovery. Quanto à ação de restabelecimento, observa-se que as atividades realizadas pelos recursos em SPFs possuem naturezas distintas: atividades de transformação e atividades de transporte. Conforme destacado por Wu e Zhou (2007), um sistema de transporte como o AGVS pode contribuir para a resolução dos problemas de deadlock em recursos de transformação, uma vez que por definição, os transportadores neste caso atribuem flexibilidade de processo de transporte, isto é, flexibilidade de rotas.

Um outro aspecto é quanto à divisão do controle em uma arquitetura hierárquica apresentado em Santos Filho (2000), Fanti (2004) e Wu e Zhou (2007). Observa-se que este tipo de abordagem permite a aplicação simultânea de um conjunto de estratégias de controle preservando o objetivo de cada domínio semântico do controle. O que justifica também adotar esta abordagem no presente trabalho. 


\section{CAPÍTULO}

\section{SISTEMÁTICA PARA GERAÇÃO DO SISTEMA DE CONTROLE}

Os diversos aspectos relacionados ao compartilhamento de recursos entre processos concorrentes e as conseqüências decorrentes deste compartilhamento, contribuem para a complexidade funcional destes sistemas. No capítulo anterior, foi apresentada a natureza distinta que existe entre as atividades de transformação e de transporte e o impacto na modelagem e controle destes sistemas. Entretanto, tal diferença pode ser explorada no sentido de potencializar uma representação semântica de cada uma das atividades dentro do seu respectivo contexto, respeitando a identidade dos diferentes processos que constituem um SPF, mantendo como diretriz o controle do processo global do sistema.

Portanto, faz-se necessário considerar uma arquitetura de controle que preserva os diferentes módulos semânticos de controle e que permita os fluxos adequados de comunicação entre eles para que se realizar o efetivo controle do SPF.

Neste sentido, o presente capítulo tem como objetivo a apresentação da arquitetura hierárquica de controle para SPFs. Primeiramente, são apresentadas as considerações que nortearam a proposição desta arquitetura e uma breve descrição dos módulos de controle que compõem a arquitetura. Em seguida, é apresentada a sistematização de cada um dos módulos, bem como o formato e a dinâmica de comunicação entre os módulos. 
O objetivo principal de um SPF é o cumprimento efetivo das metas de produção estabelecidas pelo planejamento. Um outro fator é o atendimento da norma ANSI/ISA-95 parte 3. Considerando-se as funcionalidades apresentadas no diagrama hierárquico funcional da norma, verifica-se que o sistema de controle para SPFs está inserido nos níveis 2, 1 e 0 . Neste contexto, o sistema de controle deve:

- Executar os diversos processos concomitantemente;

Disponibilizar os recursos compartilhados, para que os processos executem as atividades;

* Evitar a ocorrência de deadlock e minimizar o seu efeito, caso venha a ocorrer.

Observa-se que a execução de um processo consiste na garantia do seqüenciamento e realização de atividades dentro de um contexto que pode ser classificado como controle local. Por sua vez, a disponibilização de recursos compartilhados entre os processos envolve um contexto global, ou seja, é necessário uma visão global de utilização de recursos pelos processos.

Quanto às atividades que devem ser executadas, observa-se que a natureza destas atividades é distinta, isto é, envolve a transformação e o transporte de itens, conforme apresentadas no capítulo anterior. Consequentemente, a natureza dos processos também é distinta. Enquanto nos processos de transformação o seqüenciamento das atividades é pré-estabelecido, no processo de transporte a seqüência de atividades é indefinida. $O$ transporte envolve a movimentação de itens ponto a ponto, percorrendo trajetos definidos por uma origem até um destino e rotas disponíveis, associando-se ainda atividades de carregamento e descarregamento. Verifica-se também que os transportadores compartilham entre si o uso das vias resultando e assim existe a possibilidade de ocorrência de deadlock também no transporte.

Observa-se com isto que o sistema de controle deve atuar em diversos domínios de forma integrada, garantindo a execução das atividades de transformação, a disponibilização de recursos entre os processos, a realização das atividades de movimentação de itens e coordenação do tráfego de transportadores nas vias. 
Ainda, considerando-se a aplicação dos conceitos de flexibilidade e automação em SPFs apresentadas anteriormente, adota-se neste trabalho um sistema de controle modular distribuído, exemplificado na Figura 4.1.

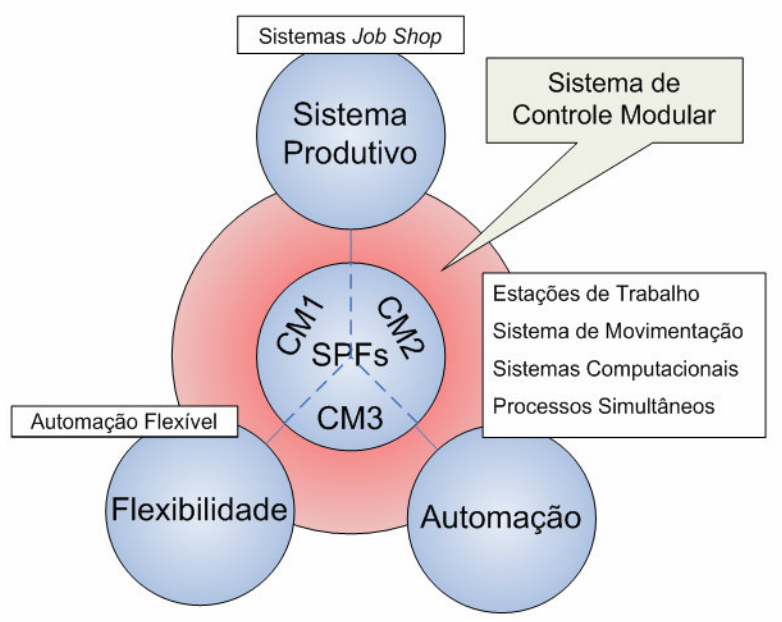

Figura 4.1 SPF, Flexibilidade, Automação e Controle Modular.

Neste sentido, é fundamental a adoção de uma arquitetura de controle que permita a integração dos módulos de controle que atuam nos diversos domínios. Um outro aspecto também importante é a escolha das ferramentas para projetar, modelar e implementar os módulos de controle e as suas respectivas interfaces.

Desta forma, a partir da verificação dos diferentes domínios de ação de controle em SPFs, identifica-se uma arquitetura composta de três módulos de controle conforme ilustrada a Figura 4.2:

* Controle de Atividades de Transformação;

* Controle de Utilização de Recursos;

* Controle de Atividades de Transporte.

A arquitetura visa a realização efetiva do controle de SPFs mediante a modularização das funções de controle de acordo com o domínio considerado. Ou seja, o controle de atividades de transformação preocupa-se somente com a produção do item (produto), isto é, executa o seqüenciamento das atividades de transformação, enquanto que o controle de utilização de recursos gerencia a disponibilização dos recursos de transformação entre os processos paralelos a fim de evitar o problema de deadlock. Por fim, o controle de atividades de transporte 
fornece o serviço de transporte de itens entre as estações de trabalho para o controle de atividades de transformação. Porém, conforme observado anteriormente, a atividade de transporte envolve o compartilhamento de recursos entre os transportadores que, no caso específico, são as vias.

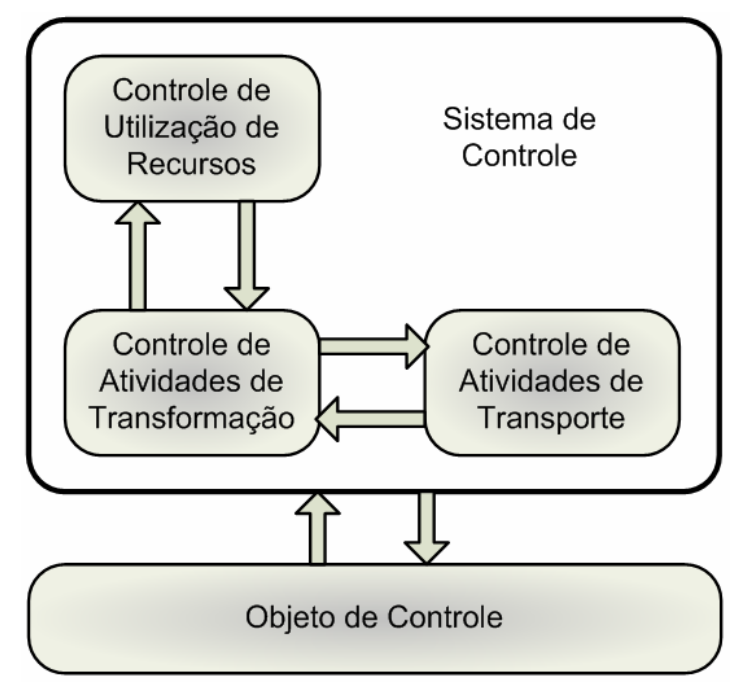

Figura 4.2 Identificação dos módulos de controle para SPF.

Desta forma, o controle de atividades de transporte também deve gerenciar a utilização destas vias pelos transportadores a fim de evitar o problema de deadlock. Sendo assim, a arquitetura de controle proposta é apresentada na Figura 4.3.

Os módulos de controle desta arquitetura são:

* Controle de Atividades de Transformação (CAT). Responsável pelo seqüenciamento das atividades de transformação;

* Controle de Utilização de Recursos (CUR). Gerencia a utilização global dos recursos de transformação (estações de trabalho) entre os processos;

* Controle de Designação de Transportadores (CDT). Responsável pela designação de transportadores para a realização de transporte de itens entre as estações de trabalho e a definição dos trajetos de transporte;

* Controle de Utilização de Vias (CUV). Gerencia a utilização das vias pelos transportadores;

* Controle de Vias (CV). Controla o tráfego de transportadores pelas vias. 


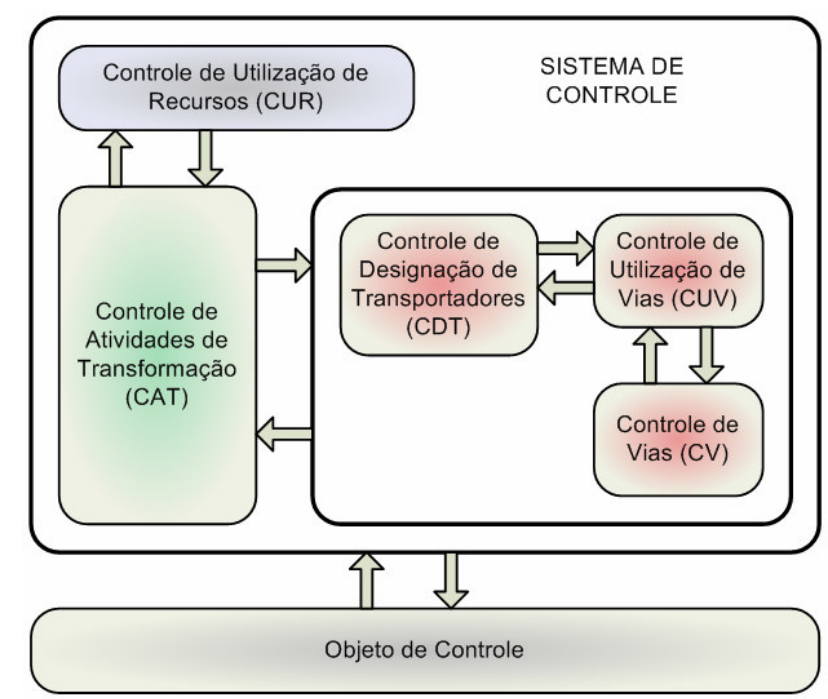

Figura 4.3 Proposta de arquitetura de controle para SPF.

\subsection{Módulos de Controle}

Apresenta-se nos próximos itens um detalhamento de cada um dos módulos de controle e a interface entre eles.

Considera-se o seguinte exemplo de SPF com as seguintes características:

* Um conjunto de processos $P=\left\{\Pi_{1}, \Pi_{2}, \Pi_{3}\right\}$, sendo que, as seqüências de alocação de recursos e as respectivas atividades são: $\Pi_{1}: R_{2} \rightarrow R_{4} \rightarrow R_{3} \mathrm{e}$ $S_{1}=\left\{\Xi_{11}, \Xi_{12}, \Xi_{13}\right\} ; \quad \Pi_{2}: R_{1} \rightarrow R_{2} \quad$ e $S_{2}=\left\{\Xi_{21}, \Xi_{22}\right\} ; \quad \Pi_{3}: R_{3} \rightarrow R_{4} \rightarrow R_{1} \quad$ e $S_{3}=\left\{\Xi_{31}, \Xi_{32}, \Xi_{33}\right\}$ (as atividades $\Xi_{11}$ e $\Xi_{12}$ são executadas no recurso $R_{2}$ );

* Um conjunto de recursos de transformação $R=\left\{R_{1}, R_{2}, R_{3}, R_{4}\right\}$ que correspondem às estações de trabalho compostas por um dispositivo processador com capacidade unitária, dispositivos de recepção $m_{R} \mathrm{e}$ despacho $m_{D}$, de capacidade três em ambos os casos;

Observando-se o layout apresentado na Figura 4.4, o exemplo de SPF é composto de uma entrada de itens a produzir (ENTRADA), uma saída de itens produzidos (SAíDA), um buffer destinado para armazenamento temporário de itens e um estacionamento/manutenção de transportadores. As vias que são de sentido único, indicadas pelas setas na figura em questão. 


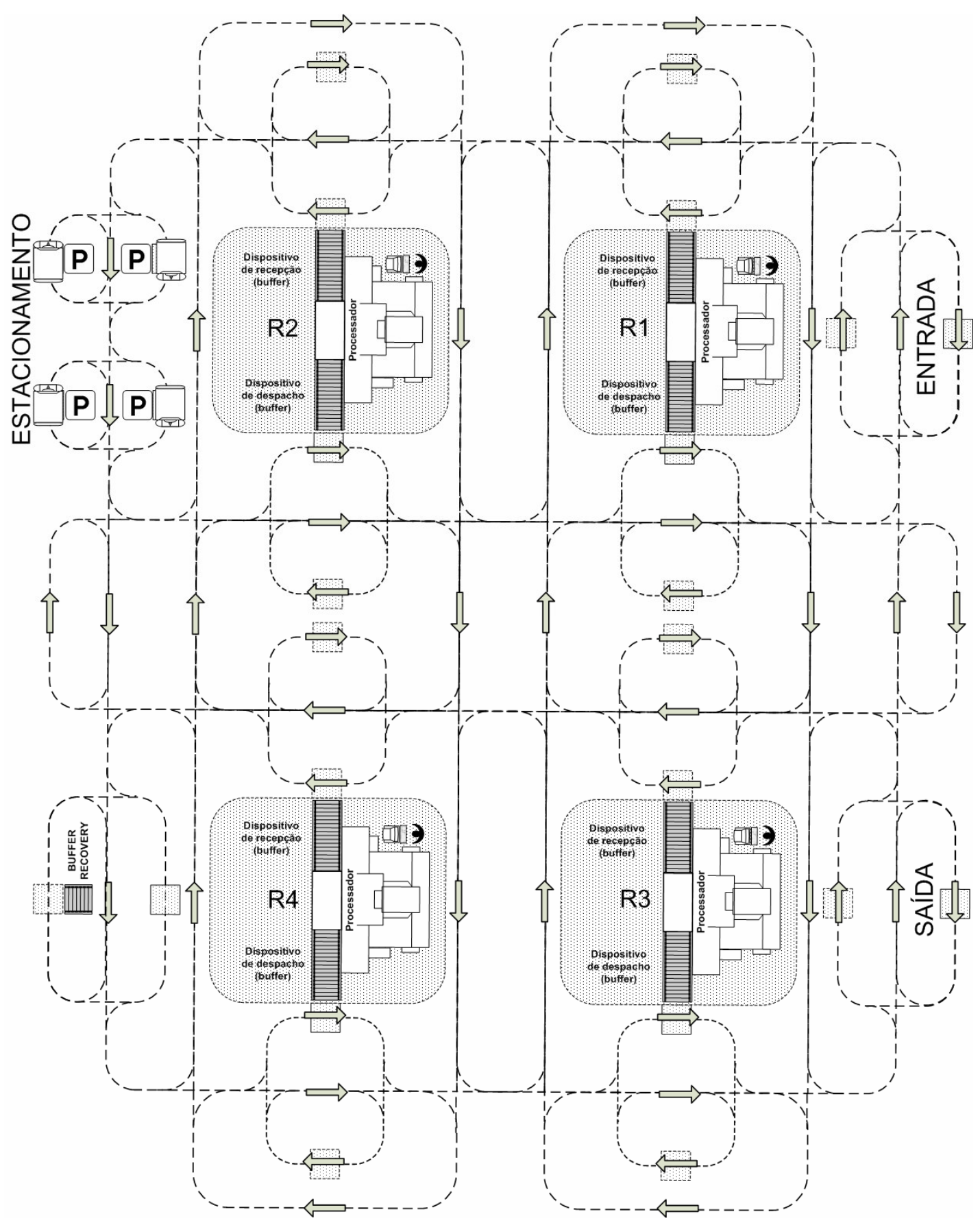

Figura 4.4 Layout do exemplo de SPF.

Destaca-se que as atividades de carregamento e descarregamento nas estações de trabalho possuem vias exclusivas para este fim com o objetivo de não obstruir as vias principais. Adota-se a inclusão de uma via alternativa do lado dos dispositivos de recepção e de despacho. A finalidade desta via alternativa é para o estacionamento temporário de transportadores aguardando a disponibilidade do 
dispositivo ou para desviar-se de outros transportadores que estejam trafegando na via principal.

\subsubsection{Controle de Atividades de Transformação (CAT)}

O CAT controla a execução seqüencial das atividades de cada processo que são executadas nas estações de trabalho do SPF. Destaca-se que entre as atividades de transformação, há a necessidade de realizar-se uma atividade de transporte, isto é, movimentação do item (produto) entre as estações de trabalho.

Considerando-se o exemplo, o CAT é responsável pelos controles dos processos $\Pi_{1}$, $\Pi_{2}$ e $\Pi_{3}$, e deve garantir o seqüenciamento das respectivas atividades utilizando-se o conjunto de recursos R. Entretanto, alguns aspectos importantes quanto à utilização de recursos devem ser destacados (SANTOS FILHO, 2000):

* Os processos seguem as regras de alocação: requisitar, alocar, utilizar e liberar;

* Uma vez que o processo alocou um recurso, utiliza-o de modo exclusivo e somente ele, isto é, o próprio processo que alocou o recurso poderá liberálo. Entretanto, isto ocorre somente quando o processo aloca o próximo recurso $0^{6}$

* A função capacidade dos recursos $C\left(R_{i}\right) \equiv C_{i}$ é unitária, ou seja, existe somente uma única instância de cada tipo de recurso no SAR. Entretanto, é considerado como capacidade do recurso o maior valor entre a capacidade do dispositivo de recepção (buffer de recepção) $m_{R}$ e de despacho (buffer de despacho) do recurso $m_{D}$, sendo que $m_{R} \geq 1 \wedge m_{D} \geq 1$. Destaca-se ainda que os itens (objeto de transformação) aguardam no dispositivo de recepção para a execução da respectiva atividade de acordo com a ordem de chegada.

O CAT comunica-se com o CUR e com o objeto de controle por meio de comunicações que estabelecem os fluxos das informações ilustrados na Figura 4.5. O objeto de controle citado aqui é composto por elementos autônomos que podem

\footnotetext{
${ }^{6}$ Princípio da preempção.
} 
possuir diferentes níveis de flexibilidade operacional. Supondo-se que o processo $\Pi_{1}$ esteja utilizando 0 recurso $R_{2}$ para a execução da atividade $\Xi_{11}$ em um dado momento, após o término da atividade $\Xi_{11}$, o processo $\Pi_{1}$ requisitará a alocação do recurso $R_{4}$. Para esta finalidade, o processo deverá seguir as regras de alocação apresentada anteriormente.

O fluxo (1) da Figura 4.5 representa a requisição de utilização do recurso $R_{4}$ ao CUR. Observa-se aqui que o CAT não possui informações de âmbito global quanto à utilização de recursos, consequentemente, o controle de um processo não saberá qual a influência da alocação de um recurso sobre outros processos.

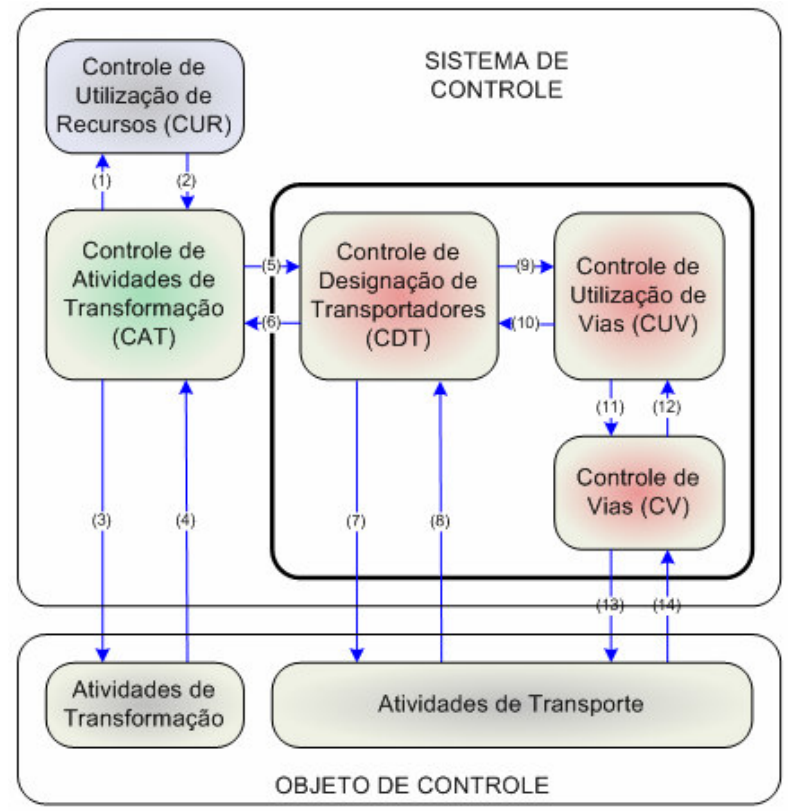

Figura 4.5 Fluxo das informações entre os módulos da arquitetura proposta.

O CUR recebe a requisição do CAT e avalia de acordo com regras de produção préestabelecidas se a requisição poderá ser ou não atendida. O fluxo (2) representa a autorização do CUR quanto à requisição enviada pelo CAT.

Uma vez autorizado a utilização pelo CUR, o processo $\Pi_{1}$ poderá alocar o recurso $R_{4}$. A autorização recebida pelo CAT pode ser de dois tipos: normal ou prioritária. Uma autorização prioritária emitida pelo CUR significa que foi identificada uma situação de deadlock. O CAT deverá então requisitar o transporte ao CDT em caráter prioritário para que o mesmo tome as devidas providências quanto ao tratamento do deadlock. 
O próximo passo é a alocação efetiva do recurso, representada pelo fluxo (3) e a respectiva resposta (4). Desta forma, é garantida ao item a entrada no dispositivo de recepção do recurso $R_{4}$.

Após a efetiva alocação do recurso ao do processo $\Pi_{1}$, o CAT solicita ao CDT um serviço de transporte (normal ou prioritário) da estação de trabalho $R_{2}$ para $R_{4}$, representada pelo fluxo (5). A resposta representada pelo fluxo (6) indica que um transportador foi designado e está a caminho para realizar a atividade de carregamento em $R_{2}$. Uma observação a ser feita neste passo é que o processo $\Pi_{1}$ está utilizando uma capacidade disponível do recurso $R_{2}$ e somente irá liberá-lo para os demais processos após a realização efetiva do transporte.

Por fim, é importante destacar que o início da execução de cada atividade dos processos é estabelecido com bases no gráfo de Gantt fornecido pelo planejamento da produção.

A modelagem do CAT é realizada mediante o uso das ferramentas GAR e E-MFG com comunicadores (ANEXO A). O processo de modelagem é baseado em uma sistemática proposta neste trabalho, denominada de GAR/E-MFG, que é apresentada no item 4.2 .

\subsubsection{Controle de Utilização de Recursos (CUR)}

O CUR é responsável pelo controle global de utilização de recursos de transformação entre os processos que são executados pelo CAT. O CUR possui as seguintes funções:

Monitora os processos quanto à alocação de recursos;

* Recebe as requisições de utilização de recursos pelos processos;

* Verifica de acordo com regras de controle quais das requisições devem ser atendidas.

Basicamente, em linhas gerais, o CUR resolve os conflitos decorrentes da alocação de recursos compartilhados entre os processos que são executados paralelamente. Assim, quando o CAT necessita alocar um recurso para a execução de uma determinada atividade, este requisita ao CUR a utilização do recurso, pois este possui o controle global de utilização dos recursos. 
Conforme apresentado no Capítulo 3, um dos problemas que ocorrem em ambientes caracterizados pelo compartilhamento de recursos é o deadlock. A solução proposta no presente trabalho para tratar o problema de deadlock baseia-se em modelo de restrições de acordo com Santos Filho (2000), agregando-se um novo método híbrido envolvendo as técnicas de deadlock avoidance, detection e recovery.

A aplicação do método consiste em identificar a formação de CFEs no GAR global de utilização de recursos e determinar as regras que identificam a condição anterior ao travamento e as respectivas ações para evitar o deadlock.

A condição anterior ao travamento é caracterizada quando a alocação de um recurso do CFE por um processo externo ao CFE causará o deadlock, ou seja, a formação da cadeia cíclica de processos aguardando a liberação de recursos. Para evitar o travamento é adotada a técnica flow-in-suppression (SANTOS FILHO, 2000; NAKAMOTO, 2002; NAKAMOTO et al. 2003a, 2003b, 2003c), ou seja, inibe-se a evolução de um processo no CFE que possam causar o travamento.

A característica hierárquica entre CUR e CAT é adequada para a aplicação do modelo de restrições, pois as regras estabelecidas resolvem o problema global de alocação de recursos entre os processos.

Entretanto, para se abordar de uma forma mais abrangente o problema de compartilhamento de recursos de transformação faz-se necessário considerar as seguintes questões:

* Um primeiro aspecto a ser considerado é quanto à ocorrência de deadlock. As três primeiras condições das quatro necessárias para a ocorrência do deadlock são inerentes ao SAR, restando a condição de espera circular que pode ser controlada;

* O segundo aspecto é quanto ao método de deadlock avoidance. No caso de formação de CFEs consecutivos, o método pode causar um novo estado de deadlock devido às regras de controle. O GAR ilustrado na Figura 4.6 indica a formação dos CFEs consecutivos. O processo $\Pi_{1}$ utiliza seqüencialmente os recursos $R_{2}, R_{4}$ e $R_{3}$, enquanto que o processo $\Pi_{2}$ utiliza os recursos $R_{3}, R_{4} \mathrm{e}$ $R_{2}$. Considerando-se uma capacidade unitária dos recursos, se o processo $\Pi_{1}$ estiver utilizando o recurso $R_{2}$, processo $\Pi_{2}$ estiver utilizando o recurso $R_{3} \mathrm{e}$ 
recurso $R_{4}$ disponível, as regras adicionais para evitar o deadlock empregando-se a técnica flow-in-suppression (SANTOS FILHO, 2000; NAKAMOTO, 2002; NAKAMOTO et al. 2007a) causaria um novo estado de deadlock. Considerando-se a situação sem a aplicação das regras adicionais de controle de deadlock avoidance, a situação resultante é identificada como impending part flow deadlock (CHO et al, 1995, FANTI et al., 1997). Isto é, há um fluxo do processo, mas o sistema evoluirá para o estado de deadlock após a execução de algumas etapas;

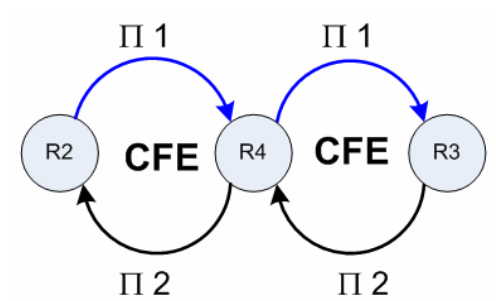

Figura 4.6 Exemplo de CFE consecutivo.

* Um terceiro aspecto é quanto à requisição de todos os recursos pertencentes ao mesmo CFE no mesmo instante. Este estado não é previsto nas regras de deadlock avoidance e certamente resultarão em deadlock.

Considerando os fatos apresentados, no presente trabalho é proposta a seguinte solução para tratar o deadlock em compartilhamento de recursos de transformação:

- Monitoramento do CFE quanto à formação do estado anterior ao deadlock e o estado propriamente de deadlock. Observa-se que o travamento efetivo é caracterizado quando todos os processos que formaram uma cadeia cíclica no CFE entram em estado de espera;

* Determinação de formação de CFEs consecutivos e regras para monitoramento desse estado. Identificando-se o estado, o controle deverá permitir a utilização do recurso, que certamente evoluirá para o estado de deadlock, necessitando ações posteriores de restabelecimento;

* Realização de ações para evitar o deadlock, ou seja, impedir a evolução de processos no CFE. 
O módulo CUR é modelado utilizando-se as ferramentas GAR e E-MFG com comunicadores (ANEXO A) e os detalhes da sistemática de síntese proposta encontra-se no item 4.3.

\subsubsection{Controle de Designação de Transporte (CDT)}

A requisição de transporte consiste em utilizar um recurso (de transporte) para movimentar um item de processo entre as estações de trabalho, estação de entrada e estação de saída de itens. A atividade de transporte é realizada por transportadores (AGV) que devem ser designados e informados a respeito do processo de transporte que devem executar. O processo de transporte consiste em dois trajetos: uma atividade de carregamento na origem e uma atividade de descarregamento no destino.

O primeiro trajeto $\Gamma_{1}$ é o deslocamento do transportador para a estação de trabalho origem, enquanto que o segundo trajeto $\Gamma_{2}$ é o deslocamento do transportador para a estação de trabalho destino.

O CDT realiza a tarefa inicial de transporte que é a designação e a definição dos trajetos. Basicamente, o CDT possui as seguintes funções:

* Recebe as requisições de transporte;

* Organiza as requisições de acordo com a ordem de chegada;

* Realiza o atendimento das requisições em ordem FIFO;

* Designa um transportador;

Define trajetos para os transportadores;

* Trata as requisições prioritárias de acordo com as solicitações do CAT para o tratamento to deadlock.

Com bases nas funções apresentadas, podem-se identificar duas atividades principais do CDT: organiza (ordena) a fila de requisições e atende as requisições. Cabe salientar que as duas atividades são mutuamente exclusivas e que a organização da fila de requisições possui maior prioridade em relação ao atendimento. Os fluxos das informações estão ilustrados na Figura 4.7, o fluxo (5) representa as requisições de transporte do CAT para o CDT. 
O CDT recebe do CAT as requisições de transporte que possuem as seguintes informações:

* Identificação do processo;

* Estação de trabalho origem;

* Estação de trabalho destino;

* Tipo de autorização.

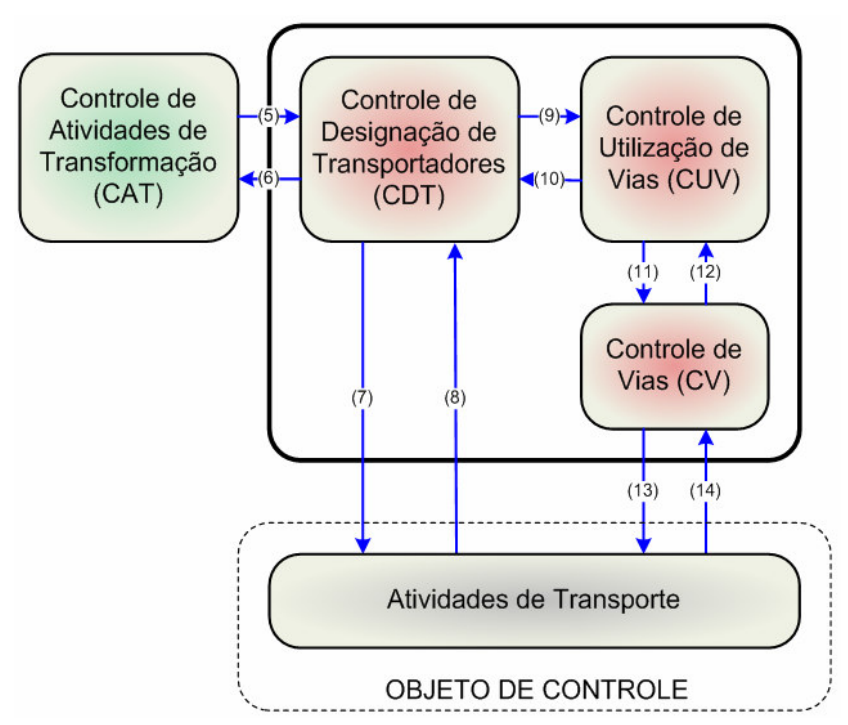

Figura 4.7 Fluxo das informações CAT/CDT/CUV/objeto de controle.

De posse do pedido, o CDT organiza os pedidos em uma fila de requisições de acordo com a ordem de chegada. Entretanto, no caso de requisição prioritária este é colocado no início da fila.

A atividade de designação inicia-se quando não houver mais requisições pendentes fora da fila. $O$ atendimento das requisições é realizado de acordo com o tipo de requisição:

* Transporte normal. A realização da atividade de designação de transportador depende da existência de transportadores disponíveis. O fluxo (7) e (8) da Figura 4.7 representam a verificação da disponibilidade de transportadores. Com as informações referentes ao estado dos transportadores, o CDT verifica qual transportador poderá atender à requisição baseado em um critério de menor custo. O critério de menor curso adotado neste trabalho é a menor distância, isto é, o transportador mais próximo da origem da requisição será designado. Uma vez realizada 
a tarefa de designação do transportador, o CDT informa ao processo solicitante que o transporte será atendido, representado pelo fluxo (6) da Figura 4.7, e informa ao CUV o transportador que foi designado para o trajeto $\Gamma_{1}$, representado pelos fluxos (9) e respectiva resposta pelo fluxo (10);

* Transporte prioritário. A requisição de transporte prioritário indica que o SPF está em estado de deadlock e, portanto, é necessária uma ação de recovery. A estratégia recovery é definida pelo CDT de acordo com o número de requisições prioritárias na fila e a quantidade de transportadores disponíveis:

- Se o número de requisições for maior que o número de transportadores, adota-se a estratégia de transferência de um processo para um buffer temporário (buffer recovery), para realizar-se o atendimento das demais requisições prioritárias e, ao término, atende-se a requisição que está no buffer recovery. $\mathrm{Na}$ prática, a fila de requisições é reordenada e se efetua a designação de modo seqüencial. A reordenação ocorre da seguinte forma: retira-se a primeira requisição da fila e gera-se a partir deste par Origem $\Rightarrow$ Destino os pares Origem $\Rightarrow$ Buffer e Buffer $\Rightarrow$ Destino . A primeira requisição é colocada no início da fila e a última é inserida após a última requisição prioritária da fila;

- Se o número de requisições for menor ou igual ao número de transportadores, atendem-se todas as requisições de modo seqüencial até o término das requisições prioritárias.

Observa-se que o atendimento de uma requisição prioritária implica que todas as requisições prioritárias da fila deverão ser atendidas. Quanto à designação de transportadores, o CDT utiliza o algoritmo Dijkstra de caminho mínimo com Heap Binomial (CORMEN et al., 2002), executado pelo box controlador do E-MFG. O algoritmo foi desenvolvido em $\mathrm{C}++$ para plataforma IBM-PC-Windows XP com o objetivo de determinar o menor caminho em um grafo orientado. $O$ algoritmo é baseado no algoritmo de Dijkstra utilizando uma estrutura de dados Heap Binomial para determinar o nó de menor custo. Cabe ressaltar que foi realizada uma 
comparação de desempenho com outros algoritmos de determinação do menor caminho, resultando-se no trabalho apresentado em Reis et al. (2007). Maiores detalhes sobre a implementação encontra-se no ANEXO B.

O módulo CDT é modelado com base na metodologia PFS/E-MFG, resultando em uma rede E-MFG, conforme descrito no item 4.4

\subsubsection{Controle de Utilização de Vias (CUV)}

A função principal do CUV é garantir o fluxo de transportadores nas vias. O CUV possui dois módulos, a saber, (Fig. 4.8):

Módulo gerador do CUV;

Módulo de controle do CUV.

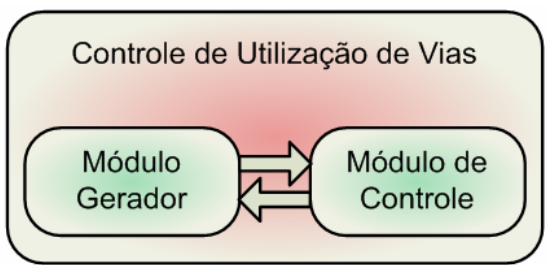

Figura 4.8 Módulos do CUV: gerador e controle.

O CDT envia para o CUV a designação do transportador e o respectivo processo de transporte composto pelas informações de origem, destino e trajeto $\Gamma_{1}$. O trajeto é composto por uma seqüência de zonas que devem ser transitadas pelos transportadores e a função do CUV é impedir a ocorrência de deadlock nas vias, permitindo ou não o trânsito do transportador por estas zonas. O módulo gerador do CUV recebe os processos de transporte e os insere na fila de transportadores designados. A fila tem o propósito de ordenar as designações em grau de prioridade. Após a realização da ordenação da fila, o módulo gerador executa o seguinte procedimento:

* Gera o GAR global dos processos de transporte;

* Determina os CFEs;

* Verifica a formação de CFEs consecutivos. Se houver CFEs consecutivos, determina-se um novo trajeto para o processo de menor prioridade e se inicia o procedimento novamente. 
Ao término do procedimento, o módulo gerador do CUV cria as regras adicionais de controle, isto é, as regras para evitar o deadlock e posterior geração do E-MFG com a incorporação das regras. A atualização do controle ocorre da seguinte forma:

* Gera-se uma interrupção no módulo de controle do CUV;

* Interrompem-se as transições de estados, mantendo-se assim os estados dos transportes;

* Atualiza-se o módulo de controle do CUV;

Atualiza-se o estado das marcas.

O módulo gerador do CUV executa este procedimento no caso do transportador realizar 0 trajeto $\Gamma_{1}$ e iniciar a atividade de carregamento. A segunda parte do processo de transporte $\Gamma_{2}$ é gerada após a conclusão do carregamento do item na estação de trabalho origem. O módulo gerador do CUV automaticamente calcula o novo trajeto $\Gamma_{2}$ para o processo de transporte, executa novamente o procedimento $\mathrm{e}$ atualiza o módulo de controle. A divisão do trajeto em $\Gamma_{1}$ e $\Gamma_{2}$ tem como objetivo o uso racional das vias, isto é, somente utilizar as vias quando realmente for necessário. Um outro aspecto é quanto à geração do módulo de controle CUV, pois com trajetos menores, reduz-se a quantidade de nós e arcos a serem processados. A Figura 4.9 apresenta o fluxo de informações entre os módulos CUV e CV.

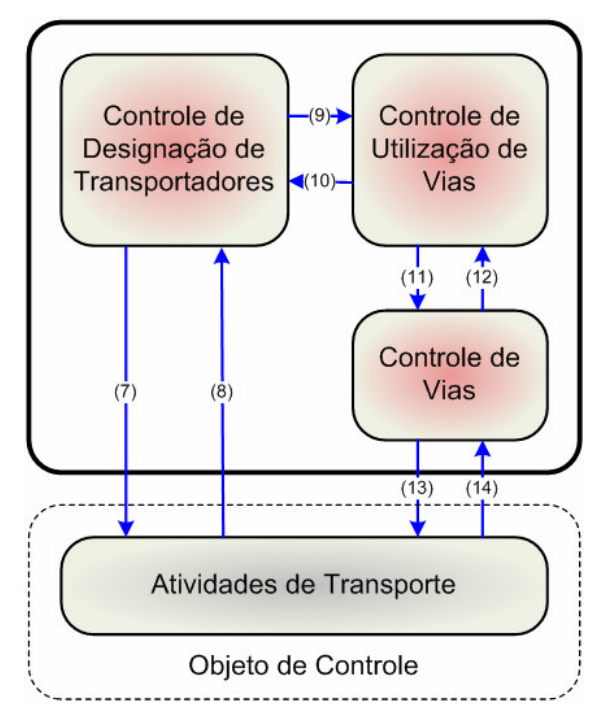

Figura 4.9 Fluxo das informações CUV/CV/objeto de controle.

O módulo gerador CUV recebe as informações do CDT quanto ao transportador designado e o trajeto $\Gamma_{1}$ a ser realizado, representado pelo fluxo (9) e respectiva 
resposta de recebimento pelo fluxo (10). O fluxo (11) indica a atualização das marcas. A comunicação do módulo de controle CUV com o CV são indicados pelos fluxos (11) e (12) que representam a requisição para trânsito em vias e as respectivas autorizações. O módulo CUV é modelado com base na metodologia PFS/E-MFG (ANEXO A), resultando em uma rede E-MFG. As ferramentas utilizadas pelo módulo gerador do CUV são o GAR e o E-MFG, conforme descrito no item 4.5.

\subsubsection{Controle de Vias (CV)}

O CV é responsável pelo mapeamento do tráfego dos transportadores nas vias. $O$ módulo CV é gerado com base na sistemática GAR/E-MFG (ANEXO A) a partir do layout do SPF. O E-MFG do CV possui marcas que representam os transportadores do SPF e estas marcas possuem o trajeto a ser percorrido pelo transportador como atributo. Desta forma, a evolução das marcas no $\mathrm{CV}$, que corresponde ao tráfego dos transportadores pelas vias, depende de autorização do CUV. Cabe destacar que a atualização das marcas é realizada pelo módulo gerador do CUV. Os detalhes de síntese estão descritos no item 4.6.

\subsection{Síntese do Controle de Atividades de Transformação}

A síntese de como o CAT deve agir baseada na sistemática GAR/E-MFG. Adota-se um procedimento de refinamento sucessivo do E-MFG gerado a partir do GAR. O refinamento sucessivo no E-MFG é ilustrado nas Figuras 4.10.

$\Pi 1$
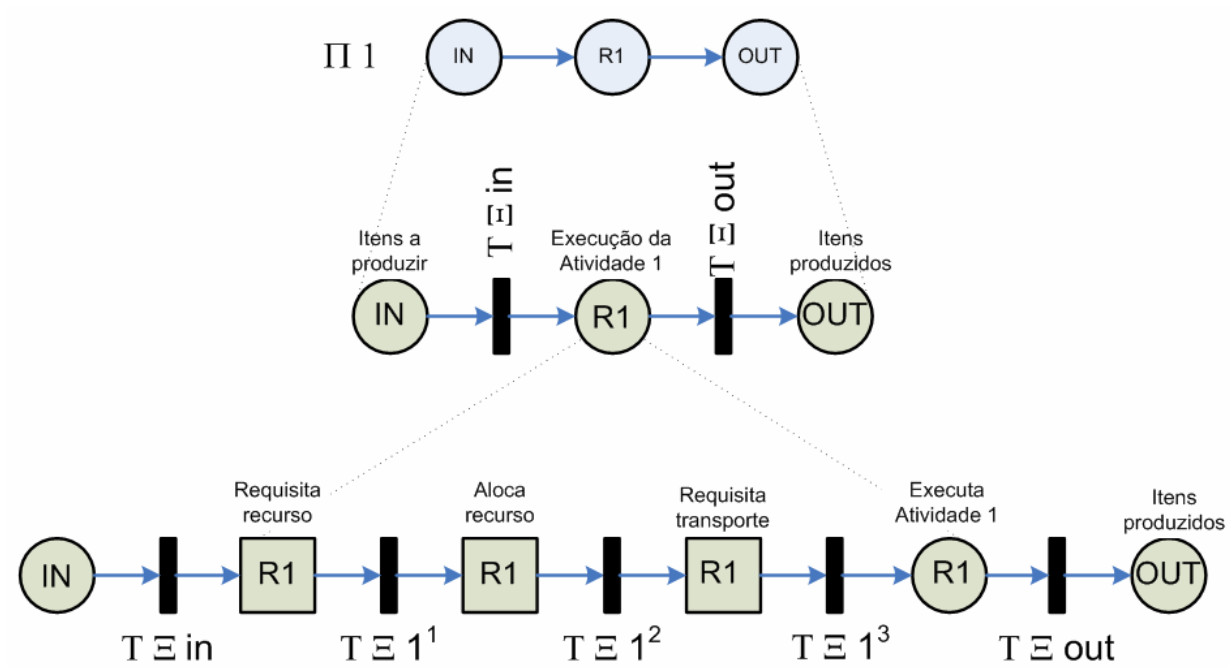

Figura 4.10 Geração do E-MFG inicial a partir do GAR do processo. 
Destaca-se que as marcas do E-MFG possuem atributos conforme apresentados na Tabela 4.1.

Tabela 4.1 Atributos da marca no CAT.

\begin{tabular}{|c|c|c|}
\hline Atributo & Descrição & Valor \\
\hline atrib1 & Identificador do processo & Inteiro \\
\hline atrib2 & Recurso atual & Inteiro \\
\hline atrib3 & Próximo recurso & Inteiro \\
\hline atrib4 & Tipo de autorização & Normal ou Prioritário \\
\hline
\end{tabular}

O E-MFG inicial do exemplo apresenta uma seqüência de boxes ${ }^{7} \mathrm{com}$ a seguinte semântica associada a cada um deles: Itens a produzir, requisita recurso, $\underline{\text { aloca }}$ recurso, $\underline{\text { requisita transporte, }}$ executa da atividade e itens produzidos.

Esta seqüência segue as regras de alocação conforme Santos Filho (2000). A partir destes boxes é aplicado o procedimento de refinamento sucessivo:

Itens a produzir. A Figura 4.11 ilustra o resultado do refinamento desse elemento. Inicia-se a produção do item a partir de uma ordem de produção recebida pelo box $\mathrm{BC} 1$. O CAT requisita autorização ao CUR para início de produção. Este mapeamento é realizado pelo box $\mathrm{B} 2$ e a resposta é aguardada no box BC2. O box controlador BCT1 altera as informações nos atributos da marca referentes ao recurso atual, próximo recurso e o tipo de autorização para caráter normal;

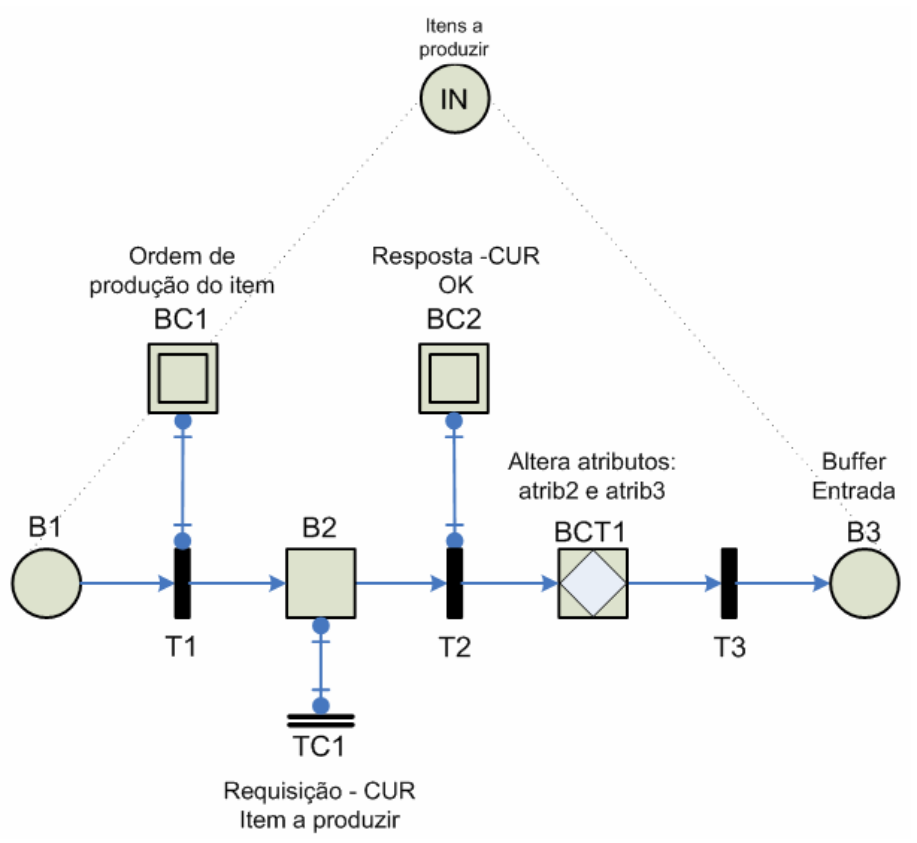

Figura 4.11 Refinamento sucessivo - Itens a produzir.

\footnotetext{
${ }^{7}$ Observa-se que o refinamento do box $\mathrm{R}_{1}$ resultou em quatro boxes, sendo que os três primeiros possuem capacidade unitária.
} 


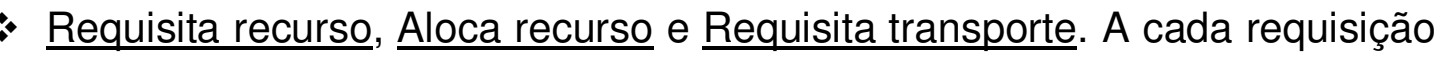
de recurso as três atividades devem ser concluídas para que o item possa ser processado (Figura 4.12). A ordem de produção recebida pelo box BC3 habilita a transição T4 que inicia o procedimento de requisição do recurso. A marca recebida pelo box B4 dispara a mensagem pela transição de envio TC2, requisitando ao CUR a utilização do próximo recurso. Observase que a informação sobre o próximo recurso (atrib3) consta nos atributos da marca alterada no box controlador BCT1. A resposta do CUR recebida pelo BC4 informa que o recurso pode ser alocado. Uma marca no B5 dispara a mensagem pela transição de envio TC3 realizando de fato a alocação do recurso e a respectiva resposta é recebida pelo box BC5. Quando a marca evolui para o box B6, o arco de leitura (ANEXO A) lê os atributos da marca e dispara a transição de envio TC4 com a requisição de transporte ao CDT, fornecendo a identificação do processo, estação de trabalho origem, estação de trabalho destino e o tipo de autorização (normal ou prioritário). A resposta do CDT é recebida pelo box de recepção $\mathrm{BC6}$ que significa o atendimento da requisição de transporte solicitada anteriormente;
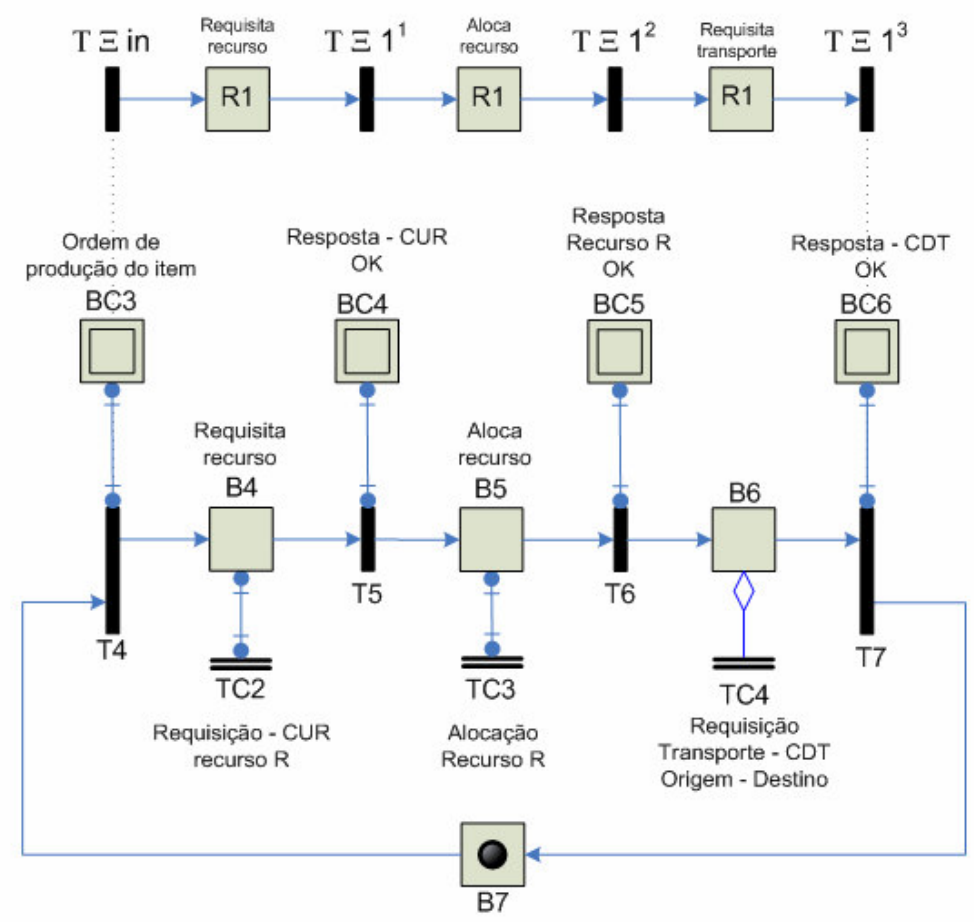

Figura 4.12 Alocação de recursos de transformação e transporte. 
* Executa atividade. A Figura 4.13 ilustra o resultado do refinamento desse elemento. A execução da atividade é realizada pelo recurso após o efetivo transporte do item até a estação de trabalho. O box B8 indica que o processo aguarda o transporte. O recurso informa que o transportador iniciou a atividade de carregamento mediante mensagem enviada ao box de recepção BC7. A marca evolui para o box B10 que significa que o item está em trânsito para a estação de trabalho destino. O início da atividade de descarregamento é indicado pela mensagem do recurso destino (estação de trabalho destino) enviado ao box comunicação BC8. A seguir o item aguarda no dispositivo de recepção da estação de trabalho para a efetiva realização da atividade, indicada pelo box BC9. Ao término da execução da atividade, o recurso informa ao CAT a conclusão da atividade, indicada pelo box comunicação $\mathrm{BC} 10$, e o item é colocado no dispositivo de despacho da estação de trabalho. Observa-se que no box controlador $\mathrm{BCT} 2$ os atributos do recurso atual e o próximo recurso são alterados, inclusive o atributo do tipo de autorização para caráter normal;

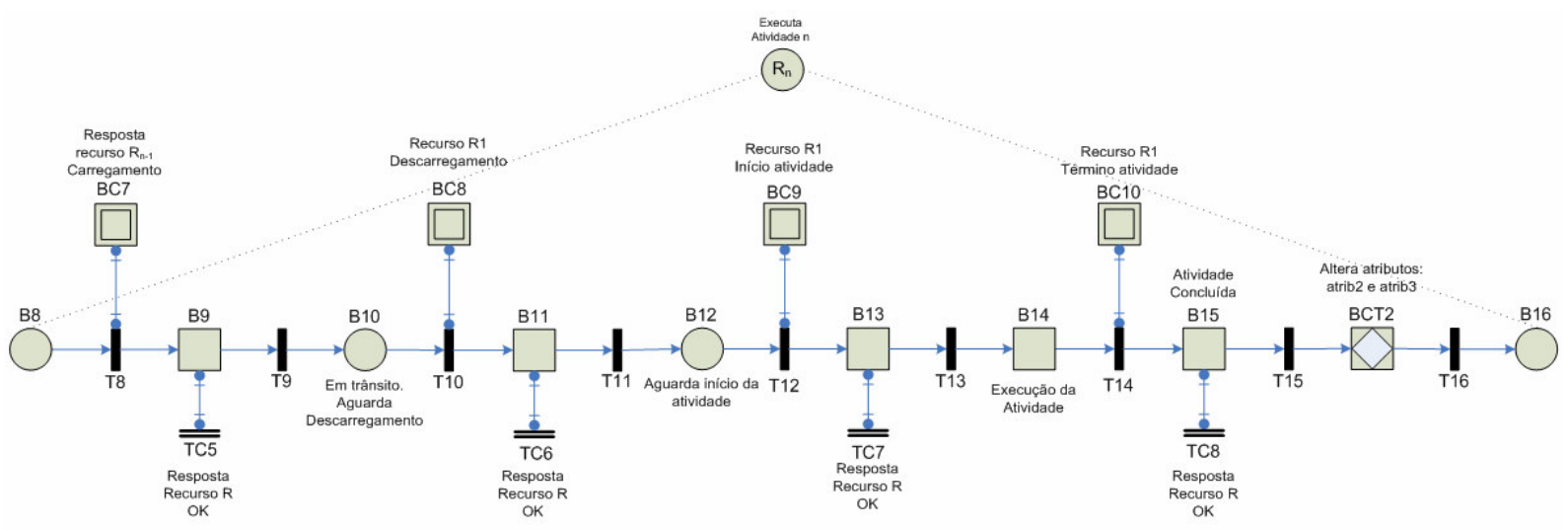

Figura 4.13 Refinamento sucessivo - Execução da atividade.

Itens produzidos: De acordo com a Figura 4.14, a transição é refinada em um sub-grafo que possui duas atividades: (i) requisição de saída do item para o buffer de itens produzidos (Estação de Saída) e (ii) requisição de transporte. A dinâmica de comunicação entre o CAT, CUR e CDT para a realização das atividades (i) e (ii) segue conforme apresentado nos itens anteriores.

O refinamento aplicado aos boxes Requisita recurso, $\underline{\text { Aloca recurso e }} \underline{\text { Requisita }}$ transporte apresentados anteriormente são para os casos de autorização de 
requisição em caráter normal, isto é, para os recursos que não correm risco de deadlock.

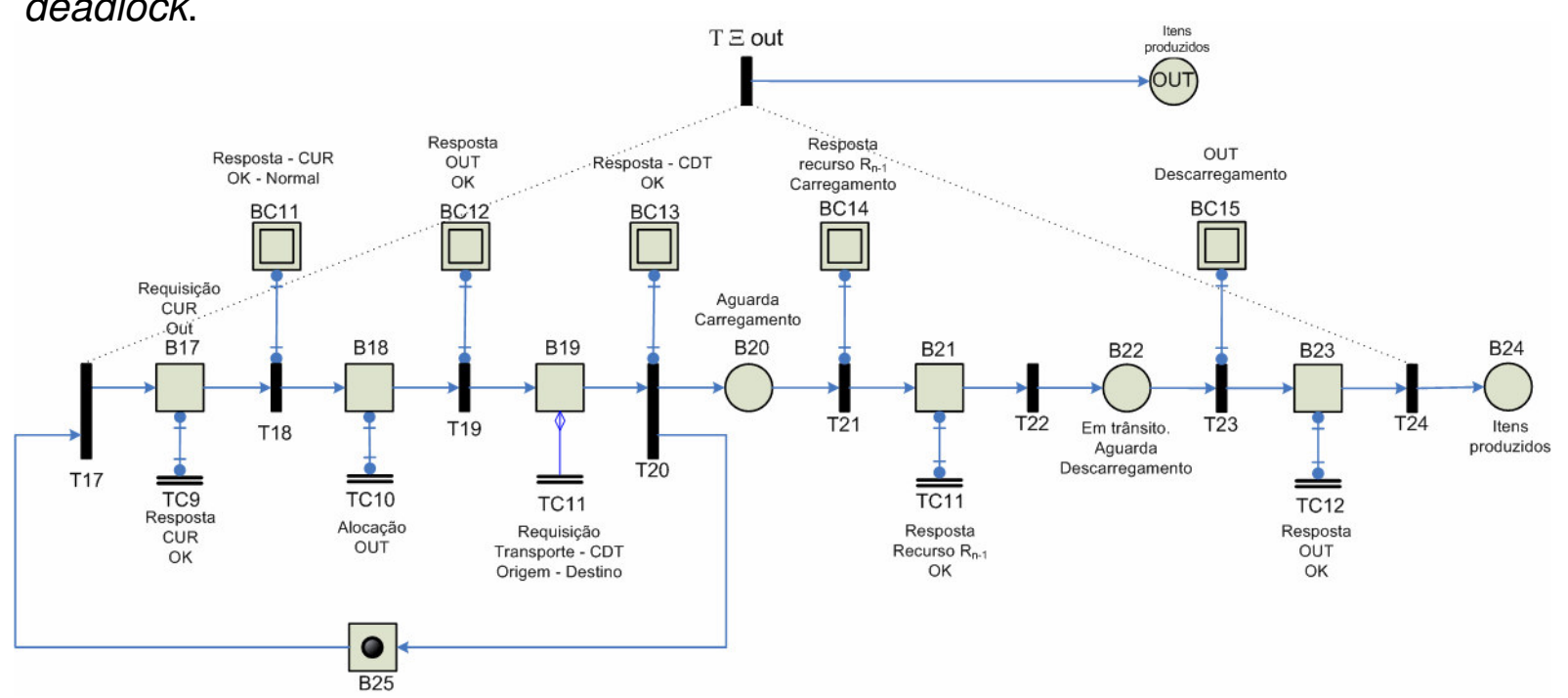

Figura 4.14 Refinamento sucessivo: itens produzidos.

Conforme apresentado no capítulo anterior, o deadlock ocorre quando forma-se uma cadeia cíclica de processos em estado de espera no CFE, desta forma, é necessário a inserção de um sub-grafo em todos os recursos que pertencem a um CFE. O subgrafo tem como objetivo refletir as ações estabelecidas pelas regras adicionais de controle de utilização global dos recursos executadas pelo CUR. A Figura 4.15 apresenta o modelo de controle para o caso de recursos compartilhados que pertencem a um CFE.
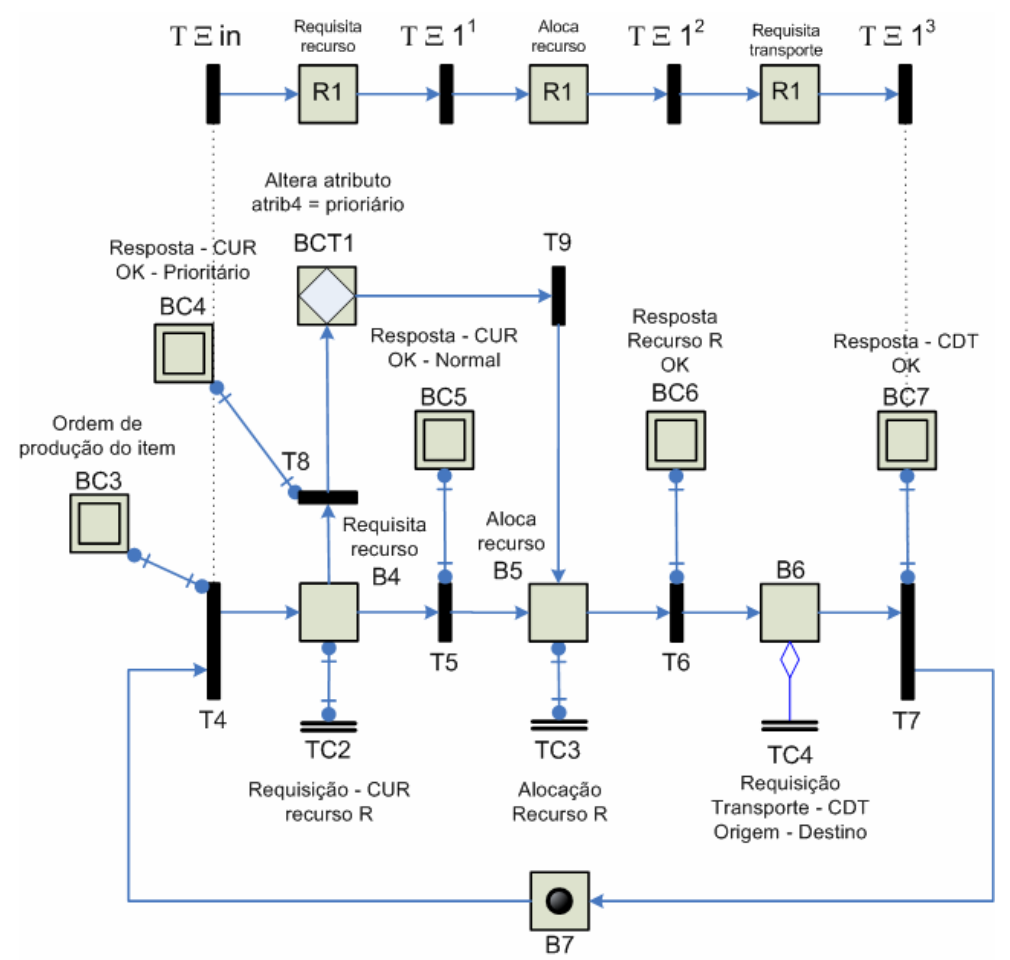

Figura 4.15 Alocação de recursos de transformação e transporte prioritário. 
O box de recepção $\mathrm{BC} 4$ é responsável por receber a mensagem de autorização de utilização do recurso em caráter prioritária estabelecido pelo CUR. A mensagem habilita a transição T8 permitindo que a marca evolua para o box controlador BCT1. O box controlador altera o atributo do tipo de autorização para prioritário e, após a marca evoluir para o box B5, dispara a transição de envio TC3 que inicia a alocação do recurso. Observa-se que o atributo atrib4 é utilizado pela transição de envio TC4 que envia a requisição de transporte ao CDT em caráter prioritário.

\subsection{Síntese do Controle de Utilização de Recursos}

A síntese de como o CUR deve agir é baseada na metodologia proposto por Santos Filho (2000). Conhecido o conjunto de processos, o conjunto de recursos e o respectivo seqüenciamento das atividades dos processos, a estratégia de funcionamento do CUR segue em duas etapas:

I) Determinação das regras adicionais de controle para evitar o deadlock;

II) Síntese do controle de utilização de recursos.

A determinação das regras adicionais de controle para evitar o deadlock é baseada na metodologia desenvolvida por Santos Filho (2000). Entretanto, conforme visto anteriormente, a formação de CFE consecutivos com a aplicação da técnica de flowin-suppression (método de deadlock avoidance) pode causar um novo estado de deadlock devido às restrições impostas pelas regras adicionais de controle. Neste sentido, são adicionados à metodologia os passos V e VI para permitir a aplicação do método híbrido de deadlock avoidance, detection and recovery.

A determinação das regras adicionais de controle segue os seguintes passos:

I) Gerar o modelo GAR de cada processo;

II) Gerar o modelo GAR global de utilização dos recursos utilizando-se a técnica de fusão de nós;

III) Determinar os CFE;

IV) Determinar as regras de deadlock avoidance;

V) Verificar a formação de CFE consecutivos; 
* Para os CFEs consecutivos, determinar as condições em que pode ocorrer o travamento;

VI) Determinar as regras que identificam a ocorrência do deadlocke as ações recovery.

O passo I consiste em mapear o seqüenciamento de utilização dos recursos. Seguindo-se para o passo II, mediante a técnica de fusão de nós, o grafo GAR resultante permite a execução do algoritmo de cálculo do CFE desenvolvido em Nakamoto (2002) e aperfeiçoado em Nakamoto et al. (2007a). Considerando o SPF apresentado na Figura 4.4 os passos I, II e III podem ser exemplificados conforme a Figura 4.16. Os nós $\Pi_{1}^{I N}$ e $\Pi_{1}^{\text {oUT }}$ indicam respectivamente entrada de itens a produzir e saída de itens produzidos.
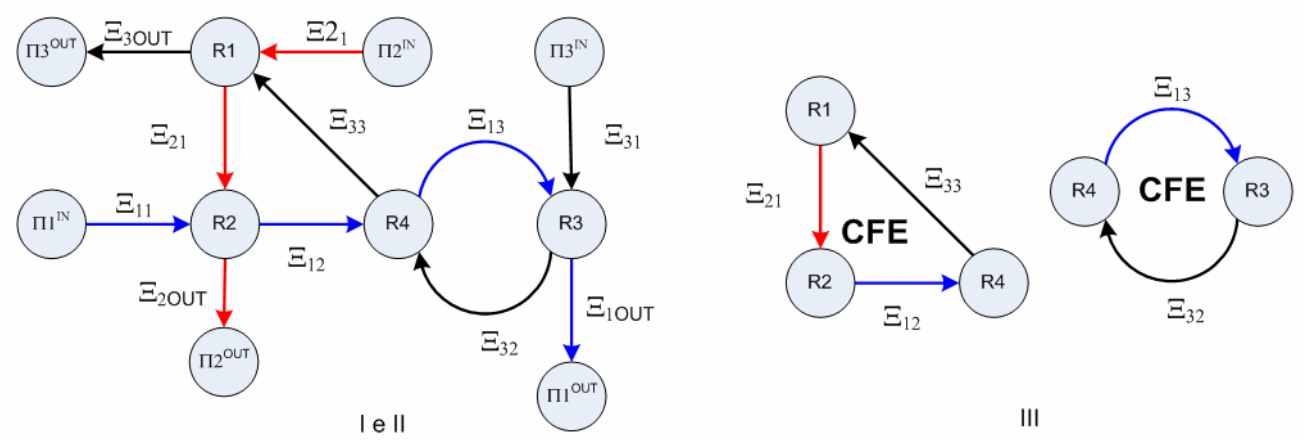

Figura 4.16 Passos I, II e III da síntese do CUR.

As regras adicionais de controle para evitar o deadlock são determinadas identificando-se o estado anterior ao travamento e execução de uma ação que impede a evolução do processo no CFE (Fig. 4.17). O passo $\mathrm{V}$ consiste em verificar a formação de CFEs consecutivos. No exemplo em questão, verifica-se que o CFE formado pelos recursos $\left\{R_{3}, R_{4}\right\}$ e $\left\{R_{1}, R_{2}, R_{4}\right\}$ possui o recurso $R_{4}$ em comum, além de compartilhar entre si o fluxo dos processos $\left\{\Pi_{1}, \Pi_{3}\right\}$.

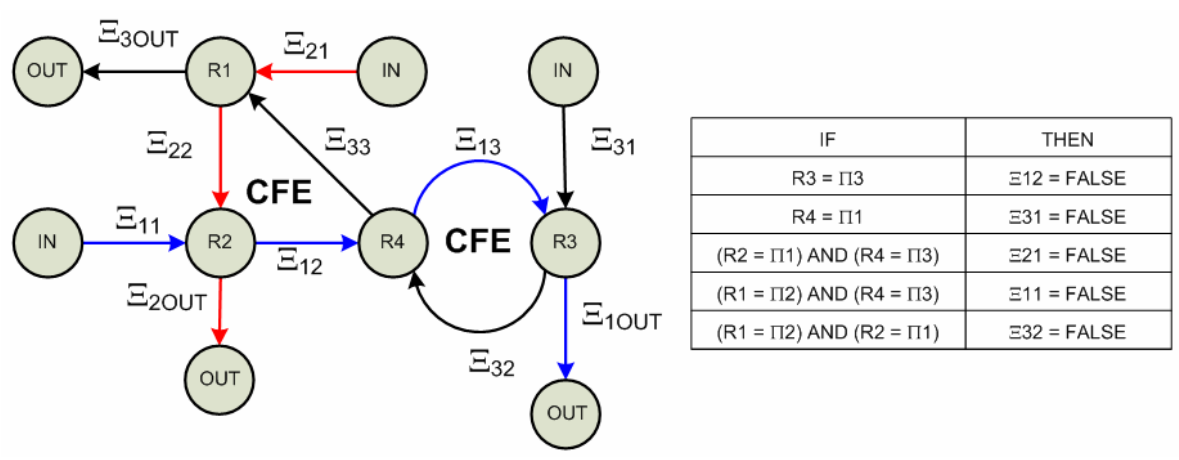

Figura 4.17 Passos IV da síntese do CUR. 
Desta forma, observa-se que as regras 1 e 5 (Fig. 4.18) causariam um novo estado de travamento. As regras 1 e 5 devem ser alteradas da seguinte forma: Se o CFE em questão e o CFE consecutivo estiverem em estado pré-deadlock então permite a entrada do processo no CFE, do contrário inibe-se a entrada do processo. $O$ passo VI consiste em determinar as regras a partir do CFE para a ação de recovery, conforme apresentado na Figura 4.18. A ação recovery consiste em autorizar a utilização dos recursos que estão em estado de deadlock mediante intervenção prioritária dos transportadores que realizam o restabelecimento do fluxo dos processos travados.

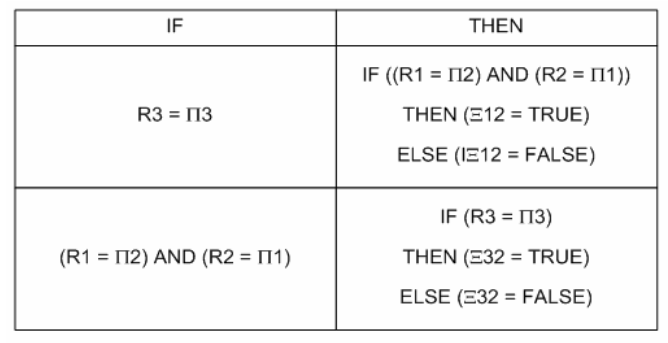

\begin{tabular}{|c|c|}
\hline IF & THEN \\
\hline $\begin{array}{c}(\mathrm{R} 1=\text { П2) AND (R2 = П1) AND } \\
(\mathrm{R} 4=\Pi 3)\end{array}$ & RECOVERY \\
\hline$(\mathrm{R} 3=$ П3) AND (R4 = П1) & RECOVERY \\
\hline
\end{tabular}

(b)

(a)

Figura 4.18 Passos V e VI da síntese do CUR.

A partir da determinação das regras para a técnica híbrida de tratamento do deadlock, inicia-se o processo de síntese de como o CUR deve agir. A síntese é composta pelos seguintes passos a partir do GAR de cada processo:

I) Mapear o E-MFG a partir do GAR conforme formalismo apresentado por Santos Filho (2000) (ANEXO A);

II) Inserir transições de início e término para cada E-MFG de processo;

III) Inserir em cada transição, exceto a última, um sub-grafo que representa a comunicação com o CAT;

IV) Gerar o E-MFG global mediante a técnica de fusão de lugares (SANTOS FILHO, 2000);

V) Inserir para cada CFE um sub-grafo recovery;

VI) Inserir as regras adicionais de controle de deadlock avoidance, detection e recovery. 
O tratamento das mensagens de requisição e autorização requer uma troca de informações entre o módulo CAT e o módulo CUR. Neste sentido, são propostos dois sub-grafos E-MFG, denominados de sub-grafo de comunicação (Fig. 4.19a) e sub-grafo de comunicação recovery ou sub-grafo recovery (Fig. 4.9b). O sub-grafo recovery considera somente as transições que pertencem a um CFE, enquanto que para as demais transições somente o sub-grafo de comunicação é considerada.

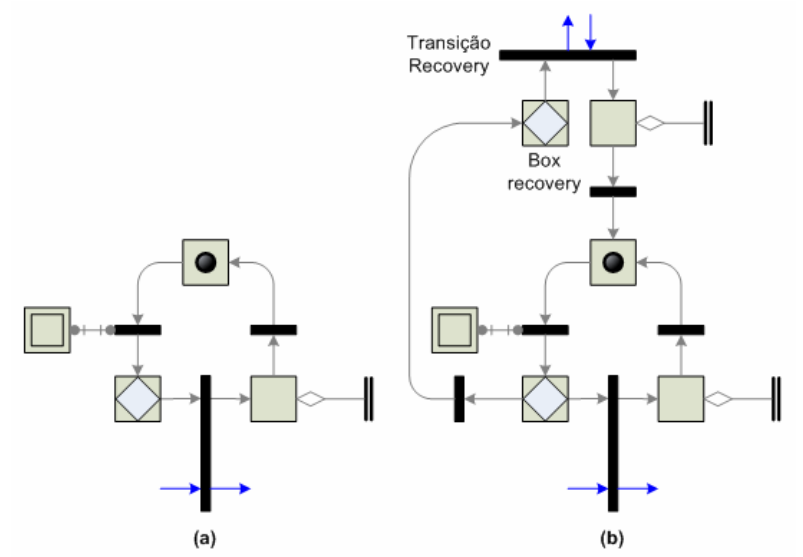

Figura 4.19 Sub-grafo de comunicação (a) e sub-grafo de comunicação recovery.

Desta forma, considerando-se o mesmo SPF para a determinação das regras adicionais de controle, os passos I e II são apresentados na Figura 4.20. O passo III consiste em incluir no CUR a comunicação com o CAT mediante a habilitação de transições do E-MFG. A requisição de utilização enviada pelo processo (CAT) é recebida pelo sub-grafo de comunicação. De acordo com as regras adicionais de controle, ocorrendo a autorização do pedido, o sub-grafo habilita a transição do respectivo CUR e envia uma mensagem de retorno autorizando o processo a alocar o recurso requisitado.

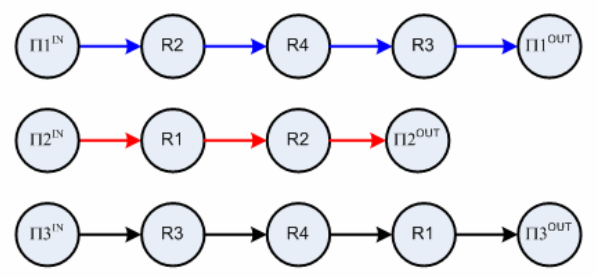

(a)

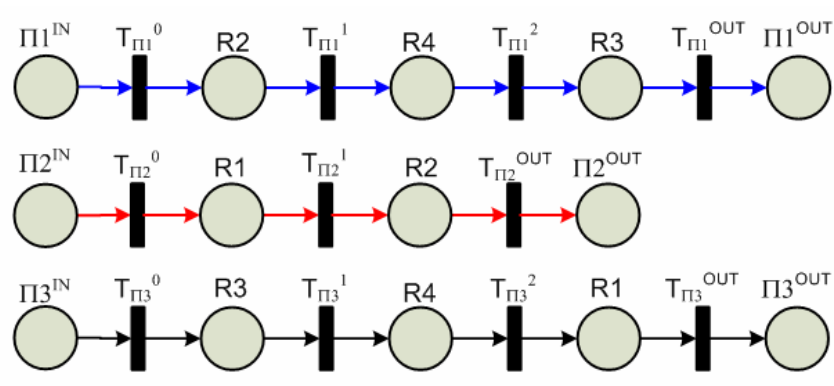

(b)

Figura 4.20 GAR individual (a) e E-MFG individual (b). 
A mensagem contém informação sobre a forma de alocação do recurso: normal ou prioritário. A Figura 4.21 ilustra como ocorre a recepção e o envio de mensagem no sub-grafo de comunicação.

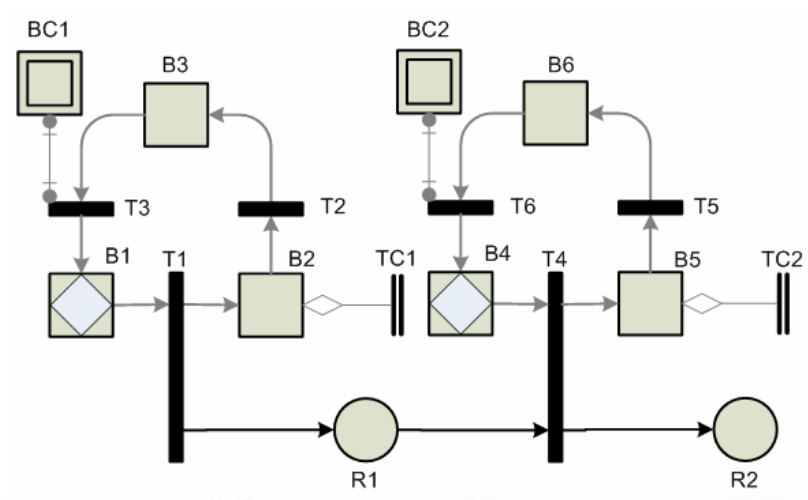

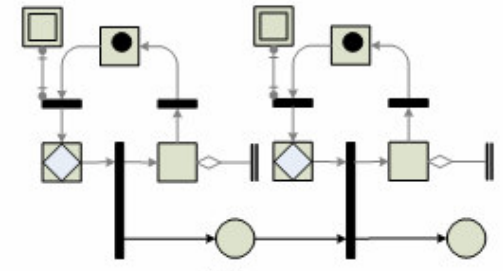

(a)

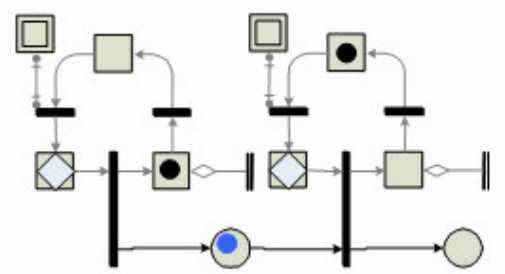

(d)

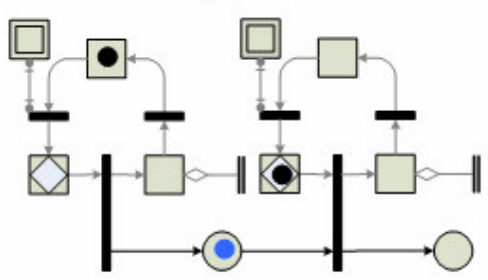

(g)

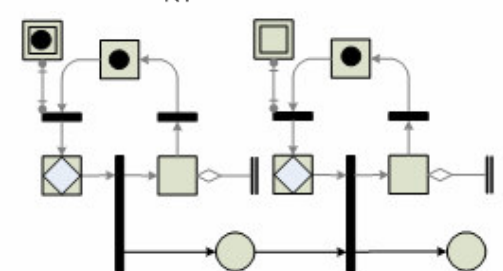

(b)

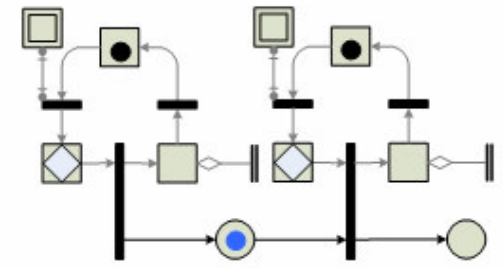

(e)

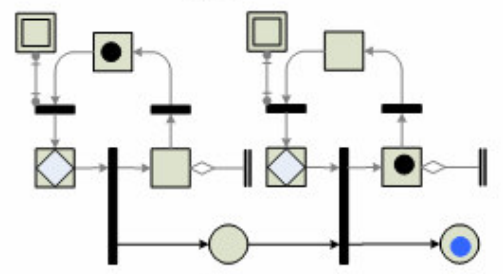

(h)

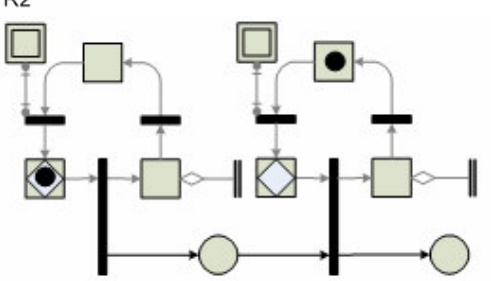

(c)

Figura 4.21 Dinâmica de recepção e envio de mensagem CAT-CUR.

O box de recepção recebe a mensagem de requisição do CAT e as informações são armazenadas nos atributos da marca do sub-grafo. Os atributos da marca são apresentados na Tabela 4.2. A requisição é recebida pelo box $\mathrm{BC} 1$ que habilita e dispara a transição $\mathrm{T} 3$. $\mathrm{O}$ box controlador $\mathrm{B} 1$ recebe a marca e altera $\mathrm{O}$ atributo atrib3 para inicializar com o valor normal. Após o disparo da transição T1, a marca evolui para o box B2 que contém uma transição de envio TC1. A transição realiza a leitura de dados (atributos das marca) e envia a mensagem ao CAT. 
Tabela 4.2 Atributos da marca no CUR.

\begin{tabular}{|c|c|c|}
\hline Atributo & Descriçăo & Valor \\
\hline atrib1 & Identificador do processo & Inteiro \\
\hline atrib2 & Recurso requisitado & Inteiro \\
\hline atrib3 & Tipo de requisiçăo & Normal ou Prioritário \\
\hline
\end{tabular}

Observa-se que a dinâmica da marca no sub-grafo garante que o mapeamento do estado de espera do processo aguardando a liberação do recurso. A Figura 4.22 ilustra o passo III com a inserção dos sub-grafos.
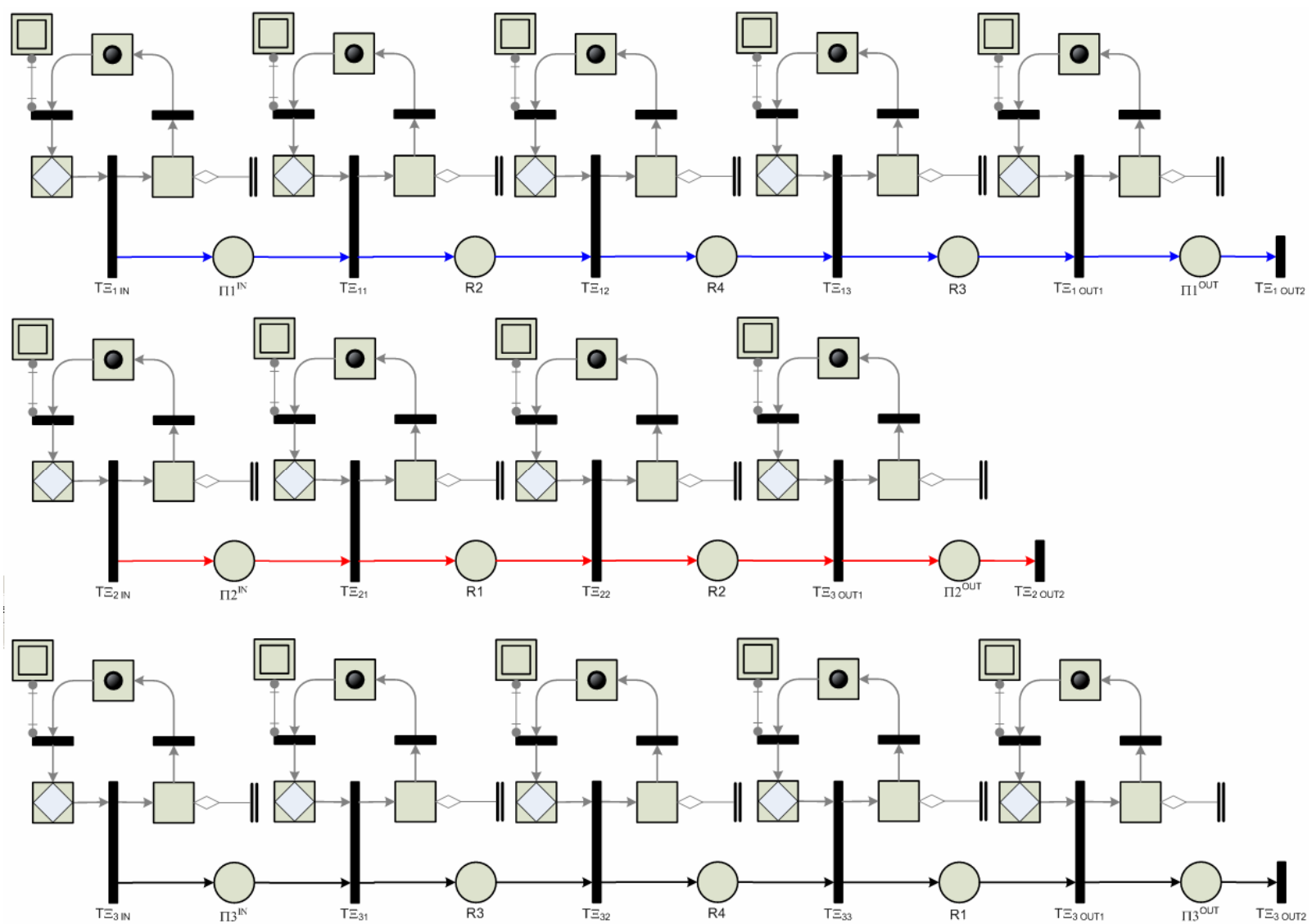

Figura 4.22 Passo III da síntese do CUR.

O passo IV consiste na geração do E-MFG global de utilização de recursos pela técnica de fusão de lugares. Primeiramente, é gerado o E-MFG individual de cada processo com a inclusão dos sub-grafos de mensagem nas transições. A seguir é utilizada a técnica de fusão unindo-se os boxes comuns formando-se o E-MFG global de utilização dos recursos (SANTOS FILHO, 2000). A Figura 4.23 exemplifica o resultado para o SPF aqui considerado (Fig. 4.4).

No passo $\mathrm{V}$ é inserido um sub-grafo recovery para cada transição que autoriza a utilização do recurso no CFE identificado. A estrutura padrão deste sub-grafo recovery foi apresentado na Figura $4.19 \mathrm{~b}$. O sub-grafo recovery identifica o estado de deadlock e permite a utilização do recurso em caráter prioritário. A Figura 4.24 
baseado no SPF da Fig. 4.4, ilustra o caso que envolve um CFE com dois processos. Basicamente o sub-grafo verifica duas condições:

* Se o CFE está em deadlock;

* Se todos os processos envolvidos estão em estado de espera.

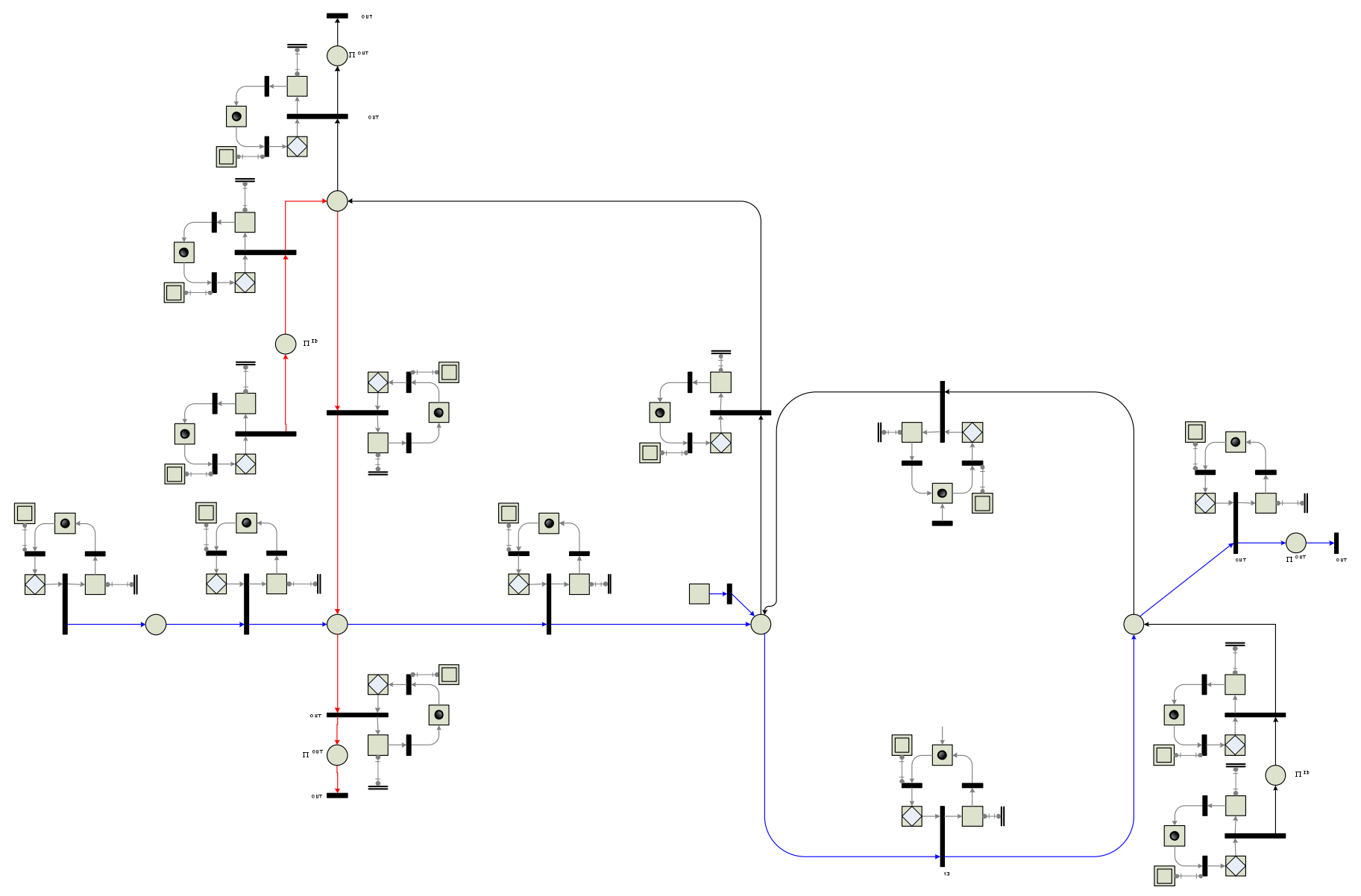

Figura 4.23 Passo IV - geração do E-MFG global de utilização de recursos.

O sub-grafo recovery interliga os sub-grafos de mensagens de requisição das transições do CFE. A interligação tem como função verificar a ocorrência da segunda condição citada anteriormente. Uma regra monitora a ocorrência do "fechamento" do CFE, isto é, formação do ciclo de processos, que consequentemente habilita as transições recovery do sub-grafo. O disparo desta transição ocorre quando o processo requisita o recurso, permitindo a evolução da marca mensagem para o box recovery no sub-grafo. Atendida as pré-condições, ocorre o disparo da transição que permite aos processos a alocação em caráter prioritário na forma de mensagem para o CAT. 


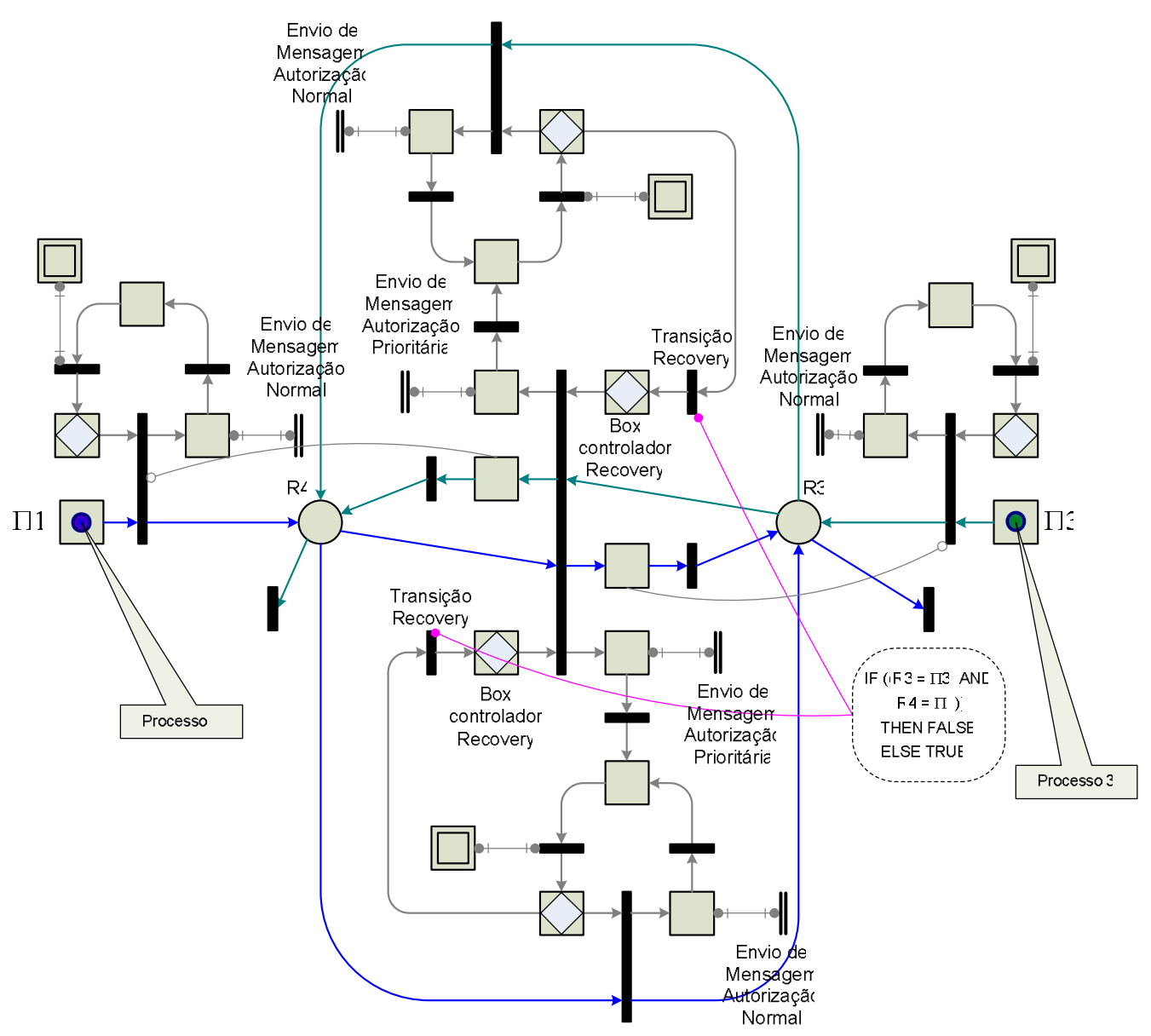

Figura 4.24 Sub-grafo recovery de um CFE com dois processos.

As Figuras 4.25 e 4.26 apresentam a dinâmica da evolução das marcas no sub-grafo recovery em um CFE composto por dois processos. O passo VI consiste na inclusão das regras adicionais de controle ao E-MFG que representa o CUR, conforme ilustrado na Figura 4.27. As regras são inseridas nas transições por meio de arcos habilitadores e/ou inibidores. As regras de deadlock avoidance são inseridas nas respectivas transições de entrada de processos que devem ser impedidos de evoluir e "fechar" o CFE, enquanto que as regras que identificam o estado de deadlock e iniciam a ação de recovery devem habilitar a transição para o box recovery (subgrafo recovery). 

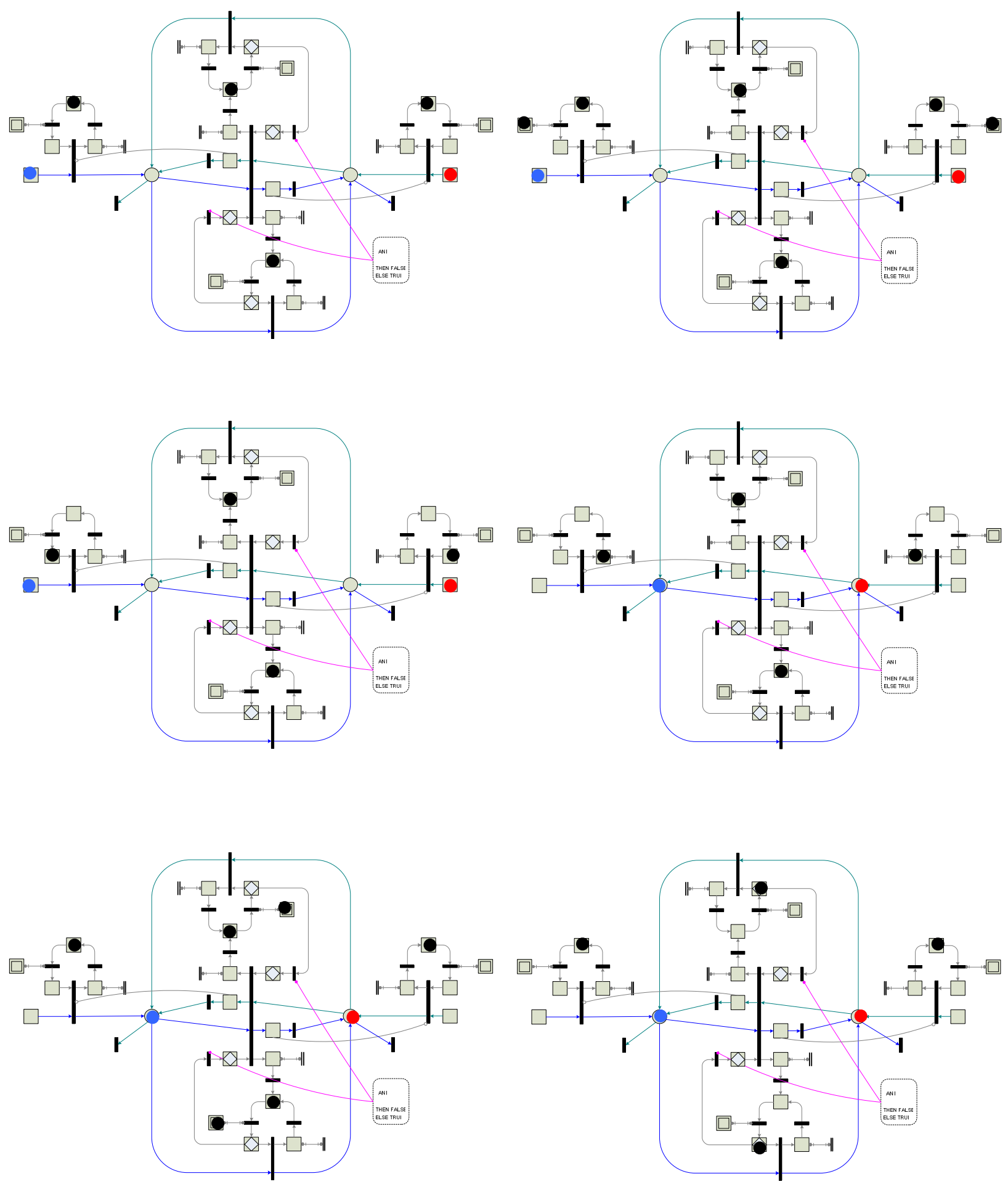

Figura 4.25 Exemplo da dinâmica do sub-grafo recovery - Parte 1. 

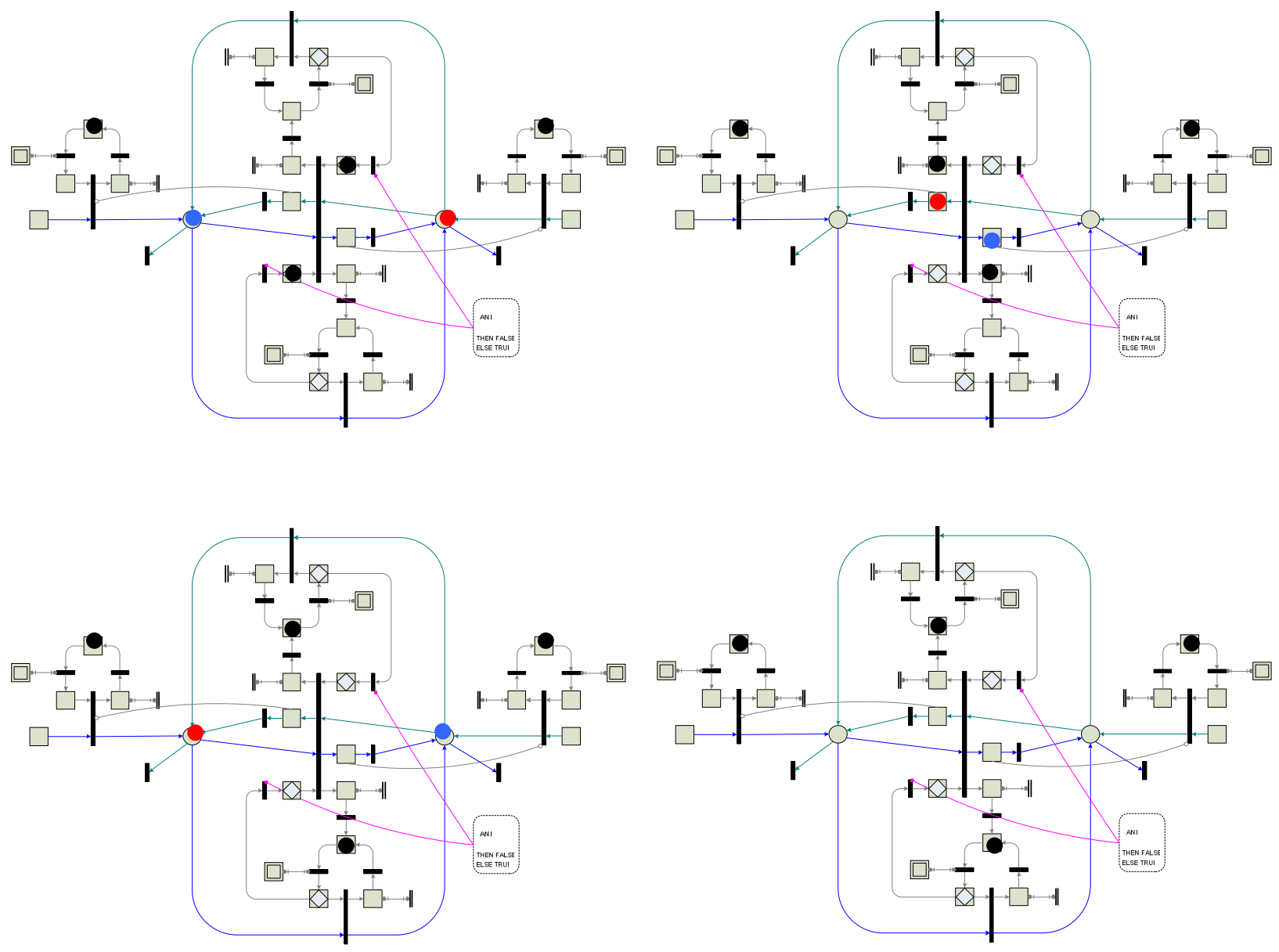

Figura 4.26 Exemplo da dinâmica do sub-grafo recovery - Parte 2. 


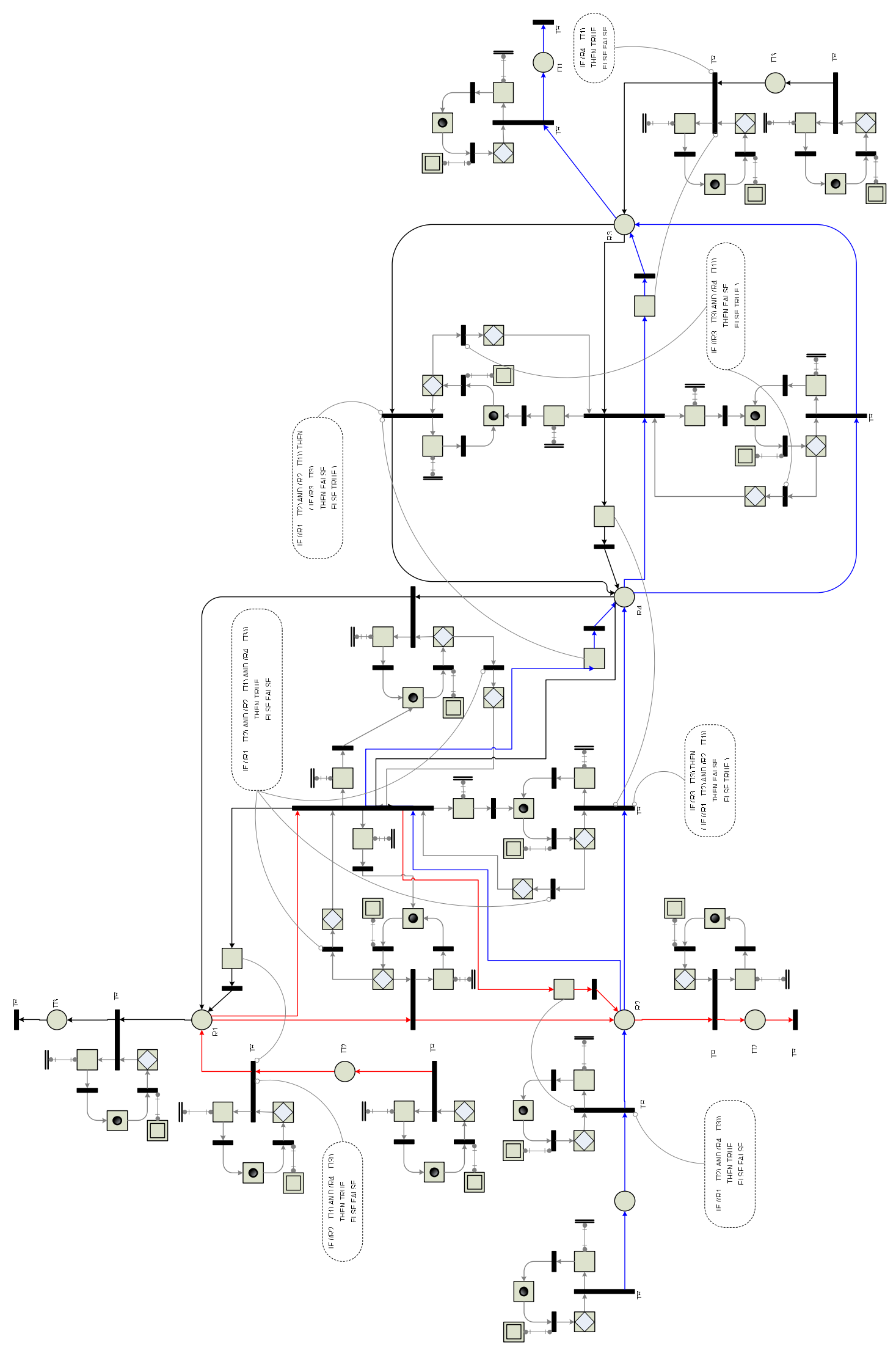

Figura 4.27 E-MFG global do CUR. 


\subsection{Síntese do Controle de Designação de Transporte}

A síntese de como o CDT deve agir é baseado na metodologia PFS/E-MFG. A modelagem inicial em PFS é apresentada e o respectivo detalhamento na Fig. 4.28. Verifica-se que o CDT realiza três atividades: atualiza os estado dos transportadores, organiza a fila de requisições e designa transportador.

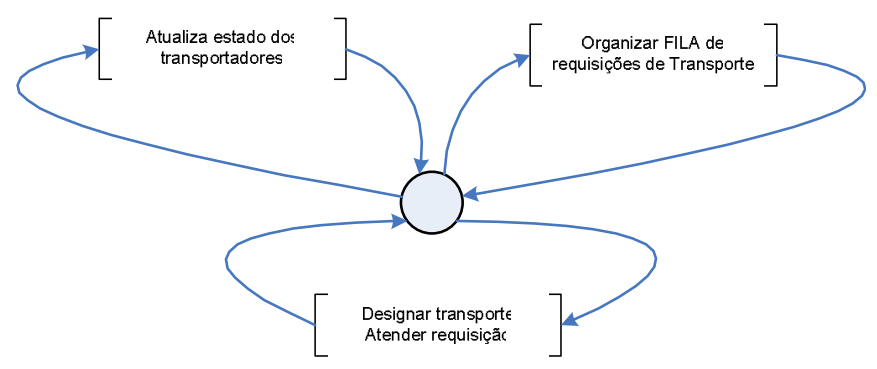

Figura 4.28 Metodologia PFS/E-MFG para a síntese do CDT.

A síntese para a geração do E-MFG deve considerar os atributos da marca, conforme apresentada na Tabela 4.3. A marca no CDT possui nove atributos, sendo que $o$ atributo sete é uma fila de requisições de transporte e $\mathrm{o}$ atributo oito uma lista de transportadores disponíveis.

Tabela 4.3 Atributos da marca no CDT.

\begin{tabular}{|c|c|c|}
\hline Atributo & Descrição & Valor \\
\hline atrib1 & Identificador do retorno de mensagem & Inteiro \\
\hline atrib2 & Identificador do processo & Inteiro \\
\hline atrib3 & Origem & Inteiro \\
\hline atrib4 & Destino & Inteiro \\
\hline atrib5 & Tipo de autorização & Normal ou Prioritário \\
\hline atrib6 & Identificador do transportador & Inteiro \\
\hline atrib7 & Fila de requisições de transporte & ponteiro \\
\hline atrib8 & Lista de transportadore disponíveis & ponteiro \\
\hline atrib9 & Trajeto de transporte & GAR \\
\hline
\end{tabular}

A Figura 4.29 apresenta o E-MFG gerado a partir do PFS da Figura 4.28. Uma das características do E-MFG do CDT é que todos os boxes, exceto B1 e B13, são de capacidade unitária. O box controlador BCT1 ordena a fila de requisições de transporte por ordem de chegada ou em caso de requisição prioritária esta é inserida no início da fila. Ao término da ordenação, copiam-se os valores da primeira requisição da fila para os atributos atrib1, atrib2, atrib3, atrib4 e atrib5. Este procedimento tem como objetivo facilitar a verificação se a requisição é normal ou prioritária. 
O atendimento inicia-se se houver transportador disponível, representado pelo disparo da transição T4. O box B3 unifica as informações de requisições e dos transportadores em uma única marca, procedendo-se a verificação se o pedido é normal ou prioritária. Em caso de pedido normal, a designação é realizada pelo box controlador BCT2 que adota o critério de menor caminho baseado no algoritmo de Dijkstra com Heap Binomial (ANEXO). A marca no box B4 dispara as transições de comunicação TC1 e TC2 que enviam uma resposta ao CAT e a ordem de transporte ao CUV, respectivamente. A mensagem de resposta ao CAT refere-se ao pedido de transporte recebido pelo CDT que somente após a efetiva designação poderá informar ao controle de processo que o pedido será atendido. O CUV recebe do CDT as informações referentes à designação: transportador, estação de trabalho origem e estação de trabalho destino. $O$ tratamento da prioridade é realizado pelo CDT que, após a designação e envio da ordem, mantém a prioridade estabelecida pela seqüência das ordens recebidas, do mais prioritário para o menos prioritário.

A marca no box B5 informa ao transportador que foi designado pelo CDT a sua alocação. O CDT aguarda uma resposta de confirmação do transportador recebida pelo box de recepção $\mathrm{BC} 3$ para que o box controlador BCT3 execute operação cópia de dados do primeiro da fila para os atributos atrib1, atrib2, atrib3, atrib4 e atrib5. Esta cópia é necessária para o CDT possa sempre atender o primeiro pedido da fila.

O atendimento recovery (pedido prioritário) é tratado pelo box controlador BCT5 que define a estratégia de recovery de acordo com a quantidade de transportadores disponíveis. 

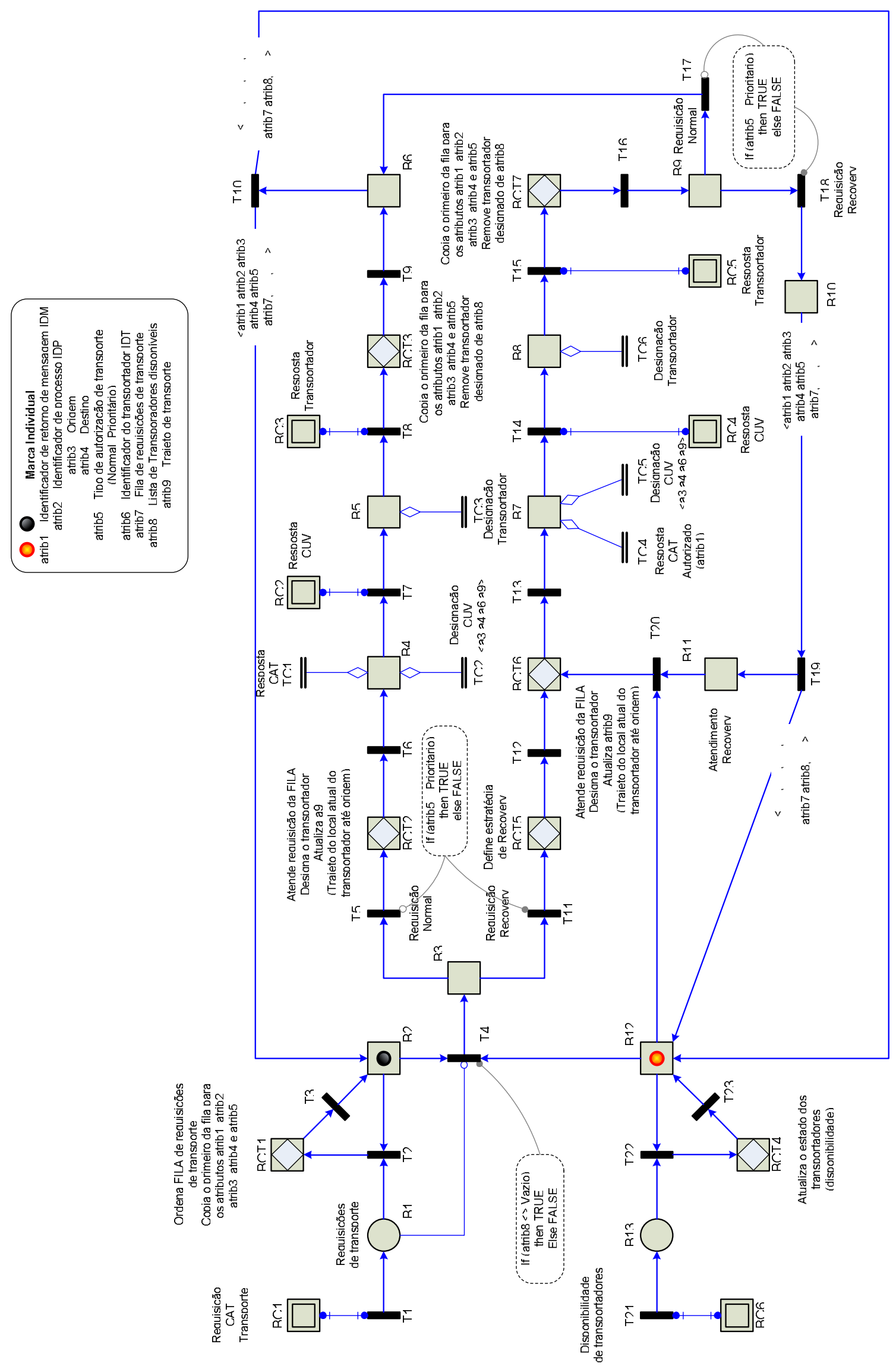

Figura 4.29 E-MFG do CDT. 
As atividades de designação, alocação do transportador e atualização segue a mesma lógica apresentada na situação de pedido de caráter normal pelos boxes BCT6, B7, B8 e BCT7. A seguir, o box B9 verifica se o próximo pedido continua sendo de caráter prioritário ou de caráter normal. Esta ação é necessária para que o CDT atenda primeiramente todos os pedidos prioritários e, somente após esta ação poderá retornar ao box $\mathrm{B} 2$ e assumir o estado inicial de atendimento.

A atualização da disponibilidade dos transportadores é realizada pelo box controlador BCT4 que atualiza o atributo atrib8 referente à lista de transportadores disponíveis. $\mathrm{O}$ transportador informa ao CDT o término do transporte que the foi designado por meio de mensagem enviada ao box BC6.

É importante salientar que este módulo CDT independe do SPF, constituindo-se em um módulo de controle padrão para designação dos transportadores.

\subsection{Síntese do Controle de Utilização de Vias}

A síntese de como o CUV deve agir é realizada com base na metodologia PFS/EMFG. A Figura 4.30 apresenta o PFS inicial e o respectivo detalhamento em E-MFG é apresentado na Figura 4.31.

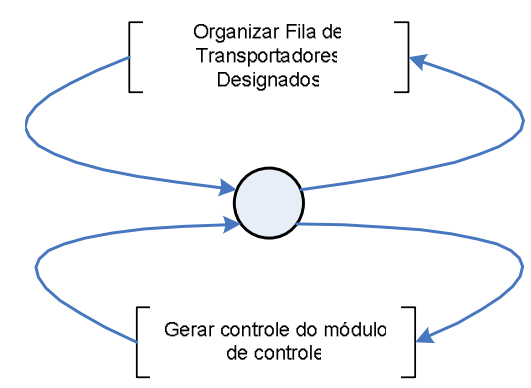

Figura 4.30 O PFS do módulo gerador. 

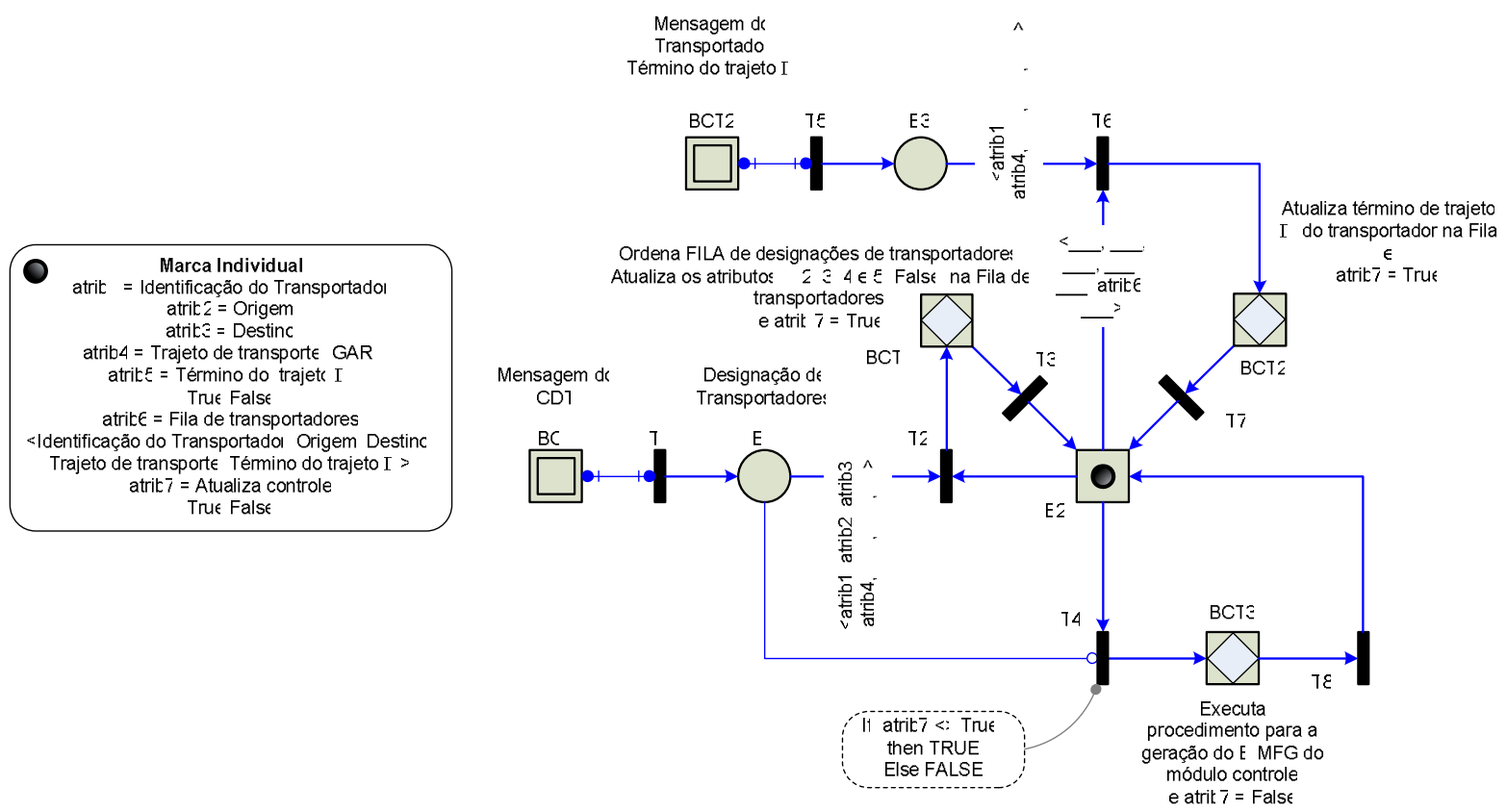

Figura 4.31 O E-MFG do módulo gerador CUV.

A ordem de transporte enviada pelo CDT é inserida na fila de designações, que altera o atributo atrib7 indicando a necessidade de atualizar o módulo controle CUV. A Tabela 4.4 apresenta a lista de atributos da marca do grafo CUV.

Tabela 4.4 Atributos da marca do módulo gerador do CUV.

\begin{tabular}{|c|c|c|}
\hline Atributo & Descrição & Valor \\
\hline atrib1 & dentificador do transportado & Inteiro \\
\hline atrib2 & Recurso origem & Inteiro \\
\hline atrib3 & Recurso destino & Inteiro \\
\hline atrib4 & Trajeto de transporte & GAR \\
\hline atrib5 & Término do trajeto 1 & Boleano \\
\hline atrib6 & Fila de transportadores & Ponteiro \\
\hline atrib7 & Atualiza controle & Boleano \\
\hline
\end{tabular}

O módulo gerador CUV deve atualizar o módulo controle CUV quando recebe uma nova ordem de transporte ou quando o transportador percorre o trajeto $\Gamma_{1}$. Este procedimento é realizado pela regra na transição T4 que verifica o valor do atributo atrib7. Após o disparo da transição habilitada, o box BC3 executa o algoritmo que cria o E-MFG com as regras adicionais de controle para evitar o deadlock nas vias. O algoritmo é apresentado na Figura 4.32. 
O módulo de controle CUV é gerado baseado no método empregado para a geração do E-MFG do módulo CUR, exceto quanto à formação de CFEs consecutivos.

\begin{tabular}{|c|}
\hline \multicolumn{2}{|c|}{ INİCIO Algoritmo de geração do E-MFG } \\
\hline \multicolumn{2}{|c|}{ seguro = FALSE } \\
\hline Gera o GAR global de processo de transporte \\
\hline \multicolumn{2}{|c|}{ Determina os CFE } \\
\hline Existe a formação de CFE consecutivos? \\
\hline $\begin{array}{c}\text { Sim Netermina um novo trajeto para o } \\
\text { processo de menor prioridade. }\end{array}$ \\
\hline Enquanto houver a formação de CFE consecutivo \\
\hline Determina as regras adicionais de controle \\
\hline Gera o E-MFG com controladores \\
\hline Interrupção do módulo de controle \\
Salva os estados das marcas \\
\hline Atualiza o controle (E-MFG) \\
\hline Atualiza as marcas (módulo de controle e a respectiva marca no CV) \\
\hline FIM \\
\hline
\end{tabular}

Figura 4.32 Algoritmo para geração do módulo controle.

Em caso de formação de CFE consecutivo, o algoritmo calcula um novo trajeto baseado no algoritmo executado pelo CDT para o transporte de menor prioridade. Concluída a identificação dos CFEs consecutivos, o algoritmo determina as regras adicionais de controle para evitar o deadlock. As prioridades das designações devem ser contempladas nas regras adicionais de controle, desta forma, em caso de conflito de transportadores para o tráfego na via, a preferência será a designação de maior prioridade, desde que sejam respeitadas as regras para evitar o travamento.

O CUV recebe a requisição do transportador para o tráfego da via $(\mathrm{CV})$ e, de acordo com as regras adicionais de controle, permite ou não o tráfego. Destaca-se que o atributo da marca do CUV é composto apenas pelo identificador do transportador.

Quanto às atividades de carregamento e descarregamento realizadas pelo transportador, não é escopo do CUV ou do CV. Sendo assim, trata-se de uma tarefa pelo próprio controlador do transportador em comunicação com a estação de trabalho.

\subsection{Síntese do Controle de Vias}

O controle de tráfego é derivado a partir do layout do SPF com base na metodologia GAR/E-MFG. As marcas do E-MFG do controle de tráfego gerado representam os 
transportadores do SPF que possuem como atributo o trajeto a ser percorrido. Uma observação a ser feita neste item é quanto ao layout do SPF aqui considerado (Fig. 4.4) neste trabalho. As zonas de carregamento e descarregamento nas estações de trabalho são distintas e possui uma via exclusiva para este fim. O objetivo é manter as vias principais livres para tráfego dos transportadores. Além disso, é previsto em todas as zonas de carregamento e descarregamento um local para parada temporária, espera ou utilização como rota alternativa (Fig.4.33).

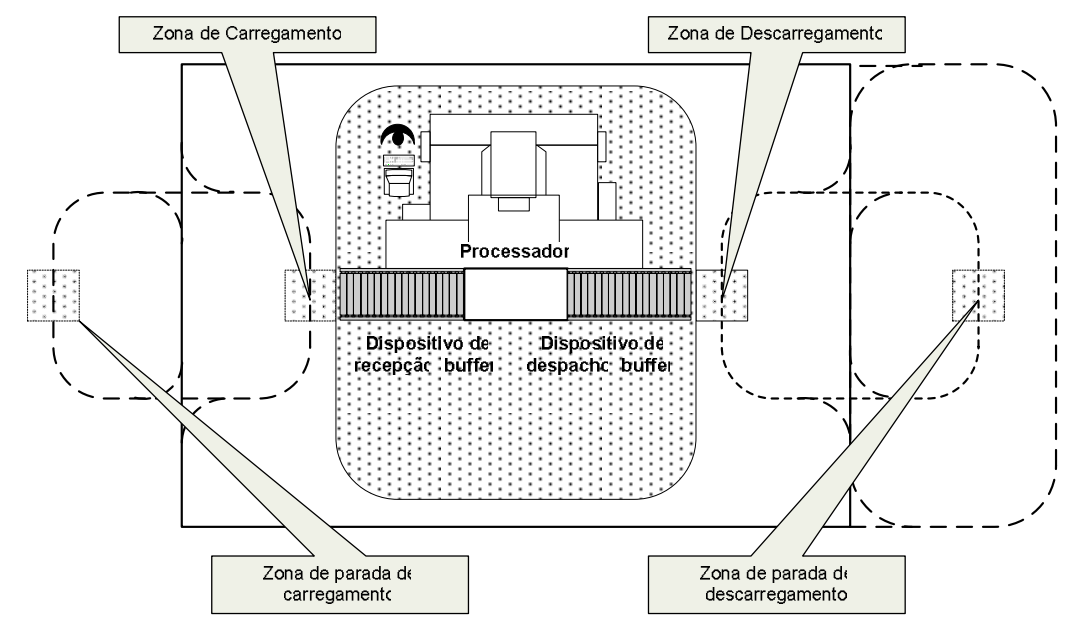

Figura 4.33 Zonas de carregamento/descarregamento e zona de parada.

Desta forma, o GAR das vias é gerado da seguinte forma:

* Identificam-se os nós principais, isto é, identificam-se os pontos de carregamento e descarregamento de itens nas estações de trabalho, estações de entrada, estações de saída, estacionamento e pontos de parada;

* Identificam-se os nós de cruzamento das vias;

* Conectam-se os nós com arcos direcionais que representam as vias.

Quanto à identificação dos nós para o mapeamento do GAR das vias, cabe salientar que somente são considerados dois tipos de nós do GAR: nó de cruzamento (Fig. 4.35a) e nó de carregamento/descarregamento ou parada (Fig. 4.34b).

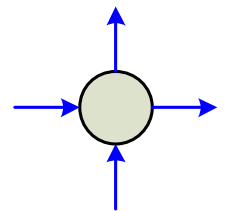

(c)

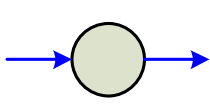

(k)

Figura 4.34 Tipos de nós do GAR das vias. 
Considerando-se o layout apresentado na Figura 4.3, a Figura 4.35 apresenta o mapeamento do GAR das vias descrito anteriormente.

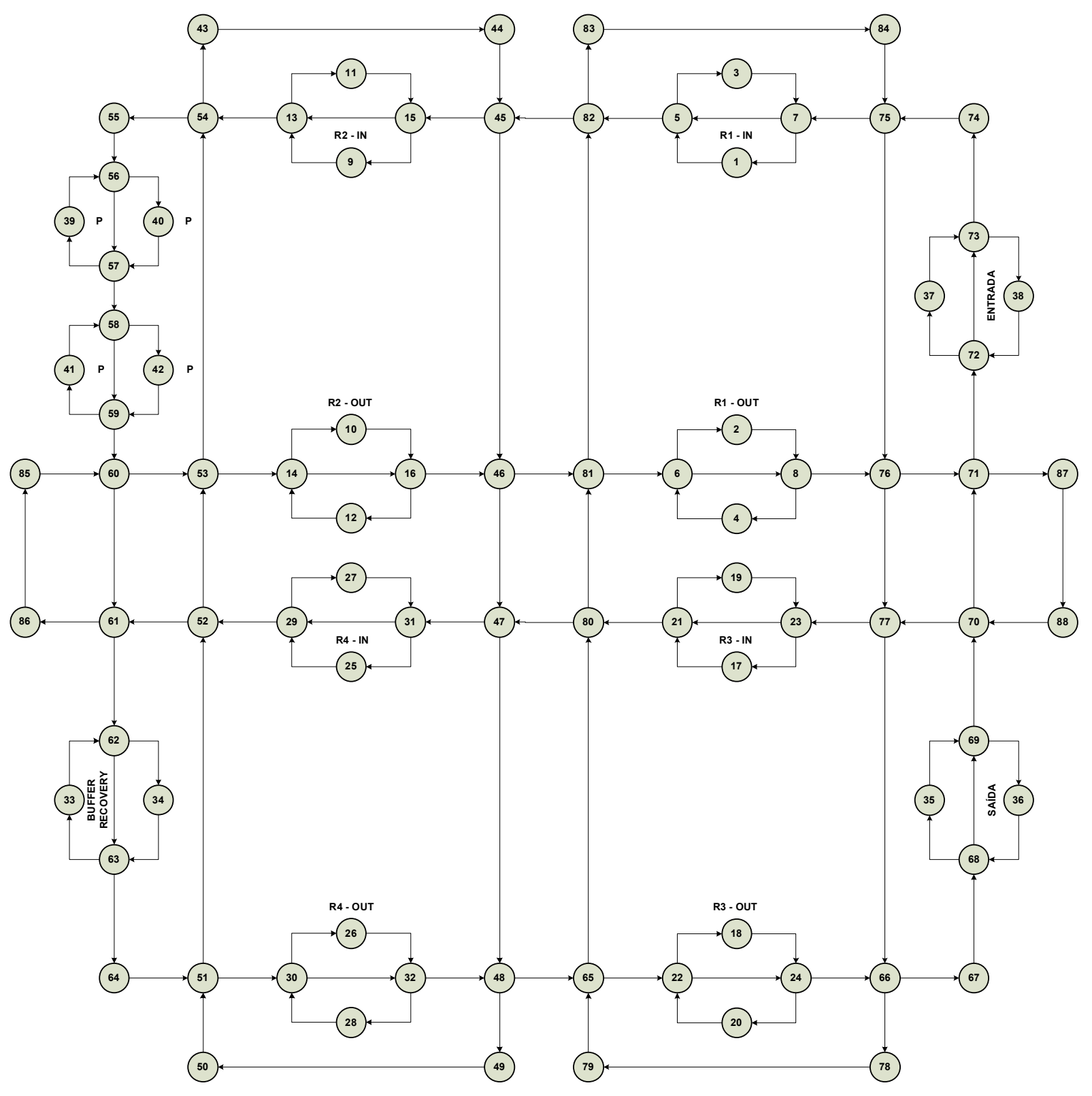

Figura 4.35 Grafo GAR de vias - CV.

A partir do GAR das vias, gera-se o E-MFG do controle de vias (Figura 4.36) mediante a técnica GAR/E-MFG (ANEXO A). Uma característica do E-MFG gerado é quanto ao box de capacidade unitária. Desta forma é possível garantir que somente um único transportador estará utilizando uma zona por vez. A zona de controle é composta por um nó e o arco orientado de entrada no GAR. O acesso e trânsito na zona somente serão permitidos mediante a autorização do CUV, assim sendo, a 
cada arco orientado do GAR é associado a uma transição no E-MFG (arco de entrada, transição e arco de saída).

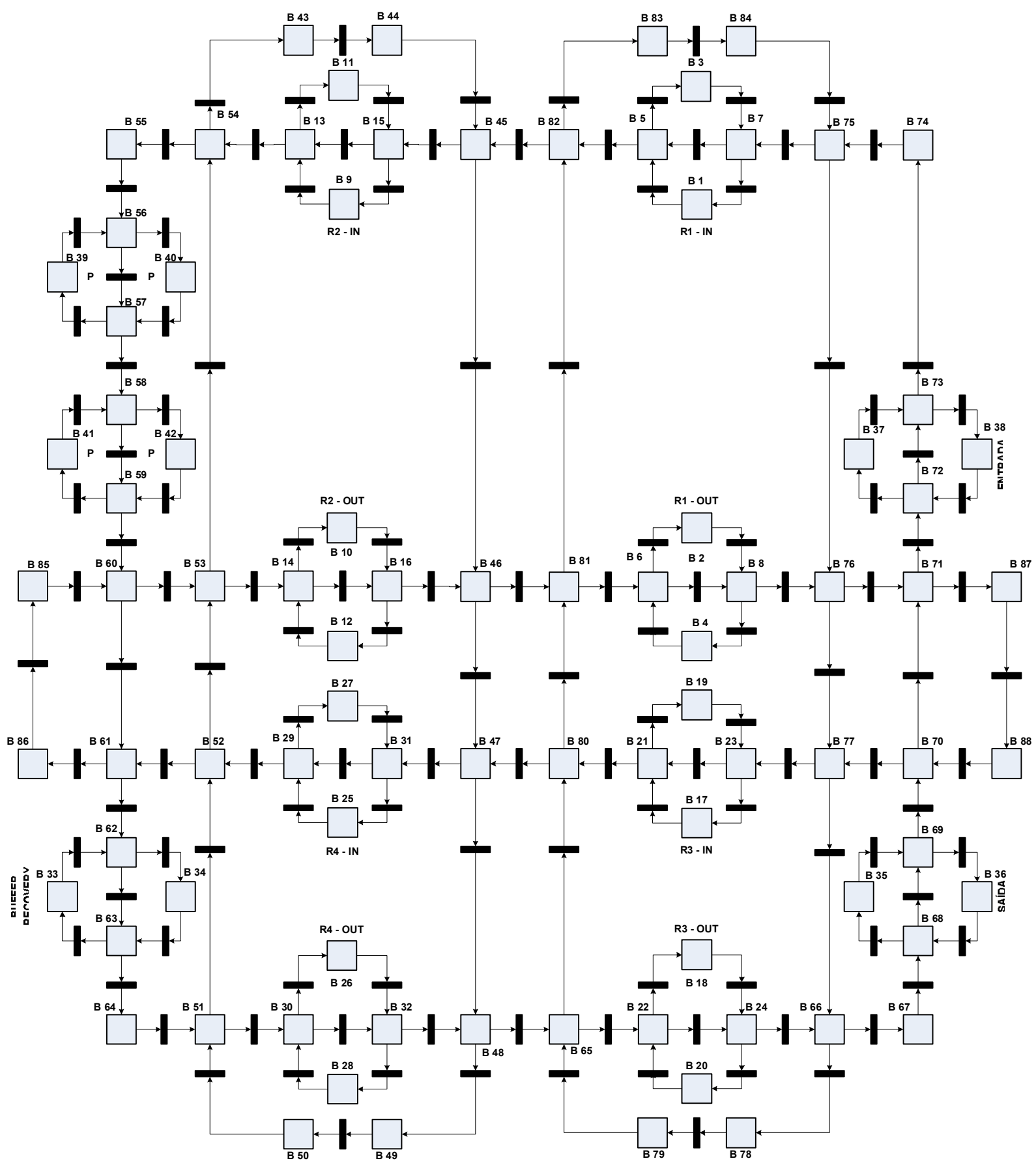

Figura 4.36 E-MFG do controle de vias - CV.

Por fim, a marca no CV representa o transportador que possui como atributo o trajeto a ser percorrido, sendo que o trajeto é composto por uma seqüência de zonas. A Tabela 4.5 apresenta os atributos da marca transportador no CV.

Tabela 4.5 Atributos da marca do módulo CV.

\begin{tabular}{|c|c|c|}
\hline Atributo & Descrição & Valor \\
\hline atrib1 & Identificador de transporte & Inteiro \\
\hline atrib2 & Estado & Inteiro \\
\hline atrib4 & Trajeto & GAR do trajeto \\
\hline
\end{tabular}




\subsection{Análise do Sistema de Controle}

O processo de análise qualitativa do sistema de controle abordará dois aspectos. O primeiro aspecto é quanto à dinâmica dos módulos e o segundo é quanto à comunicação entre os módulos.

A dinâmica dos módulos são verificadas mapeando-se a seqüência de disparo das transições. A partir de um estado inicial, verificam-se as pré-condições, estado resultante após o disparo e as alterações nos atributos da marca.

Os atributos da marca possuem um papel fundamental no controle da dinâmica dos módulos que compõem a arquitetura proposta neste trabalho. Além de habilitar ou inibir as transições, as informações de controle são armazenadas nos atributos.

Quanto à comunicação entre os módulos, a partir do disparo de uma mensagem gerada em um módulo origem, verifica a influência da informação enviada na dinâmica do módulo destino.

Desta forma, os seguintes passos são adotados no processo de análise:

1. Verificação do estado atual das marcas e os respectivos atributos;

2. Verificação das pré-condições de disparo das transições;

3. Disparo da transição;

4. Análise do estado após o disparo.

O processo de análise é realizado a partir da lista de eventos de disparo das atividades retirado do grafo de Gantt gerado pelo sistema de scheduling enviada pelo planejamento da produção.

Os eventos são divididos em dois grupos, a saber:

* Eventos1: grupo de eventos seqüenciais de início de atividades dos processos executados pelo SPF. Na presente análise, são considerados os eventos decorrentes da "ordem de produção" (Fig. 4.37);

* Eventos2: grupo de eventos seqüenciais de término de execução das atividades dos recursos. Na presente análise, são considerados os eventos gerados pelo objeto de controle (Fig. 4.37). 
Os eventos são utilizados para a análise qualitativa do controle que é apresentada no Capítulo 5. Para este propósito, foi desenvolvida uma ferramenta computacional de análise das redes E-MFG (ANEXO C).

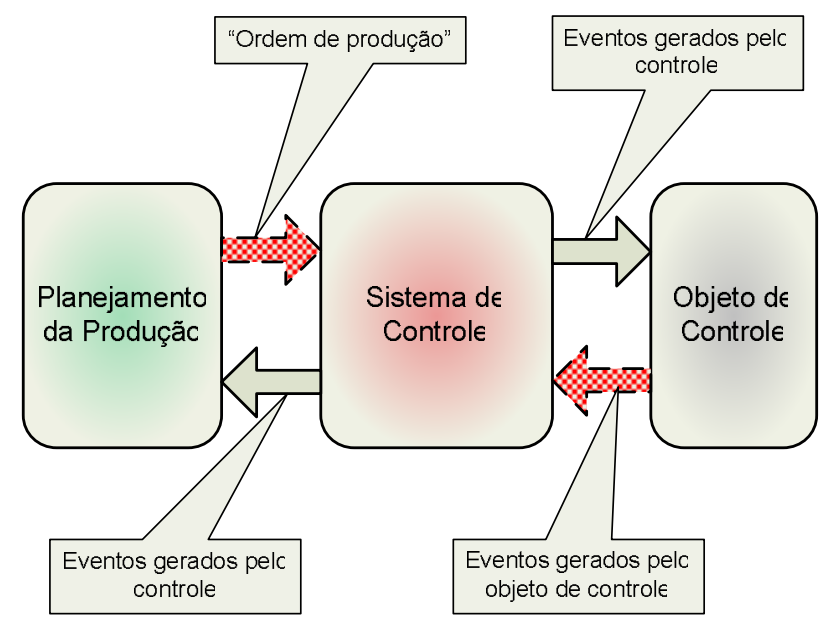

Figura 4.37 Eventos para a análise qualitativa do controle.

\subsection{Observações Complementares}

Neste Capítulo foi apresentada a proposta de arquitetura do sistema de controle para SPF e a síntese dos respectivos módulos de controles. Observando a Figura 4.38 da arquitetura proposta, verifica-se que os fluxos entre os módulos CAT e CUR são de troca de informações entre módulos subordinados hierarquicamente e que, portanto, são de mesma natureza semântica.

Por sua vez, os fluxos entre os módulos CAT e CDT envolvem a troca de informações entre módulos de controle de diferentes domínios semânticos, caracterizando a colaboração entre eles. Cabe ressaltar que no controle de transporte, os módulos CDT e CUV possuem uma relação de colaboração. Enquanto que, os módulos CUV e CV possuem uma relação hierárquica.

Um outro aspecto a ser destacado é quanto aos módulos CDT e CUV. As estratégias de controle destes módulos independem da configuração do SPF, pois executam as funções de designação de transportadores e geração do algoritmo de controle de utilização das vias. Desta forma, exemplifica-se como o conceito de arquitetura hierárquica pode ser foi implementado. 


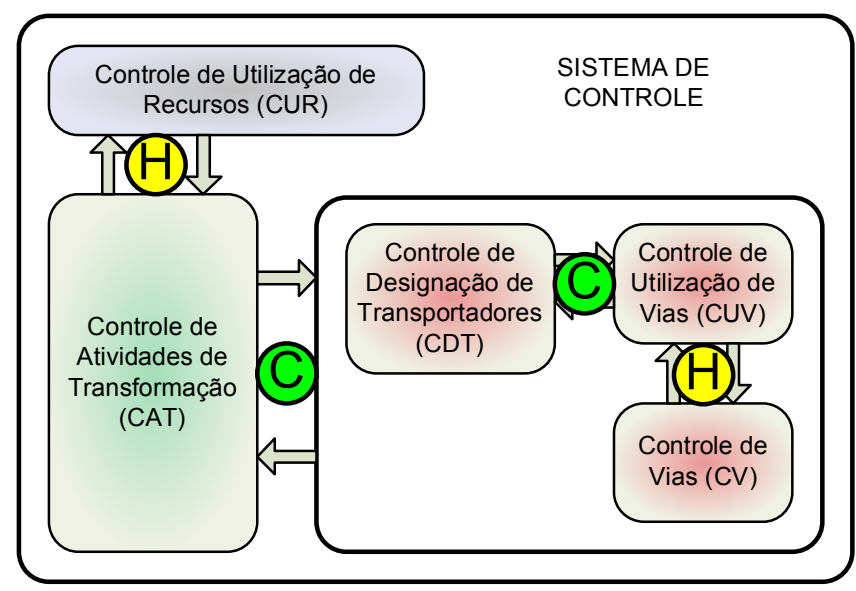

Figura 4.38 Arquitetura hierárquica modificada do controle.

As seguintes observações a respeito deste Capítulo são pertinentes de destaque:

* A arquitetura proposta permite resolver o problema de deadlock em alocação de recursos em SPF de uma forma estruturada aplicando-se o método híbrido de deadlock avoidance, detection and recovery para os recursos de transformação. Os recursos de transporte considerados no presente trabalho possuem flexibilidade relativamente maior que os recursos de transformação, desta forma, a ação recovery é realizada pelos transportadores;

* Foi apresentado um procedimento sistematizado para a síntese dos módulos que compõem a arquitetura proposta;

* As regras adicionais de controle são específicas para a solução do problema de deadlock em alocação de recursos. Entretanto, é possível inserir novas regras que representem outras estratégias de controle específicas do planejamento, por exemplo, prioridade no processo.

Um outro aspecto a ser considerado, é quanto às estratégias que podem ser aplicadas para os transportadores. A princípio, duas estratégias são destacadas em caso de término da atividade de transporte e ociosidade do mesmo:

* Retornar para o estacionamento;

* Locomover-se para a zona de parada de carregamento ou descarregamento da estação de trabalho em que se encontra. 


\section{CAPÍTULO}

\section{EXEMPLO DE APLICAÇÃO}

A arquitetura proposta no presente trabalho tem como objetivo garantir o controle de SPFs para a realização de processo s. A divisão do controle de recursos de transformação e de transporte permite a modularização do controle de acordo com o domínio de atuação, colaborando para garantir o controle global do sistema. Portanto, a integração dos módulos para a realização efetiva do controle é estratégica permitido tanto 0 fluxo de informações entre os módulos hierarquicamente subordinados quanto o fluxo de informações que permitem a colaboração entre módulos de diferentes semânticas.

Neste capítulo é apresentada em um exemplo da aplicação da sistemática proposta no capítulo anterior para a geração dos diversos módulos de controle e uma análise quanto à evolução dos estados nos modelos com enfoque na troca de informações entre os mesmos. 


\subsection{Descrição do Exemplo}

O presente exemplo possui as seguintes características:

- O SPF é composto por sete tipos de recursos $R=\left\{R_{1}, R_{2}, R_{3}, R_{4}, R_{5}, R_{6}, R_{7}\right\}$ (estações de trabalho). Cada estação de trabalho possui um dispositivo de recebimento de itens de produto, um dispositivo de despacho de itens processados e um processador que efetivamente realiza as atividades. Todos os recursos possuem capacidade 2 (dois) que corresponde à capacidade máxima dos dispositivos de recebimento e despacho. Isso implica que somente haverá no máximo dois itens de processos no recurso;

* Executa-se seis tipos de processos $\Pi=\left\{\Pi_{1}, \Pi_{2}, \Pi_{3}, \Pi_{4}, \Pi_{5}, \Pi_{6}\right\}$ concomitantemente, compartilhando o mesmo conjunto de recursos entre os processos. O seqüenciamento pré-estabelecido de utilização de recursos e as respectivas atividades dos processos são apresentados a seguir:

$$
\begin{array}{ll}
\text { ○ } \Pi_{1}: R_{1} \rightarrow R_{2} \rightarrow R_{3} \rightarrow R_{4} \text { e } S_{1}=\left\{\Xi_{11}, \Xi_{12}, \Xi_{13}, \Xi_{14}\right\} ; \\
\text { ○ } \Pi_{2}: R_{7} \rightarrow R_{4} \text { e } S_{2}=\left\{\Xi_{21}, \Xi_{22}\right\} ; \\
\text { ○ } \Pi_{3}: R_{4} \rightarrow R_{7} \text { e } S_{3}=\left\{\Xi_{31}, \Xi_{32}\right\} ; \\
\text { ○ } \Pi_{4}: R_{6} \rightarrow R_{5} \text { e } S_{4}=\left\{\Xi_{41}, \Xi_{42}\right\} ; \\
\text { ○ } \Pi_{5}: R_{5} \rightarrow R_{1} \text { e } S_{5}=\left\{\Xi_{51}, \Xi_{52}\right\} ; \\
\text { ○ } \Pi_{6}: R_{3} \rightarrow R_{2} \rightarrow R_{6} \text { e } S_{6}=\left\{\Xi_{61}, \Xi_{62}, \Xi_{63}\right\} .
\end{array}
$$

A execução das atividades dos processos é disparada de acordo com uma lista gerada a partir do scheduling de atividades fornecidas pelo planejamento da produção (grafo de Gantt);

* O transporte de itens entre as estações de trabalho é realizado por um sistema de AGV (transportadores): $V=\left\{V_{1}, V_{2}, V_{3}, V_{4}\right\}$;

* O layout da planta é apresentado na Figura 5.1; 


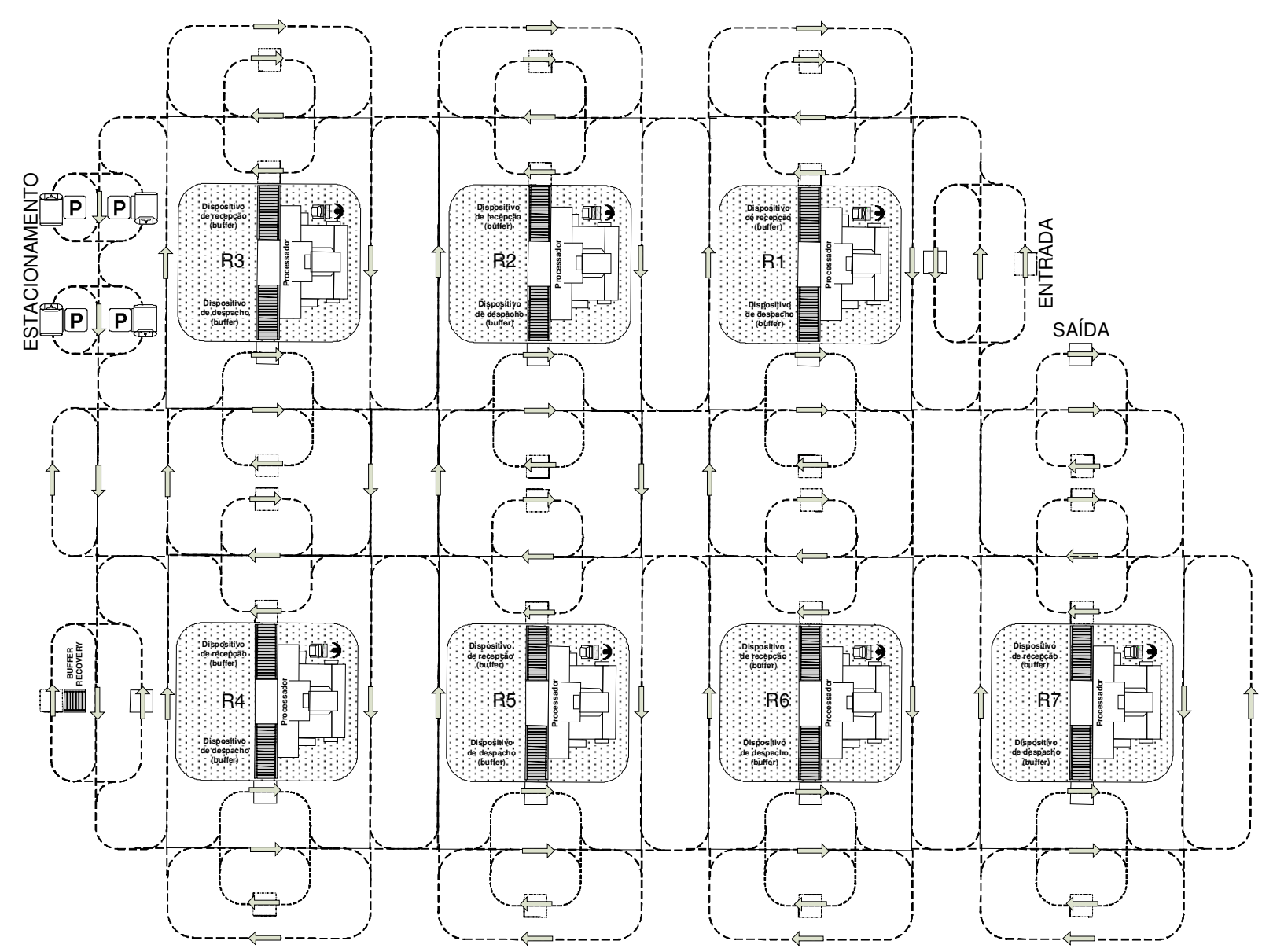

Figura 5.1 Layout do exemplo.

Um aspecto importante que deve ser destacado à propósito deste capítulo é quanto à abstração do tempo, característica da classe SDED. Desta forma, será realizada uma análise quanto à evolução dos estados do controle baseada na ocorrência de eventos, verificando se o comportamento dinâmico desejado no sistema foi alcançado, conforme descrito no Capítulo anterior.

\subsection{Geração dos Módulos de Controle}

\subsubsection{Módulo de Controle de Atividades de Transformação (CAT)}

Considerando-se o conjunto de processos no presente exemplo, a geração do módulo CAT segue os passos descritos no capítulo 4, conforme apresentado a seguir.

Passo 1: Geração do GAR individual de cada processo: o GAR individual de cada processo é apresentado na Figura 5.2(a). 
Passo 2: Geração do E-MFG inicial a partir da lista do GAR que é apresentada na Figura 5.2(b).

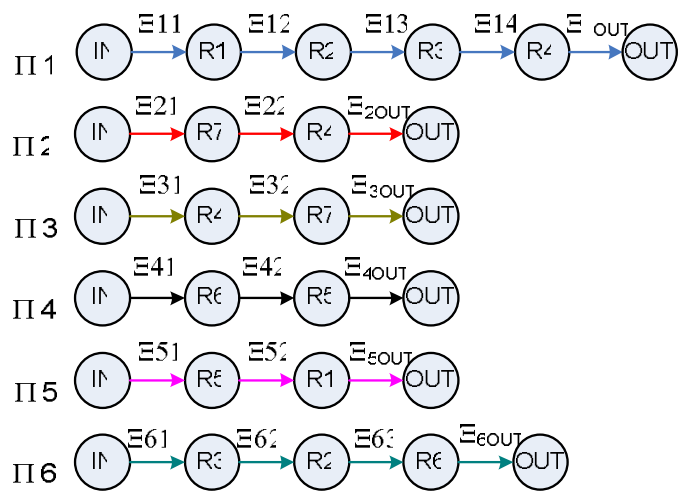

(a)

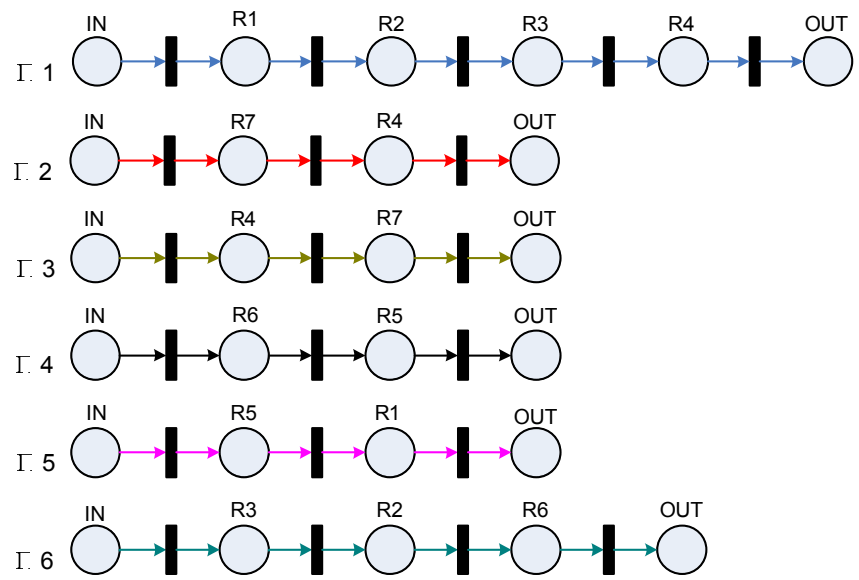

(b)

Figura 5.2 GAR individual(a) e o mapeamento para o E-MFG (b).

Passo 3: Aplica-se a técnica de refinamento sucessivo para os grafos E-MFG. São identificadas duas etapas do processo de refinamento: a Figura 5.3 ilustra o modelo intermediário e as Figuras 5.4 e 5.5 ilustram os grafos E-MFG.
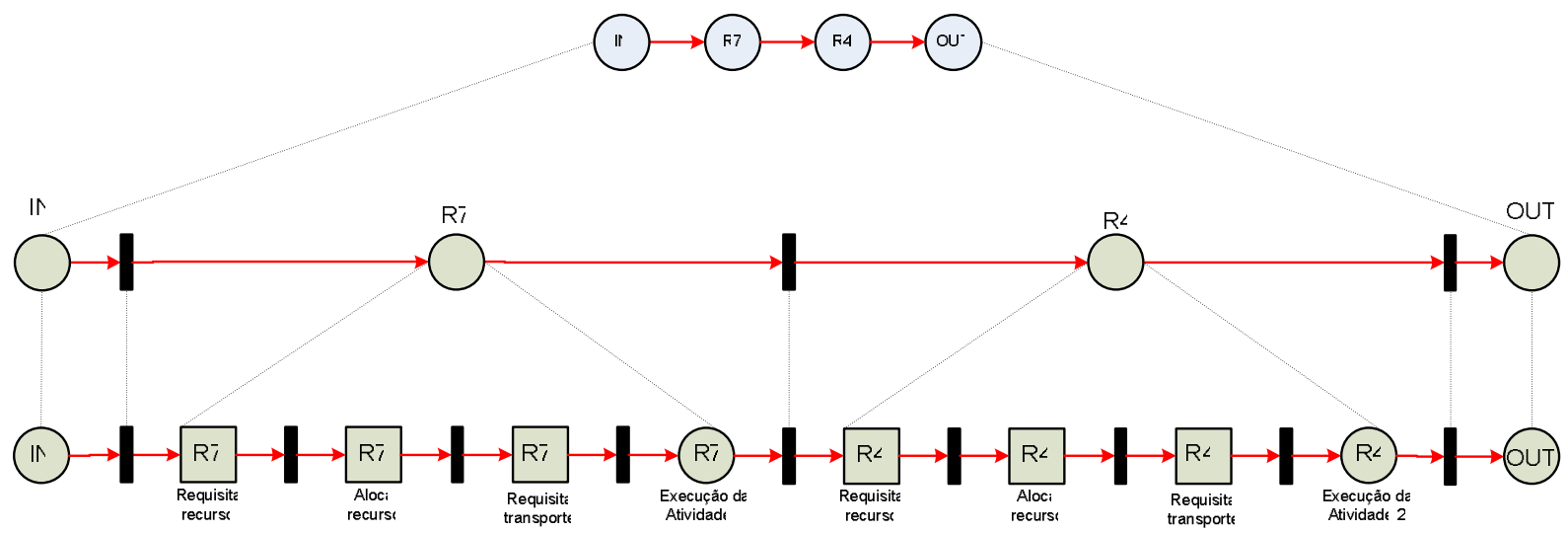

Figura 5.3 Primeiro refinamento do módulo CAT. 


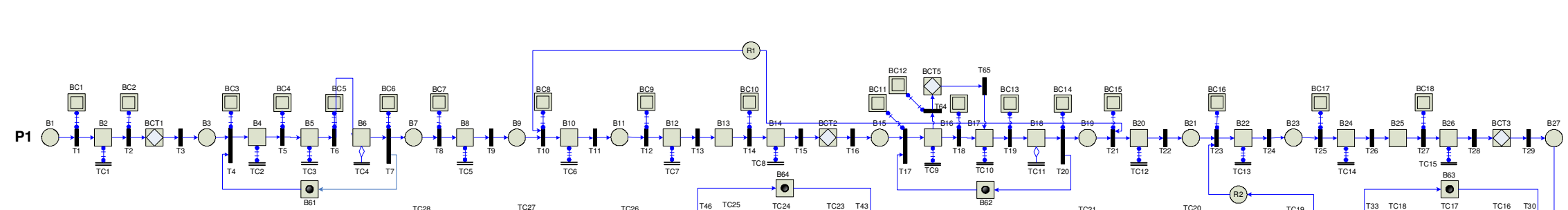

$$
\begin{aligned}
& \text { SFor }
\end{aligned}
$$

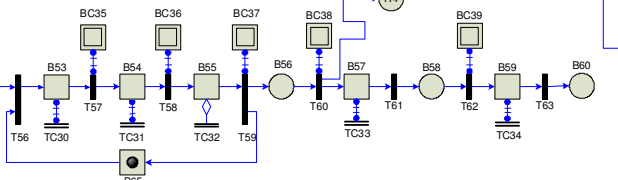

$$
\begin{aligned}
& \begin{array}{ll}
0 \\
0
\end{array}
\end{aligned}
$$

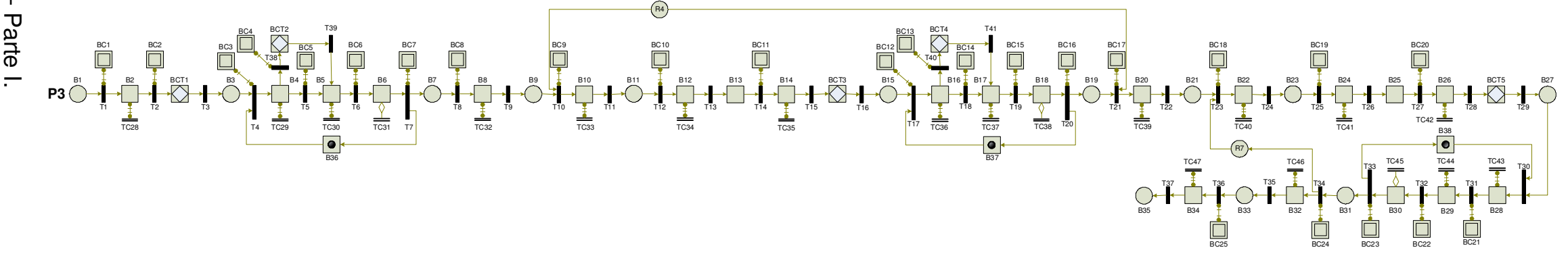

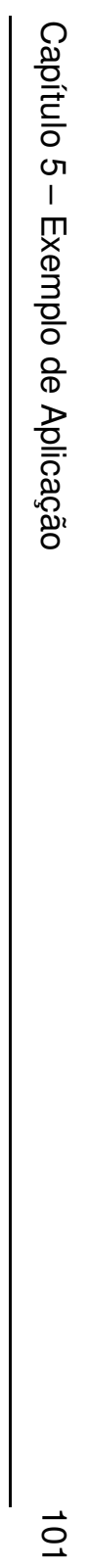




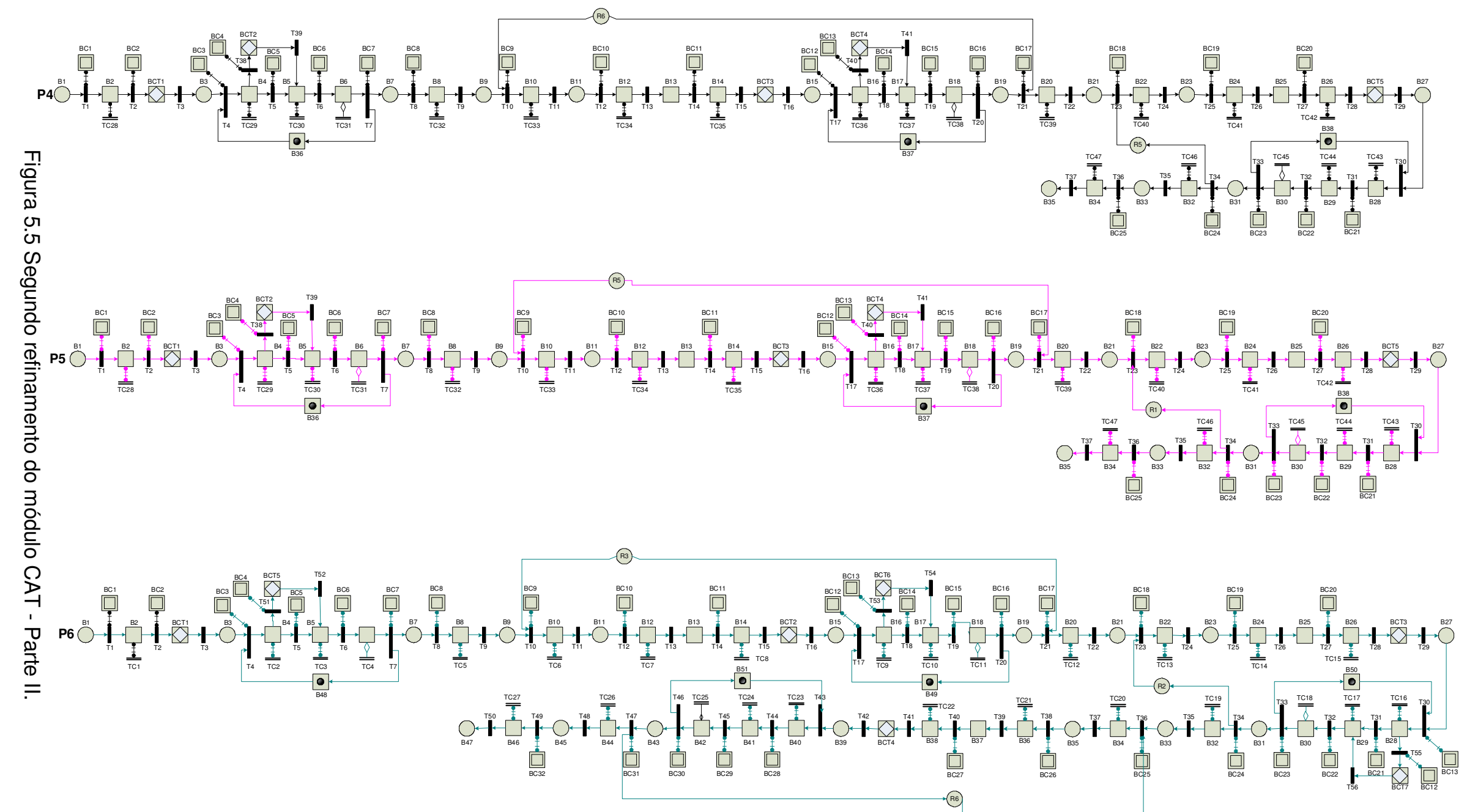




\subsubsection{Módulo de Controle de Utilização de Recursos (CUR)}

O módulo CUR é desenvolvido em duas etapas: (i) determinação das regras adicionais de controle e (ii) síntese do controle com as regras.

Os seguintes passos são executados para a determinação das regras adicionais de controle:

Passo 1: Geração do GAR individual de cada processo: o GAR individual de cada processo foi apresentada na Figura 5.2.

Passo 2: Geração do GAR global (Figura 5.6).

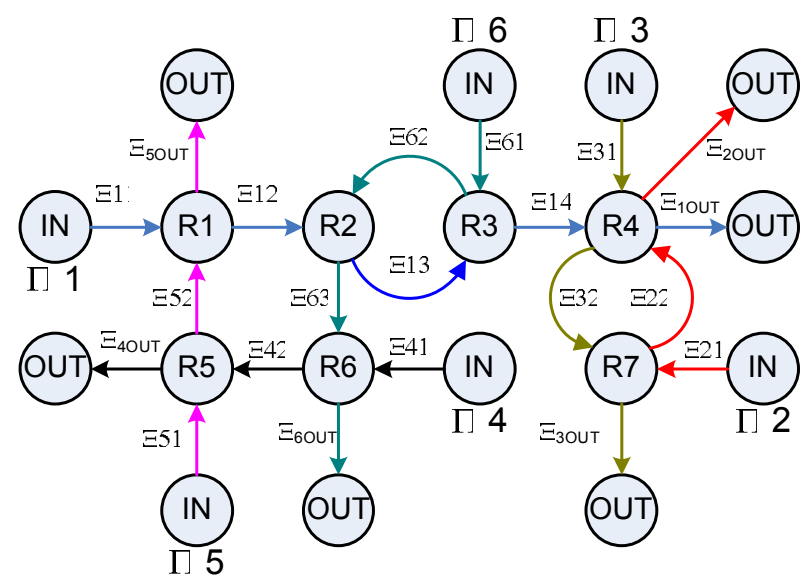

Figura 5.6 Passo 2: Determinação do GAR global do exemplo.

Passo 3: Determinação dos CFEs a partido do GAR global. Executando-se o algoritmo para determinação do CFE (NAKAMOTO, 2002) tem-se os seguintes CFEs (Figura 5.7):

$\mathrm{CFE}_{1}$ formado pelos recursos $\mathrm{R}_{4}$ e $\mathrm{R}_{7}$

* $\mathrm{CFE}_{2}$ formado pelos recursos $\mathrm{R}_{2}$ e $\mathrm{R}_{3}$;

* $\mathrm{CFE}_{3}$ formado pelos recursos $\mathrm{R}_{1}, \mathrm{R}_{2}, \mathrm{R}_{6}$ e $\mathrm{R}_{5}$;

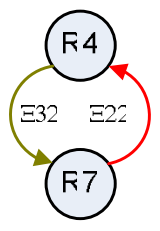

CFE

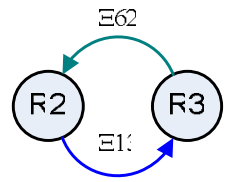

$\mathrm{CFE}_{2}$

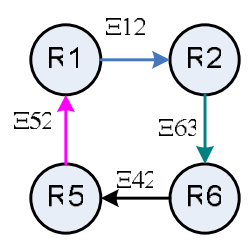

CFE:

Figura 5.7 Passo 3: Determinação dos CFEs. 
Passo 4: Determinação das regras adicionais de controle. A partir dos CFEs determinados no passo anterior, são estabelecidas as regras adicionais de controle (IF... THEN... ELSE...) para evitar o deadlock:

Regra 1: If $\left(\mathrm{R}_{4}=\Pi_{3}\right)$ then $\Xi_{21}=$ False;

Regra 2: If $\left(\mathrm{R}_{7}=\Pi_{2}\right)$ then $\Xi_{31}=$ False;

Regra 3: If $\left(\mathrm{R}_{3}=\Pi_{6}\right)$ then $\Xi_{12}=$ False;

Regra 4: If $\left(\mathrm{R}_{2}=\Pi_{1}\right)$ then $\Xi_{61}=$ False;

Regra 5: If $\left(\mathrm{R}_{2}=\Pi_{6}\right)$ and $\left(\mathrm{R}_{6}=\Pi_{4}\right)$ and $\left(\mathrm{R}_{5}=\Pi_{5}\right)$ then $\Xi_{11}=$ False;

Regra 6: If $\left(\mathrm{R}_{6}=\Pi_{4}\right)$ and $\left(\mathrm{R}_{5}=\Pi_{5}\right)$ and $\left(\mathrm{R}_{1}=\Pi_{1}\right)$ then $\Xi_{62}=$ False;

Regra 7: If $\left(\mathrm{R}_{5}=\Pi_{5}\right)$ and $\left(\mathrm{R}_{2}=\Pi_{1}\right)$ and $\left(\mathrm{R}_{3}=\Pi_{6}\right)$ then $\Xi_{41}=$ False;

Regra 8: If $\left(\mathrm{R}_{1}=\Pi_{1}\right)$ and $\left(\mathrm{R}_{2}=\Pi_{6}\right)$ and $\left(\mathrm{R}_{6}=\Pi_{4}\right)$ then $\Xi_{51}=$ False;

Passo 5: Verificação de CFEs consecutivos. A partir da lista de CFEs identifica-se a formação de ciclos consecutivos com os $\mathrm{CFE}_{2}$ e $\mathrm{CFE}_{3}$, sendo que o recurso $\mathrm{R}_{2}$ é comum aos dois. Desta forma, é necessário alterar as regras 3 e 6 para:

Regra 3: If $\left(\mathrm{R}_{3}=\Pi_{6}\right)$ then (If $\left(\mathrm{R}_{6}=\Pi_{4}\right)$ and $\left(\mathrm{R}_{5}=\Pi_{5}\right)$ and $\left(\mathrm{R}_{1}=\Pi_{1}\right)$ then $\Xi_{12}=$ True else $\Xi_{12}=$ False);

Regra 6: If $\left(\mathrm{R}_{6}=\Pi_{4}\right)$ and $\left(\mathrm{R}_{5}=\Pi_{5}\right)$ and $\left(\mathrm{R}_{1}=\Pi_{1}\right)$ then $\left(\right.$ If $\left(\mathrm{R}_{3}=\Pi_{6}\right)$ then $\Xi_{62}=$ True else $\Xi_{62}=$ False) .

Passo 6: Determinação das regras que identificam a ocorrência do deadlock e as ações recovery. A partir das informações obtidas nos passos anteriores, as seguintes regras são determinadas:

Regra 7: If $\left(\mathrm{R}_{4}=\Pi_{3}\right)$ and $\left(\mathrm{R}_{7}=\Pi_{2}\right)$ then recovery;

Regra 8: If $\left(\mathrm{R}_{2}=\Pi_{1}\right)$ and $\left(\mathrm{R}_{3}=\Pi_{6}\right)$ then recovery;

Regra 9: If $\left(\mathrm{R}_{1}=\Pi_{1}\right)$ and $\left(\mathrm{R}_{2}=\Pi_{6}\right)$ and $\left(\mathrm{R}_{6}=\Pi_{4}\right)$ and $\left(\mathrm{R}_{5}=\Pi_{5}\right)$ then recovery; 
A ação recovery consiste em habilitar a transição que permite que a marca do subgrafo recovery evolua para o box recovery, iniciando-se o procedimento de restabelecimento do fluxo dos processos travados. Cabe salientar que esta ação gera uma mensagem de autorização prioritária e, portanto, os módulos CDT designará os transportadores em caráter prioritário.

A partir da determinação das regras adicionais de controle, realiza-se o procedimento para a geração do CUR de acordo com os seguintes passos:

Passo 1 e 2: O mapeamento do E-MFG de cada processo a partir do GAR com a inclusão de transições de início e término de cada processo é apresentado na Figura 5.8 .

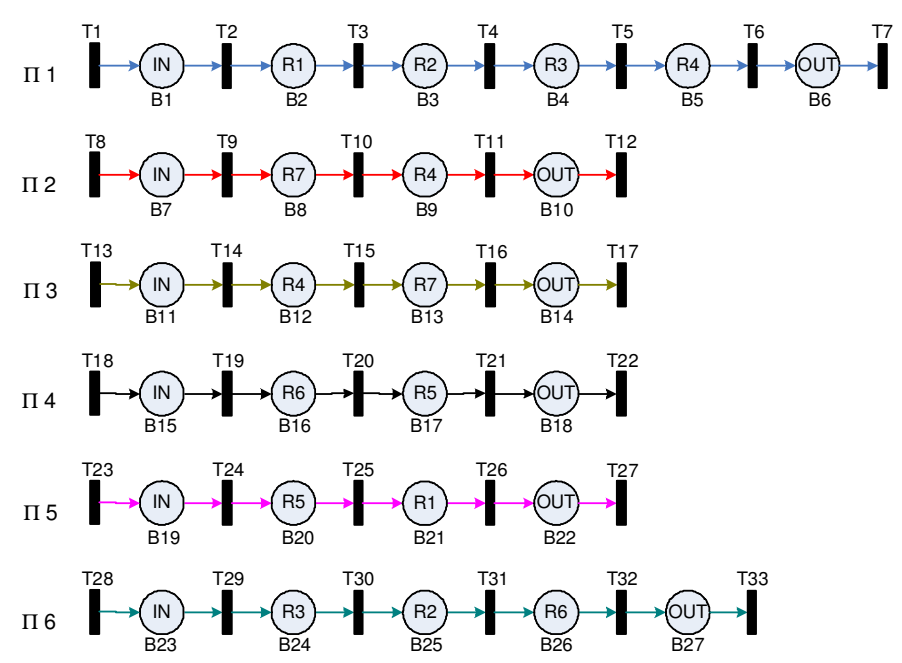

Figura 5.8 Passo 1 e 2: Mapeamento do E-MFG a partir do GAR.

Passo 3: Inserção em cada transição do E-MFG gerado no passo anterior, exceto a última transição, do sub-grafo que representa a comunicação com o CAT. A Figura 5.9 apresenta os E-MFGs de cada processo com os respectivos sub-grafos de comunicação.

Passo 4, 5 e 6: Mediante a técnica de fusão de lugares, gera-se o E-MFG global de utilização de recursos. A seguir são inseridos os sub-grafos recovery para cada CFE identificado e as regras adicionais de controle, determinadas anteriormente, mediante o uso de arcos inibidores nas transições específicas (Figura 5.10). 

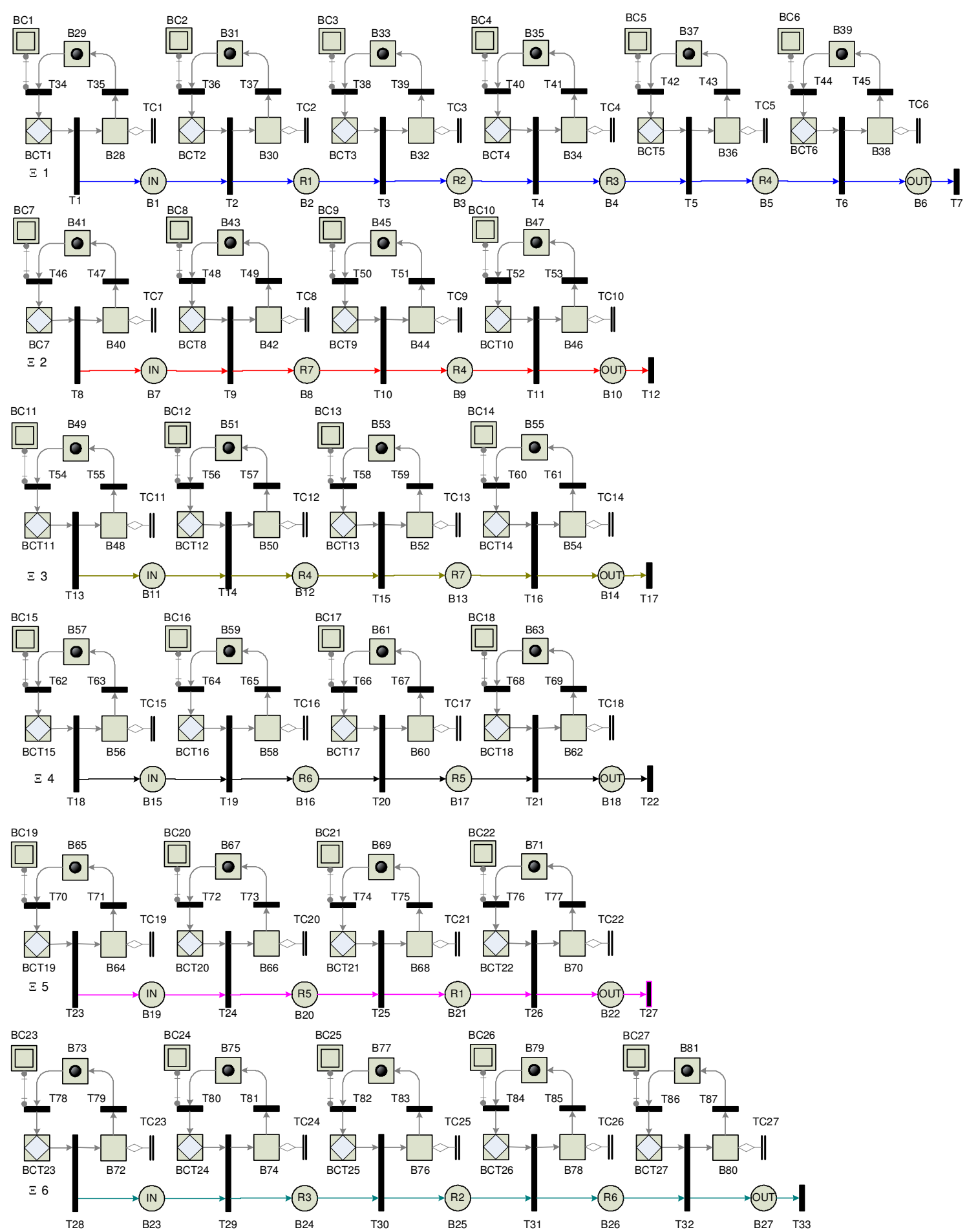

Figura 5.9 Passo 3: E-MFG de cada processo com sub-grafo de comunicação. 


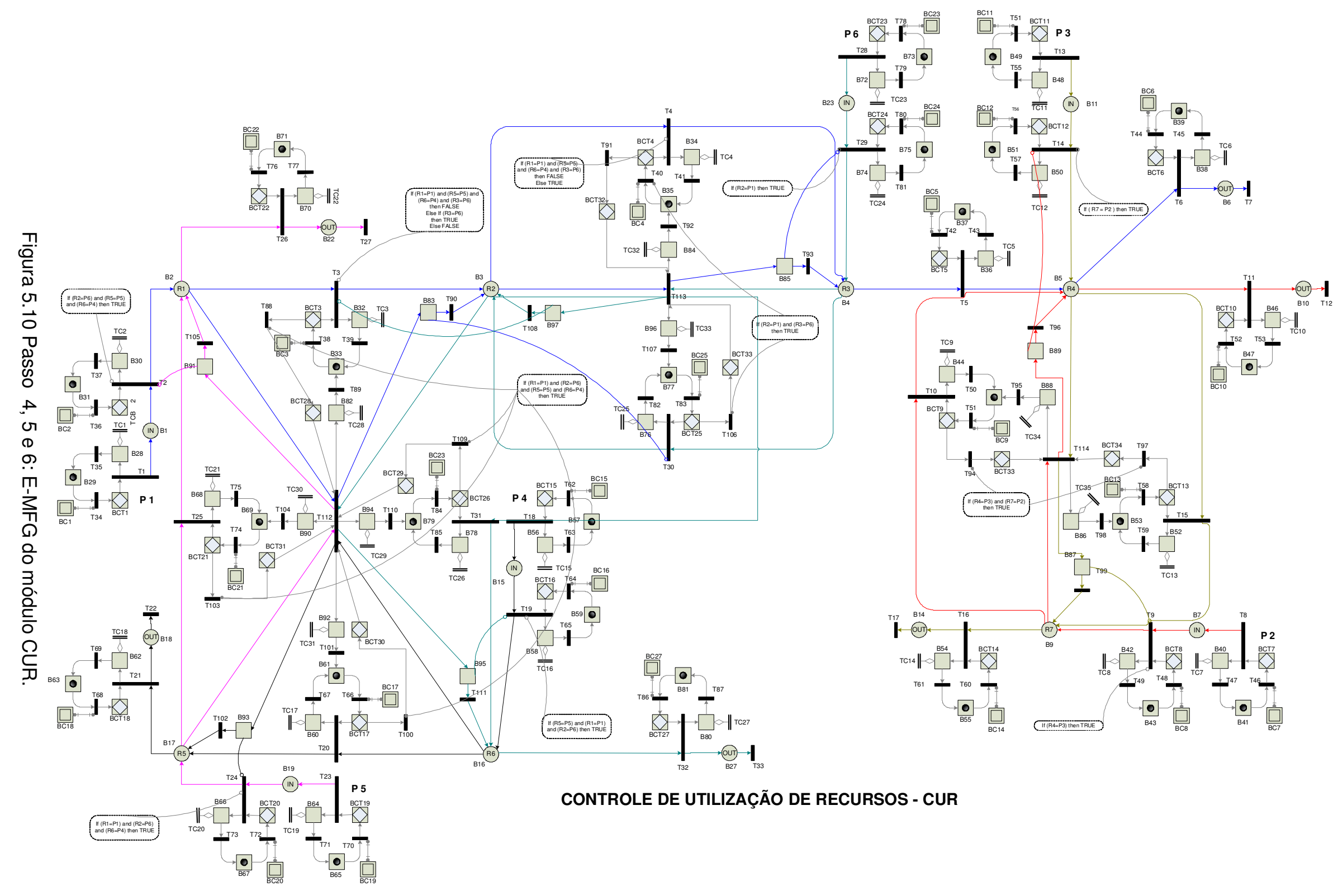




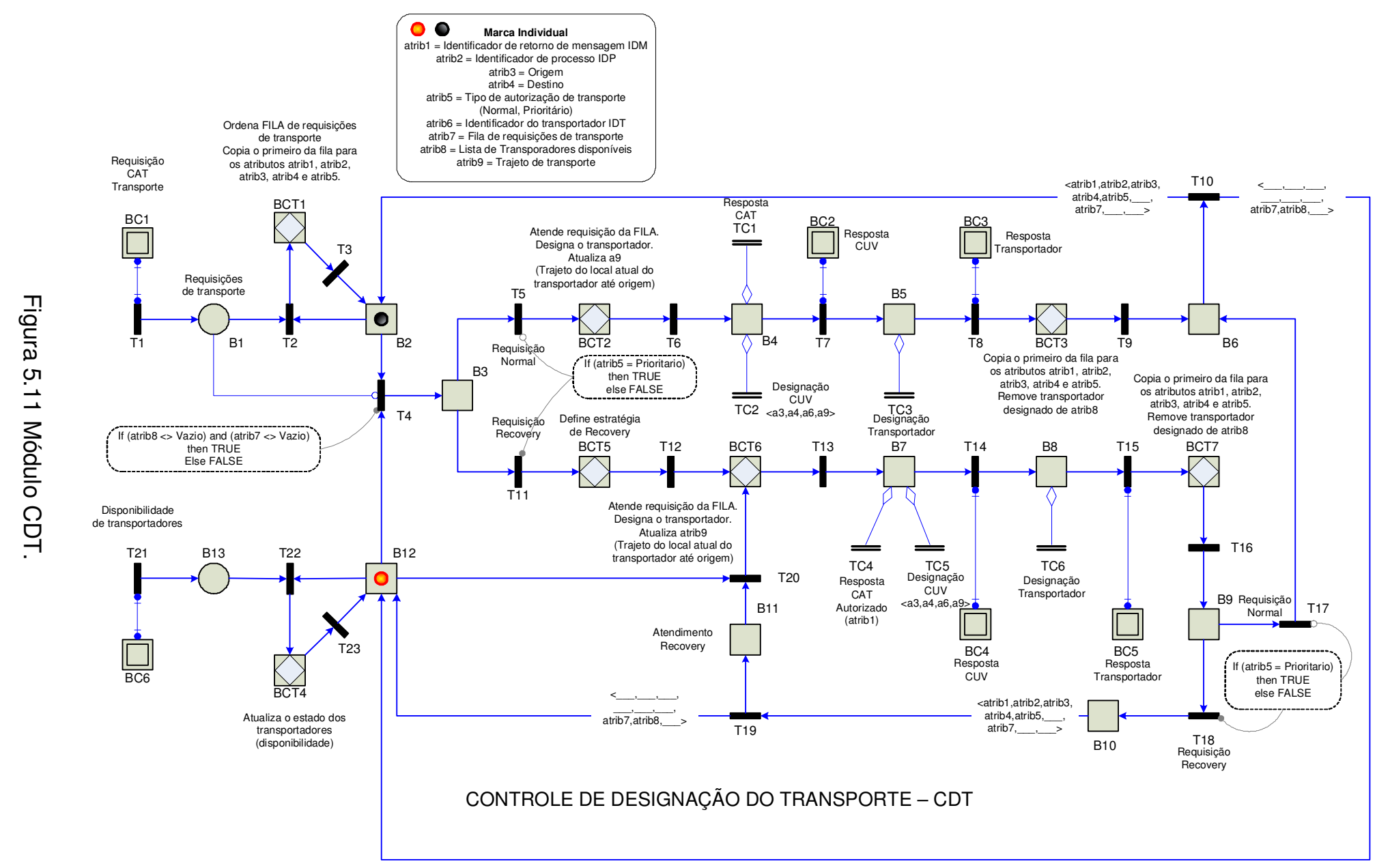

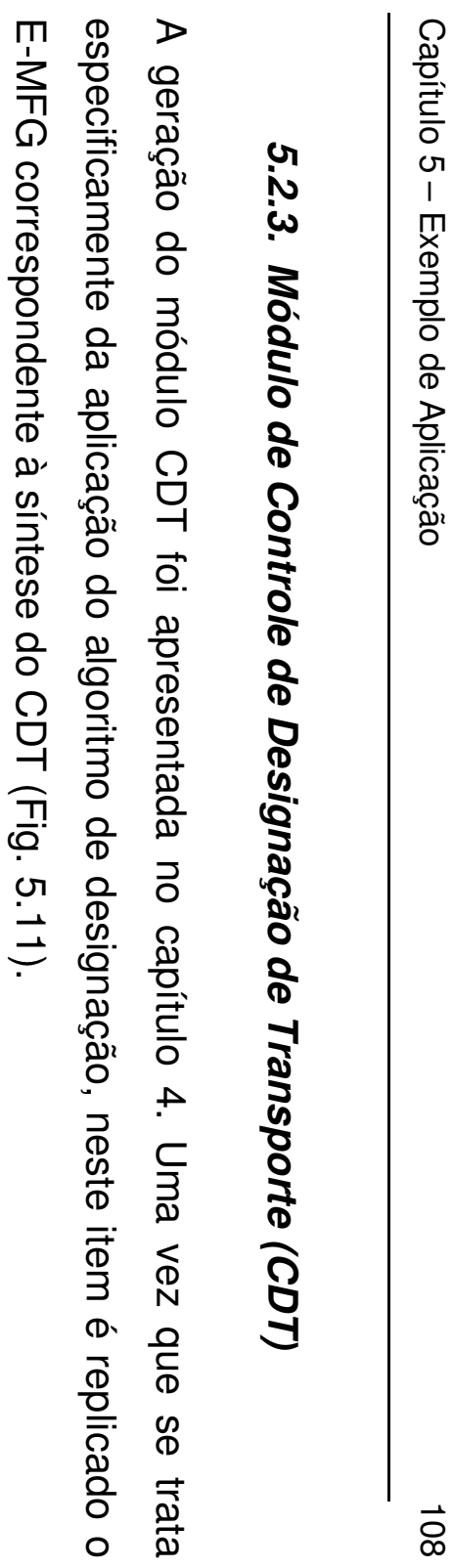




\subsubsection{Módulo de Controle de Utilização das Vias (CUV)}

Similarmente ao item anterior, o módulo gerador do CUV foi apresentado no capítulo 4. Sendo assim, apresenta-se aqui apenas o E-MFG do CDT (Figura 5.12).

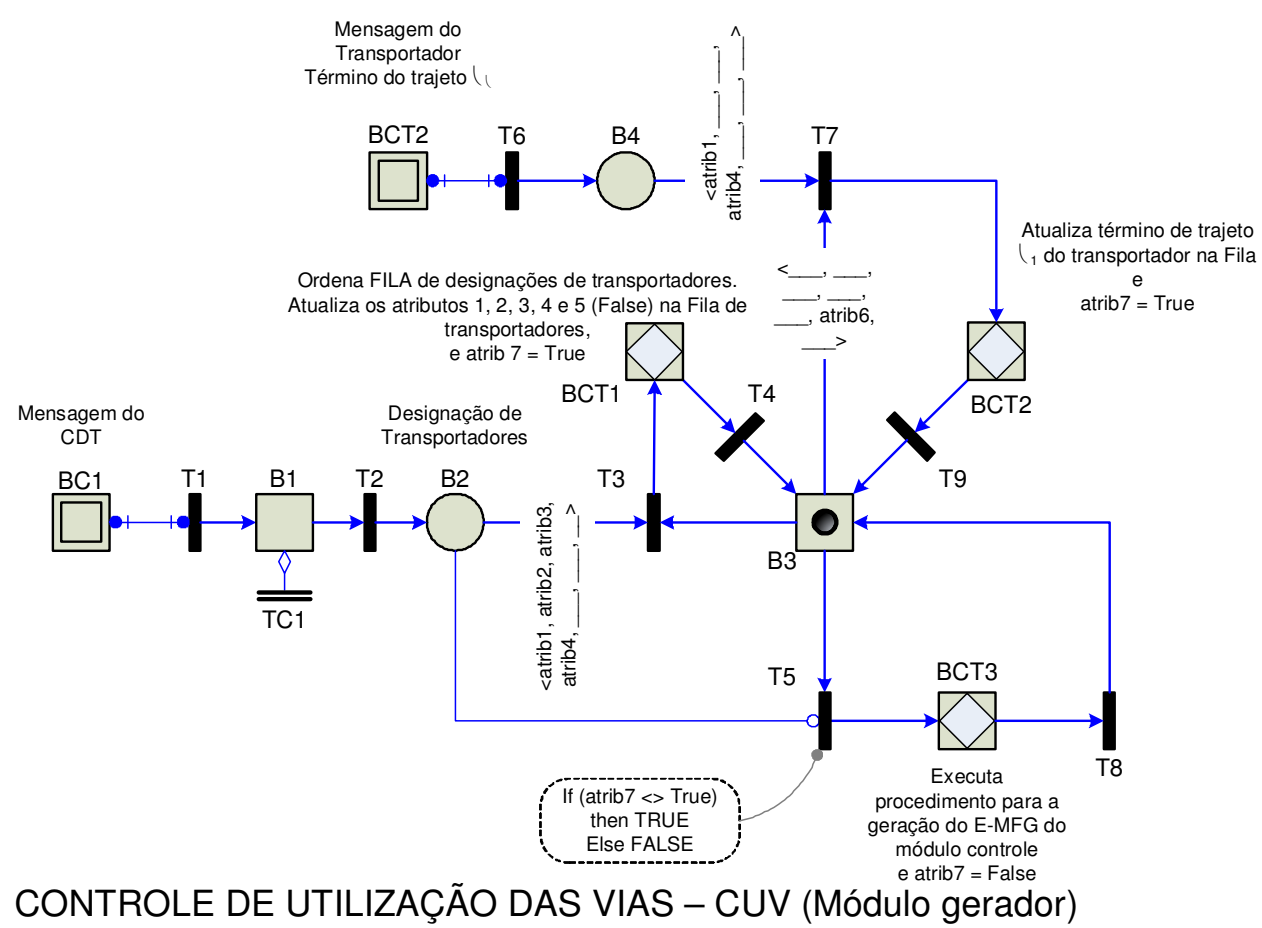

Figura 5.12 Módulo gerador do CUV.

\subsubsection{Módulo de Controle das Vias (CV)}

A geração do módulo CV depende apenas do layout da planta. Desta forma, a partir do layout apresentado na Figura 5.1, os respectivos grafos orientados e o E-MFG do CV são apresentados nas figuras que estão no Anexo D.1 e D.2.

\subsection{Execução dos Módulos}

A execução dos módulos é baseada em um grafo de Gantt fornecido pelo planejamento da produção. Uma lista de eventos de início das atividades que devem ser realizadas é gerada a partir deste grafo. Algumas hipóteses importantes são apresentadas:

* O grafo de Gantt é referente a produção de N de itens de cada tipo de produto. Desta forma, o estado inicial do E-MFG do CAT, formado por 
seis processos $\mathrm{P}=\left\{\Pi_{1}, \Pi_{2}, \Pi_{3}, \Pi_{4}, \Pi_{5}, \Pi_{6}\right\}$, possuirá $\mathrm{N}$ marcas a produzir em todos os boxes B1 dos processos. Observa-se que no grafo CUR não há marcas iniciais, exceto as marcas dos sub-grafos;

* O módulo CDT está em estado de espera pela imposição da regra na transição T4 devido ao fato de não haver nenhuma requisição de transporte inicialmente;

* O módulo CUV está inicialmente com uma marca no box B2. O atributo atrib7, inicialmente como False, indica que não há processo de transporte designado pelo CDT;

* Os transportadores $\mathrm{V}=\left\{\mathrm{V}_{1}, \mathrm{~V}_{2}, \mathrm{~V}_{3}, \mathrm{~V}_{4}\right\}$ estão inicialmente no estacionamento, posicionados nos boxes B42, B43, B46 e B47, respectivamente.

\subsubsection{Exemplo 1}

Considerando-se o grafo apresentado na Figura 5.13 e a respectiva lista de eventos na Figura 5.14, verifica-se o fluxo das informações a partir do disparo dos eventos.

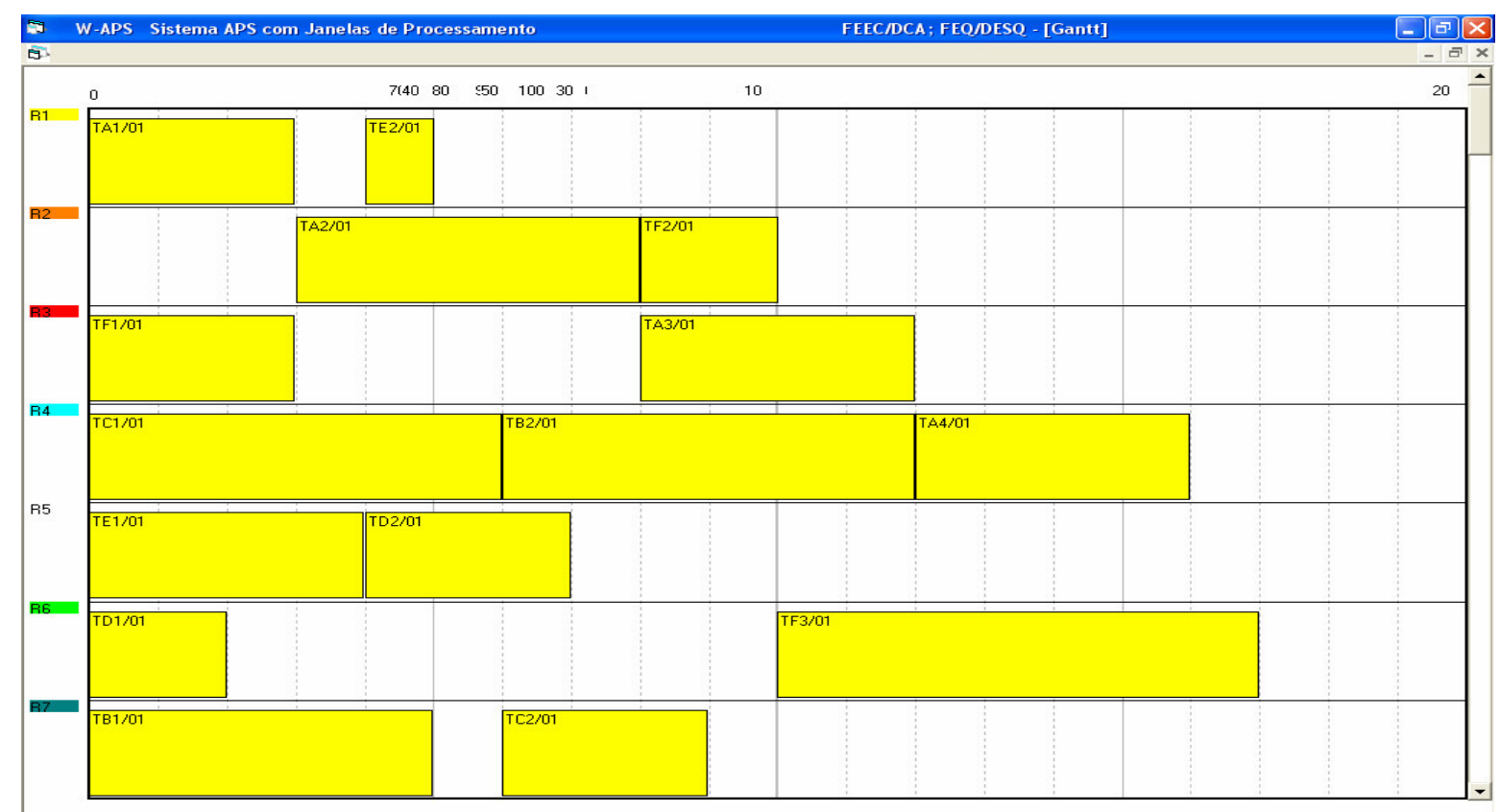

Figura 5.13 Grafo de Gantt fornecido pelo planejamento da produção. 


\begin{tabular}{|c|c|}
\hline Eventos 1 & ATIVIDADE Disparada \\
\hline e & 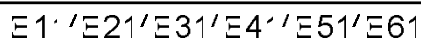 \\
\hline $\mathrm{e}_{2}$ & $\Xi 12$ \\
\hline$\overline{e_{z}}$ & E42'E5 \\
\hline$e_{L}$ & $E 22^{\prime} E 3_{L}^{\prime}$ \\
\hline$e_{E}$ & E1ミ゙こ62 \\
\hline$e_{\epsilon}$ & $E 6:$ \\
\hline$e_{\epsilon}$ & $E 14$ \\
\hline
\end{tabular}

\begin{tabular}{|c|c|}
\hline Eventos 2 & ATIVIDADE Disparada \\
\hline e & $E 41$ \\
\hline $\mathrm{e}_{2}$ & $E 61$ \\
\hline$e_{i}$ & E51 \\
\hline$e_{2}$ & E52'E21 \\
\hline$e_{E}$ & E31 \\
\hline$e_{\epsilon}$ & $E 21$ \\
\hline$e_{\bar{\imath}}$ & E3z \\
\hline$e_{\varepsilon}$ & $E 6 z$ \\
\hline$e_{\varsigma}$ & E1こ去2 \\
\hline$e_{10}$ & $\Xi 14$ \\
\hline$e_{1}$ & $E 6:$ \\
\hline
\end{tabular}

Figura 5.14 Lista de eventos de início de atividade.

\subsubsection{Execução do Exemplo 1}

Foram executadas as respectivas redes do exemplo 1 no software desenvolvido (ANEXO C) e a análise qualitativa resultante apresentou ausência de deadlock.

\subsubsection{Verificação da dinâmica do fluxo de informações}

Apresenta-se que a análise do fluxo de informações a partir do disparo dos eventos.

Disparo do evento $e_{1}$ : o evento $e_{1}$ inicia a produção dos processos listados na Figura 5.17.

O evento habilita as transições de ordem de produção dos processos a partir de uma mensagem recebida pelo box comunicação $\mathrm{BC} 1$ e $\mathrm{BC} 2$ nos seis processos (Fig. 5.4 e 5.5). Focando-se no processo $\Pi_{1}$, o disparo da transição $T 1$ faz com que a marca evolua para o box B2 iniciando-se o envio de mensagem ao CAT requisitando autorização para início do processo $\Pi_{1}$. Esta requisição é realizada pela transição de comunicação TC1. Observa-se que a marca aguarda no box B2 até que o CUR envie uma mensagem autorizando a requisição.

A requisição do processo $\Pi_{1}$ é enviada ao CUR e recebida pelo box $\mathrm{BC} 1$ (Fig.5.10), na entrada do processo $\Pi_{1}$, que habilita a transição T34 do sub-grafo de 
comunicação. A evolução da marca para o box controlador BCT1 altera o valor do atributo atrib3 para normal. Após o disparo da transição T1 no módulo CUR, a marca evolui para os boxes B28 e B1. O box B1 indica que um processo $\Pi_{1}$ iniciou as atividades e o box B28 envia a mensagem de retorno autorizando o início da produção do processo $\Pi_{1}$ no CAT.

A mensagem de retorno do CUR é enviada para o CAT e recebida pelo box $\mathrm{BC} 2$ no processo $\Pi_{1}$ que habilita a transição $\mathrm{T} 2$. Desta forma, a transição é disparada e a marca evolui para o box controlador BCT1. O box controlador altera o atributo atri2 com a informação de entrada de processo e 0 atributo atri3 com informação do próximo recurso. $\mathrm{O}$ disparo da transição $\mathrm{T} 3$ permite a evolução da marca para o box capacidade B3. Destaca-se que as marcas nos boxes capacidades são armazenadas em uma estrutura FIFO (first in, first out) aguardando a ordem para ser atendido de acordo com a disponibilidade da marca no box B61. Neste caso, como não há outro processo a frente realizando a requisição, a marca evolui para o box B4 consumindo-se a marca do box B61. Este procedimento garante que somente uma instância de processo está requisitando o recurso a cada momento.

A transição de comunicação TC2 envia uma requisição do recurso indicado no atributo atrib3 para o CUR, no presente caso o recurso $R_{1}$. Observa-se que, enquanto não houver uma autorização mediante a mensagem no box de comunicação $\mathrm{BC} 4$, enviada pelo CUR, a marca no box $\mathrm{B} 4$ permanece aguardando.

A mensagem gerada pelo processo $\Pi_{1}$ no CAT requisitando o recurso $R_{1}$ é recebida pelo box de comunicação $\mathrm{BC} 2$ do CUR. O procedimento segue a mesma dinâmica descrita anteriormente, exceto pela presença neste caso de uma regra com arco inibidor na transição T2. Como as pré-condições da regra não são atendidas na presente situação, a regra mantém a transição habilitada. A marca então evolui para o box $\mathrm{B} 2$ do CUR, indicando que um processo $\Pi_{1}$ está utilizando o recurso $\mathrm{R}_{1}$, e uma marca evolui para o box B30. A marca no box B30 é responsável por enviar uma mensagem para o processo $\Pi_{1}$ no CAT autorizando a alocação do recurso em caráter normal. Observa-se que a capacidade do box B2, que representa o recurso $\mathrm{R}_{1}$, limita a quantidade de processos que podem utilizar o recurso, desta forma garante-se que não há autorização de utilização de recursos se a capacidade do mesmo já estiver sendo utilizada. 
A mensagem é recebida pelo box de comunicação $\mathrm{BC} 4$, habilitando-se a transição T5 do processo $\Pi_{1}$. A evolução da marca para o box B5 envia uma mensagem de alocação para o recurso $R_{1}$ que aguarda uma mensagem de retorno. Recebida a mensagem do recurso $R_{1}$ confirmando a alocação do mesmo para o processo $\Pi_{1}$, requisita-se o transporte informando ao CDT os valores dos atributos da marca (processo, origem, destino e tipo de requisição) e um identificador de retorno de mensagem. Este identificador é o box de comunicação BC6 que aguarda a mensagem de retorno do CDT.

O CDT (Fig. 5.11) recebe a mensagem de requisição de transporte através do box de comunicação $\mathrm{BC} 1$ enviada pelo processo $\Pi_{1}$ no CAT. Uma marca com os atributos da mensagem é gerada no box capacidade B1 e esta é armazenada seqüencialmente por ordem de chegada. A presença da marca em B1 inibe a transição T4 impedindo que o CDT realize o procedimento de designação.

Desta forma, as pré-condições da transição T2 são atendidas e a marca é filtrada pelos arcos e unida no box controlador BCT1. O arco que conecta o box B1 e a transição $\mathrm{T} 2$ filtra os atributos atrib6, atrib7, atrib8 e atrib9, enquanto que $\mathrm{O}$ arco que conecta B2 e T2 filtra os atributos atrib1, atrib2, atrib3, atrib4 e atrib5. A marca resultante no box controlador $\mathrm{BCT} 1$ é processado por um algoritmo que ordena a fila de requisição representado no atributo atrib7.

A ordenação mantém a ordem de chegada na fila, mas em caso de requisição prioritária, o respectivo caso é colocado no início da fila de requisições. Após a execução do algoritmo de ordenação, os dados da primeira requisição na fila são copiados para os atributos atrib1, atrib2, atrib3, atrib4 e atrib5 e a marca evolui para o box B2.

Este procedimento repete-se para todas as atividades disparadas pelo evento $e_{1}$.

Observa-se que, enquanto houver pedidos de transporte, nenhuma designação será feita pelo CDT. Considerando-se que todos os demais processos realizaram o procedimento de requisição de transporte e o CDT ordenou a lista de transporte, a regra associada à transição $\mathrm{T} 4$ habilita, se houver requisição na fila, o transportador disponível. 
Neste ponto ocorre uma filtragem dos atributos pelos arcos e gera-se uma única marca. $\mathrm{O}$ arco que conecta o box B2 e a transição T4 filtra os atributos atrib8 e atrib9, enquanto que o arco que une B12 e T4 filtra os atributos atrib1, atrib2, atrib3, atrib4 atrib5, atrib6 e atrib7. A marca resultante no box B12 possui informações sobre o primeiro pedido de requisição de transporte na fila (processo $\Pi_{1}$ ), a fila de requisições e a lista de transportadores disponíveis.

A seguir, uma regra verifica a habilitação das transições T5 e T11 de acordo com o atributo atrib5 que armazena o caráter do pedido (normal ou prioritário). Observa-se que as habilitações das transições são mutuamente exclusivas.

Considerando-se que a requisição do processo $\Pi_{1}$ é de caráter normal, a transição T5 é habilitada permitindo a evolução da marca para o box controlador BCT2. O box realiza 0 atendimento do primeiro pedido executando-se o algoritmo para designar um transportador pelo critério de menor caminho (ANEXO B). A designação do transportador atualiza a lista de transportadores disponíveis, isto é, atualiza o atributo atrib6 e atrib9. O atrib6 é referente ao identificador do transportador designado e o atrib9 é o trajeto $\Gamma_{1}$ de transporte.

A evolução da marca para o box B4 permite o envio de mensagem de retorno para o processo $\Pi_{1}$ no CAT e a mensagem de designação do transportador para o módulo CUV (Fig. 5.12) contendo as seguintes informações: identificador do transportador, origem, destino e trajeto inicial.

É importante destacar que a transição T10 quando do seu disparo, processo esta marca e uma marca para cada arco de saída filtrando os respectivos atributos para atualização. A atualização da lista de transportadores disponíveis (atributo atrib8) é realizado no box controlador $\mathrm{BCT} 4$.

A mensagem de designação do transportador enviada pelo CDT ao módulo CUV é recebida pelo box de comunicação $\mathrm{BC} 1$ no CUV. O disparo da transição $\mathrm{T} 1$ no CUV gera uma marca com as informações da mensagem no box B1 que envia uma mensagem de retorno ao CDT pela transição de comunicação $\mathrm{TC1}$. A seguir, a marca evolui para o box B2. Se a marca com a lista de designações de transportador estiver disponível no box B3, então é realizada a ordenação da fila de designações e a alteração do atributo atrib7 para True afim de atualizar o módulo controle do CUV. 
Conforme as designações são enviadas pelo CDT, uma vez que a chegada de uma designação tem prioridade maior em relação à atividade de atualização do módulo de controle, o número máximo de designações é a quantidade total de transportadores disponíveis no sistema e que no presente exemplo são quatro transportadores. O disparo da transição T5 permite a evolução da marca para o box controlador BCT3 que executa o algoritmo apresentado no capítulo 4, gerando-se assim o módulo de controle do CUV. Observa-se que após a execução do algoritmo, o atributo atrib7 é alterado para False.

A mensagem de retorno do CUV enviada pela transição de comunicação TC1, é recebida pelo box $\mathrm{BC} 2$ do $\mathrm{CDT}$, habilitando-se desta forma a transição T7. A seguir, é realizado o procedimento de designação do transportador e a resposta do mesmo, através de ações que são realizadas pelos boxes B5 e BC3. O box controlador BCT3 do CDT, remove o primeiro da fila de requisições e copia dos dados da nova requisição da fila nos atributos da marca que retorna ao box B2 aguardando a próxima tarefa de designação.

A mensagem de retorno enviada pela transição TC1 do CDT para o processo $\Pi_{1}$ no CAT é recebida pelo box $\mathrm{BC} 6$ que habilita a transição $\mathrm{T} 7$ criando-se uma marca no box $\mathrm{B} 7$ e retornando a marca de controle de requisições para o box B61.

A partir deste ponto, o processo $\Pi_{1}$ aguarda a realização do carregamento, transporte e descarregamento pelo transportador designado seguindo-se a seqüência de disparo das transições T8, T9, T10 e T11.

O início da atividade no recurso e o término do mesmo são verificados mediante a comunicação entre o processo $\Pi_{1}$ no CAT e o recurso R1. Após o término da atividade, quando a marca evoluir para o box controlador BCT2, os atributos da marca atrib2 e atrib3 são alterados mapeando o recurso atual e o próximo recurso.

O procedimento descrito para o processo $\Pi_{1}$ na requisição e alocação do recurso R1, na requisição do transporte e na execução da atividade propriamente dita, repete-se a cada requisição de novo recurso para todos os processos.

Portanto, o disparo do evento $e_{1}$, resulta no seguinte estado do SPF:

* Processo $\Pi_{1}$ utilizando o recurso $\mathrm{R}_{1}$;

* Processo $\Pi_{2}$ utilizando o recurso $\mathrm{R}_{7}$; 


$$
\begin{aligned}
& \text { * Processo } \Pi_{3} \text { utilizando o recurso } \mathrm{R}_{4} \text {; } \\
& \text { * Processo } \Pi_{4} \text { utilizando o recurso } \mathrm{R}_{6} \text {; } \\
& \text { * Processo } \Pi_{5} \text { utilizando o recurso } \mathrm{R}_{5} \text {; } \\
& \text { * Processo } \Pi_{6} \text { utilizando o recurso } \mathrm{R}_{3} \text {. }
\end{aligned}
$$

Quanto ao processo de transporte, considerando-se que no momento da designação são definidos os trajetos para a quantidade disponível de transportadores, a seguinte configuração é verificada:

* Processo $\Pi_{1}$ : transportador designado $\mathrm{V}_{1}$; origem: Entrada; destino: $\mathrm{R}_{1}$; trajeto $\Gamma_{1}: 47-45-48-141-142-143-150-151-152-153-160-161-162-163-$ 170-171-3-1;

* Processo $\Pi_{2}$ : transportador designado $\mathrm{V}_{2}$; origem: Entrada; destino: $\mathrm{R}_{7}$; trajeto $\Gamma_{1}$ : 46-45-48-141-142-143-150-151-152-153-160-161-162-163170-171-3-1;

* Processo $\Pi_{3}$ : transportador designado $\mathrm{V}_{3}$; origem: Entrada; destino: $\mathrm{R}_{4}$; trajeto $\Gamma_{1}$ : 43-45-48-141-142-143-150-151-152-153-160-161-162-163170-171-3-1;

* Processo $\Pi_{4}$ : transportador designado $\mathrm{V}_{4}$; origem: Entrada; destino: $\mathrm{R}_{6}$; trajeto $\Gamma_{1}$ : 42-45-48-141-142-143-150-151-152-153-160-161-162-163170-171-3-1.

Observa-se que os trajetos $\Gamma_{1}$ são semelhantes devido ao fato da origem (Estacionamento) e destino (Entrada) serem os mesmos.

O trajeto $\Gamma_{2}$ dos processos será:

* Processo $\Pi_{1}$ : transportador designado V1; origem: Entrada; destino: $\mathrm{R}_{1}$; trajeto $\Gamma_{2}$ : 1-8-7-197-9-10-15-16;

- Processo $\Pi_{2}$ : transportador designado V2; origem: Entrada; destino: $\mathrm{R}_{7}$; trajeto $\Gamma_{2}$ : 1-8-7-197-9-170-171-172-173-180-101-102-107-108; 
Processo $\Pi_{3}$ : transportador designado V3; origem: Entrada; destino: $\mathrm{R}_{4}$; trajeto $\Gamma_{2}$ : 1-8-7-197-9-170-111-112-113-120-121-122-123-130-131132-137-138;

* Processo $\Pi_{4}$ : transportador designado V4; origem: Entrada; destino: $\mathrm{R}_{6}$; trajeto $\Gamma_{2}: 1-8-7-197-9-170-111-112-117-118$.

É importante salientar que o processo de designação de transportadores é seqüencial de acordo com a disponibilidade do mesmo. Desta forma, para se realizar uma análise quantitativa da dinâmica do CUV com o CV, deve-se ser considerar outros fatores como, por exemplo, o tempo de deslocamento entre as estações de trabalho, tempo de carregamento e descarregamento das estações de trabalho, velocidade do transportador e dimensões do layout. Cabe destacar que o enfoque dado à questão do transporte é uma análise qualitativa em relação ao tratamento do deadlock. Neste sentido, dois aspectos são tratados quanto ao tráfego de transportadores nas vias:

A formação de CFEs consecutivos. A solução adotada é a determinação de um novo trajeto para o transporte de menor prioridade;

* A determinação de regras adicionais de controle para evitar o deadlock nas vias, baseado no método de deadlock avoidance.

Disparo do evento $e_{2}$ : O evento $e_{2}$ inicia o procedimento de requisição do recurso $\mathrm{R}_{2}$ pelo processo $\Pi_{1}$. Após disparo do evento $e_{2}$, tem-se os seguintes estados do SPF:

- Processo $\Pi_{1}$ utilizando o recurso $\mathrm{R}_{2}$;

* Processo $\Pi_{2}$ utilizando o recurso $\mathrm{R}_{7}$;

* Processo $\Pi_{3}$ utilizando o recurso $\mathrm{R}_{4}$;

- Processo $\Pi_{4}$ utilizando o recurso $\mathrm{R}_{5}$;

Processo $\Pi_{5}$ utilizando o recurso $\mathrm{R}_{1}$;

* Processo $\Pi_{6}$ utilizando o recurso $\mathrm{R}_{3}$. 
Disparo do evento $e_{3}$ : 0 evento $e_{3}$ inicia o procedimento de requisição dos recursos $R_{5}$ e $R_{1}$ pelos processos $\Pi_{4}$ e $\Pi_{5}$. Após disparo do evento $e_{3}$, tem-se os seguintes estados do SPF:
* Processo $\Pi_{1}$ utilizando o recurso $\mathrm{R}_{2}$;
* Processo $\Pi_{2}$ utilizando o recurso $\mathrm{R}_{7}$;
* Processo $\Pi_{3}$ utilizando o recurso $\mathrm{R}_{4}$;
* Processo $\Pi_{4}$ utilizando o recurso $\mathrm{R}_{5}$;
* Processo $\Pi_{5}$ utilizando o recurso $\mathrm{R}_{1}$;
- Processo $\Pi_{6}$ utilizando o recurso $\mathrm{R}_{3}$.

Disparo do evento $e_{4}$ : $O$ evento $e_{4}$ inicia o procedimento de requisição dos recursos $\mathrm{R}_{4}$ e $\mathrm{R}_{7}$ pelos processos $\Pi_{2}$ e $\Pi_{3}$. Após disparo do evento $e_{4}$, tem-se os seguintes estados do SPF:
* Processo $\Pi_{1}$ utilizando o recurso $\mathrm{R}_{2}$;
* Processo $\Pi_{2}$ utilizando o recurso $\mathrm{R}_{4}$;
* Processo $\Pi_{3}$ utilizando o recurso $\mathrm{R}_{7}$;
* Processo $\Pi_{4}$ utilizando o recurso $\mathrm{R}_{5}$;
* Processo $\Pi_{5}$ concluído;
- Processo $\Pi_{6}$ utilizando o recurso $\mathrm{R}_{3}$.

Disparo do evento $e_{5}$ : $O$ evento $e_{5}$ inicia o procedimento de requisição dos recursos $\mathrm{R}_{3}$ e $\mathrm{R}_{2}$ pelos processos $\Pi_{1}$ e $\Pi_{6}$. Após disparo do evento $e_{5}$, tem-se os seguintes estados do SPF:
* Processo $\Pi_{1}$ utilizando o recurso $\mathrm{R}_{3}$;
* Processo $\Pi_{2}$ utilizando o recurso $\mathrm{R}_{4}$;
- Processo $\Pi_{3}$ utilizando o recurso $\mathrm{R}_{7}$;
* Processo $\Pi_{4}$ concluído;
* Processo $\Pi_{5}$ concluído; 
* Processo $\Pi_{6}$ utilizando o recurso $\mathrm{R}_{2}$.

Disparo do evento $e_{6}$ : O evento $e_{6}$ inicia o procedimento de requisição do recurso R6 pelo processo $\Pi_{6}$. Após disparo do evento $e_{6}$, tem-se os seguintes estados do SPF:
* Processo $\Pi_{1}$ utilizando o recurso $\mathrm{R}_{3}$;
* Processo $\Pi_{2}$ utilizando o recurso $\mathrm{R}_{4}$;
* Processo $\Pi_{3}$ concluído;
* Processo $\Pi_{4}$ concluído;
* Processo $\Pi_{5}$ concluído;
* Processo $\Pi_{6}$ utilizando o recurso $\mathrm{R}_{6}$.

Disparo do evento $e_{7}$ : O evento $e_{7}$ inicia o procedimento de requisição do recurso $\mathrm{R}_{4}$ pelo processo $\Pi_{1}$. Após disparo do evento $e_{7}$, tem-se os seguintes estados do SPF:

\footnotetext{
* Processo $\Pi_{1}$ utilizando o recurso $\mathrm{R}_{4}$;

* Processo $\Pi_{2}$ concluído;

* Processo $\Pi_{3}$ concluído;

* Processo $\Pi_{4}$ concluído;

* Processo $\Pi_{5}$ concluído;

* Processo $\Pi_{6}$ utilizando o recurso $\mathrm{R}_{6}$.
}

Pelo exposto, é possível verificar que não houve a formação de situações anteriores ao deadlock ou a ocorrência do deadlock propriamente dito. Isto se deve ao fato de que a produção de itens de processo não superou em nenhum momento a capacidade disponível de recursos do sistema.

\subsubsection{Resultados}

A análise do fluxo comprovou os resultados da execução. 


\subsubsection{Exemplo 2}

Considera-se a seguinte lista de eventos de atividade para o exemplo 2 (Fig. 5.15).

\begin{tabular}{|c|c|}
\hline Eventos 1 & ATIVIDADE Disparada \\
\hline $\mathrm{e}$ & $\Xi 2^{\prime} \Xi 3$ \\
\hline $\mathrm{e}_{\bar{z}}$ & $\Xi 2$ \\
\hline $\mathrm{e}_{3}$ & $\Xi 3$ \\
\hline $\mathrm{e}_{4}$ & $\Xi 22$ \\
\hline $\mathrm{e}_{\varepsilon}$ & $\Xi 32$ \\
\hline $\mathrm{e}_{5}$ & $\Xi 22^{\prime} \Xi 32$ \\
\hline
\end{tabular}

\begin{tabular}{|c|c|}
\hline Eventos 2 & ATIVIDADE Disparada \\
\hline$e$ & $\Xi 2$ \\
\hline$e_{\bar{z}}$ & $\Xi 3$ \\
\hline$e_{3}$ & $\Xi 3$ \\
\hline$e_{4}$ & $\Xi 2$ \\
\hline$e_{\varepsilon}$ & $\Xi 32$ \\
\hline$e_{\epsilon}$ & $\Xi 22$ \\
\hline$e_{\overline{7}}$ & $\Xi 32$ \\
\hline$e_{\varepsilon}$ & $\Xi 22$ \\
\hline
\end{tabular}

Figura 5.15 Lista de eventos de início de atividade - Exemplo 2.

\subsubsection{Execução do Exemplo 2}

Foi realizada a análise qualitativa e o resultado mostrou ocorrência de deadlock com a execução do método avoidance. Após a ocorrência do travamento e aplicação do método de deadlock avoidance, a execução foi encerrada.

\subsubsection{Verificação da dinâmica do fluxo de informações}

$\mathrm{O}$ CUR recebe a requisição pelo box de comunicação $\mathrm{BC} 12$ do módulo. A evolução da marca para o box controlador BCT12, após o disparo da transição T56 no CUR, satisfaz a pré-condição da transição T14. Entretanto, a regra na transição (regra 2) inibe o respectivo disparo, pois o recurso $\mathrm{R}_{7}$ está com a capacidade total consumida, sendo que o primeiro é o processo $\Pi_{2}$, e o recurso $R_{4}$ está apenas com uma capacidade disponível. Observa-se que o processo em $\mathrm{R}_{4}$ permanecerá no CFE, pois requisitará o recurso $\mathrm{R} 7$ para a execução da próxima atividade.

Desta forma, a regra não permitirá que o processo $\Pi_{3}$ utilize $\circ$ recurso $R_{4}$, bloqueando-o enquanto a condição anterior ao deadlock estiver presente no CFE.

\subsubsection{Resultados}

A análise do fluxo comprovou os resultados da execução para o Exemplo 2. 


\subsubsection{Exemplo 3}

Considerando-se a seguinte lista de eventos de atividade para o Exemplo 3 (Fig. 16):

\begin{tabular}{|c|c|}
\hline Eventos 1 & ATIVIDADE Disparad \\
\hline e & $\Xi 1^{\prime} \Xi \leq 1^{\prime} \Xi<1^{\prime} \Xi<1$ \\
\hline $\mathrm{e}_{2}$ & $\Xi 62^{\prime} \Xi 6^{\circ}$ \\
\hline$e_{2}$ & $\Xi 1^{\prime} E \leq 1^{\prime} \Xi<1^{\prime} E \in 1$ \\
\hline$e_{4}$ & $\Xi 12$ \\
\hline$e_{\varepsilon}$ & $\Xi 1$ \\
\hline
\end{tabular}

\begin{tabular}{|c|c|}
\hline Eventos 2 & ATIVIDADE Disparad $\varepsilon$ \\
\hline $\mathrm{e}$ & $\Xi 6$ \\
\hline $\mathrm{e}_{2}$ & $\Xi 12$ \\
\hline
\end{tabular}

Figura 5.16 Lista de eventos de início de atividade - Exemplo 3.

\subsubsection{Execução do Exemplo 3}

Foi realizada a análise qualitativa e o resultado mostrou ocorrência de deadlock e execução do método recovery. Após a ocorrência do travamento e aplicação do método de deadlock recovery, a execução foi encerrada.

\subsubsection{Verificação da dinâmica do fluxo de informações}

O disparo de um evento $e_{4}$ inicia o processo de requisição de utilização do recurso $R_{2}$ pelo processo $\Pi_{1}$. A mensagem de requisição do recurso $R_{2}$ é enviada pela transição TC9 para o CUR.

A mensagem é recebida pelo box de comunicação $\mathrm{BC} 3$ no CUR que dispara a transição T38 e gera a marca no box controlador BCT3. O atributo da marca é alterado no box BCT3 para caráter normal. Entretanto, a regra associada à transição T3 habilita-o para o disparo devido ao atendimento das pré-condições estabelecidas na regra, isto é, estado anterior ao deadlock em dois CFE consecutivos.

O disparo da transição $\mathrm{T} 3 \mathrm{faz}$ com que a marca que representa o processo $\Pi_{1}$ evolua para o box B3, permitindo-se a utilização do recurso $R_{2}$ pelo processo $\Pi_{1}$. Observa-se que $\circ \mathrm{CFE}_{2}$, formado pelos recursos $R_{2}$ e $R_{3}$ estará evoluindo certamente para o deadlock. Iniciando-se o processo de requisição do recurso $\mathrm{R}_{2}$ pelo processo $\Pi_{6}$ e do recurso $\mathrm{R} 3$ pelo processo $\Pi_{1}$, a mensagem de requisição do recurso $R_{2}$ é enviada pela transição $B C 9$ do processo $\Pi_{6}$ no CAT, enquanto que a mensagem de requisição do recurso $R_{3}$ é enviada pela transição TC9 do processo $\Pi_{1}$ no CAT. As mensagens são recebidas pelo CUR nos boxes $\mathrm{BC} 25$ e BC4, 
respectivamente. Entretanto, este estado é mapeado pela regra de identificação do estado de deadlock, habilitando-se a transição T106 e T91. O disparo da transição T106 permite a evolução da marca para o box controlador BCT33, que indica a situação de deadlock, e inicia o processo de autorização prioritária. O mesmo ocorre com o disparo da transição T91 que permite a evolução da marca para o box controlador BCT32.

Destaca-se que as marcas de mensagem de requisição nos boxes BCT33 e BCT32 indicam quarta condição para a ocorrência do deadlock que é a espera cíclica de processos. O conjunto formado pelas marcas dos processos e as marcas de requisição de recursos são as pré-condições que habilitam a transição recovery T113. Destaca-se que esta condição caracteriza o estado de espera cíclica de processos aguardando a liberação de recursos utilizados por outros processos.

O disparo da transição permite a evolução das marcas que representam os processos $\Pi_{6}$ e $\Pi_{1}$ nos boxes B93 e B85 respectivamente. As marcas das mensagens evoluem para os boxes B84 e B92 que enviam a autorização recovery para os respectivos processos no CAT. Observa-se que após o envio das mensagens, as marcas do sub-grafo de comunicação retornam para a posição inicial.

É importante destacar que durante o processo de recovery nenhum processo poderá ingressar no CFE, condição garantida pelo arco inibidor associado aos boxes: B83, B85, B87, B89, B91, B93, B95 e B97.

As mensagens enviadas pelo CUR são recebidas pelos processos $\Pi_{6}$ e $\Pi_{1}$ no CAT. $O$ processo $\Pi_{1}$ recebe a mensagem pelo box de comunicação $\mathrm{BC} 12$ que permite a evolução da marca para o box controlador BCT5. O box promove a alteração do atributo do tipo de autorização para prioritário. $\mathrm{O}$ mesmo procedimento ocorre para o processo $\Pi_{6}$ através dos boxes BC13 e BCT6.

Após a realização da alocação dos respectivos recursos em caráter prioritário, os processos enviam as mensagens de requisição de transporte para o CDT. O processo $\Pi_{1}$ envia a mensagem de requisição de transporte pela transição $\mathrm{BC} 25$, enquanto que o processo $\Pi_{6}$ envia a mensagem de requisição pela transição TC11. 
$\mathrm{O}$ CDT recebe as mensagens pelo box $\mathrm{BC} 1$. Quando a marca evolui para o box controlador BCT1, é verificado que o caráter do pedido de transporte é prioritário, desta forma, o pedido é colocado no início da fila de requisições.

Durante 0 atendimento do pedido de transporte, a marca no box $\mathrm{B} 3$ habilita a regra associada à transição T11, pois o atributo atrib5 é prioritário. A evolução da marca para o box controlador BCT5 executa a definição da estratégia recovery a ser aplicada conforme apresentada no capítulo 4. Neste caso, como são apenas duas requisições de transporte e considerando-se que os quatro transportadores estão disponíveis, a designação será realizada seqüencialmente. A evolução da marca para o box BCT6, inicia o processo de designação para o primeiro da fila e o procedimento a seguir segue conforme apresentado anteriormente. Quando o box B9 recebe a marca, a regra associada às transições $\mathrm{T} 17$ e $\mathrm{T} 18$ verificam se o primeiro da fila é requisição normal ou prioritário. A regra garante que todas as requisições prioritárias serão atendidas antes de retornar para o procedimento de ordenação de requisições.

O sub-grafo recovery permite que a identificação do estado de travamento baseado em regras associadas nas transições e dispara a ação recovery mediante a autorização de utilização do recurso em caráter prioritário. Observa-se que a ação recovery é realizada efetivamente pelos transportadores do SPF.

\subsubsection{Resultados}

A análise do fluxo comprovou os resultados da execução para o Exemplo 3.

\subsubsection{Exemplo 4}

Considerando-se a seguinte lista de eventos de atividade para o Exemplo 4 (Fig.5.17):

\begin{tabular}{|c|c|}
\hline Eventos 1 & ATIVIDADE Disparada \\
\hline $\mathrm{e}$ & $\Xi 2 \cdot \Xi \Xi 1$ \\
\hline $\mathrm{e}_{2}$ & $\Xi 3$ \\
\hline $\mathrm{e}_{3}$ & $\Xi 2$ \\
\hline
\end{tabular}

\begin{tabular}{|c|c|}
\hline Eventos 2 & ATIVIDADE Disparada \\
\hline $\mathrm{e}$ & $\Xi 3$ \\
\hline $\mathrm{e}_{\overline{\mathrm{z}}}$ & $\Xi 22$ \\
\hline
\end{tabular}

Figura 5.17 Lista de eventos de início de atividade - Exemplo 4. 


\subsubsection{Execução do Exemplo 4}

Foi realizada a análise qualitativa e o resultado mostrou ocorrência de deadlock e execução do método recovery. Após a ocorrência do travamento e aplicação do método de deadlock recovery, a execução foi encerrada.

\subsubsection{Verificação da dinâmica do fluxo de informações}

O disparo de um evento $e_{1}$ inicia o processo de requisição de utilização do recurso $R_{4}$ e $R_{7}$ pelos processos $\Pi_{2}$ e $\Pi_{3}$. A mensagem de requisição gerada pela transição TC29 nos processos $\Pi_{2}$ e $\Pi_{3}$ do CAT é enviada para o CUR.

O CUR recebe as mensagens de requisição pelos boxes de comunicação $\mathrm{BC} 8 \mathrm{e}$ BC12 que permitem a evolução das marcas nos boxes controladores BCT12 e BCT8, respectivamente. Verifica-se que nesta situação, o CUR não identifica um estado anterior ao deadlock ou o estado de deadlock, permitindo-se a alocação dos recursos pelos processos. Após a conclusão das atividades dos processos, o subgrafo recovery será acionado para executar a ação de restabelecimento do sistema. A ação de restabelecimento do sistema ocorre conforme apresentado no item anterior.

Observa-se que neste caso não há uma falha no método de deadlock avoidance e sim uma questão de refinamento das regras para identificação do estado anterior ao travamento.

\subsubsection{Resultados}

A análise do fluxo comprovou os resultados da execução para o Exemplo 3.

\subsection{Observações Complementares}

Neste capítulo foi apresentado um exemplo aplicando-se a sistemática proposta neste trabalho. A partir da determinação dos módulos, buscou-se apresentar o fluxo das informações entre os módulos, principalmente no que tange a troca de informações.

Para auxiliar no processo de verificação dos módulos, foi desenvolvida uma ferramenta computacional para a execução de uma rede E-MFG para uma plataforma IBM-PC com sistema operacional Windows XP, desenvolvido em 
linguagem Object Pascal (ANEXO C). A ferramenta permite executar a evolução das marcas no E-MFG com os elementos comunicadores (ANEXO A).

Com base no exposto, algumas observações são apresentadas:

* O método híbrido de deadlock avoidance, detection and recovery permite o fluxo dos processos nos CFEs;

* Somente aplicando-se as regras de deadlock avoidance não se garantem fluxo no caso de CFEs consecutivos e na situação em que ocorre a alocação simultânea dos recursos que pertencem a um único CFE. 


\section{CAPÍTULO}

\section{CONCLUSÕES}

Este trabalho apresentou a proposta de uma arquitetura modular baseada no conceito de hierarquia modificada para o controle de SPFs. A arquitetura de controle proposta permite a execução das estratégias de controle considerando-se os diferentes domínios semânticos.

Inicialmente, apresentou-se uma visão geral do objeto de estudo do presente trabalho, os SPFs. São sistemas que foram concebidos para atender a uma demanda de um mercado dinâmico e competitivo em que a característica principal é a necessidade de adaptar-se rapidamente às mudanças do ambiente em que atua. Apresentou-se também as motivações que nortearam o desenvolvimento deste trabalho e os objetivos a serem atingidos.

Como premissa básica, apresentou-se os conceitos de sistemas produtivos, de flexibilidade, de automação e controle. Apresentou-se as arquiteturas de controle para SPFs e a importância da normatização para a sistematização da comunicação entre os diversos níveis do sistema. Considerando a característica maior dos SPFs que é o compartilhamento de recursos com flexibilidade operacional, apresentou-se uma caracterização de modelos de alocação de recursos quanto à forma com que esses recursos são utilizados e as atividades que são desenvolvidas no SPFs. O aspecto que foi abordado diretamente relacionado ao compartilhamento de recursos foi o fenômeno de deadlock. Foram apresentados os métodos empregados e foi proposta uma abordagem híbrida para o tratamento de deadlock com base nos métodos de deadlock avoidance e deadlock detection and recovery.

Por fim, apresentou-se uma proposta de arquitetura hierárquica modificada de controle modular para SPFs. Para cada um dos módulos apresentou-se uma sistemática para a geração de seus modelos de controle, respeitando-se as diferentes semânticas envolvidas, bem como a integração entre esses módulos.

Para ilustrar a aplicação da proposta desta tese, apresentou-se um exemplo em que se analisaram diferentes comportamentos dinâmicos de um SPF e a forma dinâmica de atuação do sistema de controle projetado. A análise foi realizada em duas 
frentes: primeiramente utilizando uma ferramenta computacional desenvolvida especialmente para a simulação das redes E-MFG e, posteriormente, verificou-se o comportamento do fluxo das diferentes informações que fluem no modelo global, justificando os resultados obtidos na simulação.

\subsection{Contribuições deste Trabalho}

A contribuição fundamental do presente trabalho foi a proposta de arquitetura de controle hierárquico modular para SPFs. Nesta arquitetura o módulo CUV, que é responsável pela utilização das vias, pode ser implementado utilizando-se a ferramenta computacional desenvolvida para determinação dos CFEs e das regras para evitar o deadlock (NAKAMOTO et al., 2003a, 2003b; 2003c; 2007a).

Quanto à otimização do processo de designação dos transportadores foi possível em virtude do desenvolvimento de um algoritmo de caminho mínimo (REIS et al., 2007) implementado no módulo CDT, que é responsável pela designação de transporte.

Desta forma, as principais contribuições do presente trabalho são:

- Proposta de uma arquitetura hierárquica de controle modular e a definição de uma sistematização para o projeto dos algoritmos de controle presentes em cada módulo;

* Proposta de um método híbrido baseado no método de deadlock avoidance e deadlock detection and recovery para o tratamento do deadlock em sistema de controle.

\subsection{Trabalhos Futuros}

Pode-se sugerir como trabalhos futuros:

* Geração automática do algoritmo de controle;

* Aperfeiçoamento da ferramenta computacional de simulação que permita análises qualitativas e, inclusive, quantitativas em relação ao desempenho da rede E-MFG;

* Desenvolvimento de um controlador E-MFG dedicado; 
* Evolução da presente proposta para abordar SPFs que utilizem arquiteturas de controle heterárquicas.

\subsection{Trabalhos Publicados}

NAKAMOTO, F.Y., MIYAGI, P.E., SANTOS FILHO, D.J. Geração Automática do Algoritmo de Controle de Sistemas Produtivos Flexíveis. Em: VI SBAI - Simpósio Brasileiro de Automação Inteligente, Bauru, 2003a.

NAKAMOTO, F.Y., MIYAGI, P.E., SANTOS FILHO, D.J. Automatic Generation of Productive System Control. In: $17^{\text {th }}$ COBEM International Congress of Mechanical Engineering, 2003, São Paulo. Proceedings of the $17^{\text {th }}$ COBEM International Congress of Mechanical Engineering, 2003b.

NAKAMOTO, F.Y., MIYAGI, P.E., SANTOS FILHO, D.J. Systematization of the Project of the Production System Control. In: IEEE ISIE03 - International Symposium on Industrial Electronics, 2003, Rio de Janeiro. Proceedings of the : IEEE ISIE03 - International Symposium on Industrial Electronics, 2003c.

NAKAMOTO, F.Y., MIYAGI, P.E., SANTOS FILHO, D.J. Um Novo Algoritmo para Determinação dos Ciclos Fechados de Espera em Grafos de Alocação de Recursos. Em: VIII SBAI - Simpósio Brasileiro de Automação Inteligente, Florianópolis, 2007a.

NAKAMOTO, F.Y., MIYAGI, P.E., SANTOS FILHO, D.J. Resource Allocation Controle In Flexible Manufacturing Systems Using The Deadlock Avoidance Method. In: $19^{\text {th }}$ COBEM International Congress of Mechanical Engineering, Brasília, 2007b;

REIS, J.V.A., CUNHA, C.B., NAKAMOTO, F.Y., RIBEIRO, F., SCHARDONG, A. Análise Comparativa de Algoritmos Eficientes para o Problema do Caminho Mínimo. Em: XXI ANPET Congresso de Pesquisa e Ensino em Transportes, Riode Janeiro, 2007. 


\section{REFERÊNCIAS BIBLIOGRÁFICAS}

ARAÚJO JUNIOR, L.O. Método de Programação de Sistemas de Manufatura do Tipo Job Shop Dinâmico não Determinístico. 2006. 175p. Tese (Doutorado) Escola Politécnica da Universidade de São Paulo. São Paulo, 2006.

BANASZAK, K.A. e KROGH, B.H. Deadlock Avoidance in Flexible Manufacturing System with Concurrently Competing Process Flows. Em: IEEE Transactions on Robotics and Automation, vol.6, 1990. pp.724-734.

BANASZAK, K.A. Distributed Bottleneck Control for Repetitive Production Systems. Em: Journal of Intelligent Manufacturing, 1997. pp.415-424.

BANASZAK, K.A. e POLAK, M. Deadlock-Free Distributed Control for Repetitive Flows. Em: IEEE WODES'02 Proceedings of the Sixth International Workshop on Discrete Event Systems, 2002. pp.273- 278.

BANG-JENSEN, J. e GUTIN, G. Diagraphs - Theory, Algorithms and Applications. London: Springer-Verlag, 2002. 754p.

BLANC, P., DEMONGODIN, I. e CASTAGNA, P. A Holonic Approach fo Manufacturing Execution System Design: An Industrial Application. Enginnering Applications of Artificial Intelligence, doi: 10.1016/j.engappai.2008.01.007, 2008. No prelo.

BOER, E.R. e MURATA, T. Generanting Basis Siphons and Traps of Petri Nets Using the Sign Incidence Matriz. Em: IEEE Transactions on Circuits and SystemsL: Fundamental, Theory and Applications, vol. 41, no.4, abril 1994. pp.266-271.

BONGAERTS, L., MONOSTORI, L., McFARLANE, D., KÁDÁR, B. Hierarchy in Distributed Shop Floor Control. Em: Computers in Industry, vol. 43, 2000. pp.123137.

CALINESCU, A., EFSTATHIOU, J., SIVADASAN, S., SCHIRN, J., HUACCHO HUATUCO, L. Complexity in Manufacturing: An Information Theoretic Approach. Em: Proceedings of the International Conference on Complexity and Complex Systems in Industry. $19^{\text {th }}-20^{\text {th }}$ September 2000 . The University of Warwick, pp.3044.

CARDOSO, J. e VALETTE, R. Redes de Petri. Florianópolis: Editora da UFSC, 1997. 212p.

CASSANDRAS, C.G. e LAFORTUNE, S. Introduction to Discrete Event Systems. Second Edition. New York: Springer Vergag, 2007. 776p. 
CASSANDRAS, C.G. Discrete Event Systems - Modeling and Performance Analysis. Richard D. Irwin, Inc., and Aksen Associates, Inc., 1993. 790p.

CHO, H., KUMARAN, T.K., WYSK, R.A. Graph-Theoretic Deadlock Detection and Resolution for Flexible Manufacturing Systems. Em: IEEE Transactions on Robotics and Automation, vol. 11, no.3, n995. pp.413-421.

COFFMAN, E.G.JR., ELPHICK, M.J., SHOSHANI, A. System Deadlocks. Em: Computing Surveys, vol.3, no. 2, June 1971. pp.67-78.

CORMEN, T.H., LEISERSON, C.E., RIVEST, R.L., STEIN, C. Algoritmos - Teoria e Prática. Tradução da $2^{a}$ edição americana. Editora Campus, 2002. 916p.

DATE, C.J. An Introduction to Database Systems. 7th Edition, Addison Wesley Longman, Inc., chapter 15, pp. 473-501, 2000. 938p.

EDMONDS, B. What is Complexity? - The philosophy of complexity per se with application to some examples in evolution. Em: Symposium The Evolution of Complexity. Belgium. Univesity of Brussels, 1995.

EZPELETA, J., COLOM, J.M. e MARTínEZ, J. A Petri Net Based Deadlock Prevention Policy for Flexible Manufacturing Systems. Em: IEEE Transactions on Robotics and Automation, vol. 11, no.2, abril 1995. pp.173-184.

FANTI, M.P., MAIONE, B., MASCOLO, S. e TURCHIANO, B. Control Policies Conciliating Deadlock Avoidance and Flexibility in FMS Resource Allocation. Em: ETDA 95, Proceeding of the INRIA/IEEE Symposium on Emerging Technologies and Factory Automation, vol.1, Oct. 10-13 1995. pp.343-351.

FANTI, M.P., MAIONE, B., MASCOLO, S. e TURCHIANO, B. Event-Based Feedback Control for Deadlock Avoidance in Flexible Production Systems. Em: IEEE Transactions on Robotics and Automation, vol.13, issue 3, Jun 1997. pp.347-363.

FANTI, M.P., MAIONE, B. e TURCHIANO, B. Comparing Digraph and Petri Net Approaches to Deadlock Avoidance in FMS. Em: IEEE Transactions on Systems, Man, and Cybernetics - Part B, vol.30, issue 5, Oct 2000. pp.783-798.

FANTI, M.P. e TURCHIANO, B. Deadlock Analysis in Automated Manufacturing Systems with Conjunctive Resource Service. Em: Proceedings of the IEEE/ICRA International Conference on Robotics and Automation, vol.1, 2002. pp.181-186.

FANTI, M.P. Deadlock Resolution Strategy for Automated Manufacturing Systems Including Conjunctive Resource Service. Em: IEEE Transactions on Systems, Man, and Cybernetics - Part A, vol.34, issue 1, Jan 2004. pp.80-92. 
GANESHARAJAHA, T., HALL, N.G., SRISKANDARAJAH, C. Design and Operational issues in AGV-served Manufacturing Systems. Em: Annals of Operations Research, vol. 76, no 1, 1998. pp109-154.

GANG, X. e MING, W.Z. Systemic Solution to Deadlock in FMS. Em: Proceding of the 2004 American Control Conference. June 30 - July 2, 2004. Boston, Massachusetts, pp.5740-5745.

GANG, X. e ZHIMING, W. A New Method for FMS Modeling and Formal Verification. Em: ETFA - IEEE Conference on Emerging Technologies and Factory Automation, vol. 1, 2003. pp.224-231.

GLEGHORN, R. Enterprise Application Integration: A Manager's Perspective. Em: IEEE - Computer Society - IT Professional, vol. 7, 2005. pp.17-23.

GOLDBARG, M.C. e LUNA, H.P.L. Otimização Combinatória e Programação Linear - Modelos e Algoritmos. $2^{a}$ Edição. São Paulo: Elsevier Editora Ltda, pp.2579 e 167-213. 2005. 518p.

GROOVER, M.P. Automation, Production Systems, and Computer-Integrated Manufacturing. $3^{\text {rd }}$ Edition. New Jersey: Prentice-Hall, 2007. 840p.

HASEGAWA, K. et.al., Proposal of Mark Flow Graph for Discrete System Control, Trans. of SICE, v.20, n.2, p.122-129, 1984.

HOUAISS, A. Dicionário Eletrônico Houaiss da Língua Portuguesa. $2^{a}$ Edição. Editora Objetiva. CD-ROM, 2007.

HUANG, Z. WU, Z. A New Distributed Deadlock Avoidance Strategy for Flexible Manufacturing Systems Using Digraph Models. Em: Proceedings of the IEEE $8^{\text {th }}$ International Workshop on Discrete Event Systems, July 10-12, 2006. Ann Arbor, Michigan, USA. pp.276-281.

ITO, Y. A Diserable Production Structure Looking Toward The $21^{\text {st }}$ Century Anthropocentric Intelligence-Based Manufacturing. Em: COBEM - XI Congresso Brasileiro de Engenharia Mecânica, São Paulo, pp. 23-32, 1991.

INSTRUMENTATION, SYSTEMS, AND AUTOMATION SOCIETY. EnterpriseControl System Integration: Part 3: Models of Manufacturing Operations, 95.00.03, Draft 13. Available from ISA, 2003.

JIN-HAI, L., ANDRESON, A.R. e HARRISON, R.T. The Evolution of Agile Manufacturing. Em: Business Process Management Journal, vol. 9, no.2, 2003. pp.170-189. 
KALPAKJIAN, S. e SCHMID, S.R. Manufacturing, Engineering \& Technology. $5^{\text {th }}$ Edition. New Jersey: Prentice Hall, 2005, 1320p.

LAWLEY, M.A. e FERREIRA, P. An Automation Based Framework for Analysis and Control of Flexible Manufacturing Systems. Em: Proceedings of 1994 Mid-America Conference on Intelligent Systems. Kansas City, KS. 1994. pp.144-152.

LAWLEY, M.A., REVELIOTIS, S.A. e FERREIRA, P. Design Guidelines for Deadlock Handling Strategies in Flexible Manufacturing Systems. Em: International Journal of Flexible Manufacturing Systems, vol.9, no.1, Jan 1997. pp.5-30.

LAWLEY, M.A., REVELIOTIS, S.A. e FERREIRA, P. The Application and Evaluation of Banker's Algorithm for Deadlock-Free Buffer Space Allocation in Flexible Manufacturing Systems. Em: International Journal of Flexible Manufacturing Systems, vol.10, no.1, February, 1998. pp.73-100.

LAWLEY, M.A. e REVELIOTIS, S.A. Deadlock Avoidance for Sequential Resource Allocation Systems: Hard and Easy Cases. Em: International Journal of Flexible Manufacturing Systems, vol.13, no.4, October, 2001. pp.385-404.

LAWLEY, M.A. e SULISTYONO, W. Robust Supervisory Control Policies for Manufacturing Systems with Unrealiable Resource. Em: IEEE Transactions on Robotics and Automation, vol.18, issue 3, Jun 2002. pp.346-359.

LI, Z.W. e ZHOU, M.C. A Deadlock Control Method Using Elementary Siphon of Petri Nets. Em: IEEE Conference on Systems, Man, and Cybernetics, vol.3, Oct. 2003. pp.2716-2720.

LI, Z.W. e ZHOU, M.C. Elementary Siphon of Petri Nets and Their Application to Deadlock Prevention in Flexible Manufacturing Systems. Em: IEEE Transactions on Systems, Man, and Cybernetics - Part A: Systems and Humans, vol.34, no.1, January 2004. pp.38-51.

LI, Z.W. e ZHOU, M.C On Siphon Computation for Deadlock Control in a Class of Petri Nets. Em: IEEE Transactions on Systems, Man, and Cybernetics - Part A: Systems and Humans, vol.38, no.3, May. 2008a. pp.667-679.

LI, Z.W. e ZHOU, M.C, WU, N. A Survey and Comparison of Petri Net-Based Deadlock Prevention Policies for Flexible Manufacturing Systems. Em: IEEE Transactions on Systems, Man, and Cybernetics - Part C: Applications and Reviews, vol.38, no.2, March. 2008b. pp.173-188.

LI, Z.W., WEI, N. e ZHU, R. A Deadlock Prevention Policy for FMS Using Petri Nets. Em: IEEE 2005 International Conference on Control and Automation (ICCA2005), June 27-29, Budapest, Hungary. 2004. pp.1187-1192. 
MAGEE, C.L. e WECK, O.L. Complex System Classification. Em: Fourteenth Annual Internation Symposium of the International Council On Systems Engineering (INCOSE). 20-24 Junho. 2004. pp.1-18.

MASIP, R.F. La Fábrica Flexible. Colección Prodúctica. Barcelona (España): Marcombo Boixareu Editores, 1988. 148p.

MARTINS, R.W.C. Uma Arquitetura Modular para Controle de FMS. 2005. 81p. Dissertação (Mestrado) - Centro de Ciências Exatas e de Tecnologia da Universidade Federal de São Carlos. São Carlos, 2005.

MATSUSAKI, C.T.M. Modelagem de Sistemas de Controle Distribuídos e Colaborativos de Sistemas Produtivos. 2004. 154p. Tese (Doutorado) - Escola Politécnica da Universidade de São Paulo. São Paulo, 2004.

MIYAGI, P.E. Controle Programável - Fundamentos do Controle de Sistemas a Eventos Discretos. São Paulo: Editora Edgard Blüncher Ltda, 1996.194p.

MORAES, C.C. e CASTRUCCI, P.L. Engenharia de Automação Industrial. Rio de Janeiro: LTC - Livros Técnicos e Científicos Editora S.A., 2007. 358p.

MURATA, T. Petri Nets: Properies, Analysis and Applications. Em: Procedings of the IEEE, vol.77,no4, 1989. pp.541-580.

NAKAMOTO, F.Y. Sistematização do Projeto do Controle de Sistemas Produtivos. 2002. 147p. Dissertação (Mestrado) - Escola Politécnica da Universidade de São Paulo. São Paulo, 2002.

NAKAMOTO, F.Y., MIYAGI, P.E., SANTOS FILHO, D.J. Geração Automática do Algoritmo de Controle de Sistemas Produtivos Flexíveis. Em: VI SBAI - Simpósio Brasileiro de Automação Inteligente, Bauru, 2003a.

NAKAMOTO, F.Y., MIYAGI, P.E., SANTOS FILHO, D.J. Automatic Generation of Productive System Control. In: $\mathbf{1 7}^{\text {th }}$ COBEM International Congress of Mechanical Engineering, 2003, São Paulo. Proceedings of the $17^{\text {th }}$ COBEM International Congress of Mechanical Engineering, 2003b.

NAKAMOTO, F.Y., MIYAGI, P.E., SANTOS FILHO, D.J. Systematization of the Project of the Production System Control. In: IEEE ISIE03 - International Symposium on Industrial Electronics, 2003, Rio de Janeiro. Proceedings of the : IEEE ISIE03 - International Symposium on Industrial Electronics, 2003c.

NAKAMOTO, F.Y., MIYAGI, P.E., SANTOS FILHO, D.J. Um Novo Algoritmo para Determinação dos Ciclos Fechados de Espera em Grafos de Alocação de Recursos. Em: VIII SBAI - Simpósio Brasileiro de Automação Inteligente, Florianópolis, 2007a. 
NAKAMOTO, F.Y., MIYAGI, P.E., SANTOS FILHO, D.J. Resource Allocation Controle In Flexible Manufacturing Systems Using The Deadlock Avoidance Method. In: $19^{\text {th }}$ COBEM International Congress of Mechanical Engineering, Brasília, 2007b.

NASCIMENTO JR, C.L., YONEYAMA, T. Inteligência Artificial em Controle Automação. São Paulo: Editora Edgard Blüncher Ltda., 2000. 218p.

OU-YANG, C. e LIN, J.S. The Development of a Hybrid Hierarchical/Heterarchical Shop Floor Controle System Applying Bidding Method in Job Dispatching. Em: Robotics and Computer-Integrated Manufacturing, vol. 14, 1998. pp.199-217.

PELS, H.J., WORTMANN, J.C. e ZWEGERS, A.J.R. Flexibility in Manufacturing: An Architectural Point of View. Computers in Industry, vol. 33, 1997. p.271-283.

PETERSON, J.L. Petri Net Theory and the Modeling of System. Englewood Cliffs, N.J., Prince-Hall, pp.1-78, 1981, 290p.

QIU, L., HSU, W-J., HUANG, S-Y., WANG, H. Scheduling and Routing Algorithm for AGVs: A survey. Em: International Journal of Production Research, 2002, vol. 40, n.3, pp.747-70.

RAMAN, S. E-Commerce and Globalization - Yesterday, Today and Tomorrow. Em: IEEE - Proceedings of the Engineering Management Society. 2000. pp.249-254.

REIS, J.V.A., CUNHA, C.B., NAKAMOTO, F.Y., RIBEIRO, F., SCHARDONG, A. Análise Comparativa de Algoritmos Eficientes para o Problema do Caminho Mínimo. Em: XXI ANPET Congresso de Pesquisa e Ensino em Transportes, Riode Janeiro, 2007.

REISIG, W. Petri Nets: An Introduction. Springer-Verlag, Berlin Heidelberg, 1985. $161 \mathrm{p}$.

REVELIOTIS, S.A. Accommodating FMS Operational Contingencies Through Routing Flexibility. Em: IEEE Proceedings of the International Conference on Robotics and Automation, vol.15, issue 1, Feb 1998. pp.3-19.

REVELIOTIS, S.A. Avoidance versus detection and recovery problem in bufferspaceallocation of flexibly automated production systems. Em: IEEE Transactions on Systems, Man, and Cybernetics - Part B, vol.30, issue 5, Oct 2000. pp.799-811.

REVELIOTIS, S.A. Real-Time Management of Resource Allocation Systems - A Discrete Event Systems Approach. Atlanta: Springer Science+Business Mecia, Inc. 2005. 242p. 
SAAD, S., PERERA, T., WICKRAMARACHI, R. Simulation of Distributed Manufacturing Enterprises: A New Approach. Em: IEEE - Proceedings of the 2003 Winter Simulation Conference, 2003. pp.1167-1173.

SANTOS FILHO, D.J. Controle de Sistemas Antropocêntricos de Produção Baseado em Redes de Petri Interpretadas. 1998. 287p. Tese (Doutorado) - Escola Politécnica da Universidade de São Paulo. São Paulo, 1998.

SANTOS FILHO, D.J. Aspectos do Projeto de Sistemas Produtivos. 2000. 000p. Tese (Livre docência) - Escola Politécnica da Universidade de São Paulo. São Paulo, 2000.

SILBERSCHATZ, A., GALVIN, P., GAGNE, G. Sistemas Operacionais - Conceitos e Aplicações. Editora Campus, capítulo 8, pp.160-176, 2004. 618p.

TANENBAUM, A.S. Sistemas Operacionais Modernos. LTC - Livros Técnicos e Científicos Editora S.A., capítulo 6, pp. 163-179, 1995, 493p.

TANENBAUM, A.S. Computer Networks. $4^{\text {th }}$ Edition, Prentice Hall, chapter 3, pp. 229-233, 2002, 912p.

TRINCAS, F. e EZPELETA, J. Some Results on Siphon Computation for Deadlock Prevention in Resource Allocation Systems Modeled with Petri Nets. Em: Proceedings of the IEEE/ETFA Conference Emerging Technologies and Factory Automation, vol.1, Sept. 2003. pp.322-329.

VILLANI, E. Modelagem e Análise de Sistemas Supervisórios Híbridos. 2004. 339 p. Tese (Doutorado) - Escola Politécnica da Universidade de São Paulo. São Paulo, 2004.

VIS, I.F.A. Survey of Research in the Design and Control of Automated Guided Vehicle Systems. Em: European Journal of Operational Research. 2006. pp677709 .

VISWANADHAM, N., NARAHARI, Y., JOHNSON, T.L. Deadlock Prevention and Deadlock Avoidance in Flexible Manufacturing Systems Using Petri Net Models. Em: IEEE Transactions on Robotics and Automation, vol. 6, no.6, 1990. pp.713-723.

WANG, A.R., LI, Z.W. e JIA, J.Y. A Petri Nets Based Deadlock Avoidance Policy for Flexible Manufacturing Systems. Em: IEEE - The $30^{\text {th }}$ Annual Conference of the IEEE Industrial Electronics Society, 2-6 November. 2004. pp.1896-1901.

WU, N. e ZHOU, M.C. AGV Routing for Conflict Resolution in AGV Systems. Em: Proceedings fo the 2003 IEEE International Conference on Robotics and Automation, September 14-19, Taipei, Taiwan. 2003. pp.1428-1433. 
WU, N. e ZHOU, M.C. Modeling and Deadlock Control of Automated Guided Vehicle Systems. Em: IEEE/ASME Transactions on Mechatronics, vol. 9, no.1, 2004. pp.50-57.

WU, N. e ZHOU, M.C. Modeling and Deadlock Avoidance of Automated Manufacturing Systems With Multiple Automated Guided Vehicles. Em: IEEE Transactions on Systems, Man, and Cybernetics - Part B: Cybernetics, vol. 35, no.6, 2005. pp.1193-1202.

WU, N. e ZHOU, M.C. Shortest Routing of Bidirecional Automated Guided Vehicles Avoiding Deadlock and Blocking. Em: IEEE/ASME Transactions on Mechatronics, vol. 12, no.1, 2007. pp.63-72. 


\section{ANEXO A - FERRAMENTAS DE MODELAGEM}

\section{ANEXO A. 1 Redes de Petri}

A rede de Petri $(\mathrm{RdP})$ é um modelo matemático foi proposto por Carl Petri para a modelagem de sistemas de comunicação. Basicamente uma RdP é representado por um grafo direcionado, bi-partido e ponderados com uma marcação inicial, composto de nós (lugares) e transições, interligado por arcos orientados. Os arcos podem possuir um peso $k$ que representa $k$ arcos paralelos e as marcações são atribuídos nos nós (PETERSON, 1981; REISIG, 1985; MURATA, 1989; CASSANDRAS e LAFORTUNE, 2007; CARDOSO e VALETTE, 1997). Uma RdP é uma quádrupla $R d P=\left\{P, T, A_{r}, K, W, M_{0}\right\}$, sendo que (Figura A.1):

* $P=\left\{p_{1}, p_{2}, p_{3}, \ldots p_{m}\right\}$ é um conjunto finito de lugares;

* $T=\left\{t_{1}, t_{2}, t_{3}, \ldots t_{n}\right\}$ é um conjunto finito de transições;

* $A_{r} \subseteq(P \times T) \bigcup(T \times P)$ é um conjunto finito de arcos;

* $K: P \rightarrow N \bigcup\{\infty\}$ é a função de capacidade;

* $W: A_{r} \rightarrow N^{+}$é a função de ponderação;

* $M_{0}: P \rightarrow N$ é a função de marcação inicial que satisfaz $\forall p \in P: M_{0}(p) \leq K(p)$

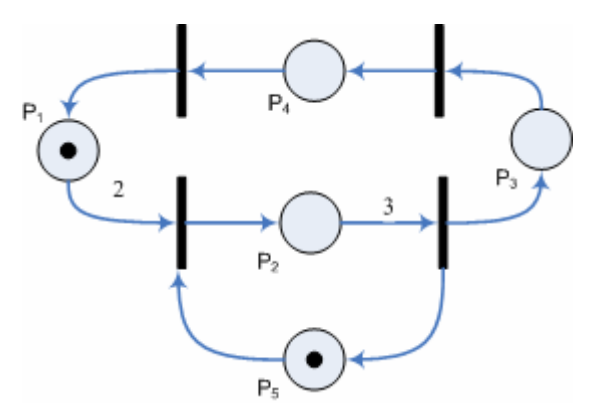

Figura A.1 Um exemplo de RdP. 


\section{ANEXO A. 2 Siphon e Traps}

Os elementos estruturais siphons estão relacionados com a ocorrência de deadlock na rede (Fig. A.2). O siphon é um elemento estrutural que dado uma $\operatorname{RdP} N$, o subconjunto não vazio de lugares $S$ é chamado de siphon se $\bullet S \subseteq S \bullet$, isto é, todas as transições de entrada de $S$ é também transição de saída de $S$. O subconjunto não vazio de lugares $Q$ é chamado de trap se $S \bullet \subseteq \bullet S$, isto é, todas as transições de saída de $S$ é também transição de entrada de $S$ (PETERSON, 1981; REISIG, 1985; BOER e MURATA, 1994; MURATA, 1989). A estrutura siphon permite um esvaziamento das marcas enquanto que a estrutura trap permite o acúmulo de marcas. Desta forma, observa-se que em algum estado poderão existir transições que não serão mais habilitadas por não atender as pré-condições ou as póscondições.

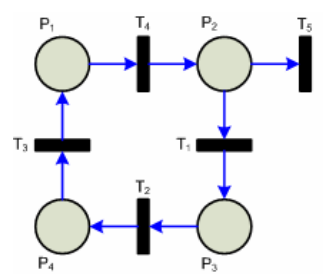

(a)

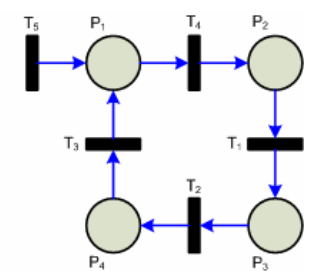

(b)

Figura A.2 Estruturas Siphon (a) e Trap (b).

O siphon é classificado como mínimo se não contiver nenhum outro siphon como subconjunto. Observa-se que um siphon mínimo é um siphon básico (MURATA, 1989). O algoritmo proposto por Boer e Murata (1994) possui complexidade exponencial para a determinação de siphon básico utilizando-se matrizes de incidência de sinais. O siphon básico é elemento estrutural na rede que não são compostos por outros siphons. Contudo, Boer e Murata (1994) salientaram quanto ao esforço computacional de acordo com o tamanho da rede. Propôs inclusive na época, a aplicação de processamento paralelo para reduzir o esforço computacional.

\section{ANEXO A. 3 Grafo de Alocação de Recursos - GAR}

Um Grafo de Alocação de Recursos (GAR) (SANTOS FILHO, 2000) é um grafo bipartido, não marcado e que representa a utilização de recursos pelos processos. $O$ grafo $\operatorname{GAR} G=(R, A)$ é um conjunto não vazio tal que R é um conjunto de nós, que 
representam os recursos $R=\left\{r_{1}, r_{2}, r_{3}, \ldots, r_{n}\right\}$, e A o conjunto de arestas ou arcos orientados, que representam a alocação e requisição de recursos. Um arco orientado é um par ordenado $a_{i j}=\left(r_{i}, r_{j}\right)$, onde $r_{i}$ e $r_{j}$ são elementos de $R$.

Um par contendo um nó e o respectivo arco orientado de saída é denominado par de alocação enquanto que um par contendo um nó e o respectivo arco de entrada é denominado par de requisição. Em um par de alocação, o nó representa um determinado recurso $r_{i}$ e o arco orientado de saída possui uma inscrição fixa que representa a etapa do processo $a_{\mathrm{ij}}$ que aloca $\mathrm{r}_{\mathrm{i}}$ para ser executada. Por sua vez em um par de requisição o nó também representa um determinado recurso $r_{j}$ e $o$ arco orientado de entrada possui uma inscrição fixa que representa a etapa do processo $a_{i j}$ que o requisita para ser utilizado na próxima etapa do processo. A Figura A.3 ilustra graficamente a representação destes pares para o caso de um mesmo produto em uma determinada etapa de sua seqüência de produção.

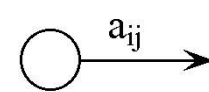

$\mathrm{r}_{\mathrm{i}}$

(a) Par de Alocação

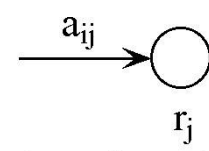

(b) Par de Requisição

Figura A.3 Elementos fundamentais de um GAR.

A representação de um GAR é feita através de sua Matriz de Adjacência (BANGJENSEN, J. e GUTIN, 2006). Seja G um GAR de ordem $n$, isto é, $n$ recursos: R. A matriz de adjacência é uma matriz $n \times n$, onde o valor de cada elemento $e_{i j}=a_{i j}=\left(r_{i}\right.$, $\mathrm{r}_{\mathrm{j}}$ ) da matriz é determinado da seguinte maneira: Se $a \mathrm{a} \neq \varnothing \mathrm{e} a \mathrm{aj} \neq \varnothing$ então $\mathrm{e}_{\mathrm{ij}}=\mathrm{a}_{\mathrm{ij}}$ do contrário $e_{i j}=0$; Por exemplo, um processo q que possui a seguinte seqüência de utilização de recursos: $r_{1}, r_{3}$ e $r_{2}$.

Admitindo-se uma entrada e uma saída para o processo ( $\mathrm{q}_{\text {in }}$ e $\mathrm{q}_{\text {out }}$ ) a sua respectiva representação através da Matriz de Adjacência é:

$$
\begin{gathered}
r_{1} \\
r_{2} \\
r_{3} \\
q_{I N} \\
q_{\text {OUT }}
\end{gathered} \quad\left(\begin{array}{ccccc}
0 & 0 & q_{1,3} & 0 & 0 \\
0 & 0 & 0 & 0 & q_{2, \text { OUT }} \\
0 & q_{3,2} & 0 & 0 & 0 \\
q_{I N, 1} & 0 & 0 & 0 & 0 \\
0 & 0 & 0 & 0 & 0
\end{array}\right)
$$




\section{ANEXO A. 4 Ciclo Fechado de Espera (CFE)}

A condição de espera circular pode ocorrer em SPFs onde há compartilhamento de recursos. Essa condição de espera circular no modelo GAR é denominada Ciclo Fechado de Espera (CFE). A Figura A.4 apresenta os elementos que compõem um CFE em um modelo GAR. O nó que corresponde à interseção é denominado nó de interseção. O nó de interseção é formado pelo cruzamento de um ou mais segmentos. Cada seguimento possui:

* Um Par de Alocação de Interseção (PAI);

* Um Par de Alocação Terminal (PAT).

O PAT de um seguimento aponta o nó de intersecção que, por sua vez, é o PAI do próximo seguimento.

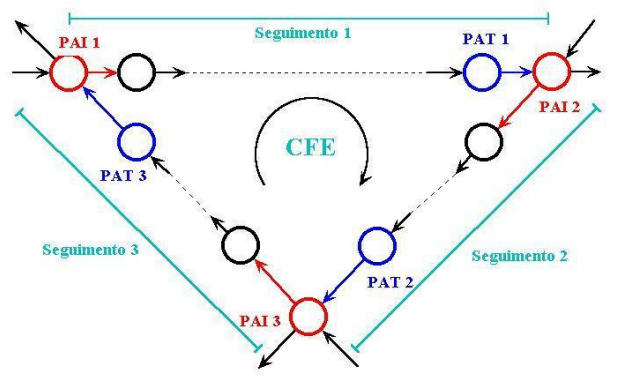

Figura A.4 Elementos de um CFE.

\section{ANEXO A. 5 Mark Flow Graph - MFG}

O MFG (HASEGAWA et al., 1984; MIYAGI, 1996) é uma rede interpretada derivada de RdP desenvolvida para a modelagem e controle de sistemas. O MFG é composto basicamente pelos seguintes elementos estruturais (Fig.A.5):

a) As transições que indicam a ocorrência de eventos;

b) Os boxes que representam as pré e pós-condições;

c) Os arcos orientados que estabelecem uma relação causal entre os eventos e as condições;

d) As portas que habilitam ou inibem a ocorrência dos eventos e;

e) As marcas que indicam a manutenção de uma condição. 
No processo de modelagem de um SP, os boxes representam as condições, operações ou tarefas associadas aos dispositivos e as transições representam o início e término de um processo. O comportamento dinâmico do sistema é indicado pela evolução das marcas no grafo, de acordo com uma regra pré-definida de disparo das transições e que correspondem ao fluxo de itens (materiais ou informações) no sistema real.

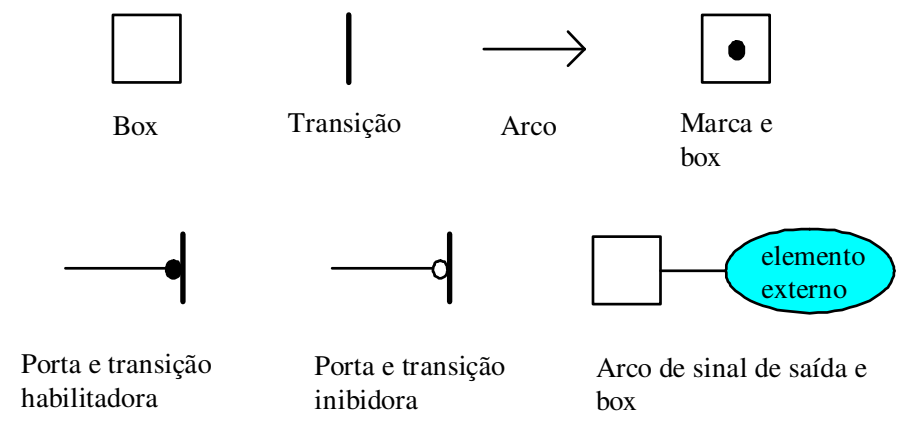

Figura A.5 Elementos básicos do MFG.

A interface do modelo do sistema com o sistema real é realizada mediante uso de elementos estruturais denominados arcos de sinal de saída e as portas habilitadoras/inibidoras, sendo que as portas ainda podem ser classificadas em portas externas ou internas, dependendo da natureza do sinal de origem.

\section{ANEXO A. 6 Enhanced Mark Flow Graph - E-MFG}

O E-MFG é uma técnica de modelagem que permite a manipulação de marcas individuais com atributos, sendo capaz de modelar e controlar alterações de fluxo (rotas alternativas) das marcas e seleção de tarefas (condições) associadas aos boxes (SANTOS FILHO, 2000). A estrutura básica do grafo MFG e de seus principais elementos é mantida. Apresenta-se a seguir os elementos estruturais fundamentais do E-MFG e a dinâmica de disparo das transições e atualização da marcação.

\section{A 6.1. As Marcas Individuais}

Os elementos estruturais básicos apresentados na Figura A.5 constituem um caso particular em que não há marcas individuais e não há regras adicionais associadas às transições. No E-MFG as marcas são acompanhadas por um vetor de atributos 
que Ihes garantem individualidade. A estes atributos podem-se associar diversas informações referentes ao produto, ao processo e ao controle. $O$ atributo zero significa a ausência deste atributo. A Figura A.6 representa um exemplo de estrutura de uma marca individual.

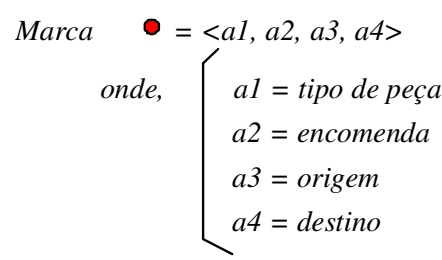

Figura A.6 Exemplo de estrutura de uma marca individual.

\section{A 6.2. Marcas Individuais Compostas}

A modularização do MFG é realizada utilizando-se macro-elementos elementos para simplificar a representação de diversos dispositivos comuns presentes no ambiente de manufatura. Os boxes funcionais do tipo capacidade, agrupador e dispersor manipulam apenas marcas indistintas, isto é, um box agrupador ou dispersor ou mesmo capacidade controlam apenas a quantidade de peças na situação em que são modelados por exemplo, um processo de empacotamento, ou desempacotamento, ou ainda um buffer de armazenamento temporário em um sistema de manufatura. No caso de utilizarem-se marcas individuais nestes boxes, é possível controlar também a seqüência de entrada e saída de materiais e registrarse o conteúdo das cargas.

Quando se modela processos de agrupamento (montagem, carga, etc.) e dispersão (desmontagem, descarga, etc.) através de boxes agrupadores e dispersores em EMFG, a marca que representa o conjunto de itens é denominada marca individual composta. Esta denominação justifica-se pela sua estrutura que armazena a informação de cada item antes do agrupamento, ou então distribui a informação para cada item após a dispersão. Estas informações armazenadas são representadas por um atributo adicional, através de um código de controle.

A Figura A.7 ilustra a representação dos boxes funcionais tipo agrupador, dispersor e capacidade e um exemplo de marca individual composta. 


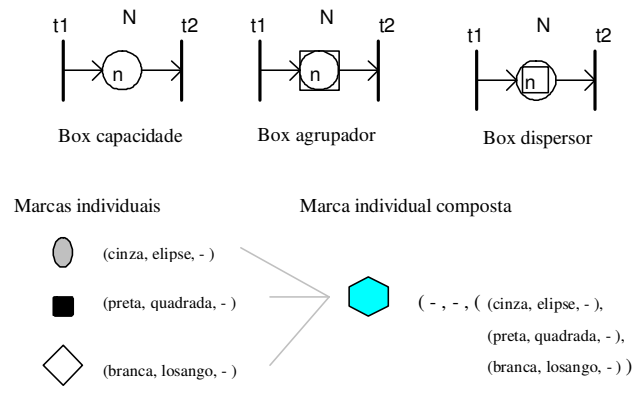

Figura A.7 Os boxes funcionais básicos e um exemplo de marca individual composta.

\section{A 6.3. Manipulação dos Atributos das Marcas}

O problema de manipulação dos atributos associados às marcas pode ser interpretado de duas maneiras. Ou podem ser modificados através de alterações condicionadas, ou através de filtragens seletivas.

A alteração condicionada significa que os estados dos atributos podem ser alterados dependendo do estado presente destes próprios atributos da marca, realizando-se desta forma a função de atualização do estado do sistema. Esta tarefa é executada por um outro box funcional denominado box controlador. Este box é assim denominado porque exerce a função de controlar o estado dos atributos de uma marca, no sentido de atualizar o estado global do sistema a partir da manutenção do estado local representado por cada uma destas marcas. Regras de produção do tipo 'if...then...' são aplicadas para a verificação e atualização dos atributos previamente especificados. A Figura A.8 ilustra um exemplo de box controlador alterando os atributos de uma marca.

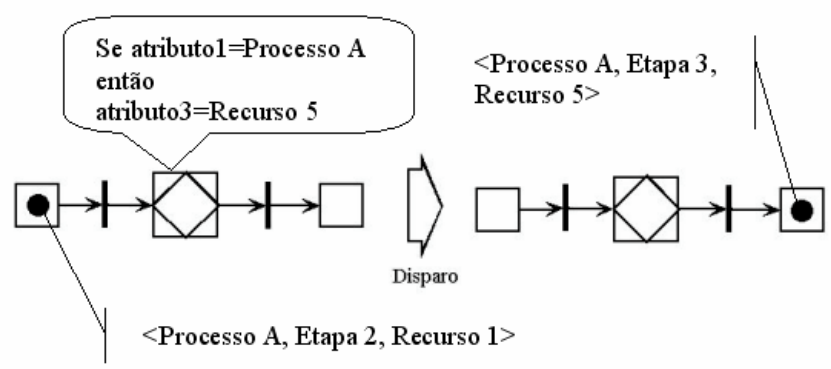

Figura A.8 Representação de um box controlador alterando o estado de uma marca individual. 
Outra forma de alterarem-se os atributos de uma marca corresponde à filtragem seletiva. Neste caso, são estabelecidos os campos correspondentes aos atributos que devem ou não acompanhar a marca, após o disparo de uma transição. Esta especificação é realizada através de inscrições nos arcos orientados. É importante observar que as inscrições não representam restrições para a habilitação da transição que possui este arco orientado do lado de entrada. Ao invés disso, representa restrições de quais campos de atributo devem ou não ser transmitidos. $A$ Figura A.9 representa a atuação do procedimento filtragem seletiva. A inscrição variável $a_{1}$ sobre $o$ arco de entrada da transição $t_{1}$ determina que apenas 0 atributo correspondente ao primeiro elemento do vetor de atributos que acompanha a marca individual deve ser mantido, enquanto os demais não são transmitidos.

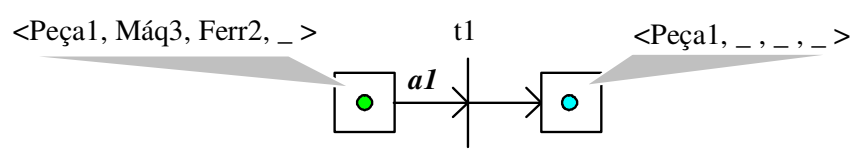

Figura A.9 Representação de um procedimento de filtragem seletiva.

\section{A 6.4. Dinâmica das Regras de Disparo}

A dinâmica de disparo de uma transição é estabelecida por regras de decisão segundo uma determinada hierarquia que estabelece três níveis hierárquicos de decisão. O primeiro nível corresponde às regras de restrições adicionais de disparo que são regras do tipo 'if...then...' de sistemas de produção, necessárias para a representação de estratégias de controle específicas. A especificação destas regras é realizada através de inscrições nas transições. Se não houver inscrições em uma transição, não há regras adicionais que limitem o seu disparo. Uma transição que satisfaz as regras de restrições adicionais é denominada transição em prontidão.

O segundo nível corresponde às regras de habilitação de disparo. Uma transição é denominada transição habilitada se for uma transição em prontidão que satisfaz as seguintes condições:

a. Não existe box no lado de saída com marcas;

b. Não existe box no lado de entrada sem marcas ou com marcas com restrições; 
c. Não existe porta habilitadora (interna ou externa) que esteja no estado de desabilitação;

d. Não existe porta inibidora (interna ou externa) que esteja no estado de inibição.

O terceiro e último nível corresponde às regras de realização de disparo propriamente ditas. Estas regras correspondem à verificação das regras de arbitragem em situações que envolvem conflito e a verificação das regras de filtragem seletiva dos atributos, de acordo com as inscrições nos arcos orientados. Uma transição habilitada que atende as regras de realização de disparo denominase transição disparável.

Uma transição disparável dispara imediatamente, fazendo com que as marcas fluam pelo grafo, descrevendo o comportamento dinâmico do sistema, a exemplo do que já se realizava no MFG. A Figura A.10 ilustra um grafo E-MFG em que ocorre o disparo de uma transição e a conseqüente manipulação dos atributos das marcas envolvidas.

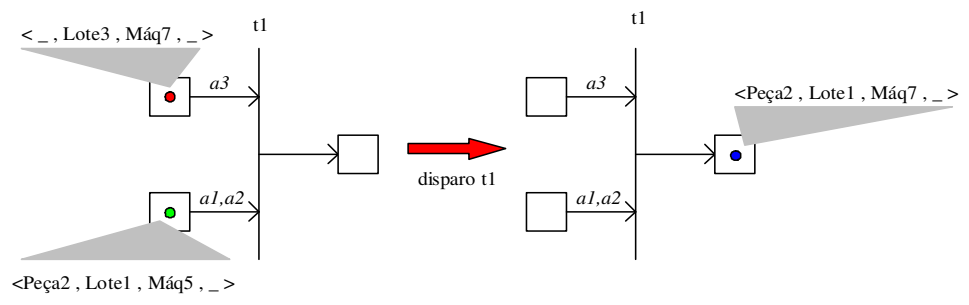

Figura A.10 Alteração dos atributos das marcas decorrentes do disparo.

\section{A 6.5. Elementos Comunicadores}

Em uma nova progressão face à necessidade de modelagem que viabilizasse a colaboração entre sistemas, a incorporação de elementos comunicadores ao E-MFG tornou-se necessária (MATSUZAKI, 2004). São criados os seguintes elementos estruturais estendidos, além de elementos de interface de envio e recepção de mensagens (Fig. A.11):

* Interfaces de envio de mensagem: substituem os arcos de sinal de saída do MFG e transmitem informações aos elementos externos, através da emissão de uma mensagem assíncrona eventual no disparo da transição de emissão; 
- Transição de envio (ou transmissor): indica a ocorrência do evento de envio da mensagem. A chamada do método é indicada pela sua inscrição.

- Arco de envio (ou arco transmissor): conecta a transição de envio ao box de origem.

- Arco de dados (opcional): cada arco de dados extrai os dados a serem transmitidos, referenciando os atributos a serem passados como parâmetros na chamada do metido. Cada arco corresponde a um dado componente da mensagem a ser enviada. Este tipo de arco recebe duas inscrições; uma próxima à origem do dado, onde indica qual atributo da marca a ser selecionado para formação da mensagem, e outro próximo a interface de envio, onde indica qual o parâmetro referente a chamada de método que será efetuada.

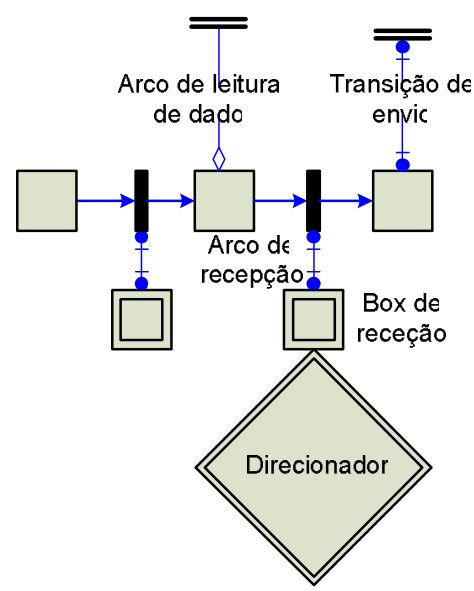

Figura A.11 Elementos comunicadores do E-MFG (MATSUSAKI, 2004).

Interfaces de recepção de mensagem: substituem as portas habilitadoras e inibidoras da ocorrência de eventos. Uma interface de recepção de mensagem é constituída por um box receptor que conecta este box à transição a ser habilitada ou inibida.

- Box de recepção (ou receptor): indica a recepção de uma mensagem, sendo que os atributos da marca contêm os dados recebidos;

- Direcionador: modifica o peso dos arcos de recepção, conforme os valores dos atributos da marca do box de recepção, de forma a direcionar a mensagem recebida; 
Arco de recepção (ou arco receptor): conecta o box de recepção à transição que inicia o processamento da mensagem.

\section{ANEXO A. 7 Mapeamento GAR/E-MFG}

Conforme apresentado em Santos Filho (2000), uma vez que o GAR é um grafo transição que representa um autômato finito (REISIG, 1985), é possível mapeá-lo em uma rede de CASSANDRAS (1993).

Definição 5.1. Considere um autômato de estados finitos dado pela quíntupla (E, $\mathbf{X}$, f, $\left.\mathbf{x}_{\mathbf{0}}, \mathbf{F}\right)$ onde (CASSANDRAS, 1993):

* E é um alfabeto finito;

* X é um conjunto de estados finito;

* f é uma função de transição de estados $\mathbf{f}: \mathbf{X} x \mathbf{E} \rightarrow \mathbf{X}$

* $\mathbf{x}_{0}$ é o estado inicial tal que $\mathbf{x}_{0} \in \mathbf{X}$;

* F é um conjunto de estados tal que $\mathbf{F} \subseteq \mathbf{E}$.

Definição 5.2. Considere o grafo Mark Flow Graph bipartido, representado por uma sêxtupla (B, T, A, G, GE, S) (MIYAGI, 1996) onde:

* $\mathbf{B}=\{\mathrm{B} 1, \ldots, \mathrm{Bi}\}$ com $(\mathrm{i} \geq 1)$ é um conjunto de boxes;

* $\mathbf{T}=\{T 1, \ldots, T j\}$ com $(j \geq 1)$ é um conjunto de transições;

* A é o conjunto de arcos orientados;

* $\mathbf{G}_{\mathbf{I}}=\left\{\mathrm{G}_{11}, \ldots, \mathrm{G}_{\mathrm{Im}}\right\}$ com $(\mathrm{m} \geq 0)$ é um conjunto de portas internas;

- $\mathrm{G}_{\mathrm{E}}=\left\{\mathrm{G}_{\mathrm{E} 1}, \ldots, \mathrm{G}_{\mathrm{En}}\right\}$ com $(\mathrm{n} \geq 0)$ é um conjunto de portas externas;

* $\mathbf{S}=\left\{S_{1}, \ldots, S_{p}\right\}$ com $(p \geq 0)$ é um conjunto de arcos de sinais de saída;

De acordo com CASSANDRAS (1993) dado um autômato de estados finitos (E, X, f, $\mathbf{x}_{\mathbf{0}}, \mathbf{F}$ ), é possível construir-se uma rede de Petri elementar (REISIG, 1985), uma vez que se pode associar o cada estado global representado pelo autômato uma determinada marcação na rede de Petri correspondente. Considerando-se que o MFG é baseado nas redes de Petri, com a ressalva de ser um grafo interpretado que possui um mapeamento dos sinais externos através de arcos de sinal de saída e 
portas externas, é possível inferir que para construir-se um modelo MFG a partir de um GAR implica no seguinte procedimento (CASSANDRAS, 1993):

* Cada estado em $\mathbf{X}$ é definido como um box em $\mathbf{B}$;

* A cada par de estados $\left(\mathbf{x}, \mathbf{x}^{\prime}\right)$, onde $\mathbf{x}^{\prime}=\mathbf{f}(\mathbf{x}, \mathbf{e})$ para $\mathbf{e} \in \mathbf{E}$, define-se uma transição em $\mathbf{T}$ tal que $\mathbf{T}=\left\{\left(\mathbf{x}, \mathbf{x}^{\prime}\right): \mathbf{x} \in \mathbf{X}, \mathbf{x}^{\prime}=\mathbf{f}(\mathbf{x}, \mathbf{e})\right.$ para qq. $\left.\mathbf{e} \in \mathbf{E}\right\}$;

* A seguir, define-se um arco a partir de cada par $(\mathbf{x}, \mathbf{t})$ e (t, $\left.\mathbf{X}^{\prime}\right)$ com $\mathbf{x} \in \mathbf{X}$ e $\mathbf{X}^{\prime} \in \mathbf{X}$ e $\mathbf{t} \in \mathbf{T}$ tal que $A=\{(\mathbf{x}, \mathbf{t}): \mathbf{X} \in \mathbf{X}, \mathbf{t} \in \mathbf{T}\} \cup\left\{\left(\mathbf{t}, \mathbf{X}^{\prime}\right): \mathbf{X}^{\prime} \in \mathbf{X}, \mathbf{t} \in \mathbf{T}\right\}$

A partir deste procedimento obtemos o modelo MFG correspondente ao GAR.

Uma extensão importante corresponde à generalização da representação de cada recurso por um box simples em E-MFG para a situação em que existem múltiplos recursos disponíveis, sendo adequado, portanto, utilizar-se o box capacidade para essa finalidade.

\section{ANEXO A. 8 Production Flow Schema - PFS}

O PFS (MIYAGI, 1996) é utilizado para descrever, graficamente e conceitualmente, os processos relacionados com a produção de itens (peças, produtos, informações, etc.) sob a forma de seqüências de etapas de atividades e de distribuição. O PFS consiste de nós de elementos-atividade, nós de elementos distribuidores e arcos de fluxo, que conectam seqüencialmente um tipo de nó ao outro (Fig. A12). Os elementos-atividade podem ser expandidos em duas transições e um lugar (lugaratividade).

$$
\text { [ACT. }
$$

(a) elemento atividade

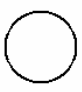

(b) elemento distribuidor

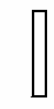

(a') elemento atividade (forma simplificada)

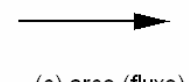

(c) $\operatorname{arco}($ fluxo)

Figura A.12 Elementos do PFS.

Os elementos-atividade podem ser expandidos em duas transições e um lugar (lugar-atividade). Quando é necessária a indicação do início e da conclusão de uma atividade, distinguimos a transição de entrada (como a transição de início) da 
transição de saída (como a transição final) (Figura A.13c). Além disso, na Figura A.13, m e n são, respectivamente, os números de entradas e saídas simultâneas de um elemento; em redes de Petri tipo lugar/transição - L/T - (REISIG, 1985; REISIG, 1992) ou em representações híbridas, eles compõem os pesos dos arcos de fluxo. Se não houver necessidade, ou $m=n=1$, eles podem ser omitidos.

Similarmente, um elemento-distribuidor pode ser também expandido em um lugar (lugar-distribuidor) com transições à entrada e à saída, como ilustrado na Figura A.14. Ainda, no caso de se expandir dois elementos conectados um ao outro em uma rede $\mathrm{L} / \mathrm{T}$, a transição de saída da primeira etapa e a de entrada da etapa seguinte formam uma única transição. Deste ponto em diante, a denominação lugares-etapa é dada tanto para os lugares-atividade como para os lugaresdistribuidores.

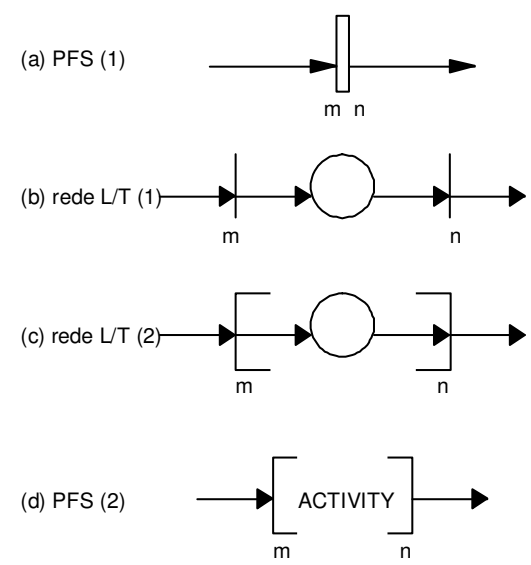

Figura A.13 Elemento atividade em rede L/T.

(a) PFS
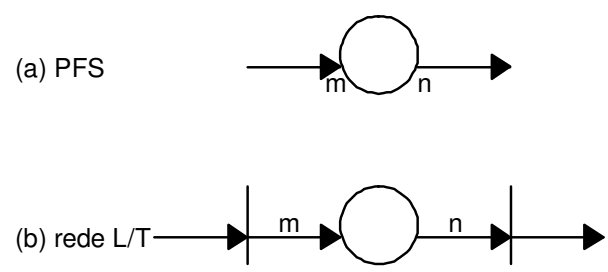

Figura A.14 Elemento distribuidor em rede L/T. 


\section{ANEXO B - FERRAMENTA COMPUTACIONAL PARA DETERMINAR O CAMINHO MÍNIMO}

\section{ALGORITMO DE DIJKSTRA COM HEAP BINOMIAL}

O algoritmo de Dijkstra que produz resultados otimizados adicionando vértices à árvore de caminho mínimo pelo processo de relaxamento de uma aresta (Fig. B.1), ou seja, consiste em verificar se há a possibilidade de melhorar o caminho obtido até o momento (CORMEN et al., 2002; BANG-JENSEN, J. e GUTIN, 2006). Uma etapa de relaxamento pode diminuir o valor da estimativa de caminho mínimo e atualizar o predecessor (CORMEN et al., 2002). O algoritmo requer que nenhum peso no grafo seja negativo (CORMEN et al., 2002; BANG-JENSEN, J. e GUTIN, 2006). A Figura B.2 apresenta o pseudocódigo do algoritmo de Dijkstra conforme apresentado em CORMEN et al. (2002).
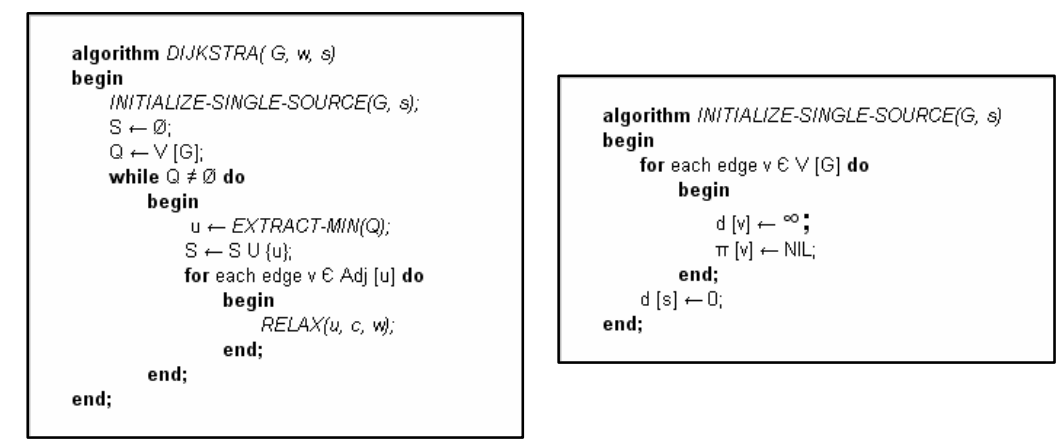

Figura B.1: Algoritmo de Dijkstra (CORMEN et al., 2002).

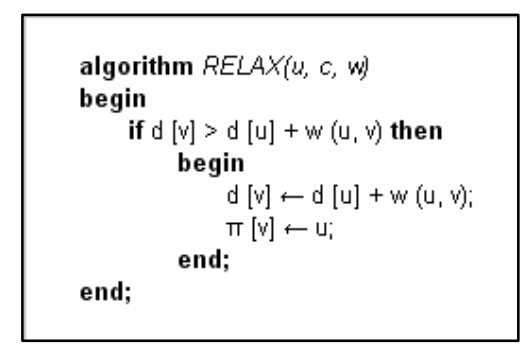

Figura B.2: Algoritmo de relaxamento (CORMEN et al., 2002).

O algoritmo de Dijkstra resolve o problema de caminho mínimo de uma única origem em um grafo orientado (CORMEN et al., 2002). O algoritmo mantém um conjunto de nós cujos pesos desde a origem já foram calculados. O algoritmo seleciona repetidamente o nó que possui a menor estimativa (peso) e calcula os pesos dos 
nós adjacentes. Considerando-se o exemplo da Figura B.3, é apresentado a seguir o processo de cálculo dos pesos utilizando o algoritmo de Dijkstra (Figura B.4).

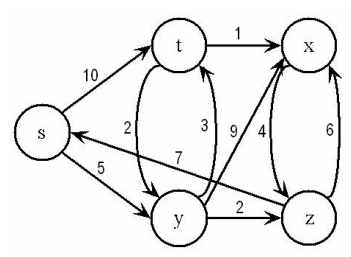

Figura B.3: Exemplo de grafo para cálculo do caminho mínimo.
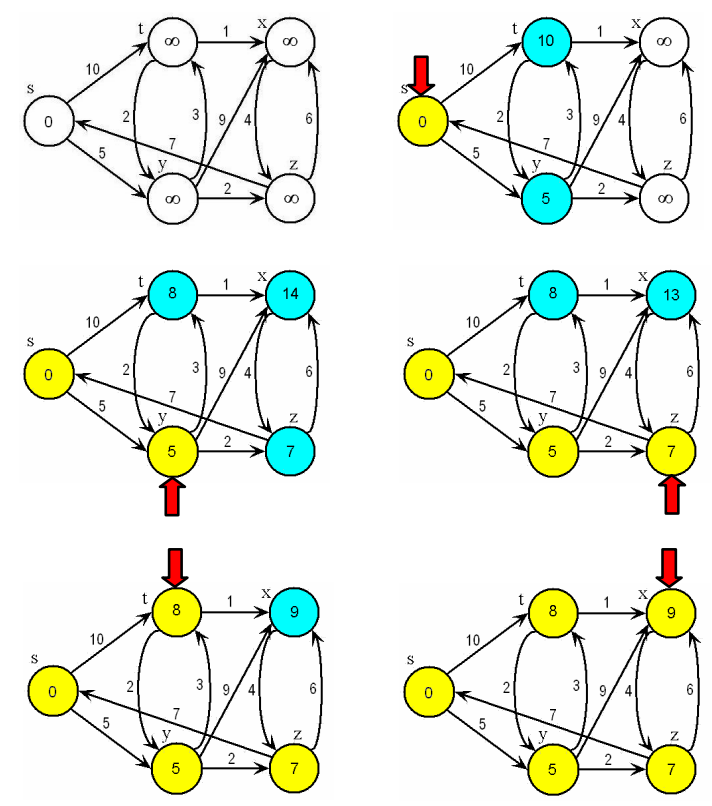

Figura B.4: Execução do algoritmo de Dijkstra.

O pseudocódigo do algoritmo de Dijkstra apresentado na Figura B.1 faz chamada à função EXTRACT_MIN(). Esta operação realiza a cada iteração uma busca do menor custo nos nós visitados anteriormente. A representação matricial para o armazenamento dos nós visitado poderá resultar uma complexidade O(1) (ZIVIANI, 2004) no melhor caso e no pior caso O(n), sendo n o número de nós visitados.

A estrutura de dados Heap Binomial, conhecida também como fila de prioridades (TENENBAUM et al., 1995), será empregado no algoritmo de Dijkstra para determinar o nó com o menor custo. O objetivo é reduzir o tempo de execução do algoritmo Dijkstra quanto à determinação deste nó em questão. Conforme será apresentado a seguir, o tempo de execução para determinar o menor custo em um Heap Binomial é sempre O $(\log n)(C O R M E N$ et al., 2002). Um Heap Binomial é uma coleção de árvores binomiais. A árvore binomial é uma árvore ordenada que possui as seguintes propriedades: 
1. Existem 2k nós;

2. A altura da árvore é $\mathrm{k}$;

3. Existem exatamente $\left(\mathrm{k}_{\mathrm{i}}\right)$ nós na profundidade i para $\mathrm{i}=0,1, \ldots, \mathrm{k}$;

4. A raiz tem grau $\mathrm{k}$, o qual é maior que o de qualquer outro nó;

5. Se os filhos da raiz são numerados da esquerda para a direita por k-1, k-2, ..., 0 , o filho i é a raiz de uma subárvore $B_{\mathrm{i}}$.

Um Heap Binomial H é definido como um conjunto de árvores binomiais que satisfaz as seguintes propriedades:

1. Cada árvore binomial $\mathrm{H}$ obedece à propriedade de heap mínimo, ou seja, a chave de um nó é maior ou igual à chave de seu pai;

2. Existe no máximo uma árvore binomial em $\mathrm{H}$ cuja raiz tem grau $\mathrm{k}$, para qualquer inteiro não negativo $\mathrm{k}$.

A Figura B.5 apresenta um heap binomial H com 13 nós. O heap consiste nas árvores binomiais B0, B2 e B3 com 1, 4 e 8 nós respectivamente, totalizando 13 nós $(\mathrm{n}=13)$. Observa-se que as árvores estão ordenadas com em heap mínimo, ou seja, a chave de qualquer nó não é menor que a chave de seu pai.

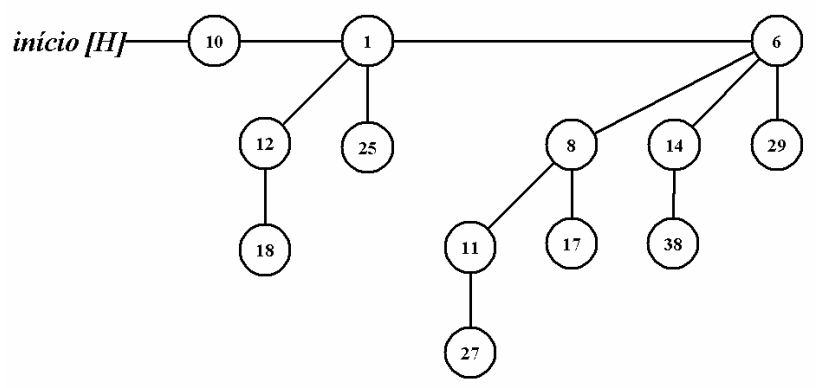

Figura B.5: Representação da árvore binomial com 13 nós.

As raízes das árvores binomiais dentro de um Heap Binomial estão organizadas em uma lista de raízes (nós 10, 1 e 6) que estão em ordem decrescente de grau (quantidade de filhos). A figura 20 apresenta uma representação mais detalhada de cada nó. A estrutura do nó armazena 3 ponteiros, a saber: ponteiro para o pai (ancestral), para o filho e para o irmão. A única situação em que o ponteiro para o pai é NULO será quando o nó for uma raiz. 
A Figura B.7 apresenta uma representação mais detalhada do heap binomial $\mathrm{H}$. Cada árvore binomial é armazenada na representação de filho da esquerda, irmão da direita e cada nó armazena o grau correspondente.

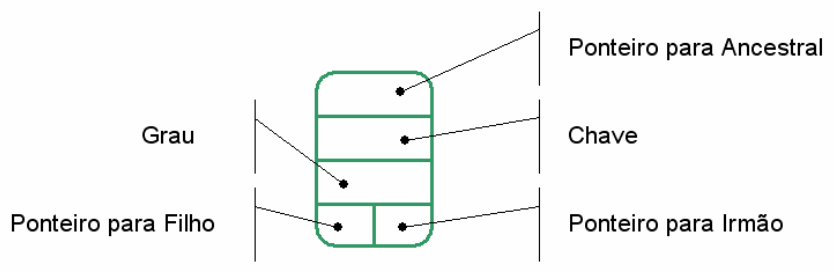

Figura B.6: Representação do nó de um Heap binomial.

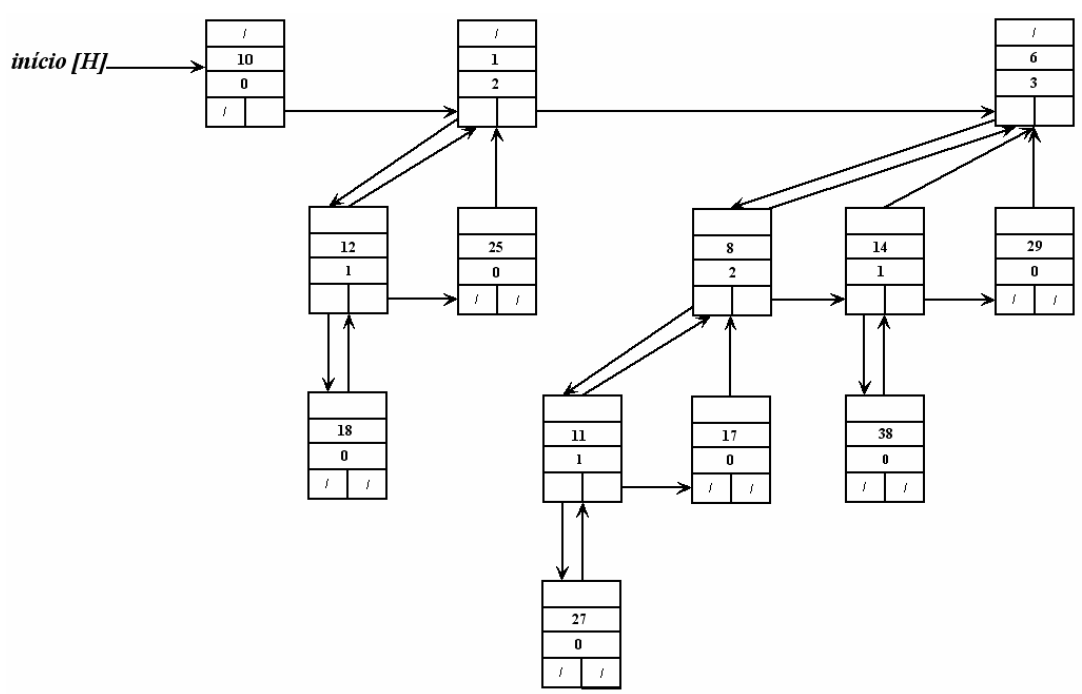

Figura B.7: Representação do nó de um Heap binomial.

As principais operações em um heap binomial são definidas em CORMEN et al. (2002):

- BINOMIAL_HEAP_INSERT(H, x) : Insere o nó $x$, cujo campo chave já foi preenchido anteriormente;

- BINOMIAL_HEAP_MINIMUM(H) : Retorna um ponteiro para o nó do heap H cuja chave é mínima;

- BINOMIAL_HEAP_EXTRACT_MIN(H) : Elimina o nó do heap H cuja chave é mínima, retornando um ponteiro para o nó;

- BINOMIAL_LINK(y, z) : Torna o nó y o novo início da lista ligada de filhos do nó z; 
- BINOMIAL_HEAP_UNION(H1, H2) : Cria e retorna um novo heap que contém todos os nós dos heaps $\mathrm{H} 1$ e H2. Os heaps H1 e H2 são "destruídos" por esta operação;

- BINOMIAL_HEAP_DECREASE_KEY $(\mathrm{H}, \mathrm{x}, \mathrm{k})$ : Atribui ao nó $\mathrm{x}$ dentro do heap $\mathrm{H}$ o novo valor de chave $k$, que se supõe não ser maior que o seu valor de chave atual;

- BINOMIAL_HEAP_DELETE $(H, x)$ : Elimina o nó $x$ do heap $H$;

- BINOMIAL_HEAP_MERGE(H1, H2) : Intercala as listas de raízes de H1 e H2 em uma única lista ligada que é ordenada por grau em ordem crescente;

- MAKE_BINOMIAL_HEAP() : Cria e retorna um novo heap que não contém nenhum elemento.

O algoritmo de Dijkstra em grafos utilizando Heap Binomial foi implementado utilizando-se a linguagem $\mathrm{C}_{++}$. Primeiramente, foi desenvolvido a classe CDados que realiza a leitura e armazenamento dos dados, aplicação do algoritmo de Dijkstra e salva os resultados obtidos em arquivo texto. A segunda classe CHeapBinomial é responsável por criar uma estrutura de dados Heap Binomial e um vetor de ponteiros destinado à atualização das chaves, desta forma, quando o algoritmo de Dijkstra é executado, cria-se um objeto da classe CheapBinomial. A classe CDados informa os nós visitados e encaminha-os à classe CHeapBinomial que gerencia o heap binomial. Todas as alterações são repassadas à classe CHeapBinomial que retorna o nó de menor custo, quando solicitado, e realiza também as atualizações de custo (chave) de cada nó. Os principais métodos implementados na classe CDados são: algoritmo de ordenação e cálculo das distâncias pelo algoritmo de Dijkstra. 


\section{ANEXO C - FERRAMENTA COMPUTACIONAL PARA SIMULAÇÃO DA REDE E-MFG}

A ferramenta computacional para a simulação foi desenvolvida em linguagem Object Pascal (Delphi 6). Foram desenvolvidas as classes TRede, TBox, TTrans e TArco. A rede é mapeada na forma de matriz de incidência, relacionando-se aos objetos box e transição. Os objetos boxes possuem uma lista de marcas, sendo as marcas um registro para armazenamento dos atributos. A habilitação das transições é realizada conforme as regras do E-MFG apresentadas nos trabalhos de Santos Filho (2000) e Matsusaki (2004). A Figura C.1 apresenta a interface para entrada da matriz de incidência e criação dos objetos box, transição e arco.

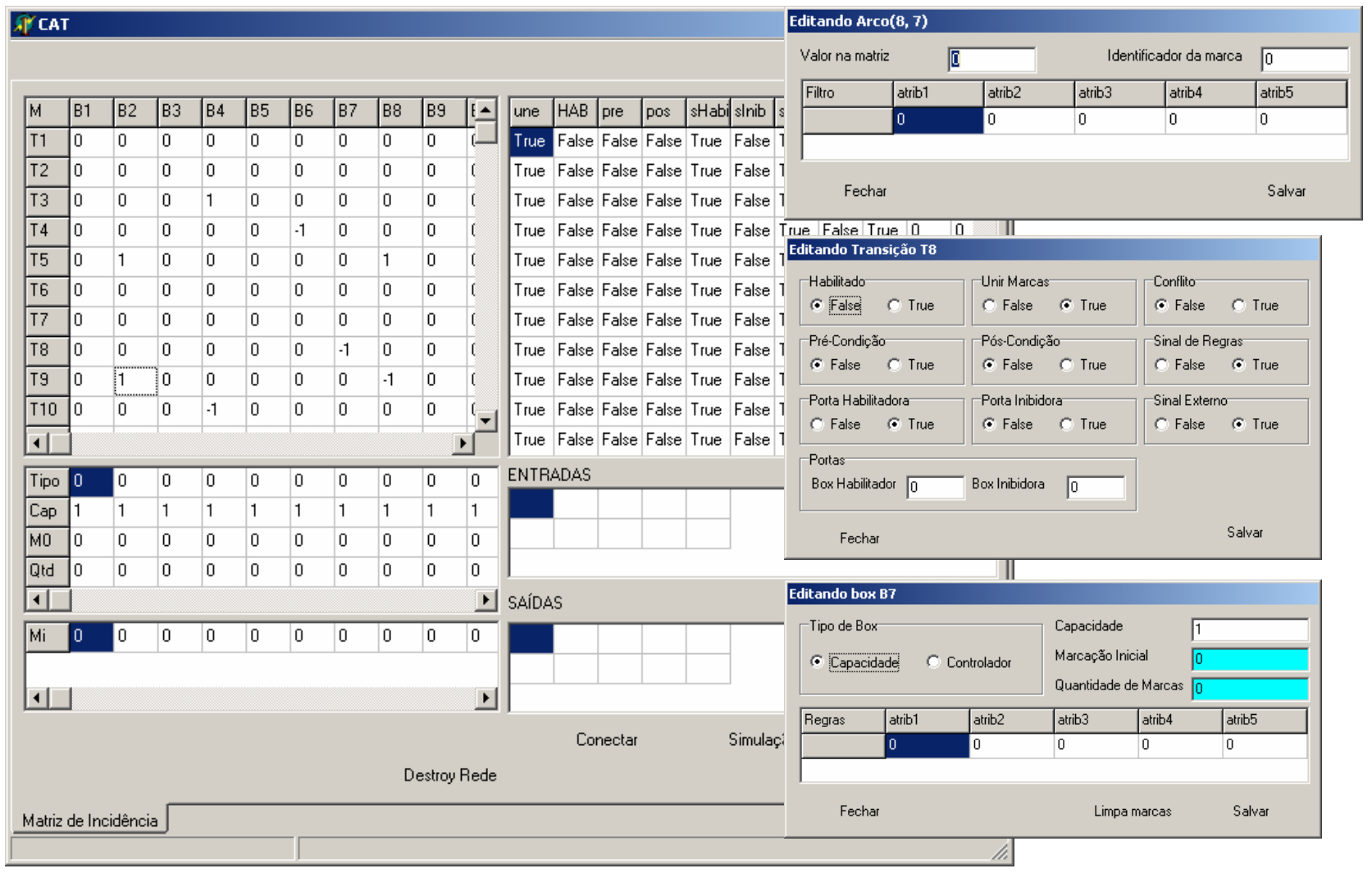

Figura C1 Interface para entrada da matriz de adjacência do simulador. 
ANEXO D - REDES 


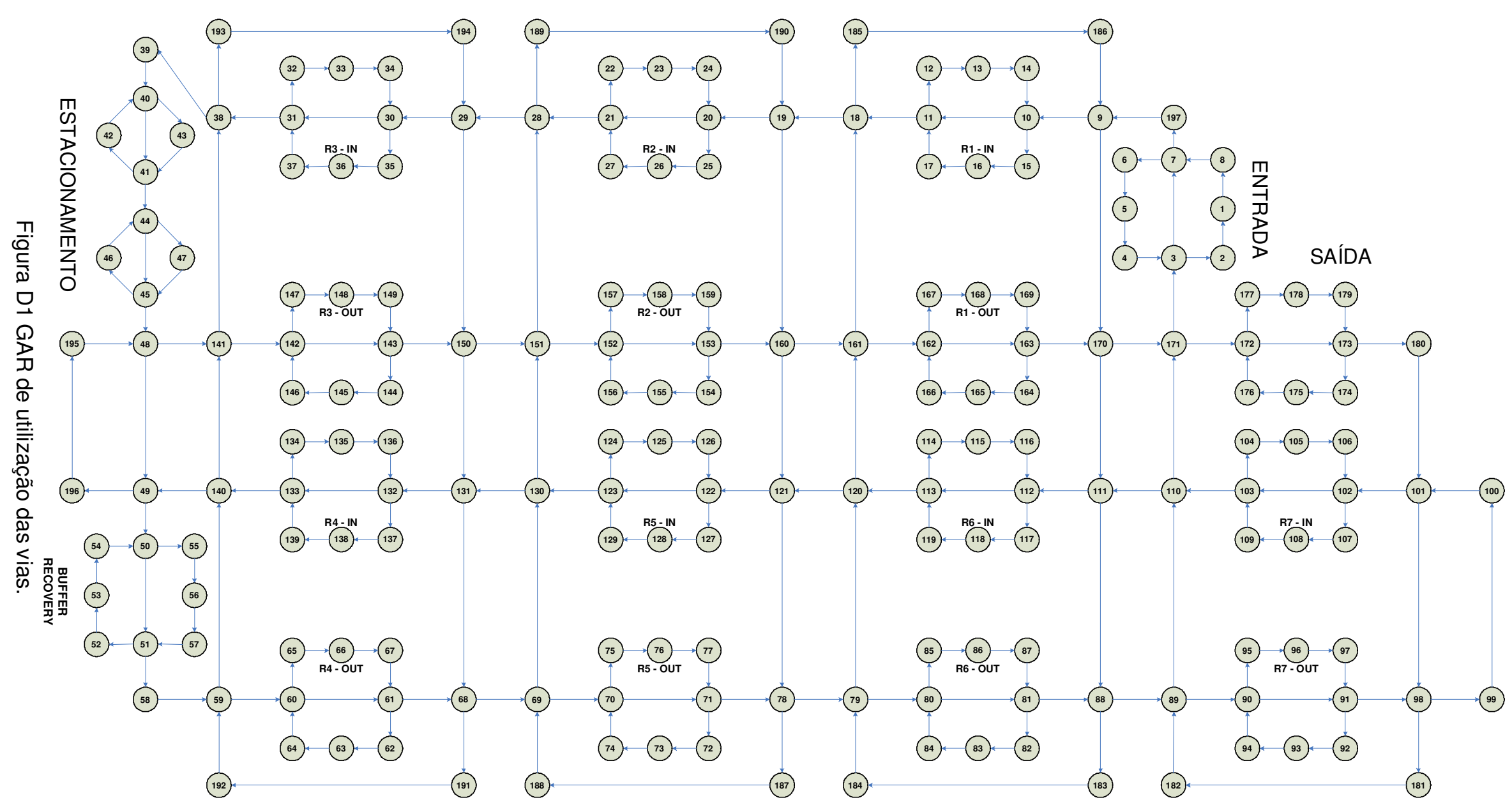

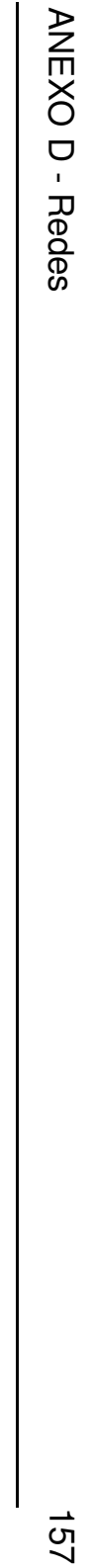




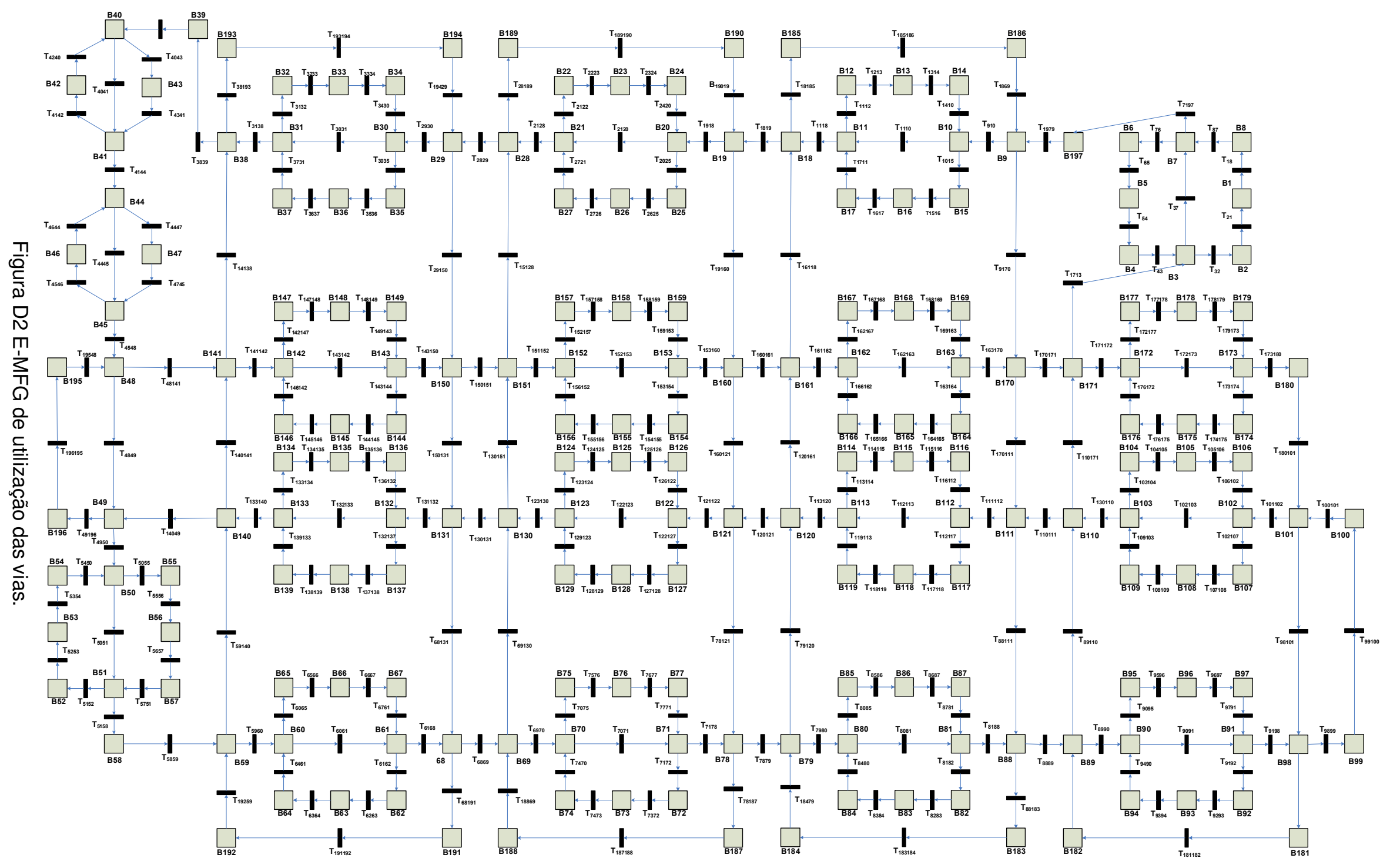

